\author{
UNIVERSIDADE DE SÃO PAULO \\ ESCOLA DE ENGENHARIA DE SÃO CARLOS \\ DEPARTAMENTO DE HIDRÁULICA E SANEAMENTO
}

\title{
DESENVOLVIMENTO E AVALIAÇÃO DE SISTEMA DE LEITO FIXO - REATOR MISTO RADIAL SEGUIDO DE REATOR ANÓXICO HORIZONTAL - PARA REMOÇÃO DE MATÉRIA ORGÂNICA E DE NITROGÊNIO DE ESGOTO SANITÁRIO
}

Luis Hamilton Pospissil Garbossa

\begin{abstract}
Dissertação apresentada à Escola de
Engenharia de São Carlos, da Universidade de São Paulo, como parte dos requisitos para obtenção do título de Mestre em Engenharia Civil - Hidráulica e Saneamento
\end{abstract}

ORIENTADOR: Prof. Dr. Eugenio Foresti

SÃO CARLOS

2003 
Ao a mor que sinto por você Katt e ao mais precioso tesouro, nosso filho Lucas. 
"Life is what happens to you while you are busy making other plans."

(John Lennon) 


\section{Agradecimentos}

À minha família, a quem agradeço de coração, pela ajuda e pelo constante incentivo.

Ao professor Dr. Eugenio Foresti pela orientação no desenvolvimento deste trabalho e colaboração para conclusão da dissertação.

Ao professor Dr. Marcelo Zaiat pela colaboração, auxílio e sugestões durante a fase experimental e na avaliação do plano de qualificação.

À professora Dra. Ruth pelo auxílio na correção do texto.

À Sávia, pela cooperação e sugestões para conclusão da dissertação.

A todos os amigos do mestrado, das disciplinas, do Laboratório de Processos Biológicos e dos churrascos e as minhas amigas Ana Paula, Andréa e Júlia.

Ao Edson e a Selma pela amizade e grande ajuda com o Lucas.

Aos amigos e colegas de laboratório Fazolo, Ronan e Sérgio.

Aos funcionários do laboratório de saneamento da EESC, Cidinha, Júlio e Paulo, obrigado pela atenção despendida.

Às funcionárias do Laboratório de Processos Biológicos, Betty, Janja e Eloísa pela permanente disposição em atender meus pedidos de ajuda durante a fase experimental deste trabalho.

Às secretárias do Curso de pós-graduação em Hidráulica e Saneamento, Rose, Sá e Pavi.

Ao Conselho Nacional de Desenvolvimento Científico e Tecnológico $\mathrm{CNPq}$ - pela bolsa de mestrado e à FAPESP pelo apoio financeiro.

Ao professor Dr. Miguel Mansur Aisse pelo incentivo durante a iniciação científica na graduação da PUC-PR

A todos aqueles que, de alguma forma, contribuíram para a realização deste trabalho.

Aos funcionários da Oficina Mecânica da EESC que foram fundamentais para a montagem da instalação experimental. 


\section{Índice}

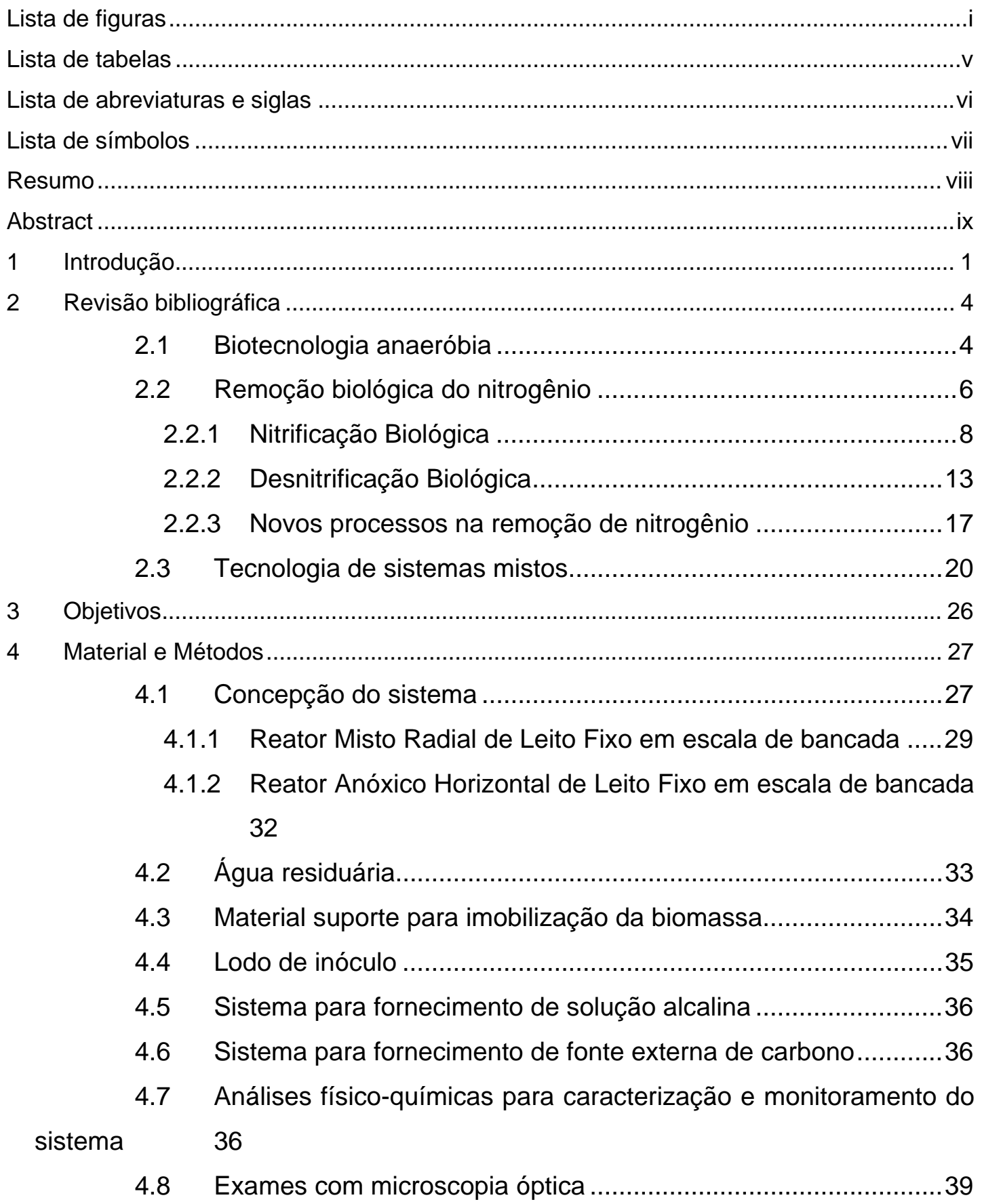




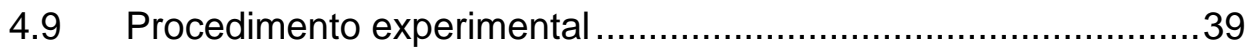

4.9.1 Partida e estabilização do sistema ......................................39

4.9.2 Operação do sistema RMRLF seguido de RAHLFa ...............40

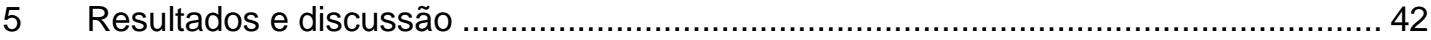

5.1 Caracterização da água residuária afluente ao sistema.............42

5.2 Avaliação do desempenho do RMRLF ......................................4 43

5.2.1 Monitoramento de parâmetros operacionais ..........................44

5.3 Avaliação do desempenho do RAHLFa.....................................63

5.3.1 Monitoramento de parâmetros operacionais .........................63

5.4 Avaliação do sistema misto de leito fixo, em escala de bancada, para tratamento de esgoto sanitário ............................................................. 76

5.4.1 Avaliação e balanço de massa de nitrogênio no sistema.......78

5.5 Exame microscópico da biomassa imobilizada no sistema..........80

5.5.1 Morfologias observadas no lodo de inóculo ............................80

5.5.2 Morfologias observadas em amostras retiradas do RAHLFa antes do início de sua operação. .82

5.5.3 Morfologias observadas em amostras retiradas da câmara 3 do RMRLF, no período de grande desenvolvimento de filamentos .84

5.5.4 Morfologias observadas em amostras retiradas do RMRLF na câmara 2 e próximo à câmara 3 , após 40 dias de operação ...........................87

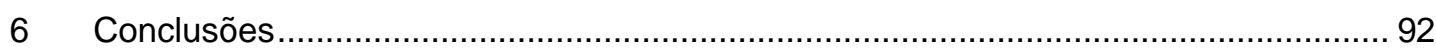

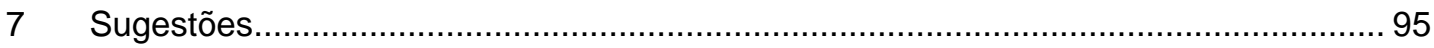

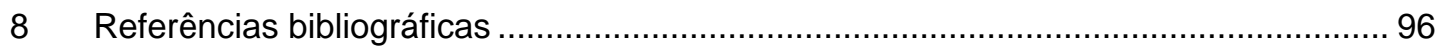

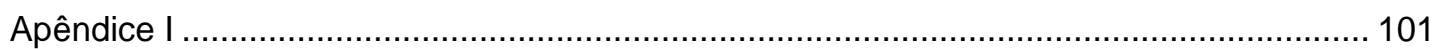




\section{Lista de figuras}

FIGURA 2.1 - Transformações do nitrogênio nos processos de tratamento biológico 07

FIGURA 2.2 - Efeito da relação $\mathrm{C} / \mathrm{N}$ sobre a eficiência de desnitrificação utilizando metanol como fonte externa de carbono 15

FIGURA 2.3 - Possível rota de degradação da amônia para nitrogênio gasoso e nitrito ..... 19

FIGURA 4.1 - Localização da instalação do sistema demarcado como E.T.E. 28

FIGURA 4.2 - Representação esquemática do sistema RMRLF seguido de RAHLFa: Esgoto afluente (01); Bomba de recalque do esgoto afluente ao RMRLF (02); Fornecimento de ar comprimido à câmara 3 (03); Fornecimento de solução alcalina à câmara 3 (04); Recipiente com solução alcalina (05); Efluente RMRLF (06); Fornecimento de fonte de carbono ao RAHLFa (07); Recipiente com solução de etanol (08); Efluente RAHLFa (09) ......... 29

FIGURA 4.3 - Projeto do RMRLF mostrando as principais características e seus componentes a) Planta baixa e b) Corte AA: Câmara 1 - distribuição do afluente; Câmara 2 - câmara anaeróbia/aeróbia; Câmara 3 - câmara de aeração; Câmara 4 - câmara aeróbia/anaeróbia; Câmara 5 - saída do efluente

FIGURA 4.4 - llustração do RMRLF em três dimensões. O corte parcial mostra a tubulação de distribuição do afluente e de coleta do efluente $\square$; a estrutura externa e ofundo do reator $\square$; a grade para retenção da espuma

FIGURA 4.5 - llustração do RAHLFa em três dimensões mostrando o dispositivo de entrada, que é ligado à tubulação efluente do RMRLF e a estrutura do reator ॠ; os suportes para sustentação $\square$; e corte parcial na parede externa mostrando o leito (recheio) composto por matrizes de espuma de poliuretano

FIGURA 4.6 - Projeto em corte do Reator Anóxico Horizontal de Leito Fixo ........................ 33

FIGURA 4.7 - Morfologia dos alvéolos. na espuma de poliuretano ....................................... 34

FIGURA 5.1 - Perfis de concentração em termos de DQO do reservatório de $750 /$ de água residuária. Jul/2002: DQO bruta $\square$ e DQOf 0 . Out/2002: DQO bruta e DQOf 
FIGURA 5.2 - RMRLF, em escala de bancada, utilizado no tratamento de esgoto sanitário e nitrificação do $\mathrm{N}$-amon

FIGURA 5.3 - Valores obtidos de vazão efluente a e efluente com adição de solução alcalina

FIGURA 5.4 - Valores obtidos de temperatura do esgoto afluente $\boldsymbol{\square}$, na câmara $3 \boldsymbol{\Delta}$ e no efluente do RMRLF

FIGURA 5.5 - Valores obtidos de DQO afluente $\boldsymbol{\square}$, na câmara $3 \boldsymbol{\Delta}$ e no efluente do RMRLF

FIGURA 5.6 - Valores obtidos da DQOf afluente $\boldsymbol{\square}$, na câmara $3 \boldsymbol{\Delta}$ e no efluente do

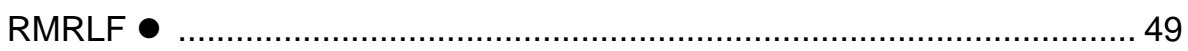

FIGURA 5.7 - Valores obtidos de eficiência de remoção de DQO e e DQOf $\bullet$..................... 50

FIGURA 5.8 - Valores obtidos de pH afluente $\mathbf{\square}$, na câmara $3 \boldsymbol{\Delta}$ e no efluente do RMRLF

FIGURA 5.9 - Valores obtidos de Alcalinidade a bicarbonato afluente $\mathbf{\square}$, na câmara 3 e no efluente do RMRLF

FIGURA 5.10 - Valores obtidos de AVT afluente $\boldsymbol{\square}$, na câmara $3 \boldsymbol{\Delta}$ e no efluente do RMRLF

FIGURA 5.11 - Valores obtidos para Sólidos Totais afluente $\boldsymbol{\square}$, na câmara $3 \boldsymbol{\Delta}$ e no efluente do RMRLF

FIGURA 5.12 - Valores obtidos para Sólidos Suspensos Voláteis afluente $\mathbf{a}$, na câmara 3 $\Delta$ e no efluente do RMRLF $\bullet$

FIGURA 5.13 - Valores obtidos para N-NTK afluente $\boldsymbol{~}$, na câmara $3 \boldsymbol{\Delta}$ e no efluente do RMRLF

FIGURA 5.14 - Valores obtidos para N-amon afluente $\boldsymbol{\square}$, na câmara $3 \boldsymbol{\Delta}$ e no efluente do RMRLF

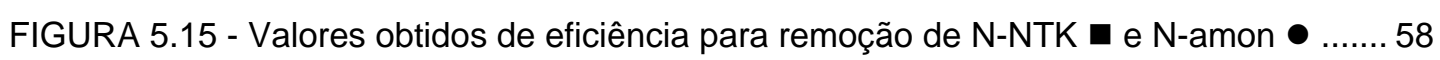

FIGURA 5.16 - Valores obtidos para $\mathrm{N}-\mathrm{NO}_{2}{ }^{-}$afluente $\mathbf{m}$, na câmara $3 \boldsymbol{\Delta}$ e no efluente do RMRLF

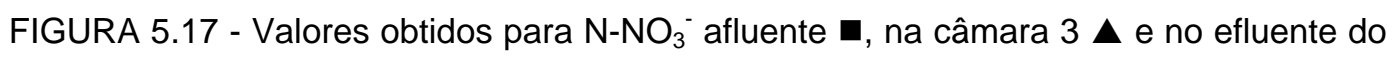
RMRLF

FIGURA 5.18 - Valores obtidos para OD na câmara $3 \boldsymbol{\Delta}$ e no efluente do RMRLF • ........ 61

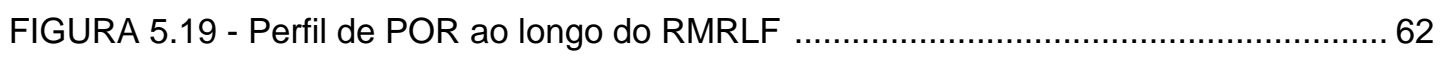

FIGURA 5.20 - RAHLFa, em escala de bancada, utilizado para promover o processo de desnitrificação do efluente do RMRLF

FIGURA 5.21 - Valores obtidos de vazão do esgoto afluente ao sistema e afluente do RAHLFa

FIGURA 5.22 - Valores obtidos de temperatura do esgoto afluente $\bullet$ e efluente $\square$ do RAHLFa 
FIGURA 5.24 - Valores de DQOf obtidos no afluente $\bullet$ e efluente $\square$ do RAHLFa 67

FIGURA 5.25 - Valores obtidos de pH afluente $\bullet$ e efluente $\square$ do RAHLFa 68

FIGURA 5.26 - Valores obtidos de alcalinidade a bicarbonato afluente $\bullet$ e efluente $\square$, do RAHLFa

FIGURA 5.27 - Valores obtidos de AVT afluente $\bullet$ e efluente $\square$ do RAHLFa ...................... 70

FIGURA 5.28 - Valores obtidos de SSV no afluente $\bullet$ e efluente $\square$ do RAHLFa ................ 71

FIGURA 5.29 - Valores obtidos de N-NTK afluente $\bullet$ e efluente $\square$ do RAHLFa, a partir do início da nitrificação no RMRLF

FIGURA 5.30 - Valores obtidos de N-amon afluente $\bullet$ e efluente $\square$ do RAHLFa, a partir do início da nitrificação no RMRLF

FIGURA 5.31 - Valores obtidos de $\mathrm{N}^{-N_{3}}{ }_{3}^{-}$afluente $\bullet$ e efluente $\square$ do RAHLFa, a partir do início da nitrificação no RMRLF

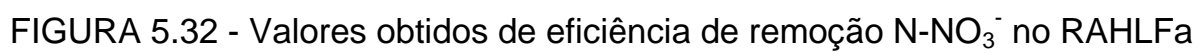

FIGURA 5.33 - Valores obtidos de $\mathrm{N}^{-N_{2}}{ }_{2}$ afluente $\bullet$ e efluente $\square$ do RAHLFa, a partir do início da nitrificação no RMRLF

FIGURA 5.34 - Balanço de massa para o nitrogênio nos pontos de amostragem do sistema experimental em escala de bancada com os valores de N-NTK

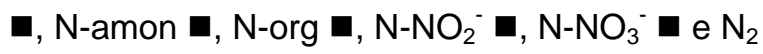

FIGURA 5.35 - Morfologias observadas no lodo de inóculo, com aumento de 1600x e barras com $3 \mu \mathrm{m}$. Estruturas semelhantes a: a) filamentos septados; b) bacilos com extremidades arredondadas e filamentos; c) filamentos delgados semelhantes a Methanosaeta, bacilos com diversas dimensões e cocos isolados; d) bacilos, diplococos e arranjo de cocos; e) bacilos de diversos tamanhos, bacilo curvo semelhante a BRS e arranjo de cocos; f) filamentos semelhantes a Methanosaeta 81

FIGURA 5.36 - Morfologia observada no lodo macerado de inóculo, com aumento de 1600x e barras com $3 \mu \mathrm{m}$. Estrutura semelhante a cisto de Methanosarcina

FIGURA 5.37 - Morfologias observadas no meio suporte do RAHLFa, com aumento de 1600x e barras com $5 \mu \mathrm{m}$. Estruturas semelhantes a: a) bacilo curvo semelhante a BRS; b) bacilos com extremidades arredondadas; c) cocobacilos; d) bacilo com extremidade arredondada e constrição central; e) filamento sem estrutura celular íntegra e f) estreptococos

FIGURA 5.38 - Morfologias observadas na câmara 3, com densa massa de filamentos. O aumento foi de 100x para a) e b), com barras de $50 \mu \mathrm{m}, 1000 x$ para c) e d), com barras de $5 \mu \mathrm{m}$ e de 1600x para e) e f), com barras de $5 \mu \mathrm{m}$. Todas as estruturas aqui apresentadas são semelhantes à Sphaerotilus . 85 
FIGURA 5.39 - Morfologias observadas na câmara 3 com densa massa de filamentos. O aumento foi de 100x para a), com barra de $50 \mu \mathrm{m}, 1000 x$ para b), c) e d), com barras de $5 \mathrm{~mm}$. As estruturas apresentadas são semelhantes a: a), b) e c) Beggiatoa e d) Thiothrix . 86

FIGURA 5.40 - Morfologias observadas na câmara 2 com valor médio de POR próximo a $-300 \mathrm{mV}$, com aumento de 1250x e barras com $5 \mu \mathrm{m}$. As estruturas apresentadas são semelhantes a: a) filamentos; b)bacilos com extremidades arredondadas e não fluorescentes; c) e d) bacilos methanogênicos e Methanosarcina

FIGURA 5.41 - Morfologias observadas na câmara 2 com valor médio do POR próximo à $-300 \mathrm{mV}$, com aumento de 1250x e barras com $5 \mu \mathrm{m}$. As estruturas apresentadas são semelhantes a: a) bacilos fluorescentes; b) fluorescência de Methanosarcina; c) filamento septado, bacilos com diversas dimensões, filamentos delgados; d) bacilos de morfologias diversas

FIGURA 5.42 - Morfologias observadas próximo a câmara 3, com aumento de 200x e barras com $30 \mu \mathrm{m}$. As estruturas apresentadas são semelhantes a: a) nematóide; b) protozoário suctória semelhante a Podophrya; c) Paramecium; d) rotífero semelhante a Epiphanes

FIGURA 5.43 - Morfologias observadas próximo a câmara 3. As estruturas apresentadas são semelhantes a: a) com aumento de $125 \mathrm{x}$ e barra com $50 \mu \mathrm{m}$, rotífero semelhante a Epiphanes; com aumento de 250x e barra com $30 \mu \mathrm{m}$ b) protozoário rizópode semelhante a Amoeba; c) protozoário ciliado semelhante a Paramecium; d) rizópode semelhante a Arcella

FIGURA 5.44 - Morfologias observadas próximo a câmara 3. As estruturas apresentadas são semelhantes a: a) com aumento de 1000x e barra com $5 \mu \mathrm{m}$, Thiotrix e Beggiatoa; com aumento de 1250x e barra com $5 \mu \mathrm{m}$ b) cocos semelhantes a Nitrosococcus; c) Beggiatoa; d) Spherotilus com bainha e Beggiatoa; e) bacilos fluorescentes; f) Spherotilus 


\section{Lista de tabelas}

TABELA 2.1- Formas e estados de oxidação do nitrogênio ................................................... 06

TABELA 2.2 - Valores das constantes cinéticas na nitrificação .......................................... 12

TABELA 2.3 - Valores das constantes cinéticas na desnitrificação ..................................... 16

TABELA 4.1 - Estimativa do diâmetro equivalente médio da abertura superficial e dos alvéolos da espuma de poliuretano .............................................................. 35

TABELA 4.2 - Condições de operação do sistema .......................................................... 41

TABELA 5.1 - Valores médios dos parâmetros analisados no esgoto sanitário afluente .... 46

TABELA 5.2 - Valores médios dos parâmetros analisados no afluente do RAHLFa, na primeira condição, com vazão de $6 ! \cdot h^{-1}$

TABELA 5.3 - Valores médios dos parâmetros analisados no afluente do RAHLFa, na segunda condição, com vazão de $2,7 \mathrm{l} \cdot \mathrm{h}^{-1}$

TABELA 5.4 - Resumo dos resultados obtidos, na primeira condição, operando sistema misto anaeróbio/aeróbio/anóxico

TABELA 5.5 - Resumo dos resultados obtidos, na segunda condição, operando sistema misto anaeróbio/aeróbio/anóxico 


\section{Lista de abreviaturas e siglas}

ANAMMOX: anaerobic ammonium oxidation;

BRN: bactérias redutoras de nitrato;

BRS: bactérias redutoras de sulfato;

$\mathrm{C} / \mathrm{N}$ : relação carbono/nitrogênio

ETE: estação de tratamento de esgoto;

OLAND: oxygen limited autotrophic nitrification denitrification;

RAHLF: Reator Anaeróbio Horizontal de Leito Fixo

RAHLFa : Reator Anóxico Horizontal de Leito Fixo;

$\mathrm{RBC}$ : rotating biological contactor;

RBN : remoção biológica de nutrientes;

RDNA: redução dissimilatória do nitrato a nitrogênio amoniacal;

RMRLF : Reator Misto Radial de Leito Fixo;

SHARON: single reactor high activity ammonia removal over nitrite;

$\mathrm{SN}$ : shorter nitrification

SND: simultaneous nitrification/denitrification;

TDH ou $\theta$ h : tempo de detenção hidráulica;

TRC : tempo de retenção celular e

UASB: upflow anaerobic sludge blanket. 


\section{Lista de símbolos}

$\mu_{\text {máx }}$ : velocidade máxima de crescimento específico, dia ${ }^{-1}$;

[N-Amon $]_{0}$ : concentração inicial de nitrogênio amoniacal, mg. $I^{1}$;

$\mathrm{AB}$ : alcalinidade a bicarbonato, $\mathrm{mg} . \mathrm{I}^{1}$;

AVT: ácidos voláteis totais, $\mathrm{mg} \cdot \mathrm{I}^{1}$;

DBO : demanda bioquímica de oxigênio, $\mathrm{mg} . I^{1}$;

DQO : demanda química de oxigênio, mg. $I^{1}$;

DQOf : demanda química de oxigênio de amostra filtrada em membrana de $1,2 \mu \mathrm{m}, \mathrm{mg} . I^{1}$

$\mathrm{K}_{1}^{\text {app: }}$ : constante cinética aparente, $\mathrm{t}^{-1}$;

Ka: constante de ionização;

Ks : constante de saturação, mg. $I^{1}$;

$\mathrm{N}$-amon : nitrogênio amoniacal, mg. ${ }^{1}$;

$\mathrm{N}-\mathrm{NH}_{3}$ : nitrogênio na forma de amônia, $\mathrm{mg} .{ }^{1}$;

$\mathrm{N}-\mathrm{NH}_{4}{ }^{+}$: nitrogênio na forma de íon amônio, mg. $\digamma^{1}$;

$\mathrm{N}-\mathrm{NO}_{2}^{-}$: nitrogênio na forma de nitrito, mg..$^{1}$;

$\mathrm{N}-\mathrm{NO}_{3}{ }^{-}$: nitrogênio na forma de nitrato, $\mathrm{mg} . \mathrm{I}^{1}$;

N-NTK : nitrogênio Total Kjeldahl, mg. $I^{1}$;

$\mathrm{N}$-org : nitrogênio orgânico, mg. $I^{1}$;

OD : Oxigênio Dissolvido, mg. $I^{1}$;

$\mathrm{pH}$ : potencial hidrogeniônico;

SSed: sólidos sedimentáveis, $\mathrm{ml} I^{1}$;

SSV: sólidos suspensos voláteis, mg. $I^{1}$;

ST: sólidos totais, mg. ${ }^{1}$;

SV: sólidos voláteis, $\mathrm{mg} . .^{1}$;

$\mathrm{Y}_{\text {máx }}$ : coeficiente máximo de produção de biomassa, mg SSV. $\mathrm{mg}^{-1} \mathrm{~N}$; 


\section{Resumo}

GARBOSSA, L.H.P. (2003). Desenvolvimento e avaliação de sistema de leito fixo - reator misto radial seguido de reator anóxico horizontal - para remoção de matéria orgânica e de nitrogênio de esgoto sanitário. 100 p. Dissertação (Mestrado) - Escola de Engenharia de São Carlos, Universidade de São Paulo.

Os sistemas combinados anaeróbio/aeróbio, para tratamento de água residuária, têm sido considerados alternativas viáveis do ponto de vista técnicoeconômico em relação aos sistemas tradicionais. Este trabalho consiste no desenvolvimento de nova configuração para um sistema, com dois reatores operados seqüencialmente, composto por Reator Misto Radial de Leito Fixo para tratamento e nitrificação de esgoto sanitário e Reator Anóxico Horizontal de Leito Fixo para desnitrificação da água residuária. O RMRLF mostrou ser uma configuração promissora, promoveu a remoção de matéria orgânica, favoreceu a transferência de oxigênio dissolvido devido à distribuição das espumas em seções circuncêntricas, obteve boa nitrificação e possibilitou a desnitrificação simultânea com a nitrificação. O RAHLFa obteve baixa eficiência no processo de desnitrificação. O bom desempenho do sistema é decorrente, principalmente, da operação do RMRLF e apresentou eficiências de $88 \%$, $86 \%$ e 95\% na remoção de matéria orgânica em termos de demanda química de oxigênio, retenção de sólidos suspensos voláteis e nitrificação, respectivamente. O efluente final do sistema atingiu valores de demanda química de oxigênio, sólidos suspensos voláteis, nitrito e nitrato de $41 \mathrm{mg} . I^{1}, 8 \mathrm{mg} . I^{1}, 0,3 \mathrm{mg} . I^{1}$ e $16,7 \mathrm{mg} . I^{1}$, respectivamente. No efluente final não foi detectada a presença de nitrogênio amoniacal.

Palavras-chave: reator radial, reatores mistos, sistemas combinados, anaeróbio/aeróbio/anóxico, esgoto sanitário, nitrificação, desnitrificação. 


\begin{abstract}
GARBOSSA, L.H.P. (2003). Immobilized bed system development and evaluation - radial mixed reactor followed by horizontal-flow anoxic reactor - for organic matter and nitrogen reduction in domestic wastewater. 100 p. Dissertação (Mestrado) - Escola de Engenharia de São Carlos, Universidade de São Paulo.

The combined, anaerobic/aerobic systems for wastewater treatment, are considered as possible alternatives from the technical-economical perspective, in relation to the traditional systems. The data obtained on the development and operation of a new system configuration of two reactor sequentially operated, composed of a Radial Flow Anaerobic/Aerobic Immobilized Biomass reactor (RFAAIB) for domestic sewage treatment and a Horizontal-flow Anoxic Immobilized Biomass (HAIBa) for wastewater denitrification are presented. The RFAAIB reactor was found to be a very promising configuration for promoting the organic matter removal, due to its round shape distribution of the foam matrix it favored the dissolved oxygen transfer, obtaining good nitrification and making possible to achieve simultaneous nitrification and denitrification. The HAIBa reactor obtained low efficiency in the denitrification process. The good system performance is mainly due to the RFAAIB reactor it achieved efficiency of $88 \%, 86 \%$ and $95 \%$ in the biochemical oxygen demand reduction process, volatile suspended solids retention and nitrification, respectively. The system final effluent achieved chemical oxygen demand, volatile suspended solids, nitrite and nitrate values of $41 \mathrm{mg} . I^{1}, 8 \mathrm{mg} . I^{1}$, $0,3 \mathrm{mg} . \digamma^{1}$ and $16,7 \mathrm{mg} . \digamma^{1}$, respectively. In the final effluent no ammonium nitrogen was detected.
\end{abstract}

Key-words: radial reactor, combined reactors, combined systems, anaerobic/aerobic/anoxic, domestic sewage, nitrification, denitrification. 


\section{Introdução}

A cada ano, morrem aproximadamente 1,7 milhão de pessoas no mundo devido ao consumo de água não potável e por falta de saneamento e de higiene; na maioria dos casos devido a diarréias infecciosas (OMS, 2002). Confirma-se, assim, a importância do tratamento das águas residuárias, como condição essencial ao bem estar e manutenção da saúde da população.

No que se refere ao controle da poluição bioquímica, a remoção do excesso de nitrogênio das águas residuárias é necessária tanto porque as formas reduzidas de nitrogênio consomem o oxigênio dissolvido dos corpos d'água, como porque a presença de concentrações elevadas de nitrogênio, em qualquer de suas formas, favorece o crescimento excessivo de algas e pode causar eutrofização de lagos e represas (BERNARDES \& KLAPWIJK, 1996). Além desses aspectos, em $\mathrm{pH}$ básico e concentrações acima de 0,25 mg. $\mathrm{I}^{1}$, a amônia pode afetar 0 crescimento de diversas espécies de peixes. No que se refere à saúde pública, a presença de nitratos, em elevadas concentrações, nas águas de abastecimento pode causar a metahemoglobinemia, doença conhecida como Síndrome do Bebê Azul. Dessa forma, é importante reduzir a emissão de compostos nitrogenados nos corpos receptores.

No Brasil, no que concerne à remoção de nitrogênio, a resolução CONAMA $n^{\circ} .20$, de 18 de junho de 1986, define que os efluentes de qualquer fonte poluidora somente poderão ser lançados nos corpos de água se a concentração de amônia for no máximo de $5 \mathrm{mg} . I^{1}$ (BRASIL, 1986).

A busca por tecnologias eficientes e de baixo custo é devida ao fato de as normas legais apresentarem a tendência de, no decorrer do tempo, tornarem-se mais restritivas. Ademais, quando se trata da saúde da população, é importante mais que seguir leis, promover o estado de bem estar a que todos têm direito. Compreende-se assim, a importância do desenvolvimento de sistemas para 
remoção de matéria orgânica e compostos nitrogenados de águas residuárias, que permitam congregar processos eficazes e economicamente viáveis. Para que isso ocorra, é necessário o desenvolvimento continuado de propostas que possibilitem a obtenção desses efluentes e a melhor compreensão dos sistemas.

Os processos biológicos são utilizados para tratar águas residuárias industriais e domésticas, nas quais é esperada grande quantidade de nutrientes. Apesar dos avanços biotecnológicos, principalmente no que se refere ao uso da tecnologia anaeróbia, nem sempre é possível a obtenção de efluente que atenda aos padrões de lançamento exigidos por lei.

O processo convencional de remoção de nitrogênio separado em duas etapas principais, nitrificação e desnitrificação, já é conhecido. Consiste na remoção de nitrogênio da água residuária através de processos biológicos que levam à formação de nitrogênio $N_{2}$ como produto final, forma esta ambientalmente inofensiva.

A literatura científica relata outros processos capazes de realizar a remoção biológica de nitrogênio, como a SND (simultaneous nitrification/denitrification), que desenvolve processos de nitrificação e desnitrificação simultaneamente no mesmo reator (MÜNCH et al., 1996; POCHANA \& KELLER, 1999); ou, processos como o ANAMMOX (Anaerobic ammonium oxidation), no qual ocorre a oxidação anaeróbia do íon amônio e o SHARON (single reactor high activity ammonia removal over nitrite) baseado no estabelecimento de curto-circuito da nitrificação para a desnitrificação (VERSTRAETE \& PHILIPS, 1998).

Segundo HOSAKA et al. (1991), o aumento da velocidade de nitrificação e a retenção de biomassa possibilitam o desenvolvimento de sistemas mais compactos para remoção de nitrogênio da água residuária.

São muitas as alternativas para o tratamento de águas residuárias. Atualmente, existem diversas opções eficientes para remoção de matéria orgânica e de macro-nutrientes. É necessária, porém, a busca contínua por tecnologias de baixo custo que sejam viáveis e não removam apenas a matéria orgânica carbonácea e sólidos suspensos mas, também, nutrientes e microrganismos patogênicos que, geralmente, são lançados nos corpos receptores.

Se comparados a sistemas anaeróbios convencionais, os sistemas combinados anaeróbio/aeróbio apresentam características promissoras, 
principalmente devido ao menor consumo de energia e à reduzida produção de lodo (CASTILLO et al., 1997).

Estudos desenvolvidos no Departamento de Hidráulica e Saneamento da EESC-USP, em escala de bancada e, posteriormente, em escala piloto, também demonstraram a viabilidade de sistemas mistos anaeróbio/aeróbio, para redução de DQO (demanda química de oxigênio) e remoção de nitrogênio (LOPES \& CAMPOS, 2000; TORRES \& FORESTI, 2000; VIEIRA et al., 2000).

VIEIRA et al. (2000) estudou sistema de pós-tratamento de efluente de reator anaeróbio. Seu objetivo era promover a nitrificação em um reator que favorecesse a distribuição de oxigênio dissolvido no meio líquido e promover a desnitrificação em outro reator. Assim, foi construído o primeiro reator radial de leito fixo para nitrificação e a configuração desenvolvida por ZAIAT et al. (1994) foi adaptada para promover a desnitrificação em um RAHLF.

Os resultados obtidos nesse sistema foram considerados satisfatórios. O valor médio de concentração de OD (oxigênio dissolvido) foi de 4,2 mg. $\digamma^{1}$. O sistema apresentou, para TDH de $4 \mathrm{~h}$, efluente final com concentração de nitrogênio amoniacal de $2 \mathrm{mg} . I^{1}$ e de nitrato de $1,1 \mathrm{mg} . I^{1}$.

Devido aos bons resultados obtidos por VIEIRA et al. (2000) no sistema apresentado, a linha de pesquisa ganhou amplitude para serem investigadas novas possibilidades dessa configuração. Dessa forma, a proposta desta pesquisa de mestrado foi estudar o reator radial de leito fixo modificando-o e criando um compartimento anaeróbio, para a remoção de matéria orgânica. O sistema, portanto, objetivou o tratamento e o pós-tratamento de esgoto sanitário, utilizandose um reator radial de leito fixo anaeróbio/aeróbio para remoção de matéria orgânica e nitrificação e um reator horizontal de leito fixo, anóxico para desnitrificação, operados seqüencialmente. Assim a proposta é avaliar a viabilidade técnica dessa nova configuração de sistema, unindo suas vantagens e contribuindo para a busca de sistemas compactos e eficientes no tratamento de águas residuárias. 


\section{Revisão bibliográfica}

\subsection{Biotecnologia anaeróbia}

O tratamento biológico de esgoto sanitário objetiva remover matéria orgânica carbonácea e macro-nutrientes, como nitrogênio e fósforo.

Dois dos ciclos biogeoquímicos desempenham importante papel na remoção de matéria orgânica: o aeróbio, no qual os microrganismos utilizam oxigênio como aceptor final de elétrons para realizar a decomposição da matéria orgânica e o anaeróbio, no qual o oxigênio não está presente, é o metabolismo que promove rearranjo dos elétrons da molécula.

A digestão anaeróbia é caracterizada pela produção de metano e dióxido de carbono, apresentado na eq. (2.1) (BUSWELL \& MUELLER, 1952 apud SPEECE, 1996).

$$
C_{X} H_{Y} O_{Z}+\left(x-\frac{y}{4}-\frac{b}{2}\right) H_{2} O \leftrightharpoons\left(\frac{x}{2}-\frac{y}{8}+\frac{z}{4}\right) C O_{2}+\left(\frac{x}{2}+\frac{y}{8}-\frac{z}{4}\right) C H_{4}
$$

$\mathrm{Na}$ conversão biológica anaeróbia de esgoto sanitário para metano, é necessário sintrofismo entre os microrganismos. O processo total foi descrito em nove etapas por HARPER \& POHLAND (1986) focando, particularmente, a função do hidrogênio em estabelecer e direcionar as transformações bioquímicas necessárias para a produção de metano:

1) Hidrólise de polímeros orgânicos para monômeros; 
2) Conversão de monômeros orgânicos a hidrogênio; bicarbonato; ácido acético, propiônico, butírico e outros produtos orgânicos como etanol e ácido lático.

3) Oxidação de produtos orgânicos reduzidos a hidrogênio, bicarbonato e ácido acético por bactérias acetogênicas produtoras de hidrogênio;

4) Respiração acetogênica de bicarbonato, por bactérias homoacetogênicas;

5) Oxidação de produtos orgânicos reduzidos a bicarbonato e acetato por BRN (bactérias redutoras de nitrato) e BRS (bactérias redutoras de sulfato);

6) Oxidação do acetato para bicarbonato pelas BRN e BRS;

7) Oxidação do hidrogênio pelas BRN e BRS;

8) Fermentação metanogênica acetoclástica e

9) Respiração metanogênica do bicarbonato.

A disposição final do lodo descartado de sistema anaeróbio é tão problemática quanto o aeróbio. Porém, em sistema anaeróbio, a produção de lodo em excesso é significativamente menor, correspondendo à cerca de $20 \%$ da produzida em sistema aeróbio, tratando esgoto sanitário. Além disso, dependendo da água residuária tratada, aproximadamente 90 a 95\% da DQO é convertida a gás metano (SPEECE, 1996). Dessa maneira, além de menor produção de lodo, o consumo de energia também é inferior, devido à dispensa do uso de aeradores; em alguns casos há, a possibilidade de uso do gás metano como fonte de energia.

Apesar de uma das vantagens da biotecnologia anaeróbia ser o baixo rendimento da biomassa, essa é também uma desvantagem, por dificultar a obtenção de alto TRC (tempo de retenção celular) dissociado do TDH (tempo de detenção hidráulica). Sistemas que promovem a retenção de sólidos no interior do reator, como por exemplo a utilização de meio suporte em reator anaeróbio para imobilização da biomassa, têm-se mostrado ótima opção para resolver esse problema, desvinculando o TDH do TRC. 


\subsection{Remoção biológica do nitrogênio}

Em reatores biológicos que tratam esgoto sanitário, as principais fontes de nitrogênio são o orgânico e o amoniacal. São essas as principais formas de nitrogênio que chegam às estações de tratamento de águas residuárias, provenientes de residências, atividades agrícolas e industriais.

A matéria nitrogenada inorgânica afluente é representada pelo $\mathrm{N}$-amon (nitrogênio amoniacal), nas formas livre $\left(\mathrm{NH}_{3}\right)$ e ionizada $\left(\mathrm{NH}_{4}{ }^{+}\right)$; a predominância de uma forma ou de outra depende do $\mathrm{pH}$. Em esgotos sanitários, as formas oxidadas em nitrito e nitrato são menos comumente encontradas.

Em esgoto municipal, a concentração do N-NTK (nitrogênio total kjeldahl) geralmente situa-se na faixa de 40 a $60 \mathrm{mg} . f^{1}$, ou seja, corresponde a, aproximadamente, 6 a 12\% da DQO afluente. Da concentração total, cerca de $75 \%$ é nitrogênio amoniacal e 25\% nitrogênio orgânico (van HAANDEL \& MARAIS, 1999).

A resolução CONAMA $n^{\circ} 20$ determina, para água doce, nas diversas classes de rios as concentrações limites de 1,0,0,02, 10,0 e 1,0 mg. $I^{1}$ para o $\mathrm{N}$ amon., $\mathrm{N}-\mathrm{NH}_{3}, \mathrm{~N}^{-\mathrm{NO}_{3}}{ }^{-}$(nitrogênio na forma de nitrato) e $\mathrm{N}^{-N_{2}}{ }^{-}$(nitrogênio na forma de nitrito), respectivamente (BRASIL, 1986).

O nitrogênio inorgânico está presente, no meio, em várias formas e estados de oxidação, conforme apresentado na Tabela 2.1 .

TABELA 2.1- Formas e estados de oxidação do nitrogênio

\begin{tabular}{ccc}
\hline Forma & Fórmula & $\begin{array}{c}\text { Estado de oxidação do } \\
\text { nitrogênio }\end{array}$ \\
\hline Amônia & $\mathrm{NH}_{3}$ & -3 \\
Íon amônio & $\mathrm{NH}_{4}{ }^{-}$ & -3 \\
Nitrogênio gasoso & $\mathrm{N}_{2}$ & 0 \\
Íon nitrito & $\mathrm{NO}_{2}^{-}$ & +3 \\
ĺon nitrato & $\mathrm{NO}_{3}^{-}$ & +5 \\
\hline
\end{tabular}

Fonte: Adaptado de van HAANDEL \& MARAIS, (1999).

A matéria nitrogenada orgânica pode ser composta por uréia, aminoácidos e outras substâncias orgânicas. O estado de oxidação do nitrogênio pode ser modificado pela ação de microrganismos. As possíveis transformações nos 
processos de tratamento biológico são simplificadamente mostradas na Figura 2.1. No decorrer da transformação biológica do nitrogênio, da forma orgânica para a forma molecular, ocorrem reações de amonificação, assimilação, nitrificação e desnitrificação.

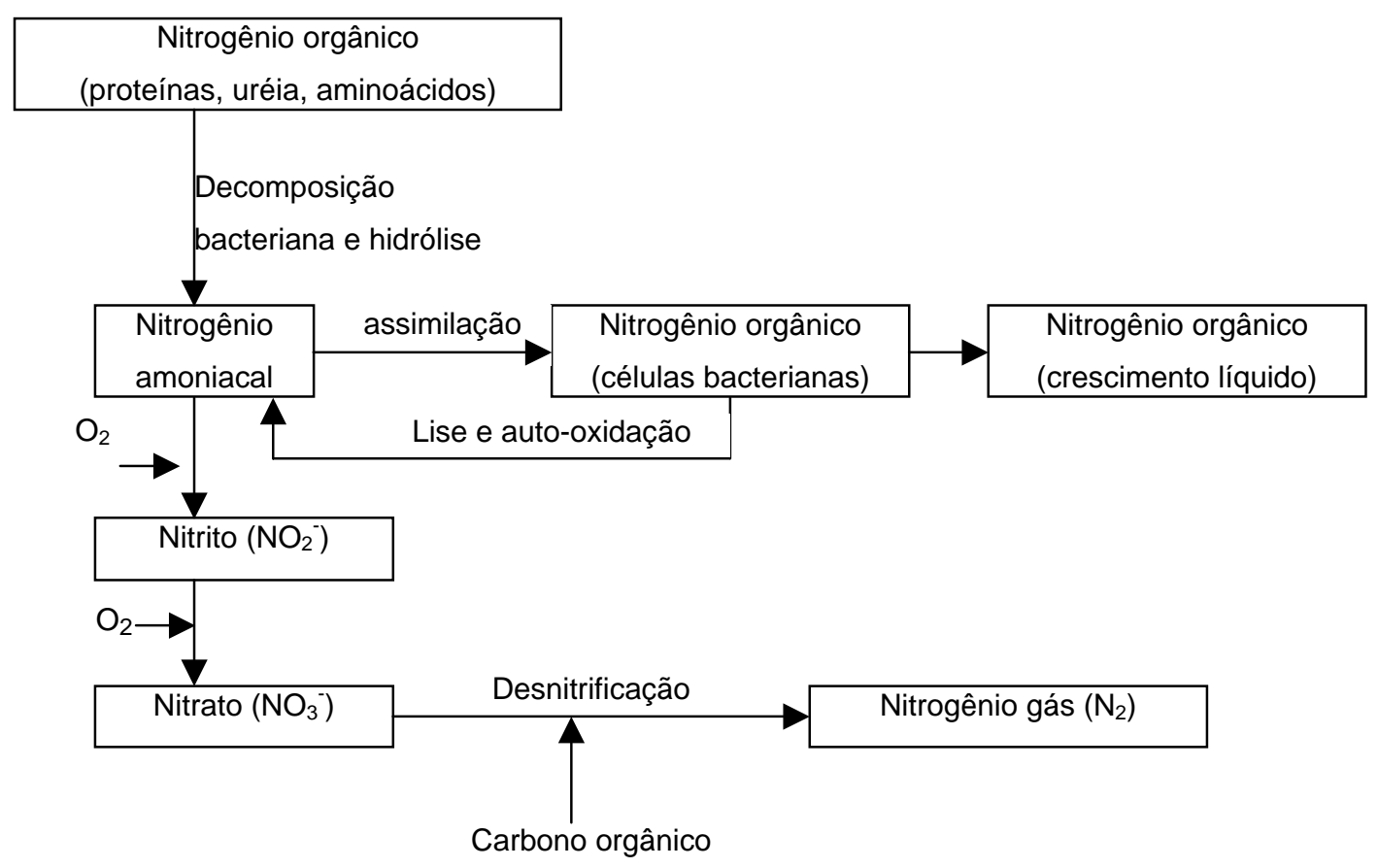
biológico.

FIGURA 2.1 - Transformações do nitrogênio nos processos de tratamento Fonte SEDLAK (1991).

Alguns processos são desinteressantes pelo fato de converterem nitrito e nitrato para óxido nitroso $\left(\mathrm{N}_{2} \mathrm{O}\right)$, composto este cuja influência sobre o efeito estufa é 320 vezes mais significativa que a do dióxido de carbono, além de promover destruição da camada de ozônio (SPECTOR, 1998).

Há interesse, portanto, em dispor de sistemas que, na primeira etapa (anaeróbia), promovam o processo de amonificação em que o nitrogênio orgânico é convertido a nitrogênio amoniacal e, na segunda etapa (aeróbia), promovam a nitrificação através da oxidação da amônia, de maneira a resultar em baixas concentrações de nitrogênio amoniacal no efluente. Embora, essas duas etapas sejam importantes, é indispensável a remoção do nitrato resultante por meio da desnitrificação para que a concentração de compostos nitrogenados no efluente seja baixa. 


\subsubsection{Nitrificação Biológica}

Em 1877, na França, Schloesing e Muntz passaram esgoto através de uma coluna de solo arenoso e giz (carbonato de cálcio) e verificaram que depois de aproximadamente 20 dias não havia mais nitrogênio amoniacal na extremidade inferior, mas apenas grande quantidade de nitrato. Porém, esse fenômeno cessava quando adicionavam clorofórmio ou água fervente. Entretanto, se após a esterilização, era adicionada pequena quantidade de solo fresco, a oxidação do nitrogênio amoniacal voltava a ocorrer, evidenciando ser o fenômeno de origem biológica, o qual denominaram Nitrificação.

Em ambiente aeróbio, ocorre a nitrificação biológica, na qual bactérias autótrofas e heterótrofas promovem a oxidação biológica do nitrogênio amoniacal para nitrito e, então, para nitrato. É valido observar que a nitrificação pelas bactérias nitrificantes autótrofas é considerada mais significativa que a realizada por bactérias heterótrofas. Entretanto, a velocidade de crescimento das autótrofas é mais baixa que a das heterótrofas; ademais as autótrofas são mais sensíveis a baixas concentrações de OD.

As etapas de nitritação, em que o $\mathrm{N}$-amon é oxidado a nitrito e nitratação, na qual o nitrito é oxidado a nitrato, podem ser descritas pelas eq. estequiométricas (2.2) e (2.3).

$$
\begin{array}{ll}
\mathrm{NH}_{4}^{+}+\frac{3}{2} \mathrm{O}_{2} \stackrel{\text { Microrganismos }}{\longrightarrow} \mathrm{NO}_{2}^{-}+\mathrm{H}_{2} \mathrm{O}+2 \mathrm{H}^{+} \Delta \mathrm{G}^{\circ}=-51,8 \mathrm{kcal} \text { (2.2) } \\
\mathrm{NO}_{2}^{-}+\frac{1}{2} \mathrm{O}_{2} \stackrel{\text { Microrgani smos }}{\longrightarrow} \mathrm{NO}_{3}^{-} & \Delta \mathrm{G}^{\circ}=-20,1 \mathrm{kcal}(\mathbf{2 . 3})
\end{array}
$$


liberam produtos solúveis, que aumentam o fornecimento de substrato às heterótrofas.

Dos microrganismos que proporcionam a nitrificação, as bactérias autótrofas Nitrossomonas sp. e Nitrobacter sp. são os exemplos conhecidos. Elas obtêm energia a partir da oxidação da amônia a nitrito e do nitrito a nitrato, respectivamente, e utilizam, preferencialmente, $\mathrm{o} \mathrm{CO}_{2}$ como fonte de carbono.

Esses microrganismos são sensíveis às condições ambientais, assim como, a outros fatores inibidores de crescimento. Para que os sistemas biológicos de nitrificação operem satisfatoriamente, é necessário atender alguns requisitos relativos ao $\mathrm{pH}$, presença de $\mathrm{OD}, \mathrm{TRC}$, temperatura, concentração de $\mathrm{N}$-amon. e relação C/N (Carbono/Nitrogênio) adequada (FORD et al., 1980; SURAMPALLI et al., 1997).

FORD et al. (1980) e HENZE et al. (1997) relataram que o pH ótimo para formação de nitrito e nitrato é superior a 7,0, mas esse valor não é bem definido. A faixa oscila entre 7 e 9; ademais as bactérias nitrificantes têm a habilidade de adaptarem-se mesmo em $\mathrm{pH}$ fora da faixa ótima, o que permite obter a mesma eficiência de nitrificação. Deve-se tomar cuidado com reatores de filme fixo, pois HENZE et al. (1997) afirmaram que, para esses sistemas, os valores de $\mathrm{pH}$ observados na fase líquida podem ser diferentes dos valores reais no biofilme.

O nitrogênio amoniacal existe em equilíbrio na solução e através da eq. (2.4) é possível definir a porcentagem de $\mathrm{N}^{-N_{4}{ }^{+}}$no meio. Os valores típicos de $\mathrm{K}_{\mathrm{a}}$ para temperaturas entre 0 e $25^{\circ}$ e os valores de $\mathrm{pH}$ próximos a 7,0, típicos de efluentes de digestão anaeróbia, permitem concluir que aproximadamente $99 \%$ do nitrogênio está como $\mathrm{N}-\mathrm{NH}_{4}{ }^{+}$(BARNES \& BLISS, 1983).

$$
\% N-N H_{4}^{+}=\frac{100}{1+K_{a} /\left[H^{+}\right]}
$$

O efeito da nitrificação sobre a alcalinidade, produção celular e consumo de oxigênio pode ser descrito por simples relações estequiométricas, como a eq. (2.5) global apresentada por HENZE et al. (1997), na qual a fórmula $\mathrm{C}_{5} \mathrm{H}_{7} \mathrm{NO}_{2}$ representa a composição das células. 


$$
\begin{aligned}
& \mathrm{NH}_{4}^{+}+1,86 \mathrm{O}_{2}+1,98 \mathrm{HCO}_{3}^{-} \leftrightharpoons \\
& 0,02 \mathrm{C}_{5} \mathrm{H}_{7} \mathrm{NO}_{2}+0,98 \mathrm{NO}_{3}^{-}+1,88 \mathrm{H}_{2} \mathrm{CO}_{3}+1,04 \mathrm{H}_{2} \mathrm{O}
\end{aligned}
$$

$\mathrm{Na}$ nitrificação observa-se o envolvimento de íons hidrogênio; eq. (2.2) e (2.3), há a produção de 2 mols de $\mathrm{H}^{+}$por mol de nitrato formado. Segundo Van HAANDEL \& MARAIS (1999), há consumo de $100 \mathrm{~g}$ de alcalinidade, na forma de $\mathrm{CaCO}_{3}$ para cada mol de nitrogênio nitrificado, equivalente a $14 \mathrm{~g}$ de nitrogênio. Assim, se não for fornecida alcalinidade suficiente, tem início a queda do pH que causa inibição do processo, levando à interrupção da nitrificação.

O número de oxidação do nitrogênio, na forma amoniacal, como apresentado na Tabela 2.1, é -3 que, na nitrificação, aumenta para +5 como nitrato, com transferência de 8 elétrons para cada átomo de nitrogênio, aceitos por 4 átomos de oxigênio. Portanto, o consumo de oxigênio é igual a $4,57 \mathrm{mgO}_{2} \cdot \mathrm{mg}^{-1} \mathrm{~N}$ na nitrificação (van HAANDEL \& MARAIS, 1999).

A concentração crítica de OD é a concentração mínima no líquido, para que não ocorra formação de ambiente anaeróbio ou anóxico no interior do reator. Essa concentração depende da velocidade de consumo de oxigênio e da quantidade de biomassa no interior do reator. No caso de lodos ativados, o consumo de oxigênio ocorre, principalmente, dentro do floco e a concentração de OD diminui do exterior para o centro do floco (van HAANDEL \& MARAIS, 1999). Não há inibição aparente da nitrificação se a concentração de oxigênio dissolvido, no meio líquido, for mantida acima de $1,5 \mathrm{mg} . \digamma^{1}$.

Segundo SURAMPALLI et al. (1997), a velocidade máxima de nitrificação ocorre em concentrações de OD maiores que $2 \mathrm{mg} . \mathrm{I}^{1}$. Por outro lado, se a concentração for menor que $0,5 \mathrm{mg} . I^{1}$, a velocidade de nitrificação cai drasticamente e pode ser totalmente interrompida.

Devido ao baixo rendimento energético das reações de oxidação, os organismos nitrificantes crescem lentamente, com baixo rendimento celular. Para levar o $\mathrm{N}$-amon a $\mathrm{N}^{-\mathrm{NO}_{3}}{ }^{-}$, faz-se necessário que o tempo de retenção celular seja suficientemente alto para permitir o desenvolvimento dos microrganismos e garantir a permanência da biomassa nitrificante no reator.

Diversos autores indicam que a faixa de temperatura ótima para o crescimento de bactérias nitrificantes encontra-se entre $30^{\circ} \mathrm{C}$ e $35^{\circ} \mathrm{C}$. Observa-se 
baixo ou nulo crescimento de bactérias nitrificantes sob temperaturas de $4^{\circ} \mathrm{C}$ (FORD et. al.,1980; HENZE et al., 1997).

O próprio substrato pode tornar-se inibidor para bactérias, em função da concentração de substrato e do meio em que elas se encontram (FORD et al.,1980). Geralmente, as Nitrosomonas sp. são consideradas mais sensíveis que as Nitrobacter sp.. Muitas substâncias orgânicas e inorgânicas podem inibir o processo de nitrificação (BARNES \& BLISS, 1983). Algumas substâncias, como os compostos de enxofre, fenóis e cianetos, têm efeito inibitório relativamente forte (HENZE et al., 1997).

Com baixa relação de $\mathrm{C} / \mathrm{N}$, as bactérias heterotróficas, limitadas pelo carbono, disponibilizam amônia em excesso para nitrificação. Para altas relações $\mathrm{C} / \mathrm{N}$, o processo de nitrificação é inibido pelo excesso de carbono orgânico e a concentração de nitrato cai, chegando a zero. Essa relação mostra a vantagem aparente em separar-se a nitrificação da remoção de matéria carbonácea (CALLADO, 2001).

BARNES \& BLISS (1983) apontaram que o modelo de Monod, apresentado na eq. (2.6), é o que melhor representa a cinética de crescimento das bactérias nitrificantes para esgoto doméstico. Entretanto, para águas residuárias com alta concentração de substrato ( $\mathrm{N}$-amon medido como $\mathrm{N}-\mathrm{NH}_{4}{ }^{+}$), encontrado em água residuária industrial ou de suinocultura, a cinética pode ser descrita por uma equação de ordem zero (HENZE et. al., 1997).

$$
\mu=\mu_{\text {máx }} * \frac{N \cdot N H_{4}^{+}}{K_{S}+N \cdot N H_{4}^{+}}
$$

A Tabela 2.2 apresenta os valores das constantes cinéticas da nitrificação obtidos por BARNES \& BLISS (1983) e HENZE et al. (1997). Ainda que se considere a nitrificação como uma única etapa e que se utilizem os dados resultantes do processo, é difícil utilizar os dados apresentados na Tabela 2.2 na elaboração de projetos. A comparação entre os valores apresentados por diferentes autores revela que os valores das constantes cinéticas apresentadas pelos primeiros autores têm faixa de abrangência maior que a dos outros, o que dificulta a adoção desses valores. 
TABELA 2.2 - Valores das constantes cinéticas na nitrificação

\begin{tabular}{|c|c|c|c|c|c|c|}
\hline & & Coeficiente & Unidade & Nitritação & Nitratação & $\begin{array}{c}\text { Resultante no } \\
\text { processo }\end{array}$ \\
\hline \multirow{4}{*}{ 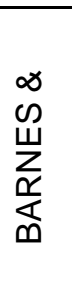 } & \multirow{4}{*}{$\frac{\dot{\mathscr{D}}}{\vec{\omega}}$} & $\mu$ máx & $\mathrm{dia}^{-1}$ & $0,46-2,2$ & $0,28-1,44$ & $0,28-1,44$ \\
\hline & & Ks & mg N-amon..$^{1}$ & $0,06-5,6$ & $0,06-8,4$ & $0,06-5,6$ \\
\hline & & $\mathrm{KsO}_{2}$ & $\mathrm{mg} \mathrm{O}_{2} \cdot I^{1}$ & $0,3-1,3$ & $0,25-1,3$ & $0,25-1,3$ \\
\hline & & Ymáx & mg SSV.mg ${ }^{-1} \mathrm{~N}$ & $0,03-0,13$ & $0,02-0,08$ & $0,05-0,21$ \\
\hline \multirow{4}{*}{$\underset{\mathrm{I}}{\mathrm{N}}$} & \multirow{4}{*}{$\frac{\dot{\sigma}}{\Phi}$} & $\mu$ máx & $\mathrm{dia}^{-1}$ & $0,6-0,8$ & $0,6-1,0$ & $0,6-1,0$ \\
\hline & & Ks & mg N-amon..$^{1}$ & $0,3-0,7$ & $0,8-1,2$ & $0,3-0,7$ \\
\hline & & $\mathrm{KsO}_{2}$ & $\mathrm{mg} \mathrm{O}_{2} \cdot I^{1}$ & $0,5-1,0$ & $0,5-1,5$ & $0,5-1,0$ \\
\hline & & Ymáx & mg SSV. $\mathrm{mg}^{-1} \mathrm{~N}$ & $0,10-0,12$ & $0,05-0,07$ & $0,15-0,20$ \\
\hline
\end{tabular}

$\mu$ máx: velocidade máxima de crescimento específico; Ks: constante de saturação do Namon: $\mathrm{KsO}_{2}$ : Constante de saturação do $\mathrm{O}_{2}$; Ymáx: Coeficiente máximo de produção de biomassa.

FONTE: adaptado de BARNES \& BLISS (1983) e HENZE et al. (1997).

DINÇER \& KARGI (2000) apresentaram o valor de 5,14 mgN-amon. $I^{1}$ para a constante de saturação do substrato. Entretanto, é difícil relacionar essa constante fazendo-se simples comparação com os valores apresentados na Tabela 2.2. Observa-se que o valor sugerido por DINÇER \& KARGI (2000) situa-se fora da faixa apresentada por HENZE et al. (1997), mas dentro da faixa de variação admitida por BARNES \& BLISS (1983).

VIEIRA (2000) estimou os parâmetros cinéticos aparentes da nitrificação para o RARLF piloto, quando operado com TDH de $4 \mathrm{~h}$, temperatura média de $25 \pm 1^{\circ} \mathrm{C}$ e concentração de OD igual a 4,19 $\pm 0,27 \mathrm{mg} \cdot \mathrm{I}^{1}$. Os parâmetros foram estimados de acordo com modelo de reações em série, apresentado na (eq 2.7).

$$
\mathrm{N}-\text { amon } \stackrel{K_{1}^{a p p}}{\longrightarrow} \mathrm{N}-\mathrm{NO}_{2}^{-} \stackrel{K_{2}^{a p p}}{\longrightarrow} \mathrm{N}-\mathrm{NO}_{3}^{-}
$$

Para o desenvolvimento das equações de balanço de massa para o $\mathrm{N}$ amon e $\mathrm{N}-\mathrm{NO}_{2}{ }^{-}$em estado transiente, o reator foi considerado contínuo de mistura completa ideal e foram desconsideradas as limitações devido a transferência de massa. Os parâmetros cinéticos aparentes, $\mathrm{k}_{1}{ }^{\text {app }} \mathrm{e}_{2}{ }^{\text {app }}$ apresentaram valores iguais 
a 1,33 $\mathrm{h}^{-1}$ e 63,96 $\mathrm{h}^{-1}$. Esses valores indicam que a velocidade de reação de nitratação foi muito mais rápida que a velocidade da reação de nitritação.

\subsubsection{Desnitrificação Biológica}

É na etapa de desnitrificação biológica que ocorre a efetiva remoção biológica de nitrogênio, em ambiente anóxico, caracterizado pela utilização do nitrogênio inorgânico nas formas de nitrito e nitrato e sua conversão para formas mais reduzidas, como $\mathrm{N}_{2} \mathrm{O}, \mathrm{NO}$ e $\mathrm{N}_{2}$. Entretanto, a redução dissimilatória do nitrato a nitrogênio amoniacal, na forma de íon amônio $\left(\mathrm{NH}_{4}^{+}\right)$, pode ocorrer no mesmo habitat no qual ocorre a desnitrificação e, até mesmo, gerar competição pelo $\mathrm{NO}_{3}$ : Nesses processos dissimilatórios, o nitrogênio reduzido não é utilizado pelas células (TIEDJE, 1988).

A desnitrificação ocorre em duas etapas: na primeira o nitrato é reduzido para nitrito e, na segunda, ocorre a redução do nitrito a nitrogênio gasoso, eq (2.8) apresentada por SURAMPALLI et al. (1997).

$$
\mathrm{NO}_{3}{ }^{-} \rightarrow \mathrm{NO}_{2}{ }^{-} \rightarrow \mathrm{NO} \rightarrow \mathrm{N}_{2} \mathrm{O} \rightarrow \mathrm{N}_{2}
$$

A redução dissimilativa do nitrato a nitrogênio amoniacal, conhecida como RDNA (redução dissimilatória do nitrato a amônia), passa pelas seguintes etapas, conforme ilustrado na eq. (2.9).

$$
\mathrm{NO}_{3}{ }^{-} \rightarrow \mathrm{NO}_{2}^{-} \rightarrow \mathrm{NOH} \rightarrow \mathrm{NO}_{2} \mathrm{OH} \rightarrow \mathrm{NH}_{4}^{+}
$$

As bactérias anaeróbias facultativas autótrofas e heterótrofas são responsáveis pela desnitrificação e utilizam matéria orgânica como fonte de carbono e energia. Nos esgotos sanitários, a desnitrificação ocorre principalmente com gêneros de organismos heterotróficos, como Achromobacter, Aerobacter, Alcaligenes, Bacillus, Brevibacterium, Flavobacterium, Lactobacillus, Micrococcus, Proteus, Pseudomonas e Spirillum. Em ambiente anóxico, esses organismos promovem a desnitrificação produzindo $\mathrm{N}_{2}$ (METCALF \& EDDY, 1991). 
As principais condições ambientais a serem atendidas são temperatura, $\mathrm{pH}$ do meio, fonte de carbono com adequada relação $\mathrm{C} / \mathrm{N}$, baixa concentração de substâncias tóxicas e ausência de OD.

Van HAANDEL \& MARAIS (1999) comentaram que a desnitrificação aumenta com a temperatura até o valor ótimo próximo a $40^{\circ} \mathrm{C}$. Contudo, SURAMPALLI et al. (1997) relataram que a faixa ótima se encontra no intervalo de 10 a $30^{\circ} \mathrm{C}$.

Diversos autores citam a faixa ótima de $\mathrm{pH}$ para desnitrificação. HENZE et al. (1997) relataram que esse valor fica entre 7 e 9; para SURAMPALLI et al. (1997), o pH ideal encontra-se entre 6,5 a 8,0; van HAANDEL \& MARAIS (1999) indicaram que a faixa ótima, observada por diversos autores, está no intervalo de 7,0 a 7,5 e que, para pH menor que 6,0 e maior que 8,5 , há grande redução de atividade de desnitrificação.

Ao contrário da nitrificação que consome alcalinidade, a desnitrificação recupera aproximadamente metade da capacidade de tamponamento do $\mathrm{pH}$, ao produzir alcalinidade a bicarbonato. De acordo com a eq. (2.10), há produção de 50 $\mathrm{g}$ de alcalinidade como $\mathrm{CaCO}_{3}$, para cada $14 \mathrm{~g}$ de nitrogênio reduzido, ou seja, para cada mol de $\mathrm{NO}_{3}{ }^{-}$reduzido, um mol de $\mathrm{H}^{+}$é consumido.

A presença de um doador de elétrons é essencial para a redução do nitrato na desnitrificação. O doador de elétrons é o material orgânico biodegradável, pois as bactérias desnitrificantes, em sua maioria, são heterótrofas.

O metanol é, usualmente, a fonte de carbono escolhida para representar a reação de redução do nitrato a nitrito e a nitrogênio $N_{2}$, eq. (2.10) (BARNES \& BLISS, 1983; METCALF \& EDDY, 1991).

$$
6 \mathrm{NO}_{3}^{-}+5 \mathrm{CH}_{3} \mathrm{OH} \leftrightharpoons 3 \mathrm{~N}_{2}+5 \mathrm{CO}_{2}+7 \mathrm{H}_{2} \mathrm{O}+6 \mathrm{OH}^{-}
$$

Como o efluente de tratamento secundário apresenta baixa concentração de carbono orgânico, é necessário o fornecimento de fonte de carbono para ocorrer a desnitrificação. Diversos pesquisadores têm estudado a influência da fonte de carbono e da relação $\mathrm{C} / \mathrm{N}$, utilizando diferentes fontes de carbono com o objetivo de otimizar a eficiência de desnitrificação e obter maior economia (HER \& HUANG, 1995; SANTOS, 2002).

Há sistemas nas quais a fonte de carbono é adicionada e outros em que essas fontes estão presentes no próprio sistema. Diversos compostos podem ser 
utilizados como fonte externa de carbono; entre os mais conhecidos estão ácido acético, glicose, metano, metanol e acetona. Seu uso representa aumento dos custos de operação nas estações de tratamento de esgoto. Pode-se, também, utilizar fontes internas de carbono; parte do afluente ou a própria biomassa são usados para redução do nitrato (SOUSA, 1996). Existe a tendência de utilizar-se fonte interna de carbono devido à busca de redução de custos e menor produção de lodo.

Segundo HER \& HUANG (1995), os fatores que influenciam na eficiência da desnitrificação são o tipo de fonte de carbono (estrutura química), peso molecular e a relação $\mathrm{C} / \mathrm{N}$. Esses autores, ao estudar algumas fontes de carbono para desnitrificação, relataram que, com uso de metanol, na primeira etapa houve crescimento linear da desnitrificação devido ao aumento da relação $\mathrm{C} / \mathrm{N}$. Após a primeira etapa, ocorreu um patamar, na qual a remoção de nitrogênio se manteve constante, em aproximadamente $98 \%$, até atingir um valor de relação $\mathrm{C} / \mathrm{N}$, na terceira etapa, para o qual há rápida queda na taxa de desnitrificação, conforme ilustrado na Figura 2.2.

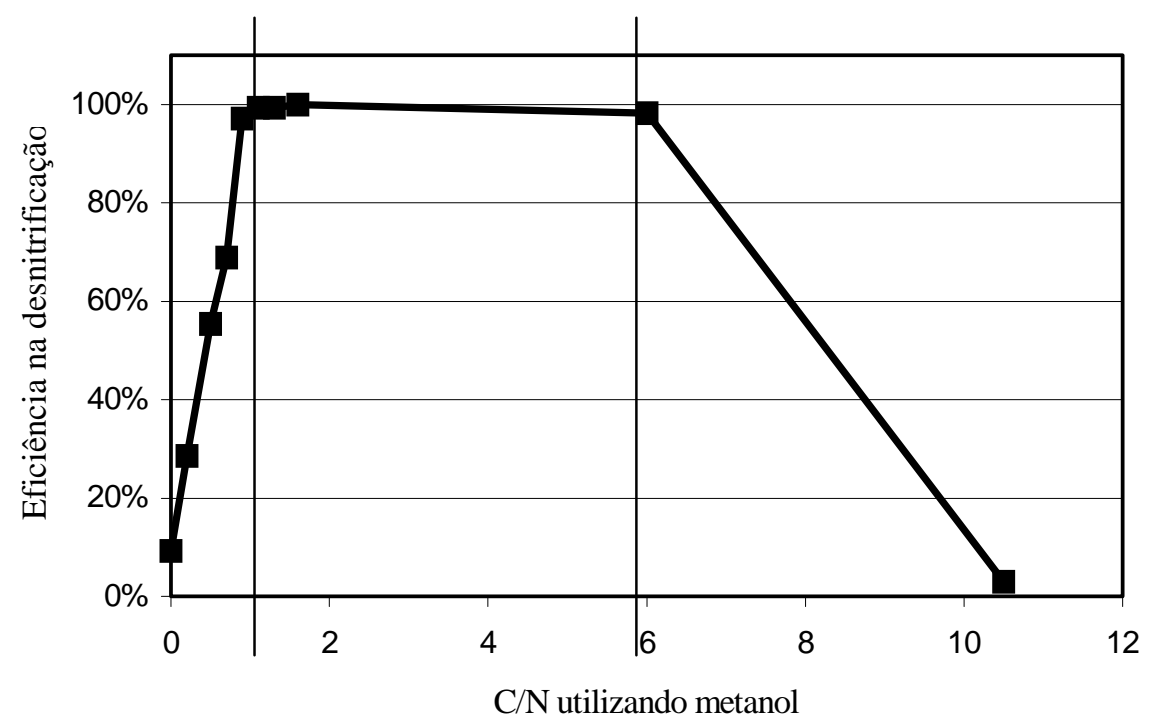

FIGURA 2.2 - Efeito da relação $\mathrm{C} / \mathrm{N}$ sobre a eficiência de desnitrificação utilizando metanol como fonte externa de carbono.

FONTE: Adaptado de HER \& HUANG (1995)

Alguns autores relatam que a melhor relação $\mathrm{C} / \mathrm{N}$ encontra-se próxima a 1 e explicam que o uso de uma relação $\mathrm{C} / \mathrm{N}$ abaixo do ideal, leva ao acúmulo de 
nitrito, devido à falta de doador de elétrons implicar em impedimento da completa desnitrificação (HER \& HUANG, 1995; SANTOS, 2002).

Altas concentrações de substâncias tóxicas podem causar a inibição do processo. No entanto, como as bactérias nitrificantes são mais sensíveis a substâncias tóxicas que as desnitrificantes, se ocorrer a nitrificação, provavelmente não haverá problema com a desnitrificação.

Altas concentrações de OD não são tóxica às bactérias desnitrificantes. Entretanto, não haverá utilização dos íons $\mathrm{NO}_{2}{ }^{-}$e $\mathrm{NO}_{3}{ }^{-}$, pelo fato de o oxigênio ser o aceptor preferencial de elétrons; porque a reação com o oxigênio é energeticamente mais favorável. Assim, é necessário manter-se baixa concentração de oxigênio no reator, preferencialmente próxima a zero, para ocorrer a desnitrificação.

Diversos autores afirmam que a cinética de desnitrificação segue o modelo de Monod. Entretanto, como na maioria dos casos a concentração de nitrato é muito maior que sua constante de saturação, a velocidade de desnitrificação independe da concentração de substrato. Por esse motivo, terá dependência de ordem zero (BARNES \& BLISS, 1983; ROS, 1995; HENZE et al., 1997).

A Tabela 2.3 apresenta valores das constantes cinéticas para esgoto sanitário.

TABELA 2.3 - Valores das constantes cinéticas na desnitrificação

\begin{tabular}{|c|c|c|c|}
\hline & Coeficiente & Unidade & $\begin{array}{c}\text { Resultante no } \\
\text { processo }\end{array}$ \\
\hline & بmáx & $\mathrm{dia}^{-1}$ & $3,0-6,0$ \\
\hline$\stackrel{\circ}{\circ}$ & Ks & $\mathrm{mg} \mathrm{DQO.} .^{1}$ & $10,0-20,0$ \\
\hline 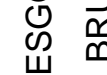 & $\mathrm{KsNO}_{3}^{-}$ & $\mathrm{mg} \mathrm{NO}_{3}^{-} \cdot I^{-1}$ & $0,20-0,50$ \\
\hline & Ymáx & mg SSV. $\mathrm{mg}^{-1} \mathrm{~N}$ & $1,60-1,80$ \\
\hline
\end{tabular}

umáx: velocidade máxima de crescimento específico; Ks: constante de saturação da matéria orgânica: $\mathrm{KsNO}_{3}$ : Constante de saturação do $\mathrm{NO}_{3}$; Ymáx: Coeficiente máximo de produção de biomassa

FONTE: adaptado de HENZE et al., (1997).

VIEIRA (2000), desenvolveu modelo cinético de primeira ordem para a desnitrificação no reator horizontal, considerando o RAHLFa como reator tubular ideal e o nitrato foi considerado o substrato limitante para 0 processo de 
desnitrificação. Obteve, a eq. (2.11), que apresenta a concentração resultante de N$\mathrm{NO}_{3}{ }^{-}$em função do comprimento do reator. Chegou-se ao valor de 0,187 $\mathrm{h}^{-1}$ para a constante cinética aparente de primeira ordem .

$$
\left[N-N O_{3}^{-}\right]=\left[N-N O_{3}^{-}\right]_{0} \cdot e^{-k_{1}^{a p p} \cdot(L / D) \cdot D /(\varepsilon \cdot V s)}
$$

Nessa equação, $\left[\mathrm{N}-\mathrm{NO}_{3}{ }^{-}\right]_{0}$ é a concentração inicial de nitrogênio na forma de nitrato, $k_{1}{ }^{\text {app }}$ é a constante cinética aparente de primeira ordem, L/D é a posição relativa no RAHLFa, $\varepsilon$ é a porosidade do leito e Vs a velocidade superficial do líquido.

\subsubsection{Novos processos na remoção de nitrogênio}

Na maioria dos sistemas em escala real projetados para que haja remoção de nitrogênio, é necessária uma etapa aeróbia para oxidação do nitrogênio amoniacal, seguida de etapa separada anaeróbia para a desnitrificação. Contudo, nos últimos anos, a literatura apresenta relatos de pesquisadores sobre processos não convencionais de remoção de nitrogênio (GÓRSKA et al., 1997; SPECTOR, 1998; VERSTRAETE \& PHILIPS, 1998).

VERSTRAETE \& PHILIPS (1998) relataram número crescente de novas configurações que utilizam processos já conhecidos e também novos, voltadas para remoção de nitrogênio no tratamento de águas residuárias. Por exemplo, o processo SHARON, baseia-se no estabelecimento de um curto-circuito nos processos de nitrificação e desnitrificação. A nitrificação é interrompida em etapa intermediária, de modo a manter o nitrogênio na forma de nitrito, procedendo-se à conversão de nitrito a nitrogênio gasoso na etapa subseqüente. Este processo economiza energia e doadores de elétrons para a desnitrificação.

Para tanto, aproveita-se o fato de, em altas temperaturas, as bactérias responsáveis pela nitratação terem crescimento mais lento que as nitritantes. A operação com tempos de detenção hidráulica menores e com altas temperaturas aplicadas devem baixar consideravelmente a concentração de microrganismos nitratantes. 
O ANAMMOX é o processo realizado por microrganismos autótrofos que dispensa a adição de fonte externa de carbono. Esse processo combina parte do nitrogênio, na forma de nitrito, com o nitrogênio amoniacal restante e produz nitrogênio gasoso $\mathrm{N}_{2}$. Isto permite redução significativa do consumo de oxigênio e da DQO na fase de desnitrificação (VERSTRAETE \& PHILIPS, 1998; JETTEN et al., 1999).

STROUS et al. (1997) avaliaram o potencial do processo ANAMMOX para remoção de amônia. O estudo foi desenvolvido em duas partes: na primeira, foram comparados dois reatores diferentes: um de leito fluidizado, com $70 \mathrm{~cm}$ de altura e $7 \mathrm{~cm}$ de diâmetro; e outro de filme fixo, com $60 \mathrm{~cm}$ de altura e $5,5 \mathrm{~cm}$ de diâmetro. Foi utilizado esgoto sintético previamente testado, e na segunda parte desse estudo, foi escolhido um tipo de reator para tratar o efluente de digestão anaeróbia de lodo de estação de tratamento de esgoto em escala real. Chegaram à conclusão que a combinação da nitrificação parcial com o ANAMMOX requer, aproximadamente, $50 \%$ menos oxigênio que o processo convencional de nitrificação seguido de desnitrificação. Os autores relataram, entretanto, que a partida de sistemas que utilizam esse processo ainda é um grande desafio, pois coeficiente de rendimento da biomassa é baixo e a adaptação do lodo é demorada (foram necessários aproximadamente 100 dias de operação). Atualmente existem poucos lugares com grande volume desse lodo disponível para inoculação.

Outra opção, denominada SN (shorter nitrification) por GÓRSKA et al. (1997) é o processo que estimula a inibição da atividade das nitrobacter e interrompe o processo de nitrificação em nitrito. As bactérias responsáveis pela oxidação do nitrato $\mathrm{NO}_{2}^{-}$são sensíveis a altas concentrações de nitrogênio amoniacal e o parâmetro decisivo na inibição da nitratação é o pH. Nos ensaios desenvolvidos para garantir a inibição da nitratação, manteve-se a concentração de amônia livre em $5 \mathrm{mg} . I^{1} \mathrm{e} \circ \mathrm{pH}$ próximo a 8 . As pesquisas confirmaram a possibilidade de obter-se a SN. Os autores concluíram que esse processo é interessante para águas residuárias com altas concentrações de nitrogênio amoniacal e que apresentam baixa relação DQO/N.

Outro processo para remoção de nitrogênio de águas residuárias, nesse caso relatado para altas concentrações de nitrogênio, é denominado deamonificação aeróbia. Nesse processo, o nitrogênio amoniacal é convertido ao gás $\mathrm{N}_{2}$, sem a necessidade de doador externo de elétrons. Os pesquisadores sugerem 
que parte do nitrito é reduzido pelo $\mathrm{NAD}^{+}$, gerado durante a oxidação do $\mathrm{N}$-amon (Figura 2.3).

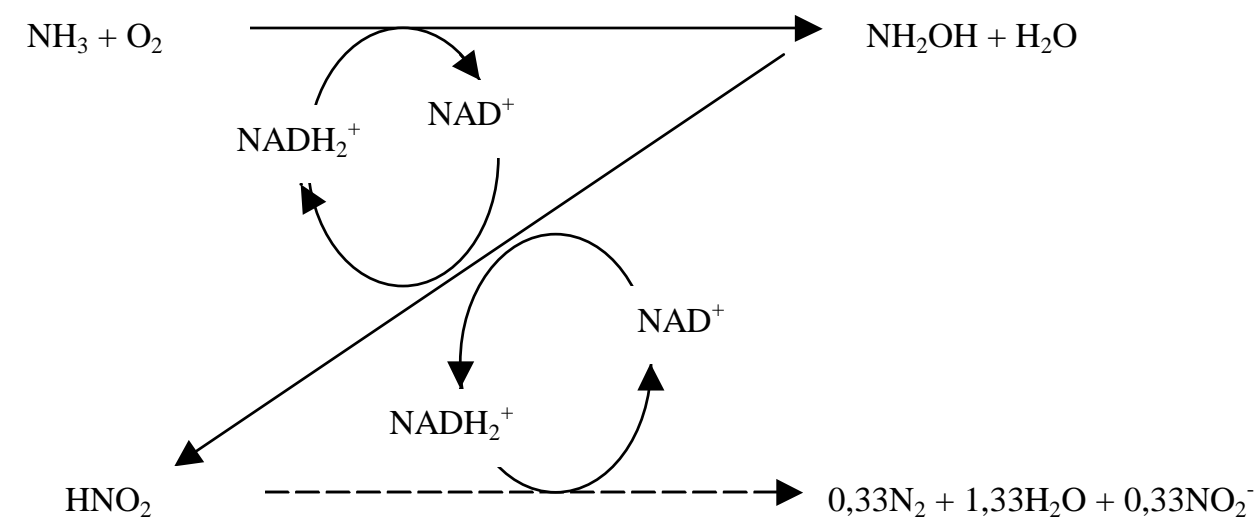

FIGURA 2.3 - Possível rota de degradação da amônia para nitrogênio gasoso e nitrito.

FONTE: Adaptado de VERSTRAETE \& PHILIPS (1998)

Neste processo, os organismos ainda não são bem conhecidos. O principal fator operacional para se conseguir a de-amonificação é o rigoroso controle do fornecimento de oxigênio. Entretanto, ainda não há um sistema estável capaz de realizar a de-amonificação. (VERSTRAETE \& PHILIPS, 1998).

Um processo, mais recentemente relatado, foi denominado OLAND (oxygen limited autotrophic nitrification denitrification) por VERSTRAETE et al. (1998). Consiste no enriquecimento de uma cultura autótrofa nitrificante, na qual o lodo autótrofo nitrificante é usado para tratar água residuária rica em $\mathrm{N}$-amon. A chave desse processo é fornecer oxigênio em concentração que leve o nitrogênio até nitrito. Então, com baixa concentração de aceptores de elétrons, as bactérias consomem o próprio nitrito para oxidar a amônia restante.

De acordo com estudos de VERSTRAETE \& PHILIPS (1998), é possível economizar aproximadamente $62 \%$ de oxigênio com uso do processo OLAND em relação aos sistemas convencionais, sem gastos com alcalinização do sistema.

O fenômeno de SND (simultaneous nitrification/denitrification) foi relatado por diversos autores. A ocorrência do SND pode ter origem física ou biológica. A explicação física, e convencional, é a ocorrência de formação no reator de microsítios anóxicos. As bactérias nitrificantes estariam em regiões com altas concentrações de OD e as desnitrificantes em zonas com baixas concentrações de 
OD. Segundo microbiologistas, o fato se deve à existência de bactérias desnitrificantes aeróbias, bem como de bactérias nitrificantes heterótrofas, responsáveis pela ocorrência simultânea dos processos de nitrificação e desnitrificação (MÜNCH et al., 1996).

HELMER \& KUNST (1998) detectaram perda de nitrogênio de até 90\% na etapa de nitrificação em reator biológico sob baixas concentrações de OD. Foram realizados testes para verificar a ocorrência dessa "perda". O biofilme foi mecanicamente homogeneizado para reduzir, quase que completamente, as possíveis microzonas anóxicas e foram feitas leituras da atividade de SND. Com os resultados obtidos, os autores admitiram que havia grande população de microrganismos autótrofos que possibilitavam a ocorrência desse processo. Os autores afirmam, ainda, que esse processo é interessante e o ganho é devido à possibilidade de remover nitrogênio com uso de baixas concentrações de $O D$, além de ser efetivo na manutenção do $\mathrm{pH}$ neutro, até mesmo sem necessidade de adição externa de alcalinidade.

POCHANA \& KELLER (1999), estudaram os principais fatores que influenciam o SND e concluíram que o uso de fonte de carbono, como DQO facilmente degradável, resulta em aumento da SND. O oxigênio dissolvido em excesso afeta negativamente a ocorrência do SND e, conforme o biofilme se torna mais espesso, maior é a atividade da nitrificação/desnitrificação simultânea. Essas conclusões, segundo os autores, confirmam que o SND depende, principalmente, da limitação de difusão do oxigênio na parte mais interna do biofilme.

\subsection{Tecnologia de sistemas mistos}

Os sistemas mistos visam combinar processos anaeróbio, aeróbio e anóxico, de acordo com condições exigidas em relação à remoção de matéria orgânica e de macro-nutrientes.

Para remoção de matéria orgânica, pode-se aplicar tanto biotecnologia anaeróbia como aeróbia. Entretanto, para obtenção de efluente que atenda aos padrões de lançamento, no que concerne à remoção de matéria orgânica e de sólidos, com remoção concomitante de macro-nutrientes, há grande vantagem em combinar processos de tratamento biológico anaeróbios com aeróbios. 
Os reatores de filme fixo apresentam-se como ótima opção para tratamento biológico de águas residuárias, pois possibilitam a obtenção de altos tempos de retenção celular, reconhecidamente o fator mais importante na estabilidade e eficiência dos processos biológicos.

Teoricamente, qualquer unidade utilizada para nitrificação pode ser combinada com qualquer unidade para desnitrificação. É necessário, entretanto, otimizar esses sistemas, observadas as condições locais, ambientais, econômicas e operacionais.

Em sistemas combinados anaeróbio/aeróbio, elimina-se grande parte da matéria orgânica biodegradável afluente na etapa anaeróbia, e assim é obtido efluente que necessita, na etapa aeróbia, muito menor capacidade de oxidação, que os efluentes sem pré-tratamento. A redução de aeração leva a grande economia no consumo de energia elétrica.

Adicionalmente, o menor rendimento energético das reações anaeróbias resulta em menor quantidade de lodo produzido, com menor quantidade de matéria orgânica biodegradável para a etapa aeróbia. Na etapa aeróbia, apesar do alto rendimento energético, resta pouca matéria orgânica biodegradável. Portanto, a produção de lodo também é menor. Conseqüentemente, há necessidade de área menor para acondicionamento e destino final do excesso de lodo.

Existem diversas configurações possíveis para sistemas de tratamento de águas residuárias destinados à remoção de matéria orgânica e de macronutrientes. A literatura reporta várias pesquisas recentes utilizando esses sistemas.

HOSAKA et al. (1991) estudaram um sistema para tratamento de esgoto sanitário, que denominaram leito fluidizado de três fases, pelo fato de o leito fluidizado ser composto de parte sólida, líquida e gasosa. O fator decisivo na redução do volume do reator foi a velocidade de nitrificação, viabilizada pelo número de bactérias nitrificantes, ou seja, alto valor de TRC. O meio suporte para imobilização da biomassa era composto de grãos de antracito. O sistema, operado no verão, forneceu valores de eficiência de remoção de N-NTK e DBO (demanda bioquímica de oxigênio) próximos a $73 \%$ e 95\% respectivamente, com TDH em torno de $2 \mathrm{~h}$ no reator destinado à nitrificação.

Com o objetivo de remover macro-nutrientes, BERNARDES \& KLAPWIJK (1996) estudaram um SBR (reator em batelada seqüencial) para tratar esgoto présedimentado de uma ETE (estação de tratamento de esgoto), em escala real. O sistema experimental, em escala piloto, foi operado durante cinco meses com 
cultura mista, capaz de remover matéria orgânica, nitrogênio e fósforo. Faziam parte do sistema dois reatores: o primeiro com volume de 350 / e o segundo com volume de 1300 l. As etapas de reação anaeróbia e aeróbia eram intercaladas, com etapas aeradas e etapas sem aeração. Os autores conseguiram boa remoção de macro-nutrientes, obtendo efluente com concentração de fósforo e nitrogênio como nitrato menor que $1 \mathrm{mg} . I^{1}$ e $12 \mathrm{mg} . \digamma^{1}$, respectivamente, e concluíram que o fornecimento de substrato prontamente biodegradável é importantíssimo.

SASAKI et al. (1996) estudaram sistema de lodos ativados anaeróbio/aeróbio com aeração intermitente. Os reatores que compunham esse sistema eram de 76 e 74 / e foram operados em série. Foi utilizado esgoto sintético para os estudos e o acompanhamento dos períodos aeróbio, anóxico e anaeróbio no sistema foi controlado com a ajuda de sondas de OD e POR (potencial de oxiredução). Durante o uso de sondas de POR para controle da aeração, foram detectados alguns problemas, pois os valores apresentados pela sonda, eventualmente, mostraram-se incorretos. O TDH utilizado pelos autores foi de $16 \mathrm{~h}$ e a temperatura do líquido afluente era de $20^{\circ} \mathrm{C}$.

Segundo MÜNCH et al. (1996) o processo de SND tem se mostrado interessante do ponto de vista operacional e econômico. Os autores operaram dois SBR em escala de bancada, com volume total de 12 I cada. Em cada ciclo, eram descartados 4 I do reator e alimentados 4 I de afluente, compondo, assim, o total de $18 \mathrm{~h}$ para cada ciclo completo. O afluente era água residuária de uma ETE que, após passar por gradeamento, alimentava o sistema, o qual foi operado durante quatro meses. Durante a etapa aeróbia, o ar foi fornecido com vazão que oscilou entre 1,5 e $2,5 / . \mathrm{min}^{-1}$; a concentração de OD foi controlada com ajuda de sonda, para ser mantida em valor próximo a $0,5 \mathrm{mg} \cdot \mathrm{I}^{1}$. O sistema era operado em ciclos. A fase anaeróbia tinha duração de 150 minutos, seguida pela aeróbia, cuja duração era de 170 minutos, para que a SND fosse completa.

KUBA et al. (1996) desenvolveram pesquisa em sistema, em escala de bancada, composto por dois SBR cujos volumes eram 3,5 l, em ciclos de $6 \mathrm{~h}$, ao qual denominaram sistema de dois lodos para remoção de fósforo e nitrogênio. $A$ temperatura controlada foi mantida a $20^{\circ} \mathrm{C}$. O primeiro reator era anaeróbio e o $\mathrm{pH}$ foi controlado para ser mantido em valor próximo a 7,0. O tempo total de ciclo do sistema equivalia a, aproximadamente, $24 \mathrm{~h}$. O sistema mostrou-se estável para remoção de macro-nutrientes, removeu $15 \mathrm{mg} . I^{1}$ de fósforo e $105 \mathrm{mg} . I^{1} \mathrm{de}$ 
nitrogênio, gastando, para isso, ácido acético na quantidade correspondente a 400 $\mathrm{mg} . I^{1}$ em termos de DQO.

SURAMPALLI et al. (1997) publicaram resultados de estudo sobre RBN (remoção biológica de nutrientes) em sistema composto por três SBR, em escala real, para tratar água residuária municipal. Os resultados mostraram efluentes que alcançaram concentrações menores que $10 \mathrm{mg} . I^{1}$ para $\mathrm{DBO}_{5}$ e SST (sólidos suspensos totais). O sistema apresentou, eficiente remoção de macro-nutrientes, obtendo concentrações de fósforo no efluente inferiores a 1,0 mg. $I^{1}$. Porém, de acordo com os autores, são necessárias algumas modificações no projeto dos reatores para que sejam obtidos efluentes que atendam à legislação quanto à remoção de nitrogênio.

CASTILLO et al. (1997) operaram uma estação piloto, com uso de esgoto filtrado com partículas menores que $5 \mathrm{~mm}$, de ETE localizada na cidade de Barcelona. O sistema piloto foi composto por duas etapas principais: a primeira, composta por UASB (upflow anaerobic sludge blanket) com aproximadamente 750 I e, a segunda por dois reatores aeróbios RBC (rotating biological contactor) em série, com capacidade de 55 / cada um; cada RBC dispunha de 10 discos de poliestireno, totalizando uma superfície de $52 \mathrm{~m}^{2}$. A combinação desses reatores mostrou-se conveniente, com uma primeira etapa anaeróbia, especialmente em áreas costeiras, pois, durante o inverno, quando as temperaturas são mais baixas, o valor do TDH aumenta, devido à redução da população. Os autores obtiveram remoção de matéria orgânica de aproximadamente $88 \%$, resultando em valores de DBO que variaram entre 7 e $35 \mathrm{mg} . \digamma^{1}$. A nitrificação também atingiu bons níveis após adaptação dos RBC e o fornecimento de ar comprimido, aumentando-se a concentração de OD de 0,5 para $4 \mathrm{mg} . I^{1}$.

ROS \& VRTOVSEK (1998) montaram experimento com vistas a encontrar metodologia simples para desenvolvimento de reator combinado que dispusesse de etapas anaeróbia, anóxica e aeróbia. Esse reator foi construído em PVC, com formato tubular e operado sob fluxo ascendente. Dispunha, na sua base, de primeira zona anaeróbia sem recheio, câmara essa inoculada com grânulos de UASB. Na segunda zona, acima da primeira, existia etapa aeróbia para estabelecer zona aeróbia/anóxica; essa câmara dispunha de recheio para servir de meio suporte, denominado NB-01, patenteado na Slovênia. Os autores chegaram à conclusão que a configuração desenvolvida para esse reator pode ser muito útil no tratamento biológico de esgoto industrial que contenha compostos orgânicos 
complexos e compostos nitrogenados, especialmente se o espaço disponível ao sistema de tratamento for o fator limitante.

AISSE et al. (2000) operaram sistema combinado composto por UASB, seguido de FBAS (filtro biológico aerado submerso), em escala piloto, para tratar esgoto sanitário proveniente da cidade de Curitiba, no Paraná. Obtiveram bons resultados de desempenho, com eficiências de remoção de DQO superiores a 78\%, atingindo concentrações, no efluente, de aproximadamente $70 \mathrm{mg} . I^{1}$ e eficiência de remoção de SST (sólidos suspensos totais) maior que 75\%.

TORRES \& FORESTI (2000) operaram UASB seguido de SBR, em escala piloto, no tratamento de esgoto sanitário. O UASB foi operado com tempos de detenção hidráulica de 8 e $6 \mathrm{~h}$, vazão de $18 \mathrm{I} \cdot \mathrm{h}^{-1}$ e $29 \mathrm{I} \cdot \mathrm{h}^{-1}$, respectivamente. O SBR foi operado com ciclos de duração de 4, 6, 12 e 24 h. O sistema combinado apresentou eficiências de remoção de DQO e SST superiores a 84\% e eficiência de remoção de N-NTK acima de 79\%, para tempo mínimo de aeração de 4 h no SBR.

VIEIRA et al. (2000) desenvolveram nova configuração de sistema misto aeróbio/anaeróbio de leito fixo, com matrizes cúbicas de espuma de poliuretano, para tratamento de efluente de RAHLF (reator anaeróbio horizontal de leito fixo) tratando esgoto sanitário, com vistas à remoção de matéria carbonácea, sólidos e macro-nutrientes. O sistema, composto por dois reatores de leito fixo, dispunha de um RARLF (reator aeróbio radial de leito fixo) e um RAHLFa (reator anóxico horizontal de leito fixo), construído em escala piloto. O sistema apresentou resultados promissores e produziu efluentes com concentrações de DQO menores que $40 \mathrm{mg} . \mathrm{I}^{1}$ e eficiência de $95 \%$ no processo de nitrificação e de $96 \%$ no processo de desnitrificação.

LOPES \& CAMPOS (2000) operaram reatores compartimentados anaeróbio/aeróbio em série, para tratamento de esgoto sanitário proveniente da rede coletora pública da cidade de São Carlos-SP. O sistema era composto por reator compartimentado anaeróbio seguido de reator compartimentado aeróbio. Os reatores tinham volume útil de 10 / e possuíam quatro câmaras cada. Eles foram operados à temperatura controlada de $30 \pm 2^{\circ} \mathrm{C}$. $\mathrm{O}$ sistema combinado apresentou eficiência média de remoção de DQO de 89 e 85\%, para TDH de 8 e 6 h, respectivamente.

CALLADO \& FORESTI (2000) avaliaram o desempenho de sistema composto por três reatores em batelada seqüenciais, em escala de bancada. Os SBR tinham seção circular, com $15 \mathrm{~cm}$ de diâmetro e volume total de 16,5 I, sendo 
operados em série formavam sistema anaeróbio/aeróbio/anaeróbio para tratar esgoto sanitário sintético. O sistema era operado em ciclos de $12 \mathrm{~h}$, com fornecimento de 8 I de substrato para cada batelada. $O$ primeiro reator tinha como função remover a maior fração de matéria carbonácea e promover a amonificação do afluente; o segundo proporcionava nitrificação e remoção biológica do fosfato e o terceiro reator era utilizado para desnitrificação. A temperatura era mantida próxima a $28^{\circ} \mathrm{C}$ e o sistema foi operado durante 54 dias. O sistema mostrou-se eficiente, desde que operado adequadamente para remoção biológica de matéria orgânica medida como DQO, nitrogênio e fósforo, com eficiências de 90, 85 e 68\%, respectivamente. As eficiências correspondem a efluente com concentrações inferiores a $60 \mathrm{mg} . I^{1}$ para DQO, $4 \mathrm{mg} . I^{1}$ para N-NTK e 3,0 mg. $I^{1}$ para fósforo.

Os sistemas biológicos combinados anaeróbio/aeróbio são promissores no tratamento de águas residuárias municipais, o mesmo podendo ser afirmado quanto aos reatores de filme fixo, que têm ponto chave no tratamento anaeróbio por permitirem altos tempos de retenção celular. As configurações aqui apresentadas mostram qualidades e defeitos inerentes a cada sistema, sendo importante que se desenvolvam pesquisas no sentido de otimizar os sistemas existentes. O sistema RMRLF seguido de RAHLFa apresenta-se promissor na remoção de matéria carbonácea, sólidos e nitrogênio, entretanto, são necessários estudos a respeito desse sistema para confirmar essa premissa. 


\section{Objetivos}

O objetivo geral desta pesquisa foi projetar, construir e avaliar o desempenho de nova concepção de sistema anaeróbio/aeróbio/anóxico, composto por RMRLF (Reator Misto Radial de Leito Fixo) e RAHLFa (Reator Anóxico Horizontal de Leito Fixo), operados em seqüência, destinado ao tratamento de esgoto sanitário.

Para a proposta de trabalho apresentada os objetivos específicos da pesquisa são:

- Verificar o desempenho do sistema na remoção de matéria orgânica, sólidos suspensos e compostos nitrogenados;

- Monitorar os principais fatores que influenciam no processo de remoção de nitrogênio do sistema, como pH, OD e temperatura, para estabelecer parâmetros operacionais para o sistema misto;

- Quantificar a adesão da biomassa e observar as morfologias microbianas no material suporte através de microscopia óptica durante a operação do sistema. 


\section{Material e Métodos}

Neste capítulo, estão descritos o material e os métodos utilizados, assim como os procedimentos para acompanhamento e avaliação do sistema anaeróbio/aeróbio/anóxico de leito fixo, composto por Reator Misto Radial de Leito Fixo seguido de Reator Anóxico Horizontal de Leito Fixo.

Esta pesquisa envolveu as seguintes etapas:

- Dimensionamento do RMRLF em função dos dados obtidos por VIEIRA (2000) e do conhecimento adquirido sobre biotecnologia anaeróbia.

- Operação do sistema, construído em escala de bancada, no tratamento de esgoto sanitário.

- Análise dos dados obtidos durante a operação, para tomada de decisões mitigadoras de problemas operacionais, com proposta de melhorar o funcionamento e o desempenho do sistema.

- Avaliação do desempenho do sistema combinado anaeróbio/aeróbio/ anóxico para remoção de matéria orgânica carbonácea, sólidos e compostos nitrogenados.

\subsection{Concepção do sistema}

A construção, instalação e operação do sistema, foram levadas a efeito na cidade de São Carlos, no Campus da USP (Figura 4.1). 


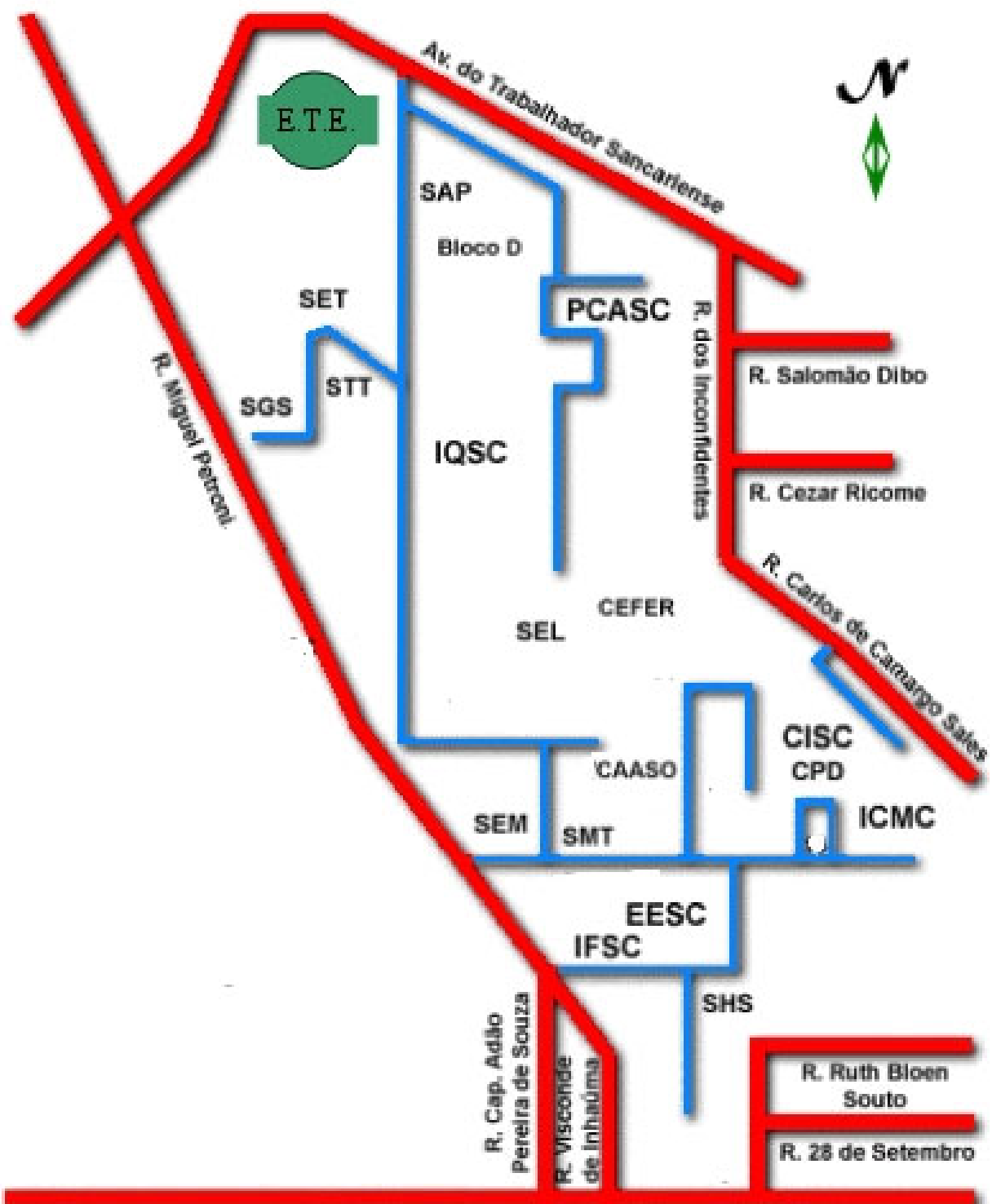

Av. Dr. Carlos Botelho

FIGURA 4.1 - Localização da instalação do sistema demarcado como E.T.E.

O sistema experimental, construído em escala de bancada, era composto de Reator Misto Radial de Leito Fixo, utilizado para remoção de fração significativa da matéria orgânica e nitrificação do afluente. O efluente do RMRLF serviu de afluente para o Reator Anóxico Horizontal de Leito Fixo utilizado para promover a desnitrificação. O sistema era alimentado com esgoto sanitário armazenado em reservatório de 750 I. Na Figura 4.2, está apresentado o desenho esquemático do sistema. 


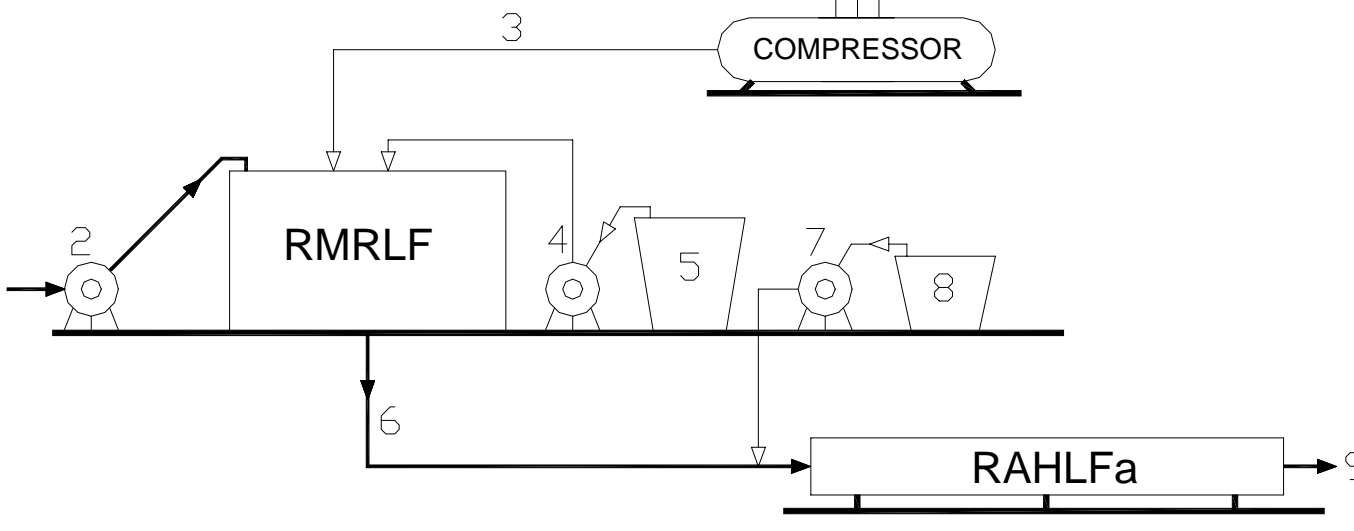

FIGURA 4.2 - Representação esquemática do sistema RMRLF seguido de RAHLFa: Esgoto afluente (1); Bomba de recalque do esgoto afluente ao RMRLF (2); Fornecimento de ar comprimido à câmara 3 (3); Fornecimento de solução alcalina à câmara 3 (4); Recipiente com solução alcalina (5); Efluente RMRLF (6); Fornecimento de fonte de carbono ao RAHLFa (7); Recipiente com solução de etanol (8); Efluente RAHLFa (9).

\subsubsection{Reator Misto Radial de Leito Fixo em escala de bancada}

O desenvolvimento do Reator Misto Radial de Leito Fixo foi baseado na pesquisa de VIEIRA (2000), que operou reator aeróbio com fluxo radial para póstratamento de efluente de reator anaeróbio. Em sua pesquisa, o efluente de reator anaeróbio entrava pelo fundo, na câmara mais próxima à parede externa, e o efluente do reator era coletado na câmara central, após atravessar as camadas de leito fixo, sendo aerado na câmara de entrada e na câmara intermediária. Foi proposta nova configuração do reator radial com intuito de obter no mesmo reator o tratamento anaeróbio e a nitrificação. Assim o projeto do reator resultou na construção da segunda câmara com dimensão que possibilitasse a obtenção de TDH maior que na quarta câmara e com aeração fornecida somente na terceira câmara. O RMRLF foi construído em acrílico, com $25 \mathrm{~cm}$ de altura útil e $60 \mathrm{~cm}$ de diâmetro, com volume total de 70,7 / (Figura 4.3). 


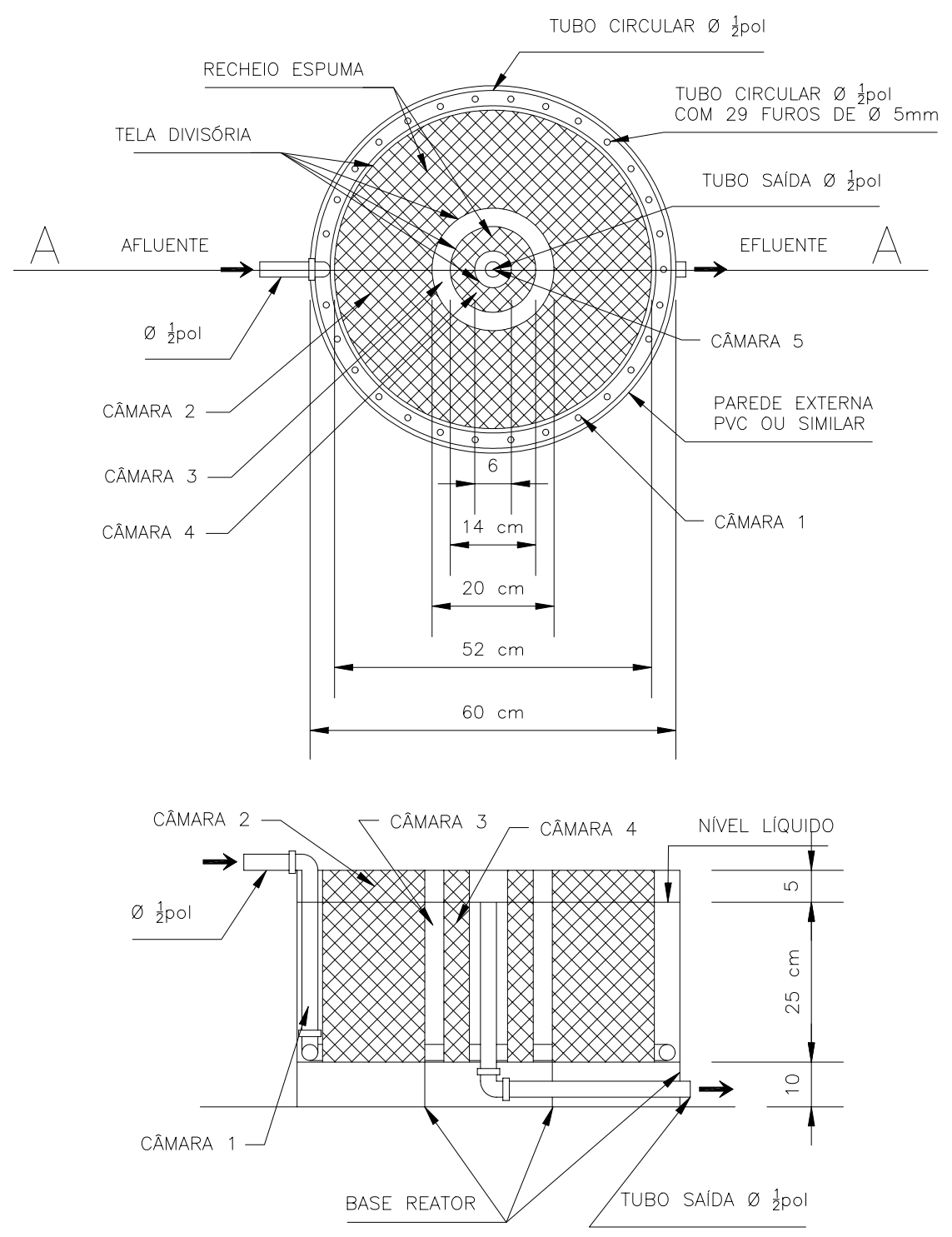

FIGURA 4.3 - Projeto do RMRLF mostrando as principais características e componentes a) Planta baixa e b) Corte AA: Câmara 1 - distribuição do afluente; Câmara 2 - câmara anaeróbia/aeróbia; Câmara 3 - câmara de aeração; Câmara 4 câmara aeróbia/anaeróbia; Câmara 5 - saída do efluente.

O reator é dividido em compartimentos circuncêntricos, separados por telas de aço inox 316, com diâmetros de 60, 52, 20, 14 e $6 \mathrm{~cm}$, a partir da parede externa do reator até o centro, formando cinco câmaras. Na câmara 3 foram colocadas oito pedras porosas junto ao fundo, uniformemente distribuídas, ligadas a um compressor para promover aeração e agitação do líquido no interior desta câmara. As câmaras 2 e 4 foram preenchidas com cubos de espuma de 
poliuretano, com $1 \mathrm{~cm}$ de aresta, para a imobilização da biomassa. $\mathrm{O}$ volume útil para o RMRLF foi considerado igual à aproximadamente $38 \mathrm{l}$, composto pelo volume útil da câmara 2 de 30,9 I, da câmara 3 de 4,1 I, da câmara 4 com 2,3 I e o volume da câmara 5 igual a $0,7 \mathrm{l}$.

A água residuária bruta peneirada, ou afluente, era recalcada para 0 reator, conduzida por tubulação e distribuída através de sistema composto por tubo perfurado, localizado na base do reator, disposto ao longo da circunferência próxima à parede externa, no interior da câmara 1. A descarga do efluente era feita por sistema instalado na câmara central do reator, câmara 5 . A canalização de descarga controlava, também, o nível de líquido no interior do reator. A Figura 4.4 ilustra a concepção do RMRLF.

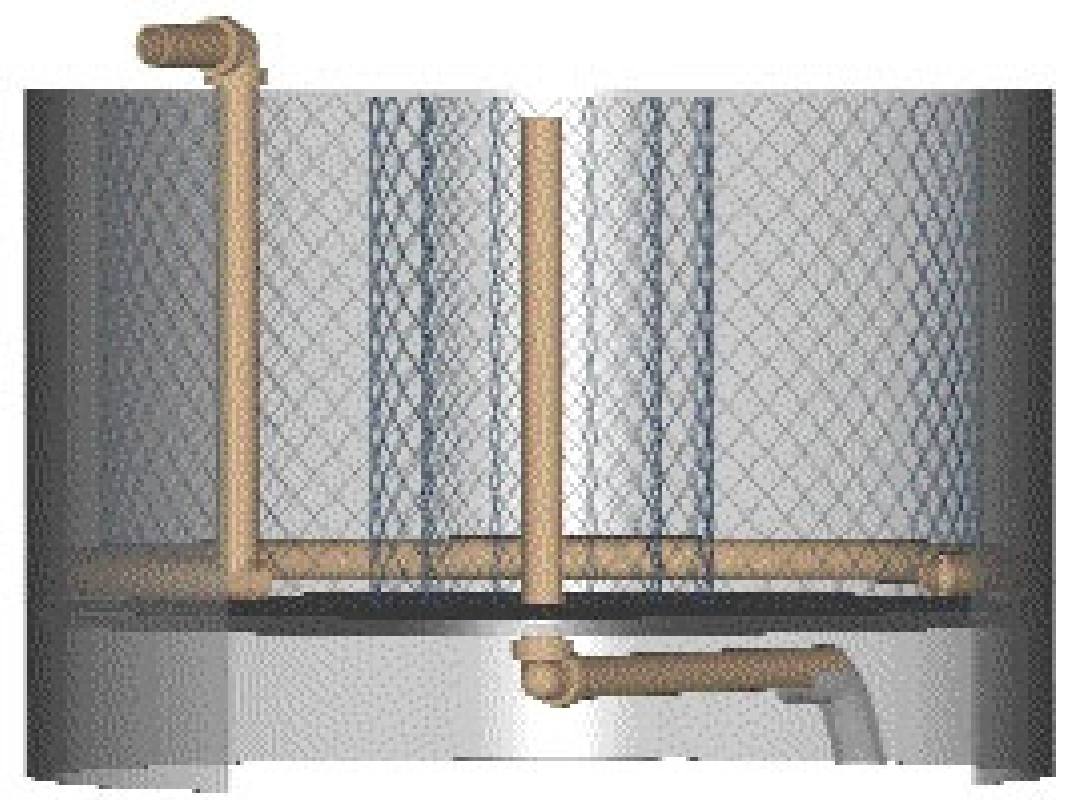

FIGURA 4.4 - llustração do RMRLF em três dimensões. O corte parcial mostra a tubulação de distribuição do afluente e de coleta do efluente $\square$; a estrutura externa e o fundo do reator $\square$; a grade para retenção da espuma $\square$. 


\subsubsection{Reator Anóxico Horizontal de Leito Fixo em escala de bancada}

O Reator Anóxico Horizontal de Leito Fixo, construído em escala de bancada, é idêntico a um módulo do reator previamente desenvolvido por ZAIAT et al. (1994) para tratamento de água residuária de indústria de papel e, posteriormente, utilizado em várias pesquisas no Laboratório de Processos Biológicos do Departamento de Hidráulica e Saneamento da EESC-USP.

O reator foi construído em tubo de PVC, com 2,88 m de comprimento e $14,5 \mathrm{~cm}$ de diâmetro, com volume total de 47 I, aproximadamente. Na Figura 4.5 está ilustrado o RAHLFa em três dimensões.

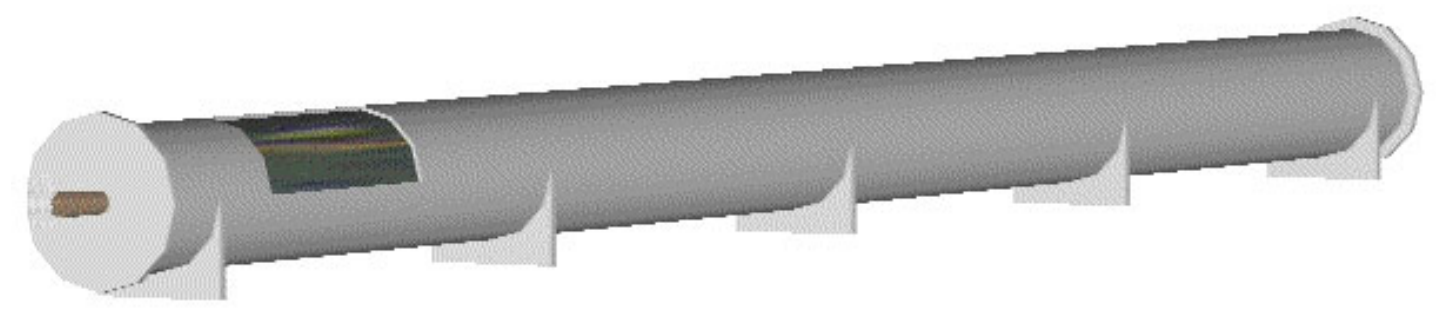

FIGURA 4.5 - Ilustração do RAHLFa em três dimensões mostrando o dispositivo de entrada, que é ligado à tubulação efluente do RMRLF e a estrutura do reator $\square$; os suportes para sustentação $\square$; e corte parcial na parede externa mostrando o leito (recheio) composto por matrizes de espuma de poliuretano.

Depois de preenchido com meio suporte para imobilização da biomassa, o volume útil reacional do reator passou a ser de $19 \mathrm{l}$, aproximadamente, com porosidade do leito de cerca de $40 \%$. No interior do reator, próximos à entrada e à saída, foram instaladas redes com malha menor que $1 \mathrm{~cm}$, para evitar arraste do meio suporte e o conseqüente entupimento das tubulações. $\mathrm{Na}$ lateral foram alocadas 3 tomadas de amostras intermediárias, eqüidistantes entre si, com vistas a obter dados sobre as características do líquido no interior do reator (Figura 4.6).

O RAHLFa foi continuamente alimentado, por gravidade, com efluente do RMRLF. 


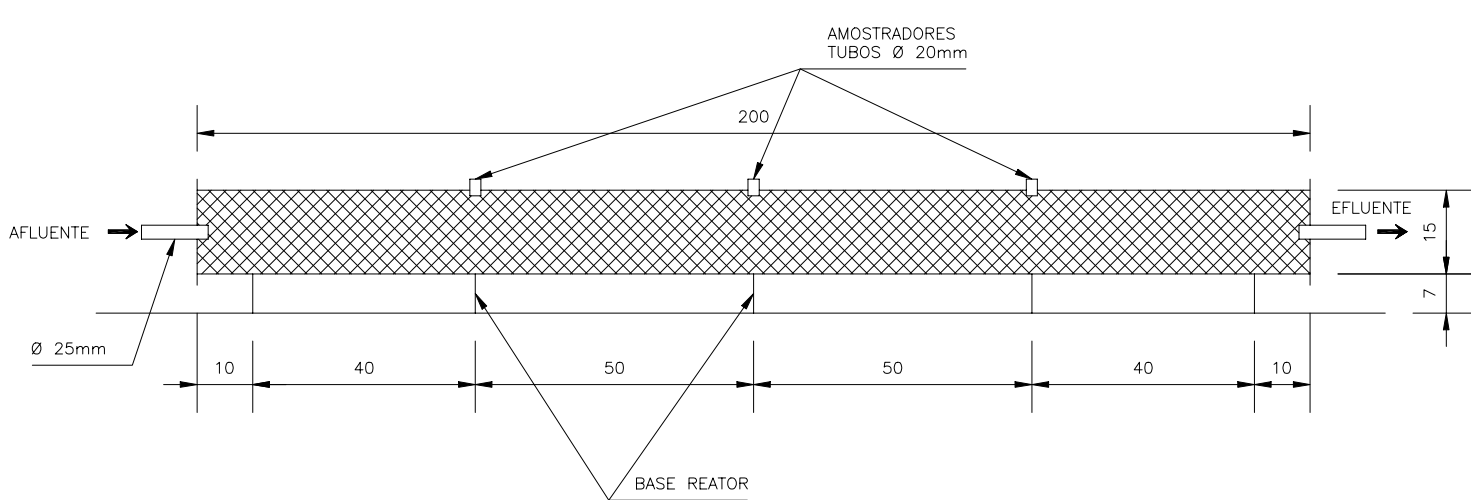

FIGURA 4.6 - Projeto em corte de perfil do Reator Anóxico Horizontal de Leito Fixo.

FAZOLO et al. (2002) operaram 5 módulos desse RAHLF em experimento anteriormente realizado. Para desenvolvimento desta pesquisa, utilizou-se o último módulo que encontrava-se desativado. Optou-se por não inocular o reator com lodo desnitrificante, ou seja, com lodo que apresentasse capacidade de promover a desnitrificação de efluentes, devido à existência de biomassa imobilizada, confirmada em análises microscópicas apresentadas no item 5.5.

\section{2 Água residuária}

Foi utilizado esgoto proveniente da rede coletora que passa pelo Campus da USP. Essa rede atende a USP - São Carlos e dois bairros do município, Vila São José e Vila Pureza.

A água residuária era recalcada durante $12 \mathrm{~h}$ por dia com uma bomba diafragma Ecosan BDN2 e ficava armazenada em reservatório de 750 I. No interior do reservatório, foram instaladas duas telas com malha de $2 \mathrm{~mm}$, para retirada de fração de sólidos em suspensão, de dimensões inconvenientes para o tamanho das unidades experimentais. Esse reservatório funcionou como tanque de equalização do esgoto afluente ao sistema.

Durante a operação do sistema, foram realizados dois perfis de $24 \mathrm{~h}$ do esgoto sanitário armazenado no reservatório de 750 l; um em julho e outro em outubro de 2002, conforme apresentado no item 5.1. O objetivo principal desse estudo foi o de avaliar se a variação de DQO, no decorrer do período de 24 h, era 
ou não significativa. Em caso positivo, haveria necessidade de analisar amostras compostas e não pontuais.

A água residuária armazenada nesse reservatório era enviada ao sistema durante $24 \mathrm{~h}$ por dia. Inicialmente, foi utilizada uma bomba Ecosan BDN2, a qual mostrou-se imprecisa para manter vazões menores que $10 \mathrm{l} \cdot \mathrm{h}^{-1}$. Optou-se, então, pela sua substituição por uma bomba peristáltica "GILSON Miniplus 3".

\subsection{Material suporte para imobilização da biomassa}

O leito fixo para imobilização da biomassa era constituído por matrizes cúbicas de espuma de poliuretano, com arestas de $10 \mathrm{~mm}$, densidade aparente de $23 \mathrm{~kg} \cdot \mathrm{m}^{-3}$ e porosidade próxima a 95\%, confeccionadas sem corantes e aditivos, fornecidas pela empresa EDMIL Indústria e Comércio Ltda.

A espuma de poliuretano, utilizada como material suporte de imobilização foi analisada pelo Centro de Caracterização e Desenvolvimento de Materiais da UFSCar. A porosidade superficial da espuma muitas vezes é composta pela soma de diversos alvéolos partidos, conforme Figura 4.7.

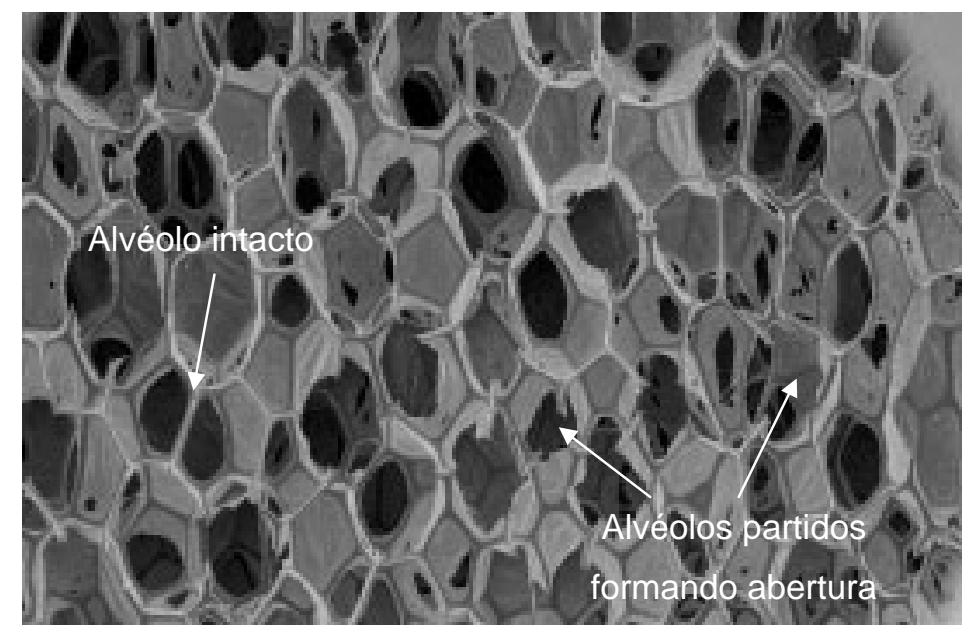

FIGURA 4.7 - Morfologia dos alvéolos na espuma de poliuretano

Alguns destes alvéolos, que se encontram na superfície da espuma, se rompem. Devido a esses alvéolos partidos o diâmetro equivalente médio da abertura apresenta-se superior ao diâmetro equivalente médio dos alvéolos. Estes resultados são demonstrados na Tabela 4.1. 
TABELA 4.1 - Estimativa do diâmetro equivalente médio da abertura superficial e dos alvéolos da espuma de poliuretano.

\begin{tabular}{ccc}
\hline Espuma & Abertura superficial & Alvéolo \\
\hline Diâmetro equivalente médio $(\mu \mathrm{m})^{*}$ & $757 \pm 174$ & $543 \pm 154$ \\
\hline
\end{tabular}

"Estimativa feita contabilizando-se $\mathbf{1 0 0}$ medidas.

FONTE: CCDM/UFSCar, laudo n 02/003279.

\subsection{Lodo de inóculo}

O sistema foi inoculado apenas na câmara 2 do RMRLF, com lodo proveniente de reator UASB da Estação de Tratamento de Águas Residuárias de Abatedouro de Aves, da empresa Dacar Industrial S.A., sediada no Tietê - SP.

O lodo anaeróbio foi imobilizado em matrizes cúbicas de espuma de poliuretano. O procedimento de imobilização consistiu em colocar os cubos de espuma em recipiente, juntamente com lodo previamente macerado, em suspensão aquosa. Essa suspensão foi adicionada ao recipiente até que todas as matrizes de espuma ficassem em contato com ela. A espuma permaneceu em contato com o lodo em suspensão por período de 24 h, em recipiente fechado com tampa. Decorrido esse período, as matrizes com células aderidas foram passadas por peneira, para eliminação do excesso de lodo. Finalmente, os cubos de espuma foram transferidos para o interior do reator, de forma uniforme, sem que fossem pressionados, evitando possíveis entupimentos ou adensamento excessivo do leito.

A câmara 4 do RMRLF não foi inoculada pois, de acordo com a literatura, a colonização por microrganismos aeróbios ocorre rapidamente, sem necessidade de inóculo.

Partiu-se do pressuposto que o RAHLFa, em escala de bancada, já continha biomassa imobilizada, sem necessidade de ser inoculado pois havia sido operado recentemente por FAZOLO et al. (2002). Para confirmar a existência de microrganismos no RAHLFa foram retiradas amostras do material suporte de três pontos do reator (início, meio e fim) para observação dos microrganismos através de microscopia óptica. 


\subsection{Sistema para fornecimento de solução alcalina}

A solução alcalina era preparada em recipiente de aproximadamente $70 \mathrm{I}$, ao qual era adicionado efluente anaeróbio proveniente de RAHLF (reator anaeróbio horizontal de leito fixo), operado por FAZOLO et al.(2002), composto por 4 módulos, e aproximadamente $100 \mathrm{~g}$ de bicarbonato de sódio, compondo solução de valor aproximado de $1400 \mathrm{mg} . I^{1}$ medido como $\mathrm{CaCO}_{3}$. O fornecimento da solução alcalina, preparada no recipiente, era feita na câmara 3 com auxílio de bomba peristáltica, a qual tinha uma mangueira de silicone conectada ao fundo do recipiente e fornecia a solução com vazão média de $0,5 \mathrm{l} \cdot \mathrm{h}^{-1}$. É importante ressaltar que o objetivo dessa operação era fornecer alcalinidade ao sistema, na câmara onde ocorre a nitrificação e não controlar seu valor com precisão.

\subsection{Sistema para fornecimento de fonte externa de carbono}

O fornecimento da fonte externa de carbono para o RAHLFa era feita através de solução preparada com efluente do sistema operado nesta pesquisa. $O$ efluente era coletado em recipiente de 10 / e era adicionado etanol ao líquido. $\mathrm{A}$ solução de fonte de carbono era fornecida na entrada do RAHLFa, juntamente com o efluente do RMRLF. Com auxílio de bomba peristáltica, com vazão de 0,2 I.h-1 procurou-se garantir concentração de etanol suficiente para manter a relação $\mathrm{C} / \mathrm{N}$ igual a 1, conforme apresentado por HER \& HUANG, 1995 e SANTOS, 2002.

\subsection{Análises físico-químicas para caracterização e monitoramento do sistema}

O monitoramento do sistema foi feito através de análises de amostras coletadas em quatro pontos distintos: afluente bruto, líquido da câmara 3, efluente do RMRLF - que coincide com a entrada do RAHLFa - e efluente do RAHLFa. As análises eram usualmente feitas no período da manhã, próximo às 7:00 h, três vezes por semana. As análises de nitrogênio, nas formas de nitrito e de nitrato, tiveram início após ter sido detectada queda na concentração de nitrogênio 
amoniacal no efluente do RMRLF, as quais eram realizadas em média, duas vezes por semana.

As análises de $\mathrm{DQO}$, nitrogênio total e amoniacal, nitrato, $\mathrm{pH}$, ST (sólidos totais) e SST (sólidos suspensos totais) foram executadas segundo métodos preconizados pelo Standard Methods for the Examination of Water and Wastewater (1998). As análises de AVT (ácidos voláteis totais), como ácido acético, foram executadas de acordo com método descrito por DILALLO \& ALBERTSON (1961). A alcalinidade foi determinada pelo método descrito por DILALLO \& ALBERTSON (1961) e modificado por RIPLEY et al. (1986), enquanto a concentração de nitrito foi medida de acordo com o método descrito por MACKERETH et al. (1978).

- Alcalinidade

O monitoramento da alcalinidade teve por objetivo avaliar e detectar possíveis alterações da capacidade tampão do sistema, bem como acompanhar possíveis efeitos de nitrificação nas alterações do valor do $\mathrm{pH}$. Para as análises foi utilizado medidor de $\mathrm{pH}$ da marca Digimed DM-20, sendo a titulação feita com bureta automática da marca BOECO, modelo DCB5000. Os resultados são apresentados como mg. $I^{1}$ de $\mathrm{CaCO}_{3}$.

- Demanda Química de Oxigênio

O valor da DQO foi utilizado para avaliar a concentração de matéria orgânica carbonácea presente no meio líquido. O método de determinação da DQO promove vantagens, como rapidez de execução, e o fato de fornecer dados confiáveis, quando são analisados reatores anaeróbios ou anóxicos de leito fixo. Utilizou-se o método colorimétrico, aplicado a amostras digeridas, em frascos fechados, no bloco digestor, e leitura em espectrofotômetro da marca $\mathrm{HACH}$, modelo DR-2000.

- Nitrogênio Total Kjeldahl

O Nitrogênio Total Kjeldahl permite constatar a quantidade total de nitrogênio orgânico e amoniacal, expressa como mg. $I^{1}$ de nitrogênio. O N-NTK foi determinado pelo método macro-Kjeldahl, composto pelas etapas de digestão da amostra, destilação para recuperação do $\mathrm{N}^{-\mathrm{NH}_{4}}{ }^{+}$, seguida de análise titulométrica, utilizando-se indicador misto 2. Os equipamentos utilizados foram o digestor e 0 destilador de nitrogênio da marca Marconi.

- Nitrogênio Amoniacal

A concentração de nitrogênio amoniacal, nas formas de amônia não ionizada e ionizada, $\mathrm{N}-\mathrm{NH}_{3}$ e N-NH${ }_{4}{ }^{+}$, foi determinada por método titulométrico, e 
utilizou-se indicador misto 2. As amostras foram analisadas após a separação desses compostos por destilação, com destilador da marca Marconi

- Nitrogênio na forma de Nitrito

A determinação do nitrogênio na forma de $\mathrm{NO}_{2}^{-}$foi realizada através de método colorimétrico, utilizando-se espectrofotômetro da marca $\mathrm{HACH}$, modelo DR4000. A preparação das amostras consistiu na diluição inicial na proporção de 1:10, adição de $2,5 \mathrm{~m} /$ de hidróxido de alumínio na alíquota para sedimentação da matéria orgânica e filtragem da amostra, antes da leitura no espectrofotômetro.

- Nitrogênio na forma de Nitrato

A concentração de nitrogênio na forma de $\mathrm{NO}_{3}{ }^{-}$, expressa em mg. $I^{1}$, foi determinada por método colorimétrico. A preparação consistiu na diluição inicial na proporção de 1:10; adição de 2,5 m/ de hidróxido de alumínio na alíquota, para sedimentação da matéria orgânica, e filtragem da amostra antes da leitura no espectrofotômetro.

- Oxigênio Dissolvido

As concentrações de OD foram medidas pelo método de eletrodo de membrana com oxímetro da marca Toledo, modelo MO128, com o objetivo de monitorar o fornecimento de oxigênio ao meio através da concentração de $O D$, de maneira a garantir a oxigenação do líquido. As concentrações foram expressas em mg. $I^{1}$.

- $\mathrm{pH}$ (Potencial Hidrogeniônico)

As análises de $\mathrm{pH}$ foram feitas através de método eletrométrico, com potenciômetro da marca Digimed modelo DM-20.

- Sólidos suspensos

As amostras foram analisadas seguindo o método gravimétrico. Foram utilizados estufa da fábrica SOC. FABBE e mufla marca EDGCON 5P. Foi utilizada balança digital da marca Mettler AT 261 DeltaRange, com os valores apresentados em mg. $I^{1}$.

- Temperatura

A medida da temperatura do líquido no reator foi feita com termômetro de mercúrio e termômetro digital do aparelho de medição de OD. A temperatura ambiente foi monitorada com termômetro de mercúrio de máximo e mínimo.

- Coliformes fecais

Os coliformes fecais foram analisados por método enzimático. As amostras eram diluídas e inoculadas com enzimas Colilert e incubadas por $24 \mathrm{~h}$ a $37^{\circ} \mathrm{C}$. Após 
o período de incubação era feita a contagem das amostras que apresentaram florescência ao serem expostas à luz ultravioleta. Após a contagem, a estimativa de coliformes fecais era feita como número mais provável NMP.100 m/1․

- Potencial de Oxi-redução

As análises de POR foram feitas através de método eletrométrico, com potenciômetro da marca Digimed.

\subsection{Exames com microscopia óptica}

Para análise das amostras de células imobilizadas utilizou-se microscópio óptico de luz comum e de contraste de fase. As amostras eram retiradas das matrizes de espuma, embebidas em água e observadas em microscópio marca Olympus, modelo BX60. As imagens eram visualizadas em computador, acoplado a câmera do microscópio, o qual dispunha de um software para registrar a escala gráfica nas fotos.

\subsection{Procedimento experimental}

\subsubsection{Partida e estabilização do sistema}

O início da operação do sistema ocorreu no dia 18 de abril de 2002, estendendo-se por 123 dias. A partida do sistema foi feita com a operação do RMRLF alimentado com vazão de $6 / \cdot h^{-1}$. Juntamente com o início da operação do sistema, iniciaram-se as análises descritas no item 4.7 com o objetivo de acompanhar o desenvolvimento dos processos durante a partida do sistema.

O oxigênio foi fornecido na câmara 3 , desde o primeiro dia de operação. Entretanto, a alcalinização do efluente à câmara 3 e o fornecimento de uma fonte de carbono para o RAHLFa foram iniciadas somente após a detecção do início da nitrificação, processo este que foi acompanhado através dos valores obtidos pelas as análises de nitrogênio. 


\subsubsection{Operação do sistema RMRLF seguido de RAHLFa}

O RMRLF era dividido em duas câmaras reacionais, e a degradação anaeróbia do afluente foi prevista para ocorrer predominantemente na primeira câmara. Com base no valor usualmente empregado em reatores anaeróbios (UASB), adotou-se o TDH de aproximadamente $8 \mathrm{~h}$ para a primeira câmara do reator. Conforme relatado por VIEIRA (2000), o TDH de $4 \mathrm{~h}$ foi suficiente para promover a nitrificação no RARLF. Por esse motivo, foi adotado esse valor de TDH para a segunda câmara do RMRLF, resultando assim no TDH total de $12 \mathrm{~h}$. Visto que a vazão foi fixada para atender a critérios de projeto da primeira unidade de tratamento biológico, o valor de TDH da segunda unidade (RAHLFa) resultou em 8 $\mathrm{h}$ considerando-se o volume total do reator. O TDH de $12 \mathrm{~h}$ em relação ao volume total de 70,7 I do RMRLF, utilizado na primeira condição de operação, exigiu vazão de $6 I \cdot h^{-1}$.

No início da segunda condição de operação, houve a troca da bomba de alimentação do sistema, porque a vazão requerida nessa etapa foi menor e a bomba que estava sendo utilizada não era precisa para manter constante a vazão requerida. A bomba Ecosan BDN2 foi substituída por uma Miniplus 3 da marca GILSON.

Na segunda condição, a fim de obter nitrificação significativa do efluente da câmara 2, o TDH na câmara 4 foi aumentado com o objetivo de obter TDH de aproximadamente 4 horas em relação ao volume útil do reator. Como as câmaras estão seqüencialmente dispostas na posição radial, houve necessidade de se reduzir a vazão afluente ao sistema para 2,0 l.h-1 . Considerou-se, também, para totalizar a vazão afluente um adicional de $0,5 \mathrm{l} \cdot \mathrm{h}^{-1}$, a partir da câmara 3 , correspondente à vazão da solução de bicarbonato de sódio, destinada a garantir a alcalinidade no sistema.

$\mathrm{O} \mathrm{TDH}$ de aproximadamente $18 \mathrm{~h}$ para o volume útil do RMRLF de aproximadamente 38 / era composto por 15,4 h na câmara 2 devido à vazão de 2 $l \cdot h^{-1}$ e por 2,8 h nas câmaras seguintes devido à vazão de $2,5 l \cdot h^{-1}$. Para o RAHLFa, além da vazão afluente, havia fornecimento de fonte de carbono junto à entrada do

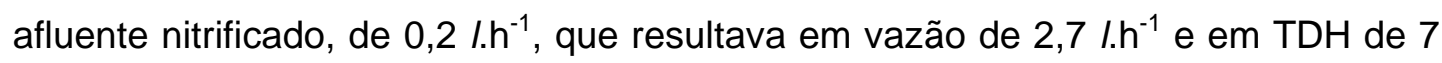
h para o volume útil do RAHLFa de aproximadamente 19 l. Esse valor está próximo ao utilizado por VIEIRA (2000), que obteve bons resultados na desnitrificação com operação do RAHLFa com TDH igual a 5,6 h, considerando o volume útil do reator. A Tabela 4.2 apresenta o resumo das duas condições de operação do sistema. 
TABELA 4.2 - Condições de operação do sistema.

\begin{tabular}{ccccc}
\hline & \multicolumn{2}{c}{ RMRLF } & \multicolumn{2}{c}{ RAHLFa } \\
\hline Condições de operação & $1^{\circ}$ cond. & $2^{\circ}$ cond. & $1^{\circ}$ cond. & $2^{\circ}$ cond. \\
\hline Volume total & $70,7 /$ & $70,7 ~ I$ & $47,0 ~ I$ & $47,0 I$ \\
\hline TDH total & $11,8 \mathrm{~h}$ & $34,5 \mathrm{~h}$ & $7,8 \mathrm{~h}$ & $17,4 \mathrm{~h}$ \\
\hline Volume útil & $38,0 I$ & $38,0 I$ & $19,0 ~ I$ & $19,0 I$ \\
\hline TDH “útil” & $6,3 \mathrm{~h}$ & $18,1 \mathrm{~h}$ & $3,2 \mathrm{~h}$ & $7,0 \mathrm{~h}$ \\
\hline
\end{tabular}

O reator foi operado à temperatura ambiente, e as medidas de temperatura eram feitas nos pontos de amostragem descritos no item 4.7. A temperatura ambiente no local que o sistema estava instalado também era acompanhada.

A periodicidade das análises foi mantida em média de três vezes por semana, para permitir o melhor acompanhamento do desempenho do sistema, assim como auxiliar na avaliação de eventuais problemas operacionais e na tomada de decisões sobre as alterações necessárias. Destaca-se, novamente, que as análises de nitrogênio nas formas de nitrito e de nitrato só tiveram início depois de ser detectado do decaimento na concentração de nitrogênio amoniacal. 


\section{Resultados e discussão}

\subsection{Caracterização da água residuária afluente ao sistema}

Durante a operação do sistema, foram realizados dois perfis de $24 \mathrm{~h}$ do esgoto sanitário armazenado no reservatório de 750 l, nos meses de julho e outubro de 2002.

Os resultados apresentados na Figura 5.1 confirmam que a variação de DQO, no período de $24 \mathrm{~h}$, não era significativa. Isso possibilitou a coleta de amostras pontuais e eliminou a necessidade de realizar amostragens compostas.

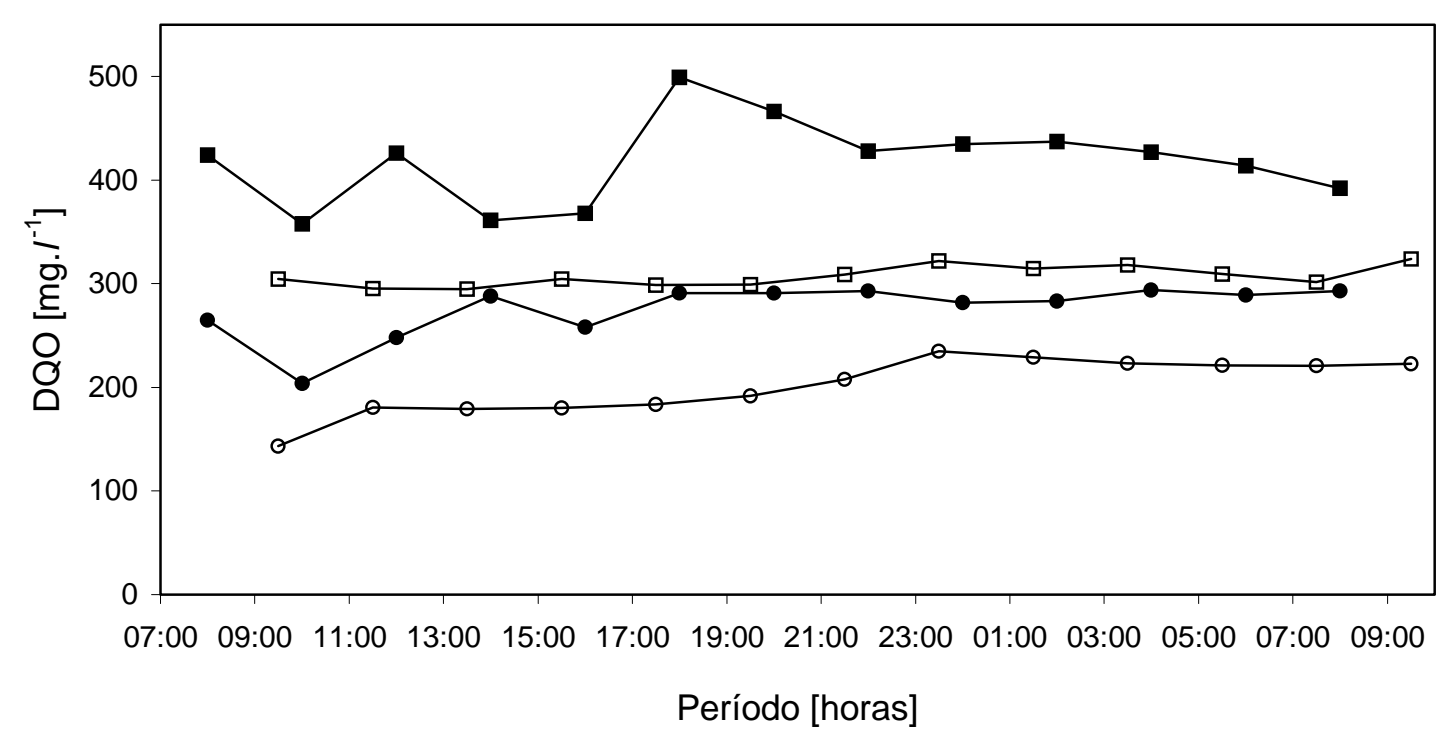

FIGURA 5.1 - Perfis de concentração em termos de DQO, do reservatório de água residuária. Jul/2002: DQO bruta $\square$ e DQOf $\bigcirc$ e Out/2002: DQO bruta $\square$ e DQOf $\bullet$. 
Em julho de 2002 o esgoto afluente apresentou valor médio de DQO de $307 \pm 10 \mathrm{mg} \cdot \mathrm{I}^{1}$ e de DQOf de $201 \pm 27 \mathrm{mg} \cdot \mathrm{I}^{1}$. Em outubro de 2002 o valor médio de DQO foi de $418 \pm 41 \mathrm{mg} . I^{1}$ e de DQOf foi de $275 \pm 26 \mathrm{mg} . I^{1}$.

Os perfis realizados nos meses de julho e outubro apresentam diferença de aproximadamente $100 \mathrm{mg} . I^{1}$ nos valores de DQO. Essa diferença é devida, provavelmente, à influência da contribuição do restaurante universitário da USP para o aumento da DQO. Em julho o restaurante universitário estava desativado devido às férias escolares e em outubro estava em funcionamento.

\subsection{Avaliação do desempenho do RMRLF}

A operação do RMRLF teve como objetivos reter sólidos, remover matéria carbonácea, nitrificar o efluente da câmara 2, na câmara 4.

A instalação experimental do RMRLF está apresentada na Figura 5.2. Podem ser observados o ponto de entrada do esgoto sanitário peneirado, a mangueira para fornecimento de ar comprimido e a canalização de saída do reator, que coincide com a canalização de entrada do afluente no RAHLFa. Os detalhes construtivos foram apresentados no item 4.1.1.

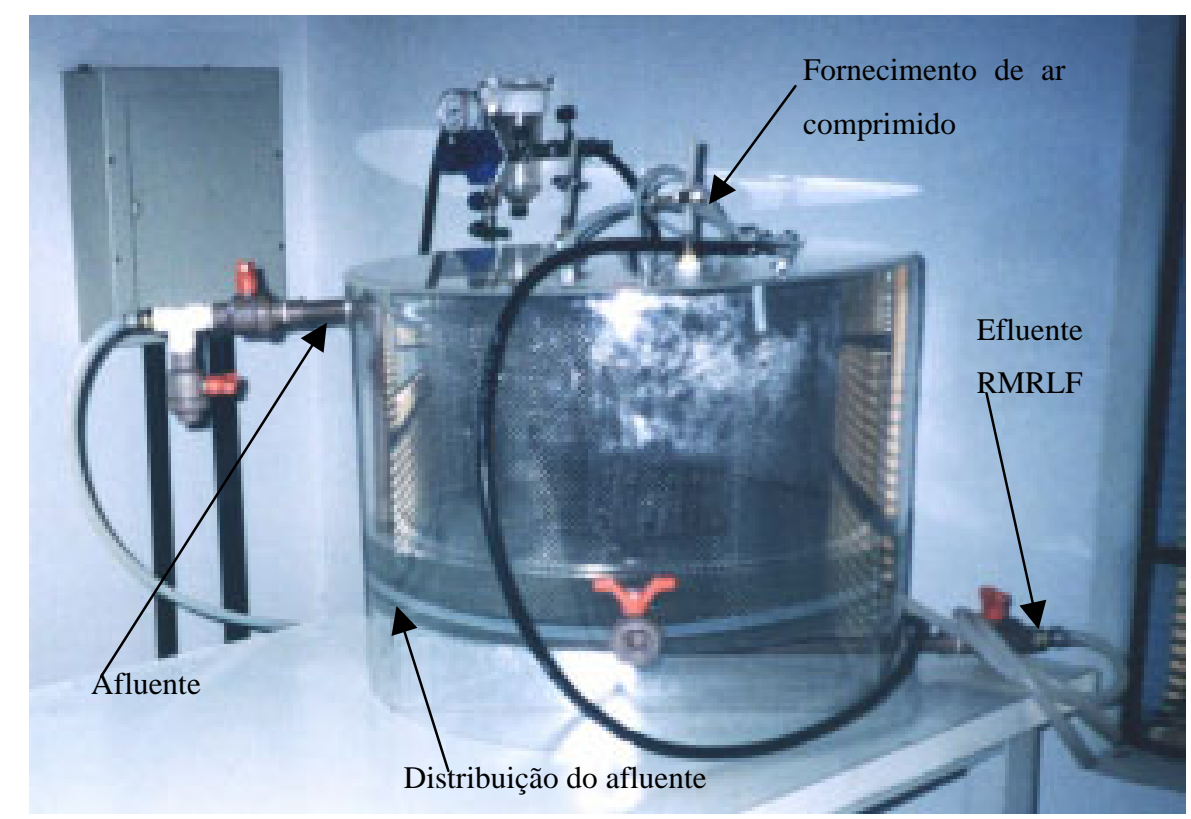

FIGURA 5.2 - RMRLF, em escala de bancada, utilizado no tratamento de esgoto sanitário e nitrificação do nitrogênio amoniacal. 


\subsubsection{Monitoramento de parâmetros operacionais}

Os resultados apresentados, neste item, são analisados em duas condições diferentes. A primeira, contém os dados de 54 dias de operação do sistema com vazão média de $6 l \cdot \mathrm{h}^{-1}$, correspondente a TDH de 6,3 h, em relação ao volume útil, na qual foi possível obter boa retenção de sólidos e remoção de matéria carbonácea. A segunda condição de operação, após o $92^{\circ}$ dia de operação e com duração de 30 dias, com vazão média de $2,5 \mathrm{l} \cdot \mathrm{h}^{-1}$, correspondente a TDH de aproximadamente $18 \mathrm{~h}$, em relação ao volume útil, em que o reator obteve significativa remoção de N-NTK, além da retenção de sólidos e remoção de DQO.

Devido a problemas com a instalação de recalque, no controle da vazão afluente, a partir do $54^{\circ}$ dia de operação, os resultados das análises ficaram prejudicados no intervalo do $55^{\circ}$ ao $93^{\circ}$ dia de operação, o qual foi denominado período de transição, devido à dificuldade em controlar a vazão afluente e a irregularidade no processo de nitrificação.

A grande instabilidade da vazão e, conseqüentemente, do TDH, principalmente na primeira condição de operação, podem ser observadas na Figura 5.3. Deve ser observado que os dados de vazão foram obtidos pontualmente e não continuamente, sem ser possível garantir que os valores interpolados representam corretamente a vazão.

Durante a operação do sistema, inicialmente utilizou-se bomba Ecosan BDN2, que se mostrou imprecisa para manter vazão média de $6 l \cdot h^{-1}$ pois, como pode ser observado, na Figura 5.3, a vazão variou muito no decorrer dos dias. Ao optar-se pelo aumento do TDH, foi necessário substituir a bomba por outro equipamento mais preciso e estável. Optou-se pela utilização da bomba Miniplus 3 Peristaltic Pump, da marca GILSON, a qual, no $92^{\circ}$ dia de operação, garantiu vazão mais regular, sem grandes oscilações. 


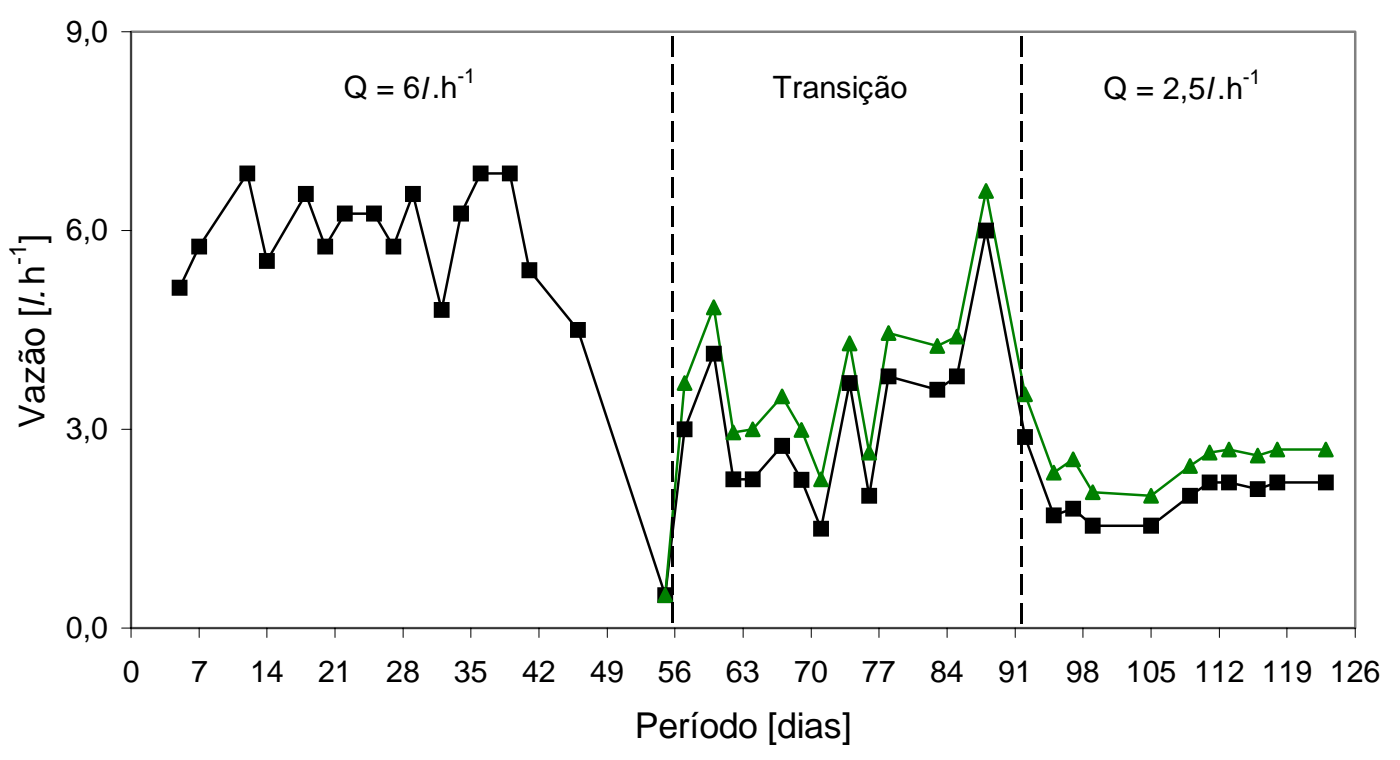

FIGURA 5.3 - Valores obtidos de vazão efluente e e afluente com adição de solução alcalina $\Delta$.

A temperatura ambiente da sala onde estava instalado o reator, apresentou valor mínimo igual a $9,0^{\circ} \mathrm{C}$ e máximo de $30,0^{\circ} \mathrm{C}$, com valor médio de $19,8^{\circ} \mathrm{C}$. O valor médio de temperatura do esgoto afluente ao RMRLF foi de 19,2 \pm $1,8^{\circ} \mathrm{C}$ e do efluente foi de $20,2 \pm 1,6^{\circ} \mathrm{C}$. Houve pouca variação de temperatura dentro do reator, sendo que no decorrer do período de operação do sistema houve grande variação, conforme pode ser observado na Figura 5.4 .

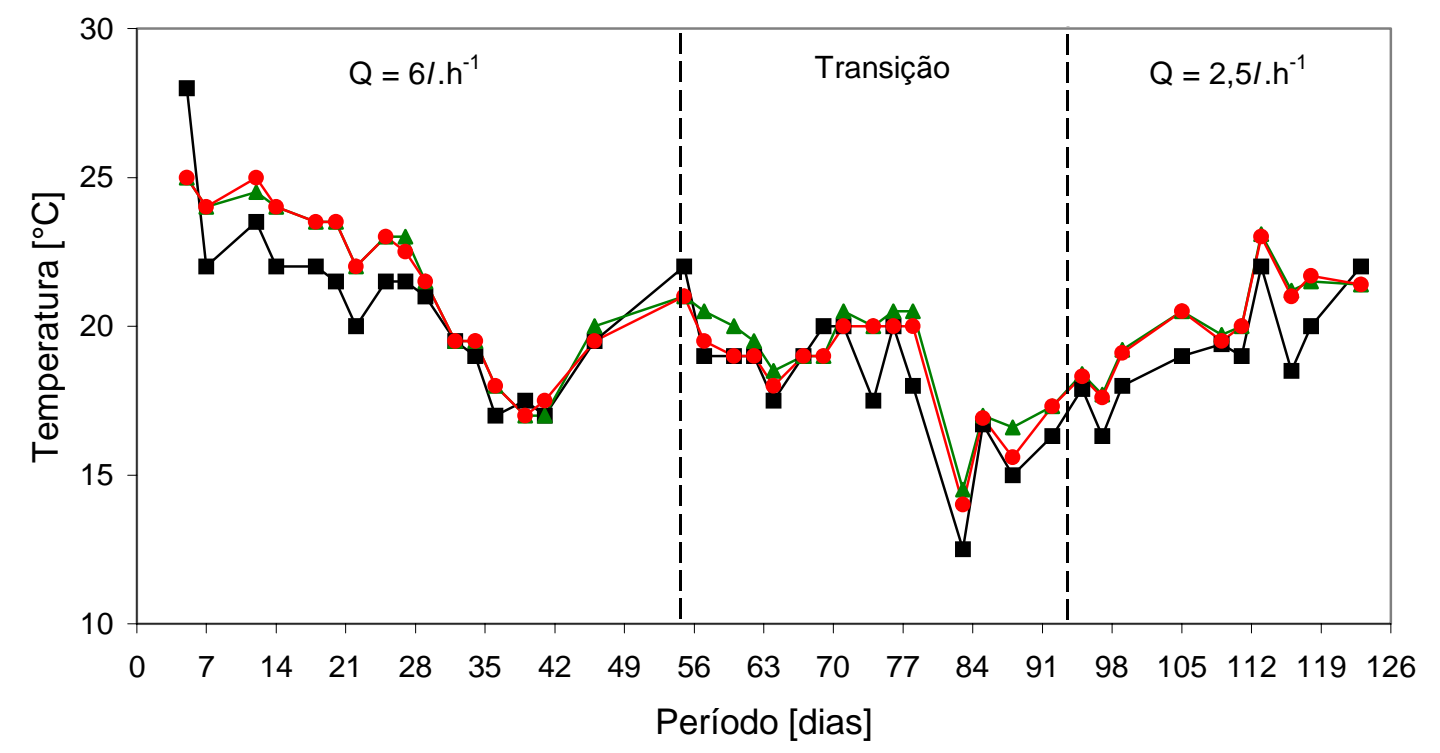

FIGURA 5.4 - Valores obtidos de temperatura do esgoto afluente $\square$, na câmara $3 \triangle$ e no efluente RMRLF $\bullet$. 
O monitoramento do reator foi feito através das análises apresentadas no item 4.7. As amostras do afluente e efluente, foram coletadas de forma pontual; devido a não ser significativa a variação da concentração do afluente de entrada, como apresentado no item 5.1 e do reator ter sido projetado para operar com vazão constante.

Na Tabela 5.1, estão apresentadas as principais características do esgoto sanitário, utilizado como afluente ao RMRLF. Esses valores médios são referentes às análises executadas durante os 123 dias de operação.

TABELA 5.1 - Valores médios dos parâmetros analisados no esgoto sanitário afluente.

\begin{tabular}{|c|c|c|}
\hline Parâmetro & Unidade & Valor \\
\hline$A B$ & $\mathrm{mgCaCO}_{3} \cdot I^{1}$ & $149 \pm 42$ \\
\hline AVT & $\mathrm{mgHAc} . I^{1}$ & $73 \pm 27$ \\
\hline DQO & $\mathrm{mg} . .^{1}$ & $429 \pm 118$ \\
\hline DQOf & $\mathrm{mg} . .^{1}$ & $286 \pm 68$ \\
\hline N-NTK & $\mathrm{mgN} . I^{1}$ & $38 \pm 5$ \\
\hline N-amon & $\mathrm{mgN} . I^{1}$ & $30 \pm 6$ \\
\hline $\mathrm{N}-\mathrm{NO}_{2}^{-}$ & $\mathrm{mgN} . I^{1}$ & $0,0 \pm 0,0$ \\
\hline $\mathrm{N}-\mathrm{NO}_{3}{ }^{-}$ & $\mathrm{mgN} . I^{1}$ & $0,0 \pm 0,0$ \\
\hline $\mathrm{pH}$ & & $7,4 \pm 0,2$ \\
\hline SST & $\mathrm{mg} . I^{1}$ & $62 \pm 23$ \\
\hline SSV & $\mathrm{mg} \cdot I^{1}$ & $53 \pm 22$ \\
\hline
\end{tabular}

As análises foram realizadas com freqüência média de três vezes por semana. As tabelas contendo todos os dados obtidos estão apresentadas no Apêndice I.

Na Figura 5.5, podem ser observados os valores de DQO do afluente, da câmara 3 e do efluente ao RMRLF, obtidos durante os 123 dias de operação do reator. A estabilidade do reator quanto à remoção de matéria orgânica carbonácea foi atingida rapidamente. Na Figura 5.6 são apresentados os valores do afluente, da câmara 3 e efluente de DQOf para primeira e segunda condição. Através dos dados 
apresentados é possível observar a alta remoção de matéria orgânica carbonácea desde o início da operação.

Os valores obtidos de DQO afluente apresentaram valor médio, na primeira condição, de $446 \pm 62 \mathrm{mg} . I^{1}$ e efluente igual a $80 \pm 8 \mathrm{mg} . I^{1}$. A alta remoção de $\mathrm{DQO}$, no início da operação, pode ser atribuída à retenção de sólidos no primeiro módulo do reator e, também, à rápida partida do RMRLF.

Durante a operação do reator, na primeira condição, com vazão de $6 I \cdot h^{-1}$ foi possível diferenciar os valores obtidos nas análises do líquido na câmara 3 e do efluente final do reator. Na segunda condição, com vazão de $2,5 \mathrm{l} \cdot \mathrm{h}^{-1}$, os valores de DQO na câmara 3 e efluente do RMRLF confundem-se em vários dias de amostragem, evidenciando superdimensionamento para remoção de matéria carbonácea. Entretanto, este TDH foi necessário para obter a nitrificação do efluente líquido.

O valor médio de DQO efluente, após o equilíbrio do reator na segunda condição, em que a nitrificação estava estabilizada, foi de $41 \pm 16 \mathrm{mg} . I^{1}$, o que resultou em eficiência aproximadamente $10 \%$ maior que a obtida durante a primeira condição.

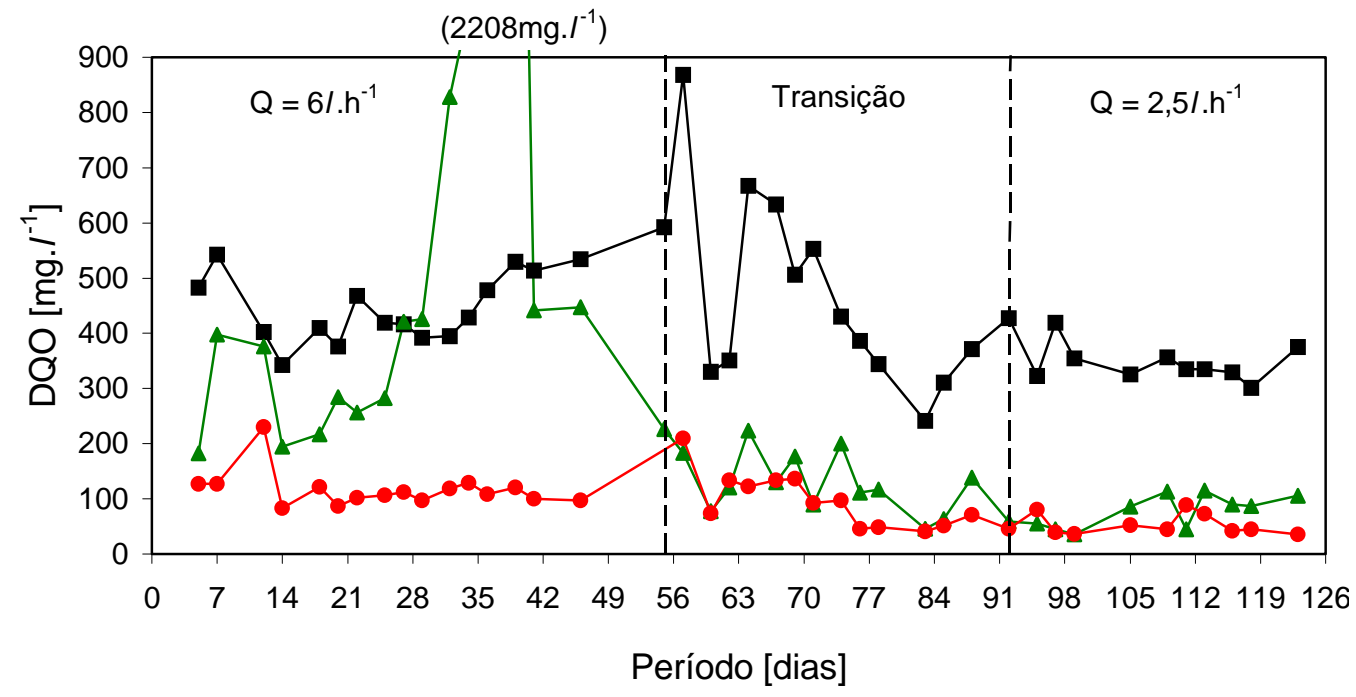

FIGURA 5.5 - Valores obtidos de DQO afluente $\square$, na câmara $3 \Delta$ e no efluente do RMRLF •

No início da operação, os valores de Ssed (sólidos sedimentáveis) se apresentavam em concentrações abaixo do limite de detecção do método utilizado para quantificação desse parâmetro. Após o crescimento de organismos 
filamentosos na câmara 3, foi atingido valor de aproximadamente $90 \mathrm{~m} / .^{1}$. Dessa forma é possível constatar que o aumento nos valores de DQO, obtidos na câmara 3 , a partir do $25^{\circ}$ dia de operação, foram devido ao crescimento excessivo desse tipo de microrganismos. Através de exames microscópicos desses filamentos, apresentados no item 5.5.3, foram constatadas a presença de morfologias semelhantes à de bactérias filamentosas microaerófilas, típicas de ambientes com insuficiência de OD. Foi verificado com sonda de OD, que a concentração média de OD era inferior a $2 \mathrm{mg} . \mathrm{I}^{1}$, o que indicou deficiência no sistema de aeração.

No $29^{\circ}$ dia de operação, foi aumentada a vazão de ar nos difusores instalados na câmara 3, com o propósito de disponibilizar maior concentração de oxigênio dissolvido no meio. Após a intensificação da vazão de ar, houve acréscimo dos sólidos sedimentáveis na câmara 3. A partir desse momento, a DQO na câmara 3, também sofreu alteração, pois a aeração revolveu o fundo do reator e o líquido da câmara 3 apresentou muitos filamentos e sólidos suspensos.

Nos dias subseqüentes, a operação do reator seguiu sem contratempos, sendo mantidas as condições impostas, com aeração suficiente para garantir concentração média de OD de aproximadamente 5,0 mg. $I^{1}$. Observou-se que durante uma semana na câmara 3, a DQO e os SSed continuaram a aumentar, atingindo aproximadamente $2.200 \mathrm{mg} . I^{1}$ e $125 \mathrm{~m} / I^{1}$, respectivamente, até cair rapidamente a níveis aceitáveis. Os sólidos em excesso não foram mais detectados e a concentração de SSed encontrava-se em $9 \mathrm{~m} / I^{1}$ no $46^{\circ}$ dia de operação.

A diminuição da DQO da câmara 3 foi acompanhada pela queda na concentração de SSed, o que confirmou que a alta no valor de DQO foi devida aos filamentos produzidos na câmara 3. Este fato pôde ser confirmado, pela comparação entre os valores obtidos para DQOf (Figura 5.6), no mesmo período de altos valores de DQO. Foi verificado que os valores da DQOf mantiveram-se relativamente constantes, sem acompanhar os valores de DQO. Portanto o incremento no valor de DQO foi basicamente devido aos sólidos que foram acumulados na câmara 3. Mesmo com o aumento da aeração e conseqüente agitação do fundo do reator não foram observadas alterações significativas nos resultados das análises de DQOf. 


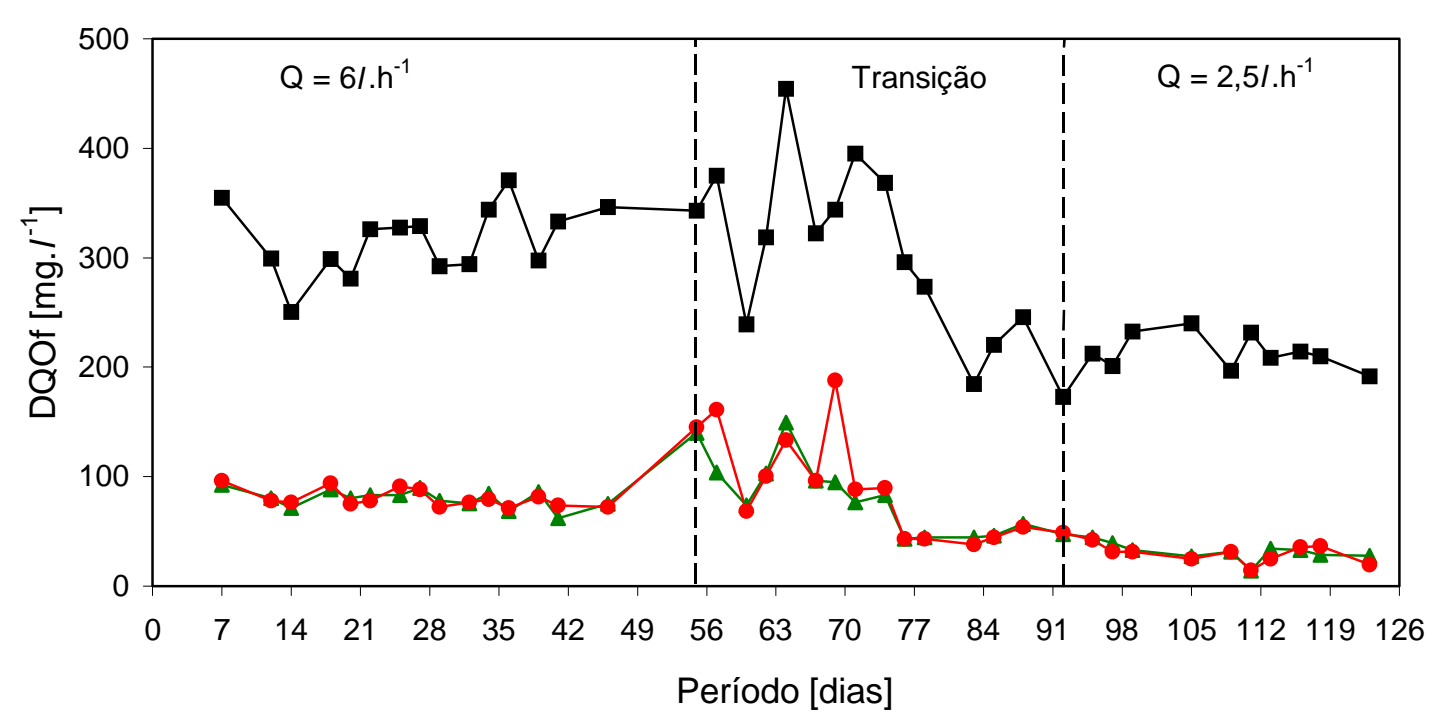

FIGURA 5.6 - Valores obtidos da DQOf afluente घ, na câmara $3 \Delta$ e no efluente do RMRLF •

O valor médio de DQOf, obtido no efluente do RMRLF, correspondente à primeira condição, foi $68 \pm 9 \mathrm{mg} . I^{1}$; enquanto que, para a segunda condição, a DQOf efluente final caiu para $36 \pm 15 \mathrm{mg} . I^{1}$.

Os valores de eficiência de remoção de DQO e DQOf, durante os 123 dias de operação, para as duas condições, estão apresentados na Figura 5.7. Apesar da grande variação da DQO bruta afluente, a eficiência do reator foi mantida relativamente constante. A instabilidade apresentada, em alguns pontos, na primeira condição e na transição, pode ser justificada pelas eventuais variações nos valores de DQO afluente. Esses problemas estiveram relacionados, principalmente, à operação da bomba. Deve ser observado que as eficiências calculadas para remoção de DQOf no efluente do reator são feitas em relação a DQO de amostra não filtrada do afluente ao sistema. 


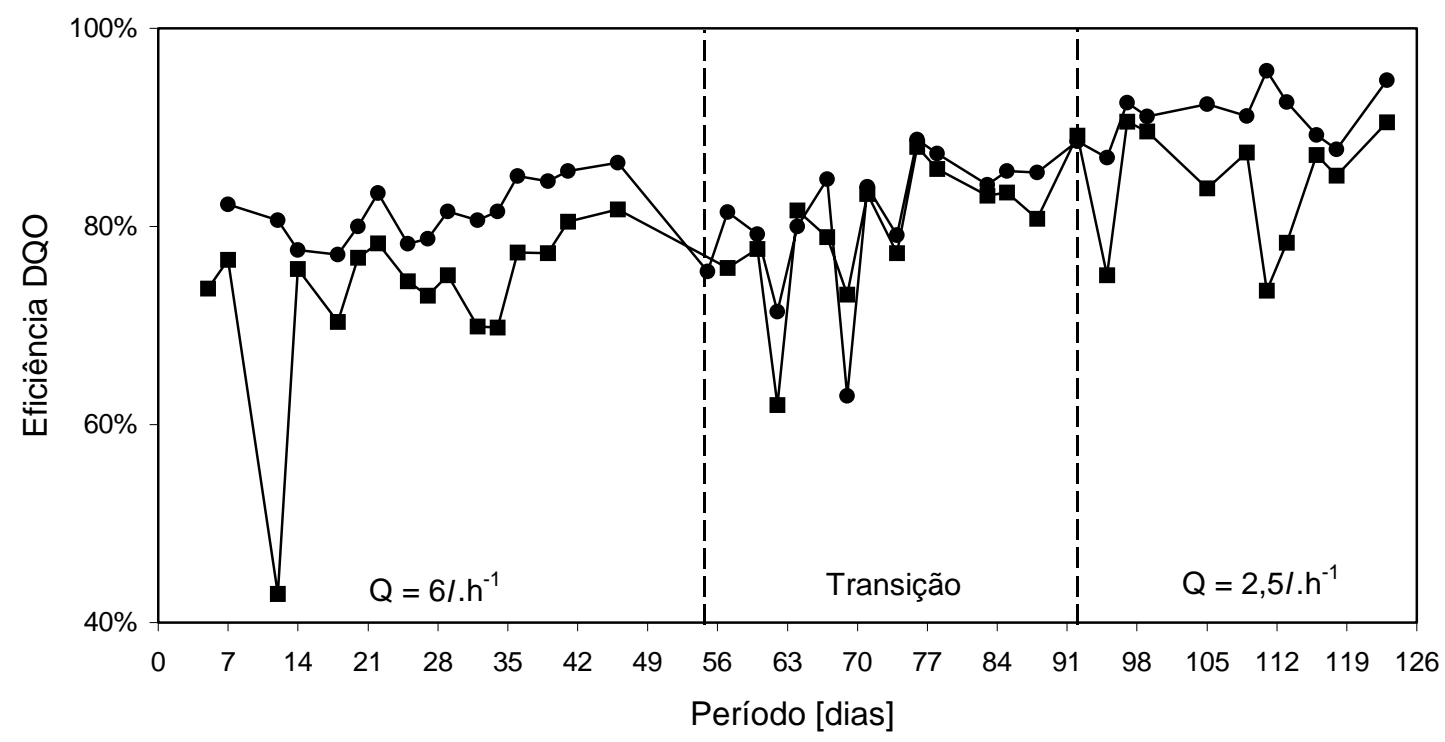

FIGURA 5.7 - Valores obtidos de eficiência de remoção de DQO घ e DQOf •.

Os valores de eficiência de remoção de DQO e DQOf para a primeira condição, que compreendeu o início da operação até $55^{\circ}$ dia, estabilizaram-se em torno de $74 \%$ e $75 \%$, respectivamente. Para a segunda condição, a partir do $92^{\circ}$ dia a eficiência média de remoção de DQO e DQOf foi $84 \%$ e $86 \%$, respectivamente. Resultados similares foram obtidos por AISSE et al. (2000) em sistema anaeróbio/aeróbio com TDH de aproximadamente 12 h, apresentado no item 2.3. Os autores obtiveram efluente com valor médio de DQO de $105 \pm 58 \mathrm{mg} . \mathrm{I}^{1}$ correspondendo à eficiência de $78 \%$.

VIEIRA (2000) tratando efluente anaeróbio de RAHLF, utilizando RARLF obteve concentração no efluente de $36 \pm 7 \mathrm{mg} . I^{1}$ para TDH de $4 \mathrm{~h}$ em relação ao volume útil do reator, valor esse, próximo ao obtido para a segunda condição de operação no RMRLF.

A Figura 5.8 apresenta valores de pH afluente, da câmara 3 e efluente, observados para as duas condições de operação. $\mathrm{O}$ pH foi medido no laboratório, após transporte das amostras do local da instalação dos reatores até o laboratório de saneamento, com demora média de uma hora, o que provavelmente provocava certo erro nas análises de $\mathrm{pH}$. Entretanto esse provável erro nas análises não interferiu no controle e monitoramento do sistema. Os valores de $\mathrm{pH}$ afluente variaram entre 6,6 e 7,7 e a média, durante toda operação, permaneceu em 7,4 \pm 0,2 . 


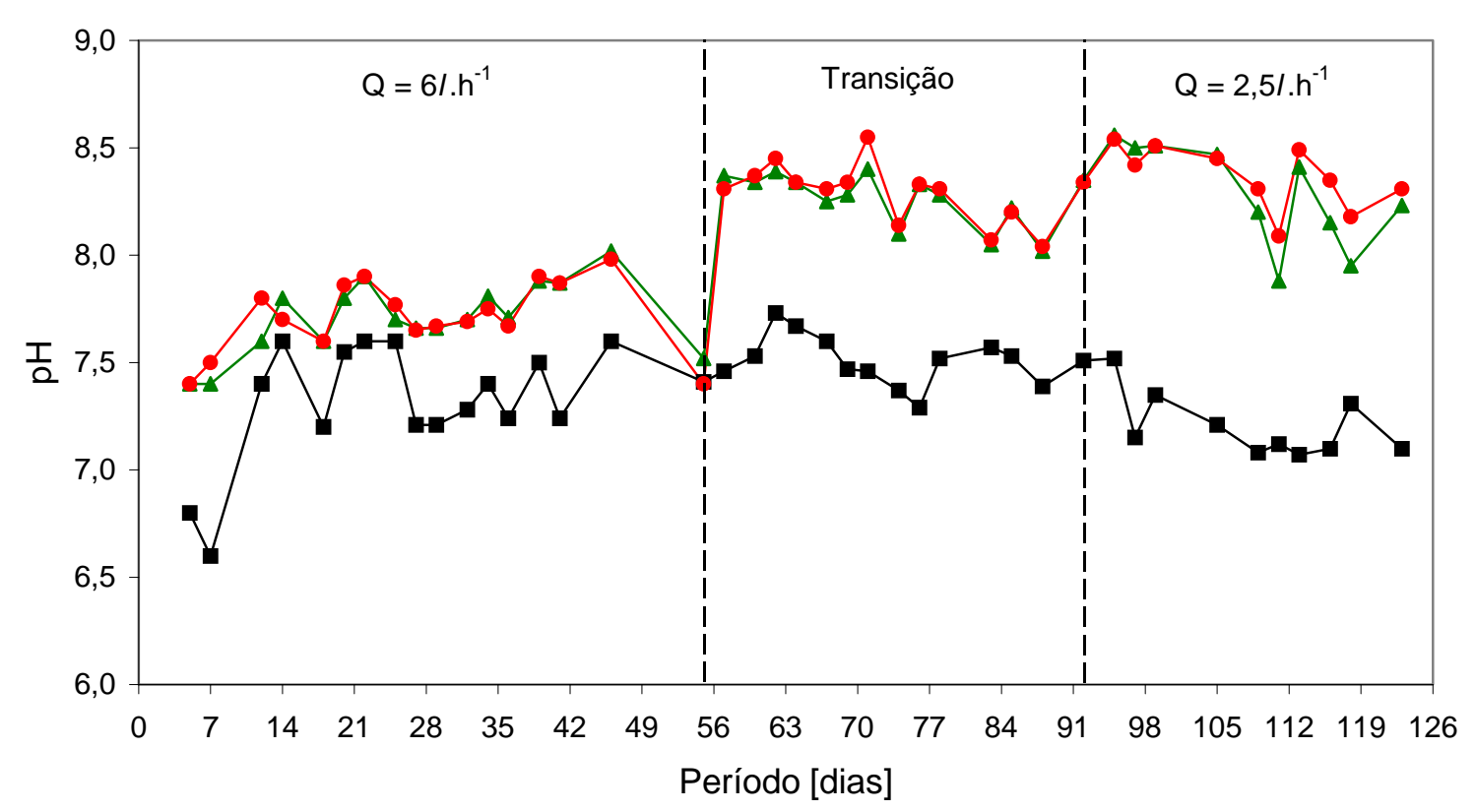

FIGURA 5.8 - Valores obtidos de pH afluente $\square$, na câmara $3 \Delta$ e no efluente do RMRLF •.

Durante a primeira condição, o pH de ambos, câmara 3 e efluente do RMRLF, mantiveram-se com média de, aproximadamente, 7,7. O início da nitrificação e conseqüente consumo de alcalinidade, causou queda do $\mathrm{pH}$, que pôde ser observada logo após o $49^{\circ}$ dia de operação. Após essa data, teve início o fornecimento de solução de bicarbonato de sódio, para se garantir a manutenção de alcalinidade e o valor de pH em níveis aceitáveis.

No período de transição e na segunda condição, o pH na câmara 3 e do efluente do RMRLF mantiveram-se relativamente iguais, com valor médio de 8,3; o que, segundo os autores FORD et al. (1980) e HENZE et al. (1997) está dentro da faixa de $\mathrm{pH}$ ótimo para formação de nitrito e nitrato.

A Figura 5.9 apresenta os valores de $A B$ do afluente, da câmara 3 e efluente ao RMRLF. 


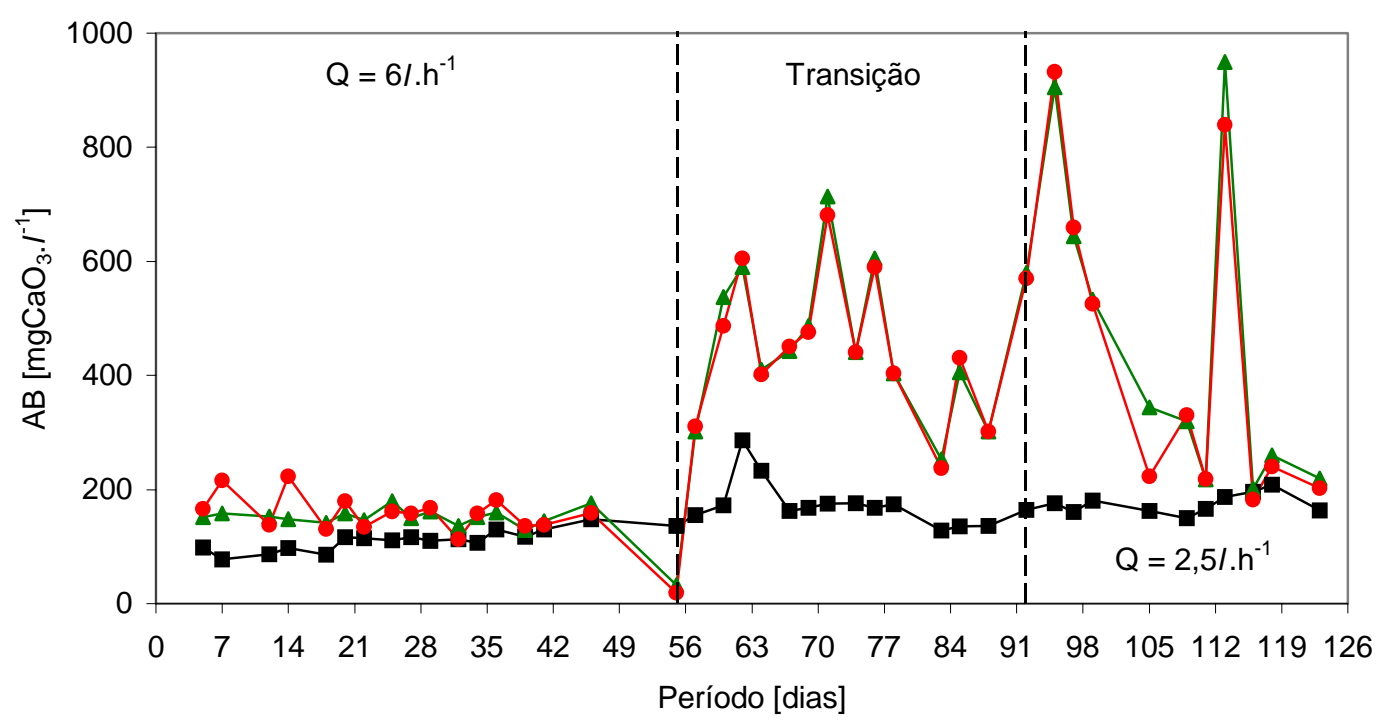

FIGURA 5.9 - Valores obtidos de alcalinidade a bicarbonato afluente $\square$, na câmara $3 \Delta$ e no efluente do RMRLF •.

A alcalinidade, até o $49^{\circ}$ dia de operação na câmara 3, permaneceu com concentração ligeiramente superior aos valores do afluente, o que indica que houve produção de alcalinidade e confirma a ocorrência de provável equilíbrio entre os microrganismos produtores de ácidos orgânicos, $\mathrm{H}_{2}$ e $\mathrm{CO}_{2}$ e os microrganismos metanogênicos, no processo anaeróbio. Entretanto, após o início da nitrificação, detectada pela rápida queda nos valores de alcalinidade, foi necessária a adição de solução de bicarbonato de sódio para evitar que a alcalinidade atingisse valores muito baixos.

O bicarbonato de sódio foi fornecido ao reator na câmara 3, com auxílio de bomba peristáltica, com vazão média de $0,5 \mathrm{l} \cdot \mathrm{h}^{-1}$, conforme descrito no item 4.5.

A partir do início do período de transição houve grande variação nos valores de alcalinidade, da câmara 3 e do efluente do RMRLF. Isso foi devido a dois motivos principais: primeiramente, o objetivo não era controlar a dosagem de alcalinidade do reator, mas garantir que houvesse capacidade tampão suficiente para não inibir a nitrificação; em segundo lugar, porque ocorreram dificuldades operacionais. A solução alcalina era utilizada para dois trabalhos de pesquisa distintos, com reatores operados simultaneamente, sendo que na preparação da solução não era possível esvaziar totalmente o recipiente de preparo. Eventualmente, o líquido residual no fundo do recipiente interferia na preparação da solução seguinte. 
A Figura 5.10 apresenta os valores de AVT afluente, da câmara 3 e efluente ao RMRLF, obtidos durante a operação do sistema.

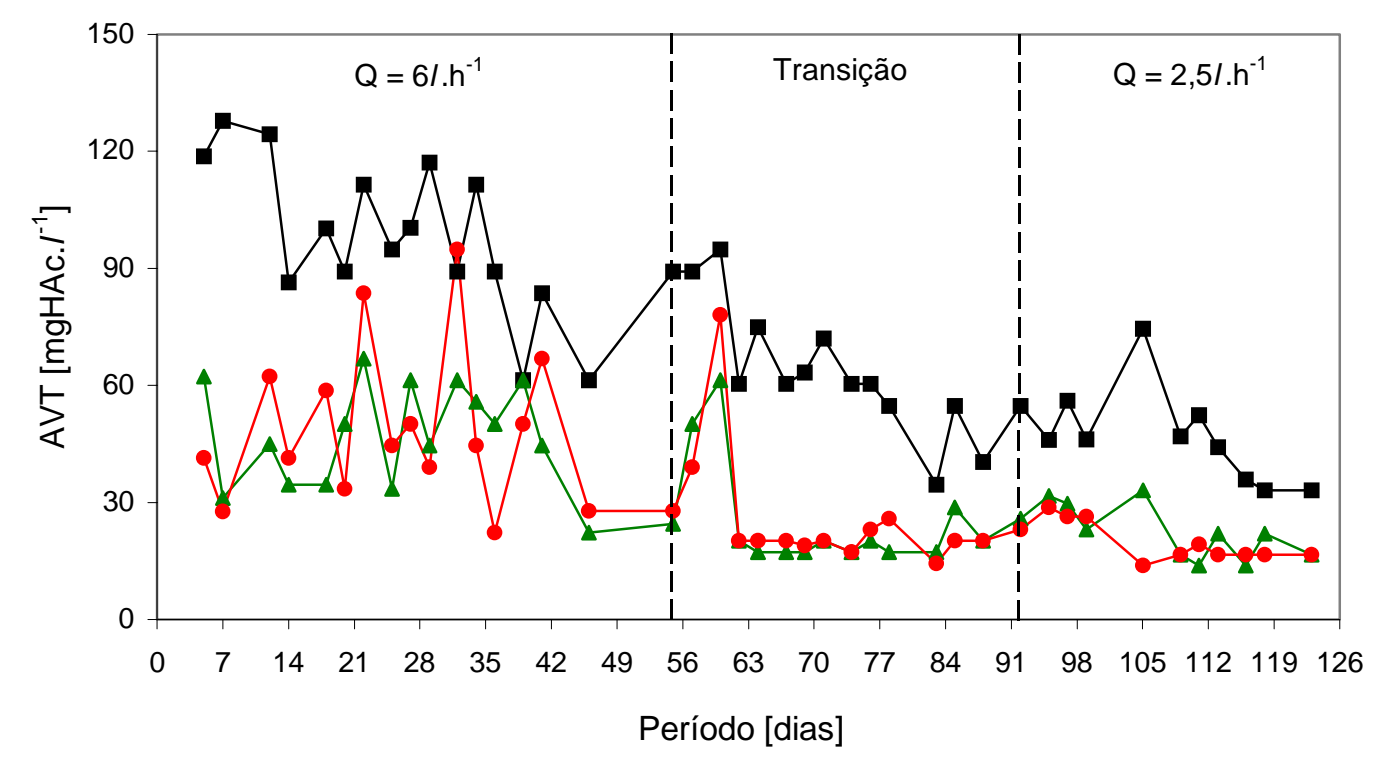

FIGURA 5.10 - Valores obtidos de AVT afluente $\square$, na câmara $3 \Delta$ e no efluente do RMRLF •

Os valores de AVT apresentaram certa variação até o $60^{\circ}$ dia de operação, provavelmente devido a problemas analíticos. Constatou-se que a solução utilizada na titulação encontrava-se muito concentrada, o que dificultou a obtenção de valores precisos. A partir do $61^{\circ}$ dia foi utilizada solução mais diluída, o que possibilitou a obtenção de valores mais precisos e, conseqüentemente, menor variação nos valores de AVT.

Os valores de AVT observados durante a primeira condição, mantiveram valor médio efluente mais baixo que o afluente, desde o início da operação do reator. $\mathrm{Na}$ segunda condição, foram obtidos praticamente os mesmos valores, contudo, foram mantidos com menor instabilidade. Os valores mais baixos de AVT observados no efluente indicaram equilíbrio entre a etapa acidogênica e metanogênica de degradação do substrato. Isso indica, também, a rápida partida do reator.

Nas Figuras 5.11 e 5.12 estão apresentados os valores obtidos de ST e SST afluente, da câmara 3 e efluente RMRLF, para tratamento de esgoto sanitário. 


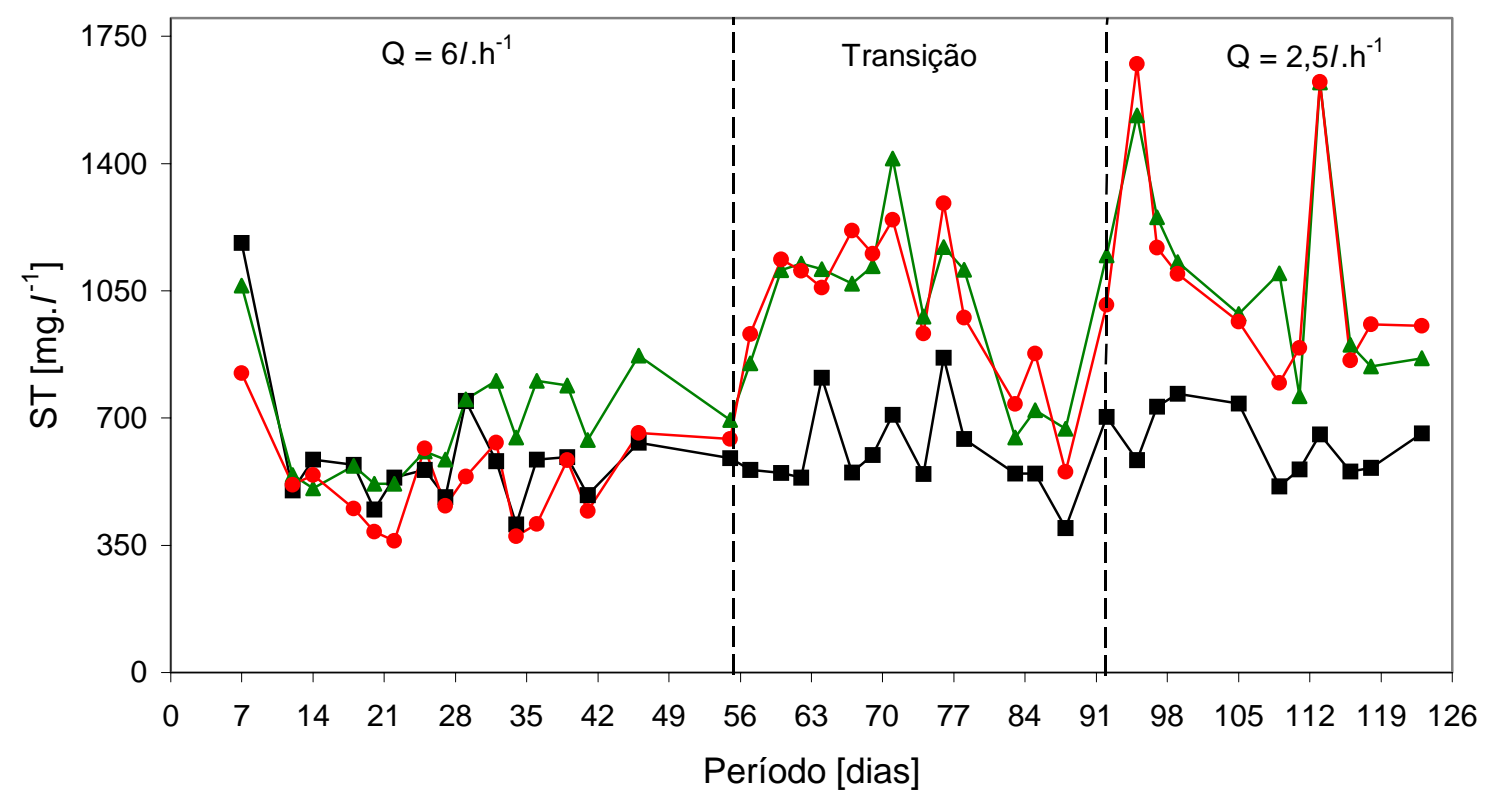

FIGURA 5.11 - Valores obtidos para Sólidos Totais afluente $\square$, na câmara $3 \Delta \mathrm{e}$ no efluente do RMRLF $\bullet$.

Os valores de ST afluente e efluente ao reator mantiveram-se praticamente constantes na primeira condição. Entretanto, após início da alcalinização, foi possível observar, claramente, o aumento nos valores de ST obtidos na câmara 3 e no efluente do RMRLF. Essa influência, da solução alcalina fornecida ao reator, prejudicou os resultados obtidos para os ST (sólidos totais) e SD (sólidos dissolvidos). Isso aconteceu, porque o $\mathrm{NaHCO}_{3}$ (bicarbonato de sódio) é convertido a $\mathrm{Na}_{2} \mathrm{CO}_{3}$ (carbonato de sódio) à $100^{\circ} \mathrm{C}$, temperatura utilizada na estufa para secagem dos sólidos. Posteriormente, na mufla a $500^{\circ} \mathrm{C}$, o $\mathrm{Na}_{2} \mathrm{CO}_{3}$ é convertido a $\mathrm{Na}_{2} \mathrm{O}$, pela perda de $\mathrm{CO}_{2}$. Portanto a perda de massa devida à calcinação das amostras não é devida apenas à volatilização de matéria orgânica, como é pressuposto para as análises de SV em condições normais.

Foi observado que os SS (sólido suspensos) encontrados na câmara 3 e no efluente do RMRLF eram basicamente SSV, devido à proximidade entre os valores obtidos nas análises de SST e de SSV. Na maioria das análises os valores de SSF eram muito baixos ou até mesmo não detectáveis. 


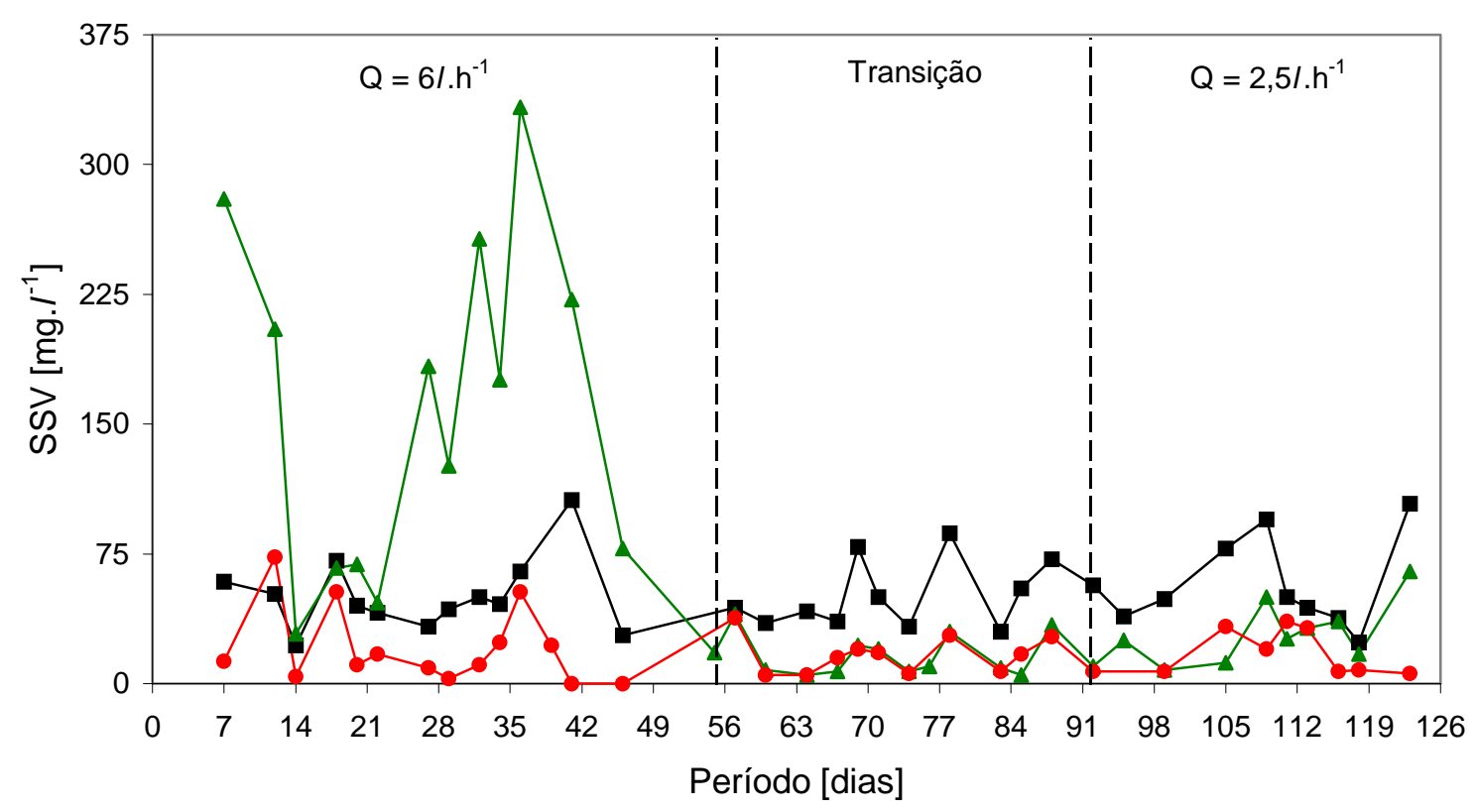

FIGURA 5.12 - Valores obtidos para Sólidos Suspensos Voláteis afluente $\square$, na câmara $3 \Delta$ e no efluente do RMRLF $\bullet$.

Através das análises de SSV, na primeira condição, obteve-se valor médio de $51 \pm 22 \mathrm{mg} . I^{1}$ no afluente do reator e de $19 \pm 22 \mathrm{mg} . I^{1}$ no efluente do RMRLF, o que resultou em eficiência de $62 \%$ na redução de sólidos. Na segunda condição, os valores médios afluente e efluente dos SSV foram $58 \pm 28 \mathrm{mg} . I^{1}$ e $8 \pm 7 \mathrm{mg} . I^{1}$, respectivamente, o que representa eficiência de $86 \%$.

Os altos valores de SSV na câmara 3, no início da operação, foram devidos à partida do reator e à inoculação da biomassa, havendo rápida queda nesses valores. O aumento nos valores de SSV, obtidos na câmara 3, a partir do $25^{\circ}$ dia de operação, foi devido ao crescimento desordenado de microrganismos filamentosos, os quais formavam grandes filamentos facilmente visíveis a olho nu.

No $120^{\circ}$ dia de operação, foram retiradas 30 matrizes cúbicas de espuma de poliuretano para estimativa da concentração de biomassa aderida ao suporte nas câmaras 2 e 4. As amostras da câmara 2, retiradas da área predominantemente anaeróbia, resultaram em valor de aproximadamente 5 mgSV.unid ${ }^{-1}$ suporte, correspondente a $0,30 \mathrm{mgSV}_{\mathrm{mg}}{ }^{-1}$ suporte. Considerando que para câmara 2 o número de cubos de espuma de poliuretano foi estimado em 46500 unidades e o volume total dessa câmara era igual a 45,25 I, a concentração de biomassa por litro de câmra foi estimada igual a $5,1 \mathrm{gSV} . I^{1}$. 
Para as espumas retiradas da câmara 4, na qual ocorreu nitrificação e desnitrificação, a concentração de biomassa aderida ao suporte foi estimada como igual a 6 mgSV.unid ${ }^{-1}$ suporte correspondente a 0,36 mgSV.mg-1 suporte. A quantidade de cubos de espuma de poliuretano foi estimada em 3500 unidades e o volume total dessa câmara igual a 3,14 l, a concentração de biomassa por litro de câmara foi estimada como $6,7 \mathrm{gSV} . \mathrm{I}^{1}$.

Comparados aos resultados obtidos por VIEIRA (2000) que obteve concentração de 9,1 gSV. $I^{1}$ para seu reator aeróbio, a concentração obtida no sistema misto foi um pouco menor, sem comprometer, entretanto, a capacidade de tratamento e nitrificação do reator.

A estabilidade do sistema quanto a nitrificação não foi atingida até ser definida a segunda condição de operação. Com o intuito de explicar a não ocorrência da nitrificação durante a primeira condição de operação, foram formuladas algumas hipóteses prováveis: baixa disponibilidade de $\mathrm{O}_{2}$, pois foi constatado que a concentração de OD no início da operação era baixa; baixo TRC (Tempo de Retenção Celular) e baixo valor de TDH.

Através da medição de OD e dos microrganismos filamentosos, característicos de ambientes microaerófilos, observados através microscopia óptica. Foi confirmada a hipótese da limitação de oxigênio no meio líquido, ser um dos motivos possíveis pela baixa capacidade de nitrificação apresentada pelo reator. Portanto foi providenciada a intensificação da aeração na câmara 3. Essa medida promoveu a eliminação dos microrganismos filamentosos. No entanto, o processo de nitrificação não se estabeleceu como esperado.

Por outro lado, a observação da biomassa presente no reator, através da microscopia óptica, revelou a presença de microrganismos semelhantes ao filo Metazoa, classe Nematoda. A presença desses microrganismos é considerada como indicação de valores elevados de TRC. Isso elimina a possibilidade de este ser o fator impeditivo do estabelecimento do processo de nitrificação.

Finalmente foi decidido, a partir do $47^{\circ}$ dia aumentar o TDH, e logo a seguir foi detectado o início da nitrificação. É importante ressaltar que havia contra difusão do ar fornecido na câmara 3 para a câmara 2, o que pôde ser confirmado pelo exame microscópico (item5.5) e pelo perfil de POR (potencial de oxi-redução) (Figura 5.19). Essa contra-difusão dificultou a delimitação de até que ponto havia nitrificação na câmara 2 e conseqüentemente inviabilizou o cálculo preciso do TDH utilizado na etapa de nitrificação. 
O nitrogênio afluente ao sistema apresentava-se, em grande parte, como $\mathrm{N}$-amon, o que pode ser observado pelos valores médios de $\mathrm{N}$-NTK e $\mathrm{N}$-amon iguais a $41 \pm 4 \mathrm{mg} . I^{1}$ e $33 \pm 4 \mathrm{mg} . I^{1}$, respectivamente. A diferença entre esses valores, de aproximadamente $8 \mathrm{mg} \cdot{ }^{1}$, corresponde à fração de $\mathrm{N}$-org, igual a aproximadamente, $2 \mathrm{mg} . \mathrm{I}^{1}$ no efluente do reator. A proximidade entre as concentrações de N-NTK e N-amon observada se deve, provavelmente, ao fato de o processo de amonificação ocorrer em parte no reservatório de $750 \mathrm{l}$.

Nas Figuras 5.13 e 5.14 estão apresentados, respectivamente, os valores obtidos de N-NTK e de N-amon, após o início da nitrificação no RMRLF.

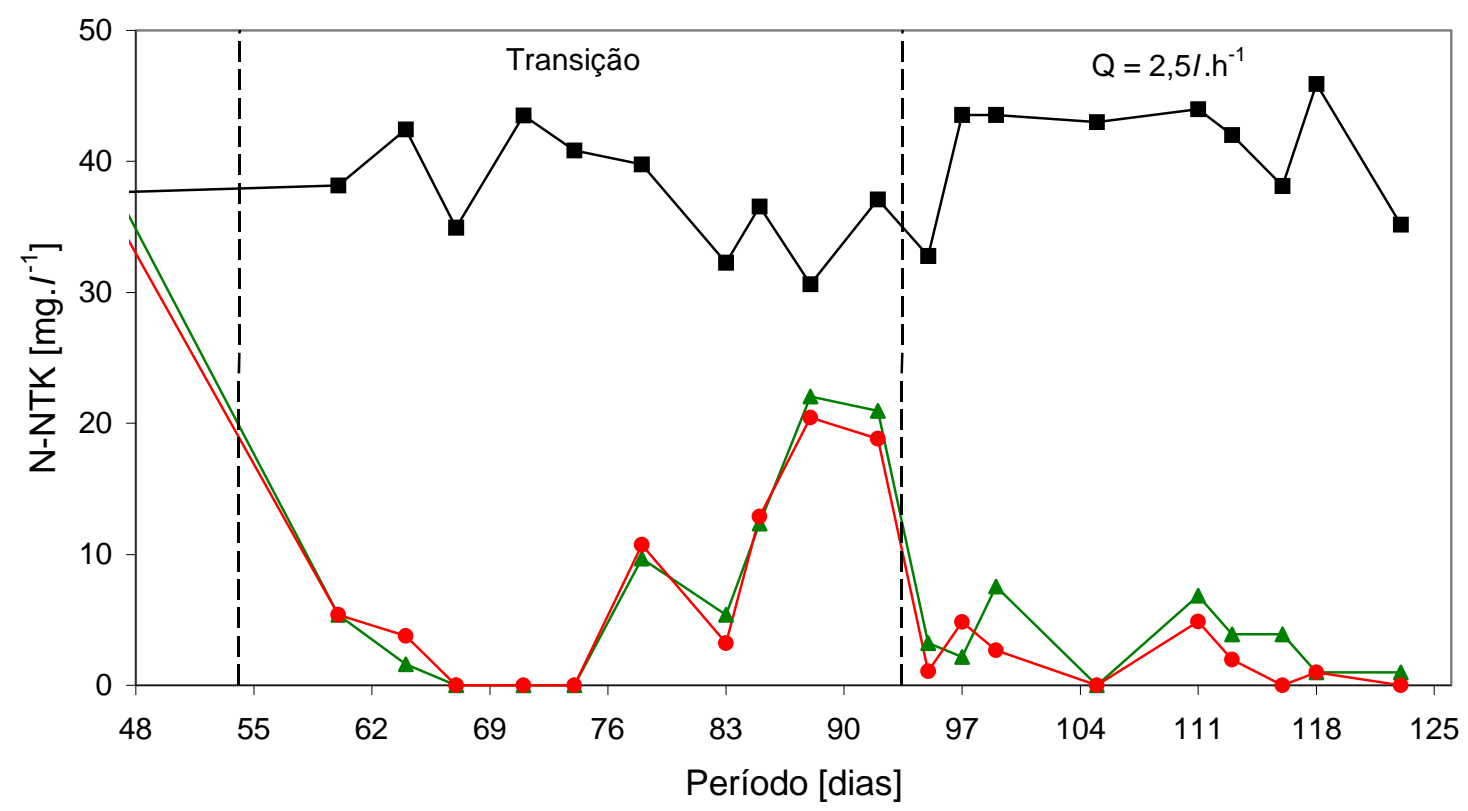

FIGURA 5.13 - Valores obtidos para N-NTK afluente $\square$, na câmara $3 \Delta$ e no efluente do RMRLF $\bullet$. 


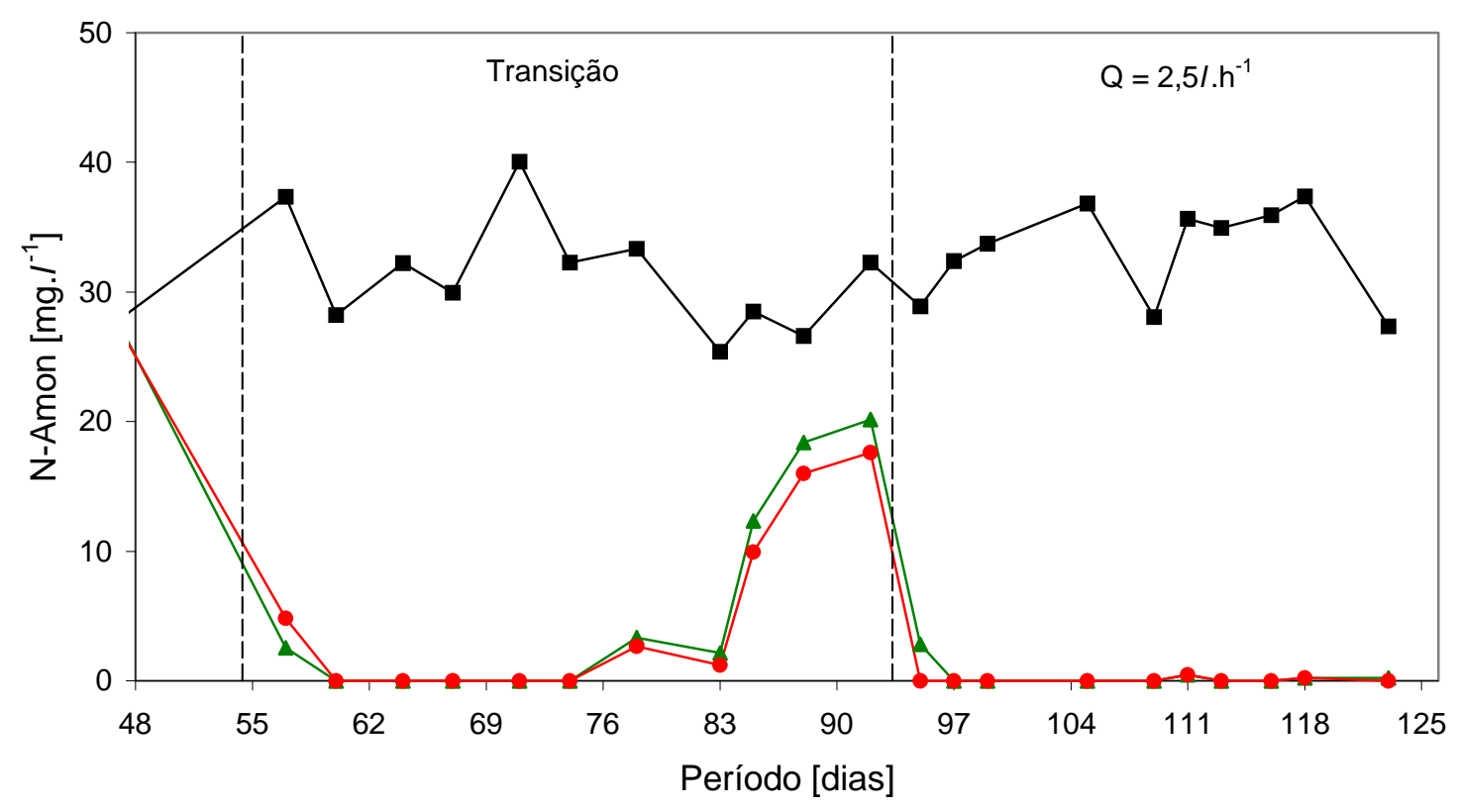

FIGURA 5.14 - Valores obtidos para $\mathrm{N}$-amon afluente $\mathrm{E}$, na câmara $3 \Delta$ e no efluente do RMRLF • .

As eficiências de remoção de N-NTK e N-amon atingiram valores médios de 95\% e 99\%, respectivamente, após equilíbrio dinâmico aparente da nitrificação, conforme pode ser observado na Figura 5.15.

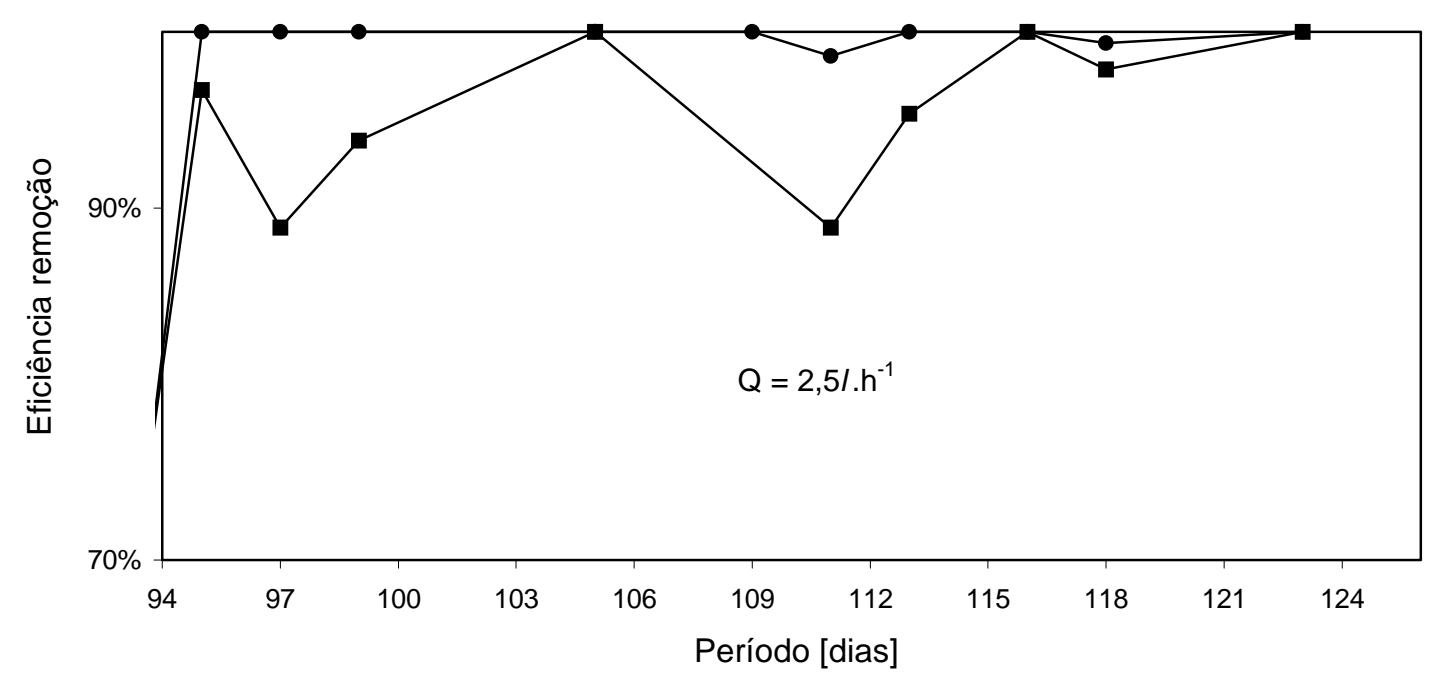

FIGURA 5.15 - Valores obtidos de eficiência para remoção de N-NTK — e Namon •. 
Nas Figuras 5.16 e 5.17 podem ser observados, respectivamente, os resultados obtidos nas análises de $\mathrm{N}-\mathrm{NO}_{2}{ }^{-}$e N-NO${ }_{3}{ }^{-}$.

A nitrificação foi obtida somente após 55 dias de operação com aumento do TDH da primeira condição para a transição e esse processo foi considerado estável apenas após 95 dias de operação.

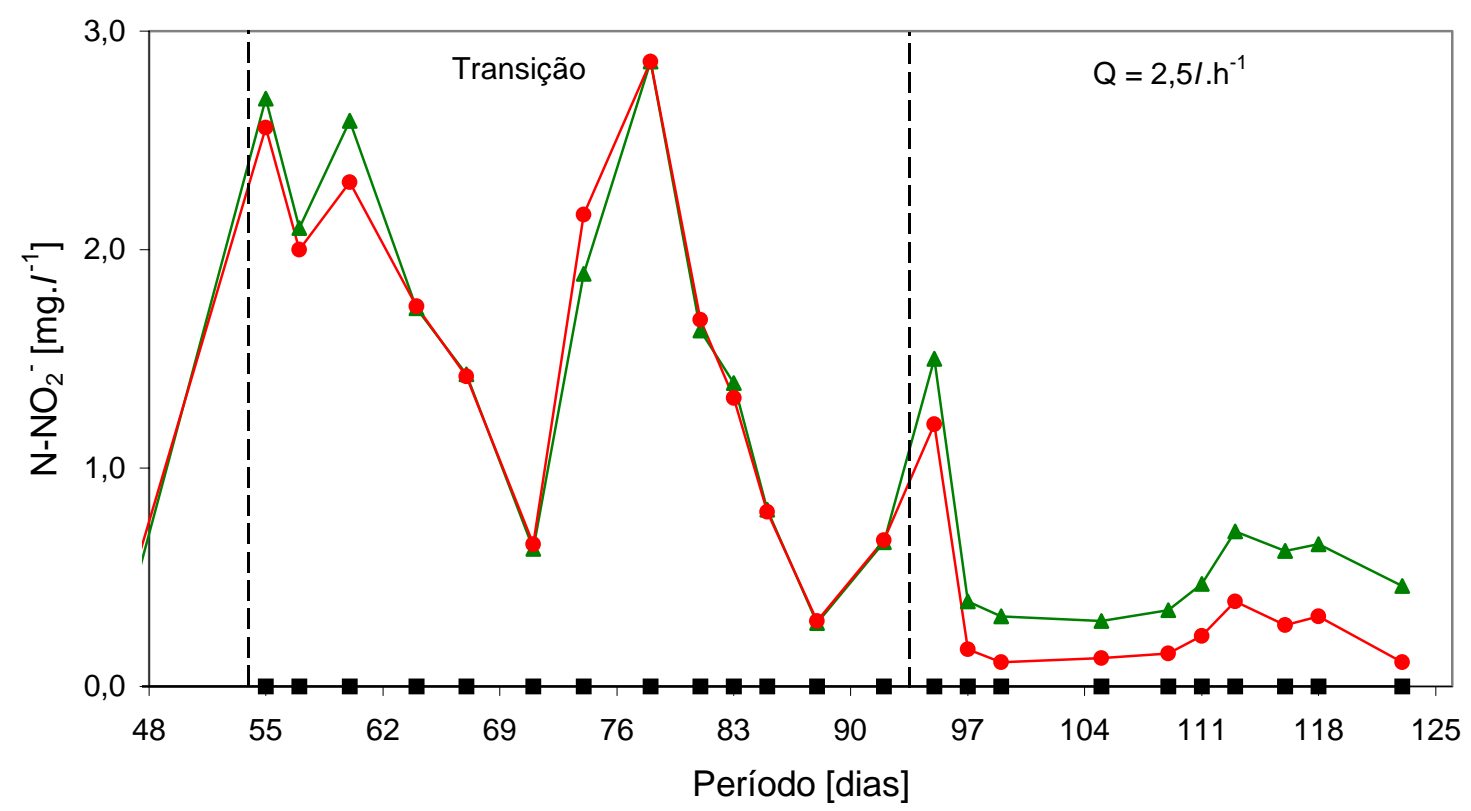

FIGURA 5.16 - Valores obtidos para $\mathrm{N}-\mathrm{NO}_{2}{ }^{-}$afluente $\mathrm{E}$, na câmara $3 \Delta$ e no efluente do RMRLF $\bullet$. 


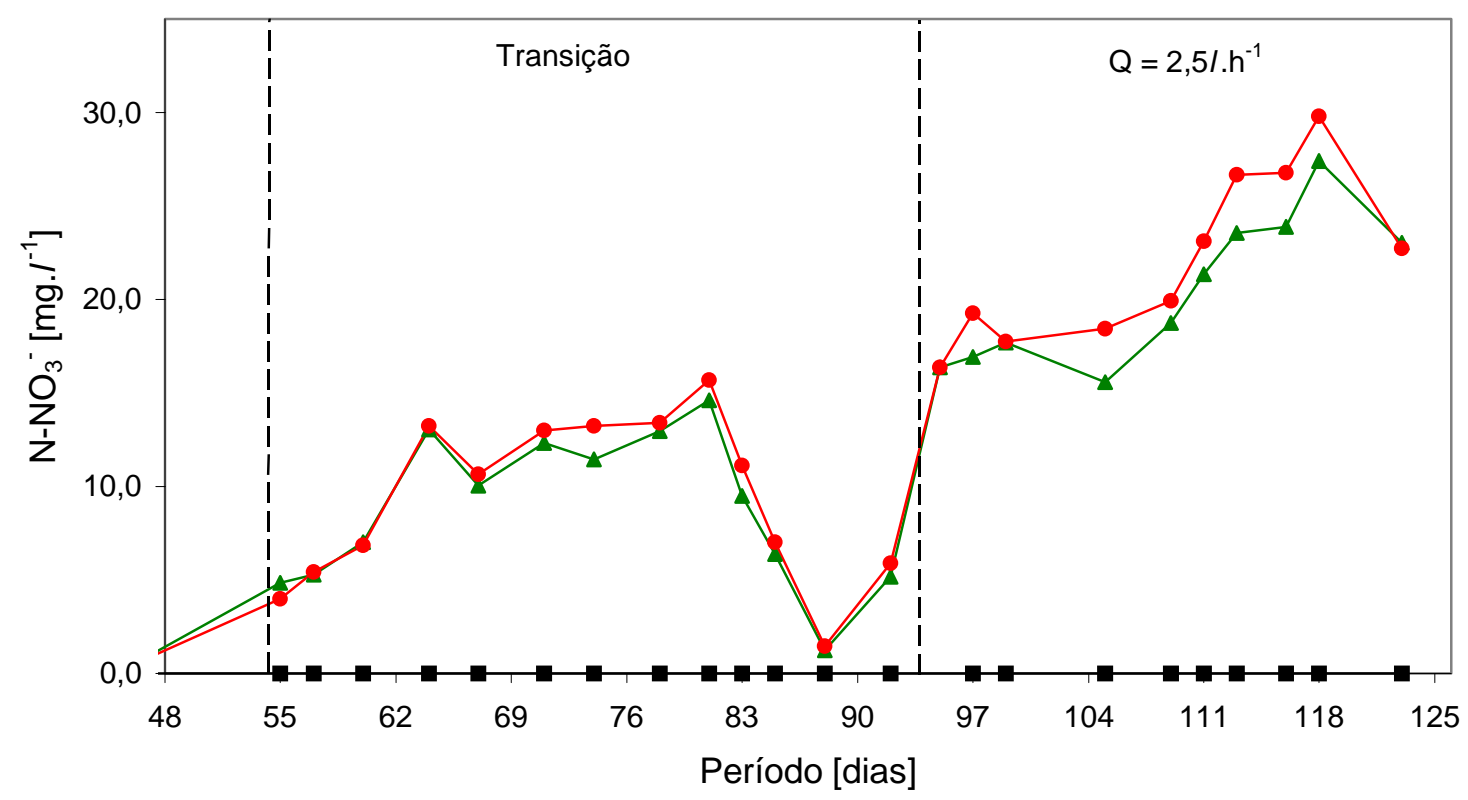

FIGURA 5.17 - Valores obtidos para $\mathrm{N}-\mathrm{NO}_{3}{ }^{-}$afluente $\mathrm{\square}$, na câmara $3 \Delta$ e no efluente do RMRLF $\bullet$.

A concentração de nitrito, após o equilíbrio no processo de nitrificação, permaneceu em valores médios de $0,6 \pm 0,4 \mathrm{mg} . I^{1}$ na câmara 3 e 0,3 $\pm 0,3 \mathrm{mg} . \digamma^{1}$ no efluente do RMRLF. Não houve acúmulo de nitrito, o qual permaneceu em valores menores que $1,0 \mathrm{mg} . I^{1}$ devido, provavelmente, à população consumidora de nitrito encontrar-se bem estabelecida no reator.

Após o equilíbrio dinâmico na nitrificação, não houve aumento significativo de nitrogênio nas formas de N-NTK ou $\mathrm{N}^{-N_{2}}{ }_{2}^{-}$na câmara 2 e no efluente do RMRLF. Entretanto, os valores obtidos nas análises de nitrato demonstram certo desequilíbrio na etapa de desnitrificação, os resultados das análises de $\mathrm{N}-\mathrm{NO}_{3}{ }^{-}$ apresentam uma tendência de aumento. O aparente desequilíbrio, devido ao aumento da concentração de nitrato no RMRLF, deve-se ao aumento da concentração de OD na câmara 5, como pode ser observado comparando-se os resultados das análises de $\mathrm{N}-\mathrm{NO}_{3}{ }^{-}$com os valores de $\mathrm{OD}$ apresentados na Figura 5.18 . 


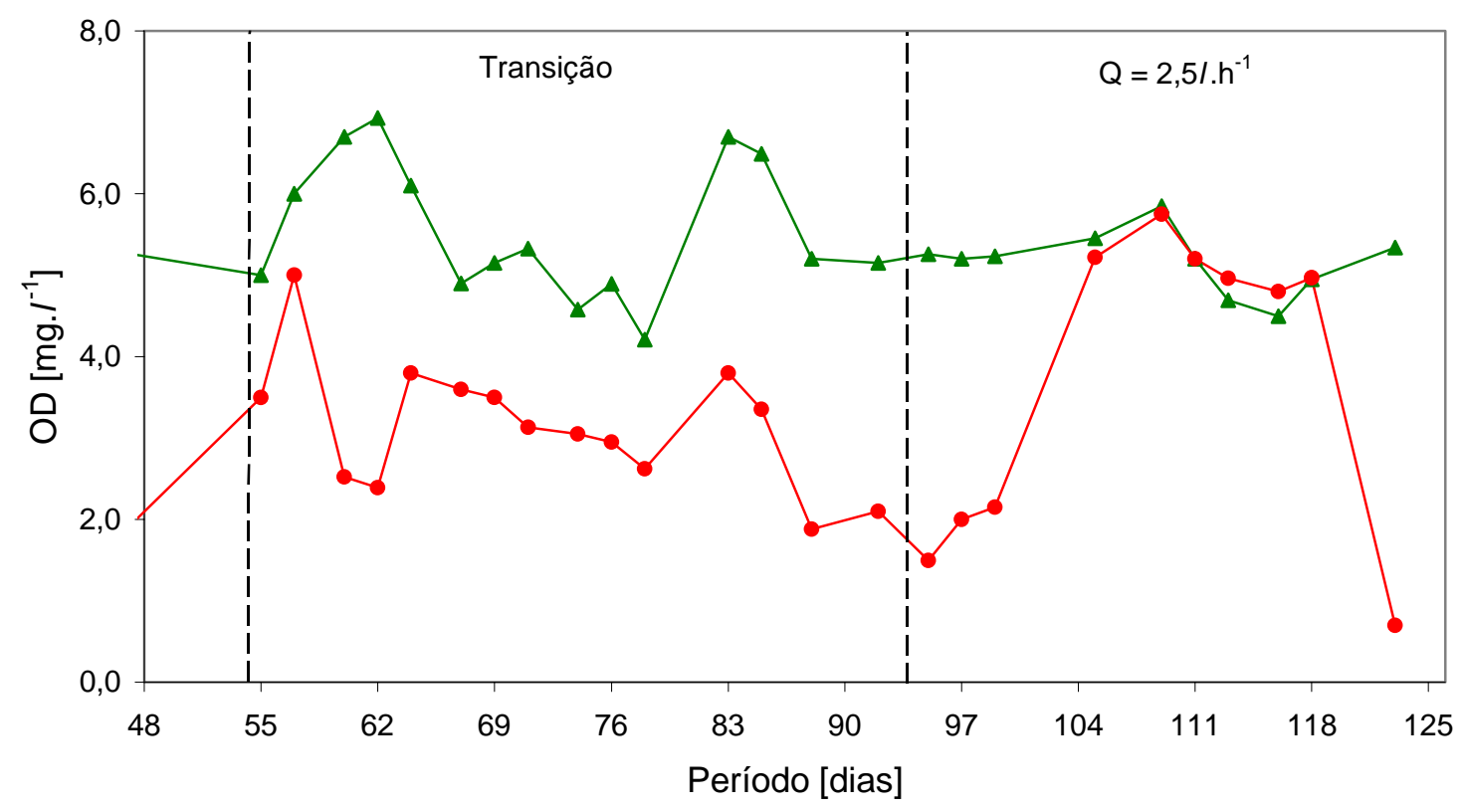

FIGURA 5.18 - Valores obtidos para OD na câmara $3 \Delta$ e no efluente do RMRLF •.

Os valores de OD na câmara 5 mantiveram-se próximos a 3,0 mg. $I^{1}$, entretanto, no período em que houve redução da eficiência na remoção de nitrato os valores mantiveram-se próximos a $5,2 \mathrm{mg} . I^{1}$.

O POR pode ser utilizado como indicador dos processos microbianos que estão ocorrendo no biofilme. BISHOP \& YU (1999) encontraram para o processo de nitrificação, valores positivos na faixa de 300 a $400 \mathrm{mV}$, medido com microeletrodos na interface entre o substrato e o biofilme. No RMRLF foram medidos valores médios de $-170 \mathrm{mV}$ na região em que ocorreu a nitrificação. Os valores de POR encontrados na região onde ocorria a nitrificação, são mais baixos que os encontrados por BISHOP \& YU (1999) possivelmente porque além da reação de nitrificação, outras reações ocorriam, por exemplo a desnitrificação.

A Figura 5.19 apresenta o perfil de POR feito no $100^{\circ}$ dia de operação. A concentração de OD na câmara 3 era $4,7 \mathrm{mg} .{ }^{1}$ e a temperatura no momento da medição era aproximadamente $20^{\circ} \mathrm{C}$. 


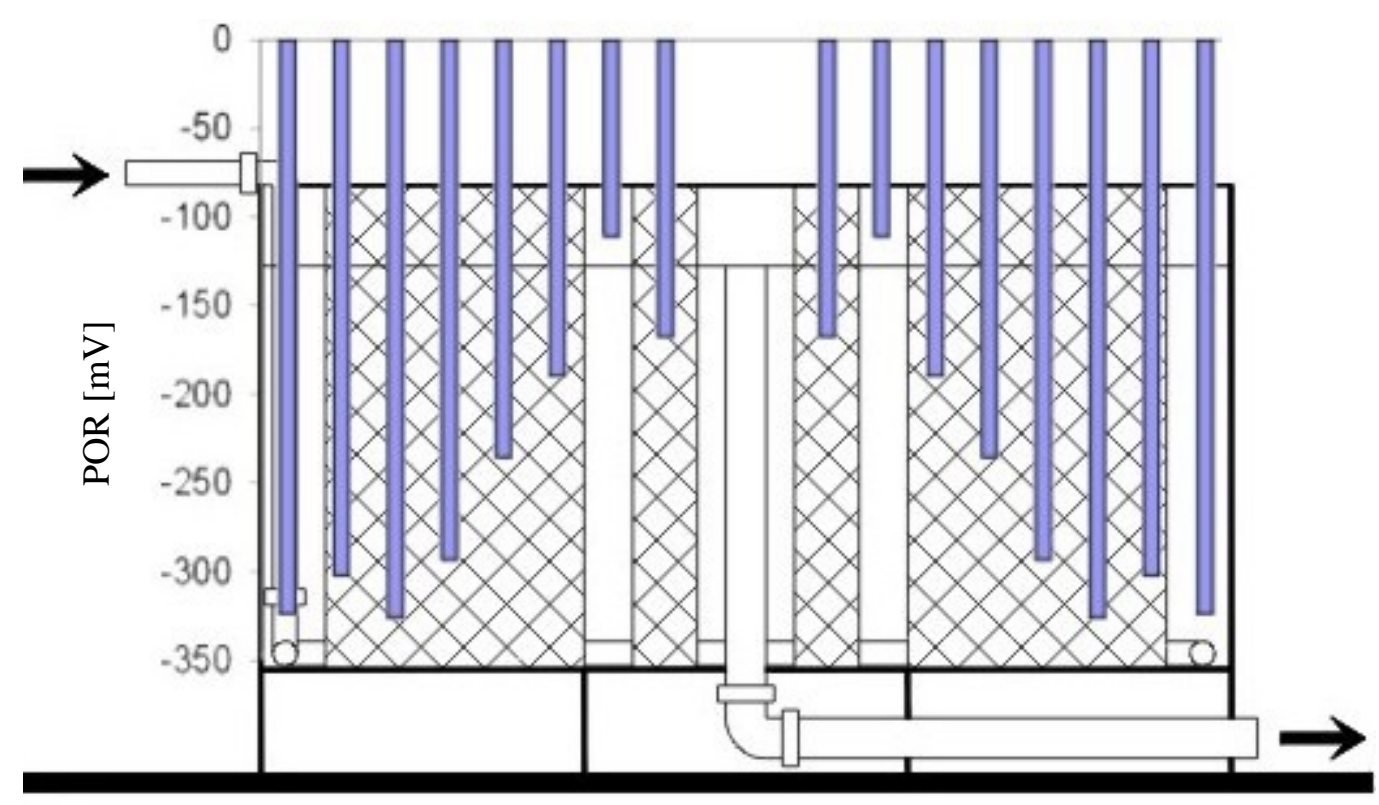

FIGURA 5.19 - Perfil de POR ao longo do RMRLF.

Pode ser observado que, na câmara 1 e no início da câmara 2, onde desenvolveram-se processos predominantemente anaeróbios, que o valor do POR era aproximadamente $-300 \mathrm{mV}$. Nas medições feitas na câmara 3, obteve-se valor médio de POR próximo a $-100 \mathrm{mV}$. Não foram detectados valores positivos de POR em nenhum ponto do RMRLF.

As medições de POR feitas nas câmaras 2 e 4, próximas à câmara de aeração, resultaram em valores muito próximos, em torno de $-170 \mathrm{mV}$, indicando que, nesses pontos, os processos microbianos eram similares. Isso pôde ser confirmado pelo exame microscópico que, nesses dois pontos, apresentou microrganismos semelhantes. Essa proximidade de valores se deve provavelmente a contra-difusão de $O D$ da câmara 3 para a câmara 2, o que proporcionava ambiente similar nesses dois locais. 


\subsection{Avaliação do desempenho do RAHLFa}

A operação do Reator Anóxico Horizontal de Leito Fixo, que tratou efluente do RMRLF, teve como objetivo principal, a desnitrificação do efluente nitrificado do RMRLF.

Na Figura 5.20 está apresentado o reator utilizado no experimento. Os detalhes de construção foram descritos no item 4.1.2 e as metodologias empregadas nas análises para monitoramento do reator, estão apresentadas no item 4.7.

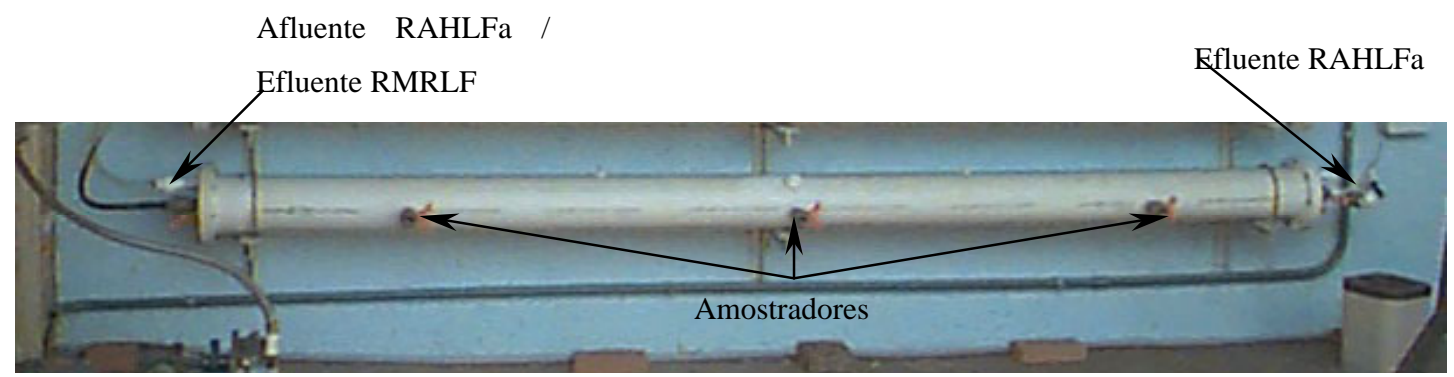

FIGURA 5.20 - RAHLFa, em escala de bancada, utilizado para promover o processo de desnitrificação do efluente do RMRLF.

O RAHLFa já se encontrava preenchido com meio suporte, devido à experimento anteriormente realizado, conforme descrito no item 4.1.2.

\subsubsection{Monitoramento de parâmetros operacionais}

A operação do RAHLFa foi iniciada juntamente com a partida do RMRLF, cujo efluente servia como afluente ao RAHLFa. Os resultados das análises, desde o início de sua operação, estão apresentados em gráficos neste item e os valores obtidos durante a operação, no Apêndice I.

Somente após aproximadamente 55 dias de operação, foi detectada a presença de nitrogênio, nas formas de $\mathrm{NO}_{2}{ }^{-}$e de $\mathrm{NO}_{3}{ }^{-}$no afluente ao RAHLFa. Por esse motivo, somente após esse período, foi possível utilizar o reator como unidade de desnitrificação. Dessa forma, nos primeiros 55 dias, esse reator, projetado para ser anóxico, operou como reator anaeróbio.

A vazão afluente empregada nesse reator, até o $55^{\circ}$ dia, era devida à vazão efluente da primeira unidade do sistema. A partir dessa data, a vazão 
afluente ao reator era composta do efluente do RMRLF acrescida da vazão de fornecimento da fonte de carbono, conforme descrito no item 4.6. A Figura 5.21 apresenta os valores médios de vazão durante a operação do sistema.

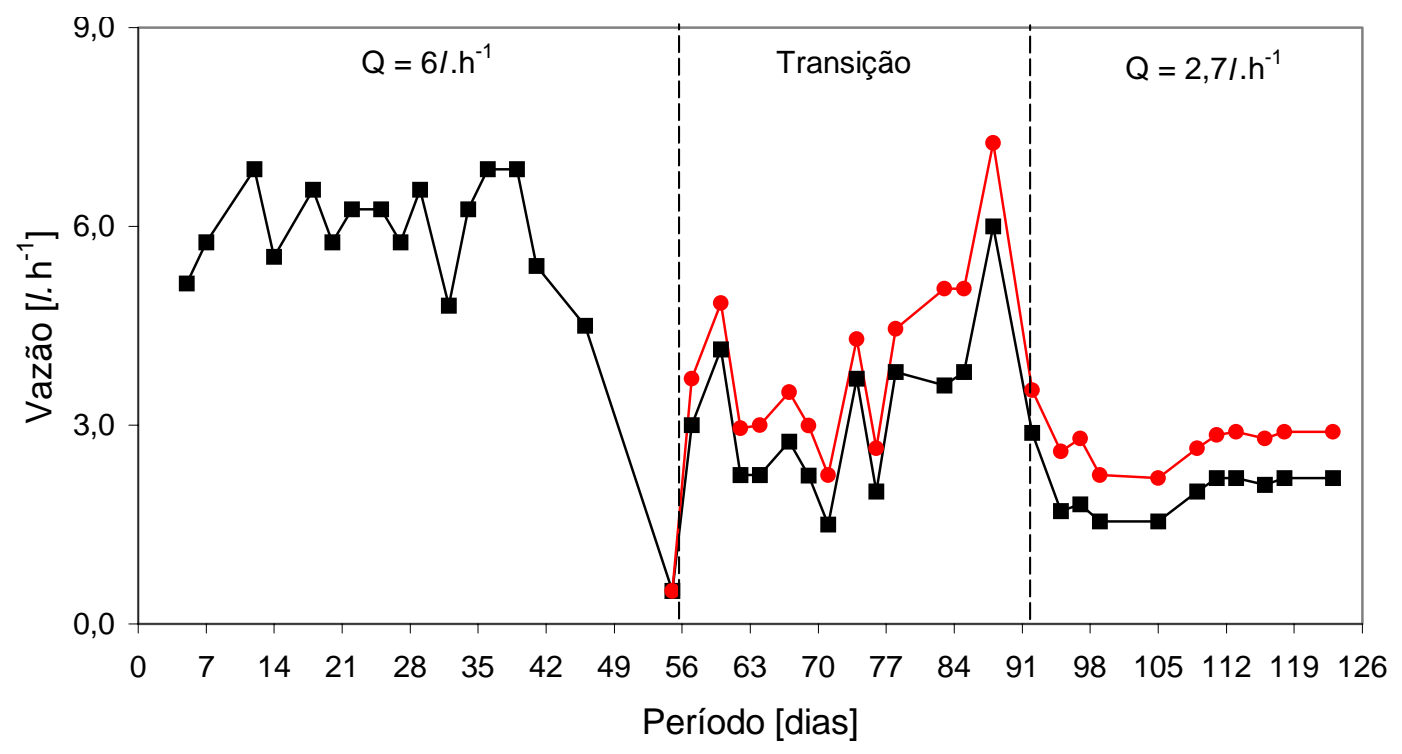

FIGURA 5.21 - Valores obtidos de vazão do esgoto afluente do sistema $\square$ e afluente do RAHLFa $\bullet$.

Durante a primeira condição de operação, o TDH utilizado em relação ao volume útil do reator era de $3,2 \mathrm{~h}$, aproximadamente, correspondendo à vazão média aplicada na entrada do sistema de $6 l \cdot h^{-1}$. Na segunda condição, o valor do TDH era de, aproximadamente, $7 \mathrm{~h}$, com vazão de 2,7 I. $\mathrm{h}^{-1}$. A vazão, de 2,7 I. $\mathrm{h}^{-1}$, era composta pela vazão média afluente igual a $2,0 \mathrm{l} \cdot \mathrm{h}^{-1}$, acrescida da vazão média da solução alcalina de $0,5 \mathrm{l} \cdot \mathrm{h}^{-1}$ e da vazão média de $0,2 \mathrm{l} \cdot \mathrm{h}^{-1}$, decorrente do fornecimento de fonte de carbono ao sistema.

Conforme apresentado no item 5.2, a temperatura ambiente da sala onde estava instalado o sistema variou de 9 a $30^{\circ} \mathrm{C}$, com valor médio de $20 \pm 3^{\circ} \mathrm{C}$. A temperatura do esgoto afluente apresentou média de $20 \pm 3^{\circ} \mathrm{C}$ e do efluente média de $19 \pm 3^{\circ} \mathrm{C}$. Os valores de temperatura afluente e efluente ao reator estão apresentados na Figura 5.22. 


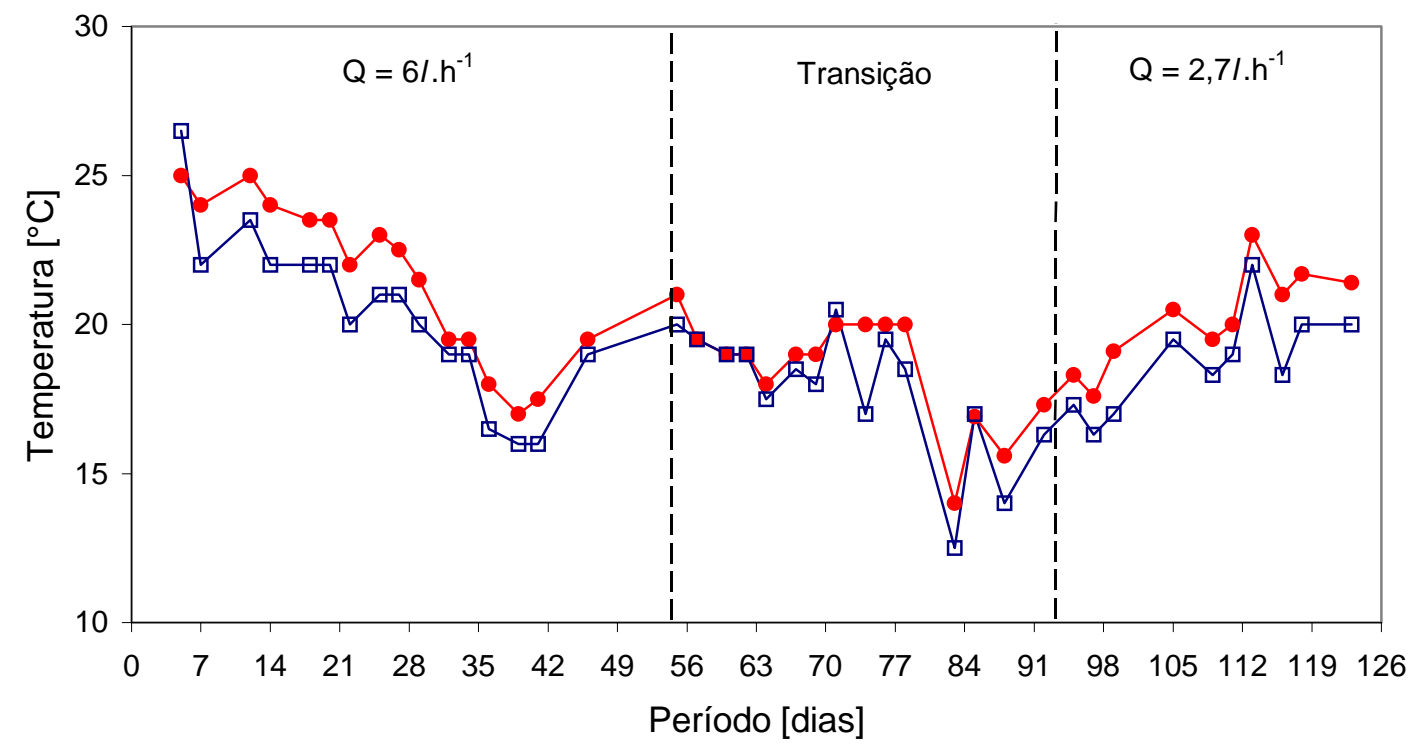

FIGURA 5.22 - Valores obtidos de temperatura do esgoto afluente $\bullet$ e efluente do RAHLFa $\square$.

O resumo dos resultados, com os valores médios das análises realizadas no afluente do RAHLFa, durante a operação do reator nas duas condições de operação, estão apresentados nas Tabelas 5.2 e 5.3.

TABELA 5.2 - Valores médios dos parâmetros analisados no afluente do RAHLFa, na primeira condição.

\begin{tabular}{ccr}
\hline Parâmetro & Unidade & Valor \\
\hline AB & mgCaCO $_{3} . \digamma^{1}$ & $160 \pm 30$ \\
AVT & mgHAc. $\digamma^{1}$ & $49 \pm 20$ \\
DQO & mg. $\digamma^{1}$ & $117 \pm 33$ \\
DQOf & $\mathrm{mg} . \digamma^{1}$ & $80 \pm 08$ \\
pH & & $7,7 \pm 0,2$ \\
ST & $\mathrm{mg} . \digamma^{1}$ & $520 \pm 128$ \\
SST & $\mathrm{mg} . \digamma^{1}$ & $25 \pm 21$ \\
SSV & $\mathrm{mg} . \digamma^{1}$ & $21 \pm 23$ \\
SSF & $\mathrm{mg} . \digamma^{1}$ & $04 \pm 05$
\end{tabular}


TABELA 5.3 - Valores médios dos parâmetros analisados no afluente do RAHLFa, na segunda condição.

\begin{tabular}{|c|c|c|}
\hline Parâmetro & Unidade & Valor \\
\hline$A B$ & $\mathrm{mgCaCO}_{3} \cdot I^{1}$ & $435 \pm 284$ \\
\hline AVT & $\mathrm{mgHAc} . I^{1}$ & $20 \pm 05$ \\
\hline DQO & $\mathrm{mg} \cdot I^{-1}$ & $54 \pm 19$ \\
\hline DQOf & $\mathrm{mg} \cdot I^{-1}$ & $29 \pm 08$ \\
\hline $\mathrm{pH}$ & & $8,4 \pm 0,1$ \\
\hline SST & $\mathrm{mg} . I^{1}$ & $26 \pm 20$ \\
\hline SSV & $\mathrm{mg} \cdot I^{-1}$ & $19 \pm 13$ \\
\hline SSF & $\mathrm{mg} . \digamma^{1}$ & $09 \pm 12$ \\
\hline N-NTK & $\mathrm{mg} . I^{1}$ & $02 \pm 02$ \\
\hline N-amon & $\mathrm{mg} . I^{1}$ & $00 \pm 00$ \\
\hline $\mathrm{N}$-org & $\mathrm{mg} . I^{1}$ & $02 \pm 02$ \\
\hline $\mathrm{N}-\mathrm{NO}_{2}^{-}$ & $\mathrm{mg} . I^{1}$ & $0,3 \pm 0,3$ \\
\hline $\mathrm{N}-\mathrm{NO}_{3}{ }^{-}$ & $\mathrm{mg} . I^{1}$ & $22,1 \pm 4,5$ \\
\hline
\end{tabular}

Na Figura 5.23 estão apresentados os valores obtidos de DQO afluente e efluente, durante a operação do sistema, nas duas condições, com vazão de 6,0 I. $\mathrm{h}^{-1}$ e 2,7 I. $\mathrm{h}^{-1}$.

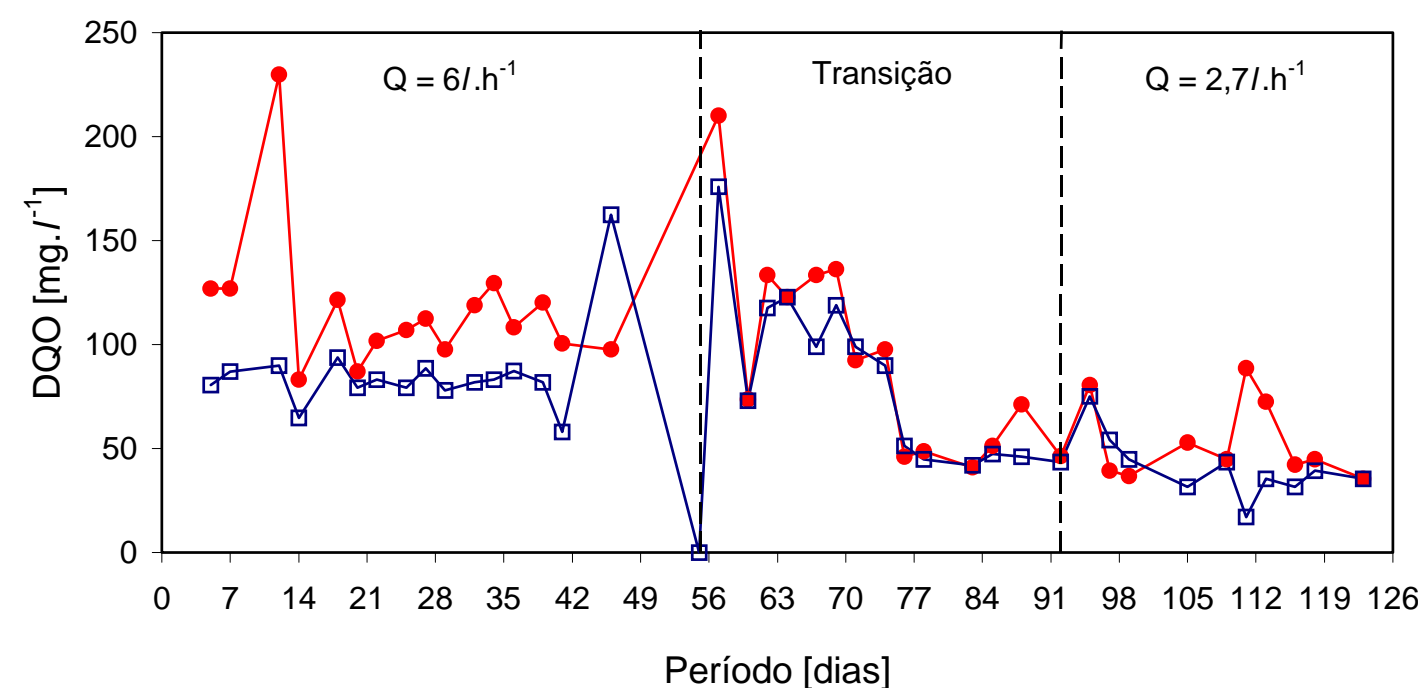

FIGURA 5.23 - Valores de DQO obtidos no afluente $\bullet$ e efluente $\square$ do RAHLFa. 
Os valores de DQO afluente apresentaram valor médio de $117 \pm 33 \mathrm{mg} . I^{1}$, para a primeira condição e de $54 \pm 19 \mathrm{mg} . I^{1}$ para a segunda condição. Enquanto que, para os resultados nas análises de DQO efluente, foram obtidos valores médios de $86 \pm 22 \mathrm{mg} . I^{1}$ e $41 \pm 16 \mathrm{mg} . \digamma^{1}$, para a primeira e segunda condição, respectivamente. Esses valores resultaram em eficiências de remoção de DQO no reator de $26 \%$ e $24 \%$, respectivamente.

Os valores obtidos de DQOf afluente e efluente podem ser observados na Figura 5.24.

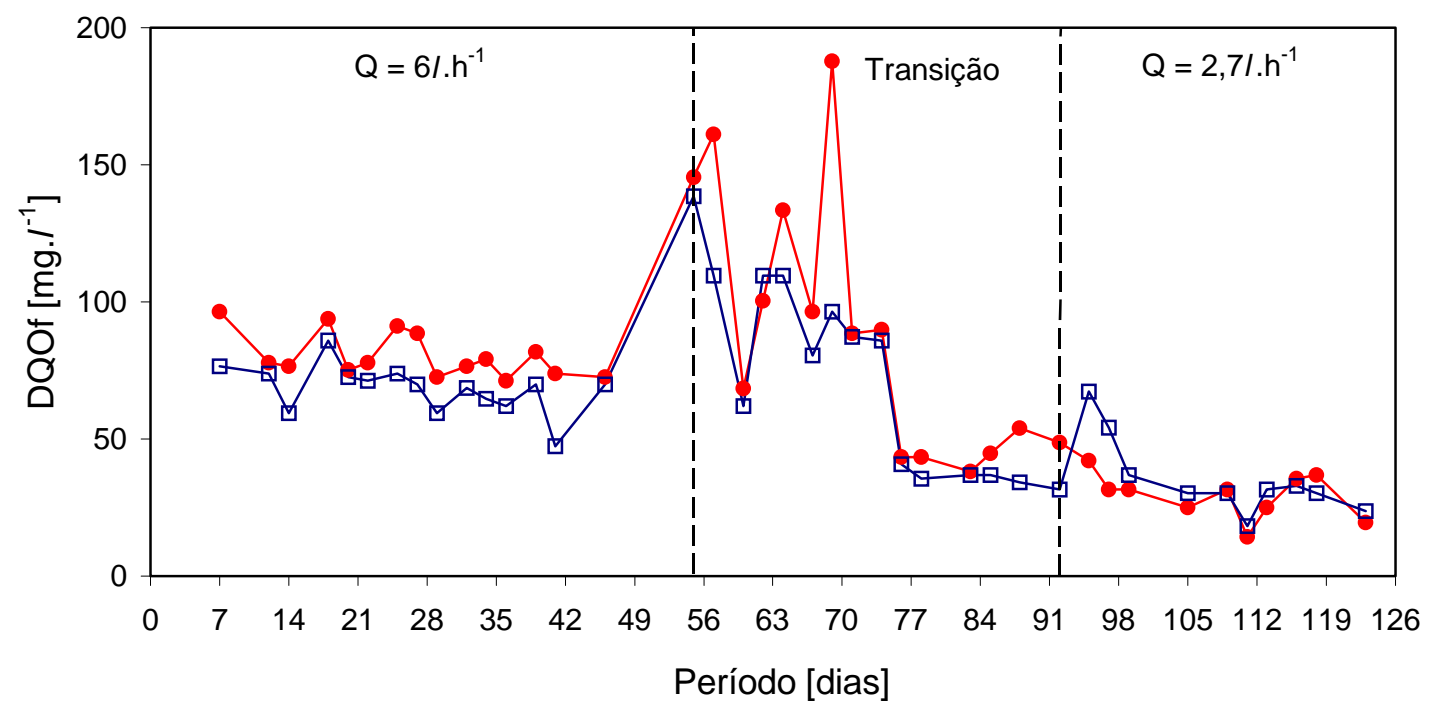

FIGURA 5.24 - Valores de DQOf obtidos no afluente • e efluente $\square$ do RAHLFa.

Os valores médios obtidos para DQOf efluente para a primeira e segunda condição foram, respectivamente, $68 \pm 9 \mathrm{mg} \cdot I^{1}$ e $36 \pm 15 \mathrm{mg} \cdot I^{1}$. Esses valores resultaram em eficiência de remoção de DQOf de $42 \%$, para a primeira condição, e de $34 \%$, para a segunda condição.

Na primeira condição de operação, pode ser observado que houve certa eficiência na remoção de DQO. Entretanto, a redução de M.O. (matéria orgânica) foi pequena devido aos baixos valores afluentes. Na segunda condição, observouse que a matéria orgânica biodegradável era quase totalmente utilizada no RMRLF.

Devido aos baixos valores de DQO, presentes no afluente do RAHLFa e ao fato de que, provavelmente, essa DQO deve ser gerada por compostos orgânicos de difícil degradabilidade, fez-se necessário o fornecimento de fonte externa de carbono (etanol) para promover desnitrificação. 
A Figura 5.25 apresenta os valores de $\mathrm{pH}$, obtidos durante a fase de monitoramento do RAHLFa. Na primeira condição, o valor médio do pH afluente foi $7,7 \pm 0,2$, que coincidiu com o $\mathrm{pH}$ do efluente do reator, que resultou em $7,7 \pm 0,1$. Durante a operação do reator, na segunda condição, o valor médio do $\mathrm{pH}$ se manteve em $8,4 \pm 0,1$ e $8,1 \pm 0,2$, para o afluente e efluente, respectivamente. Essa diferença nos valores médios de $\mathrm{pH}$, entre a primeira e a segunda condição, se deve principalmente ao início do fornecimento de solução alcalina à câmara 3 do RMRLF em função do início do processo de nitrificação.

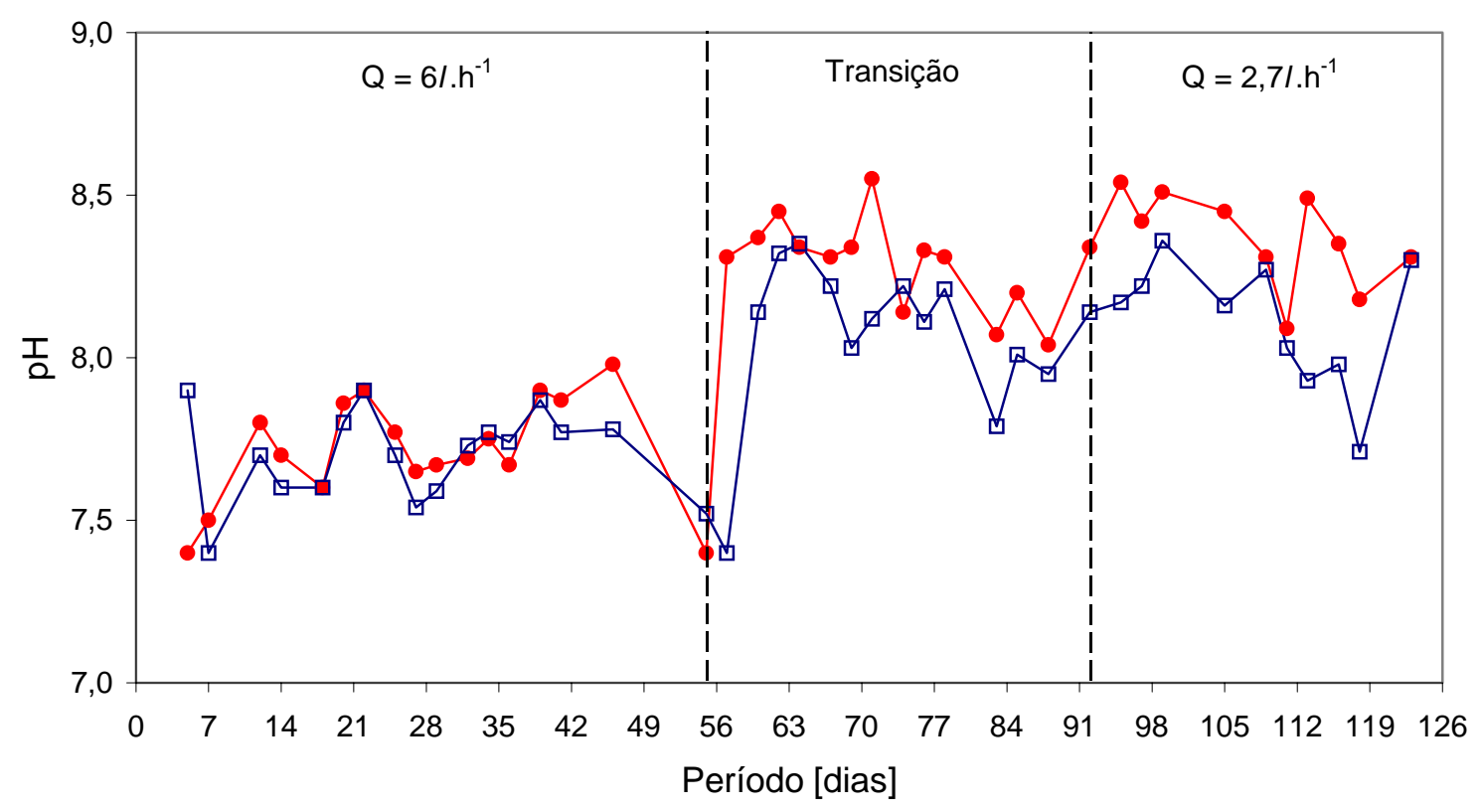

FIGURA 5.25 - Valores obtidos de pH afluente $\bullet$ e efluente $\square$ do RAHLFa.

A Figura 5.26 apresenta os valores de alcalinidade a bicarbonato afluente e efluente, registrados durante a operação do sistema misto. 


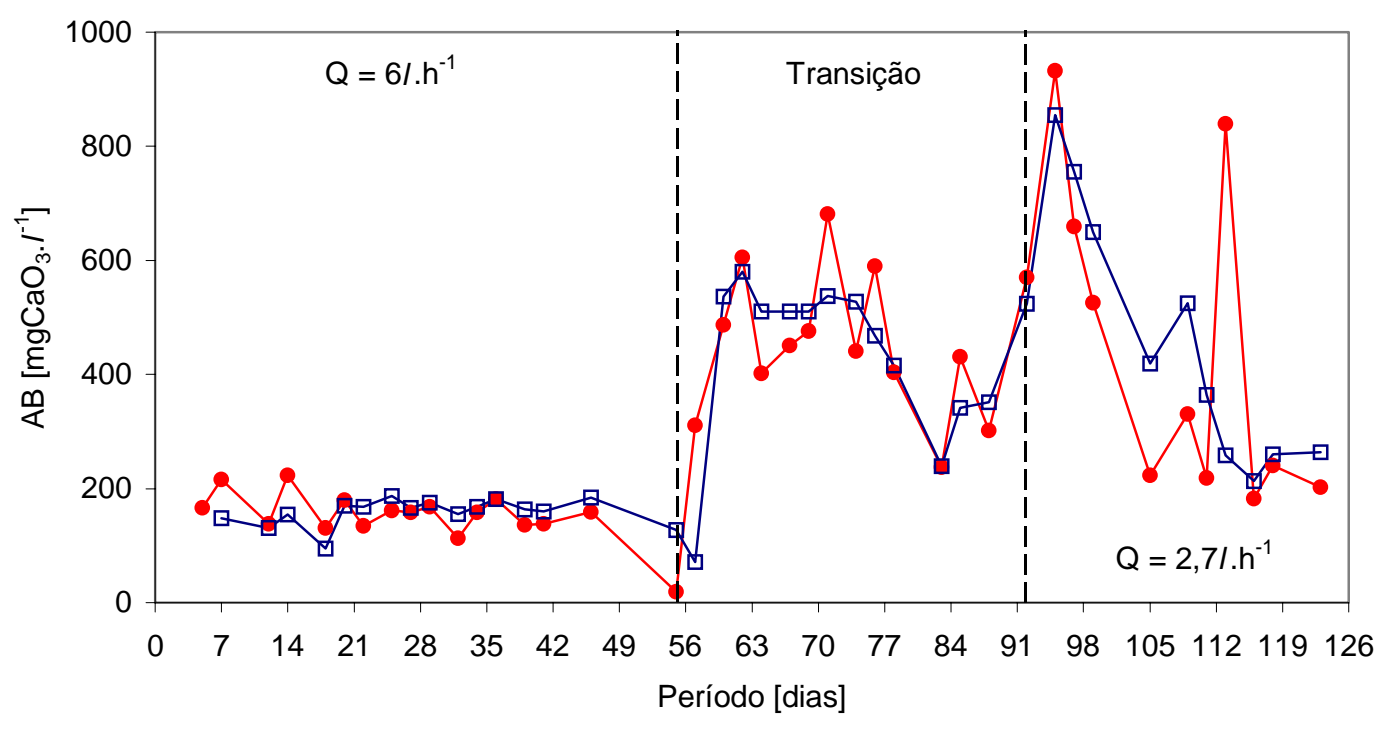

FIGURA 5.26 - Valores obtidos de alcalinidade a bicarbonato afluente $\bullet$ e efluente $\square$ do RAHLFa.

Os resultados das análises de $\mathrm{AB}$ (alcalinidade a bicarbonato) afluente e efluente, apresentaram valores médios muito próximos, sem variações significativas, na primeira condição. Antes de iniciar o fornecimento de solução alcalina os valores médios foram de $160 \pm 30 \mathrm{mg} . I^{1}$ para o afluente e $161 \pm 23$ mg. $I^{1}$ para o efluente.

Observa-se que após 20 dias de operação, o valor médio de alcalinidade a bicarbonato no efluente manteve-se ligeiramente maior que o do afluente, o que indicou haver geração de alcalinidade e provável equilíbrio entre microrganismos produtores de acetato e arqueas metanogênicas, no processo anaeróbio que ocorreu durante a primeira condição de operação do RAHLFa.

Na segunda condição, após início do fornecimento de solução alcalina ao sistema, o valor médio de alcalinidade afluente foi $435 \pm 284 \mathrm{mg} \cdot I^{1}$, e efluente foi $456 \pm 229 \mathrm{mg} \cdot I^{1}$. Tal produção de alcalinidade, foi provavelmente, devido à ocorrência do processo de desnitrificação.

Na Figura 5.27 estão apresentados os valores obtidos de AVT no afluente e efluente, durante a operação do RAHLFa. 


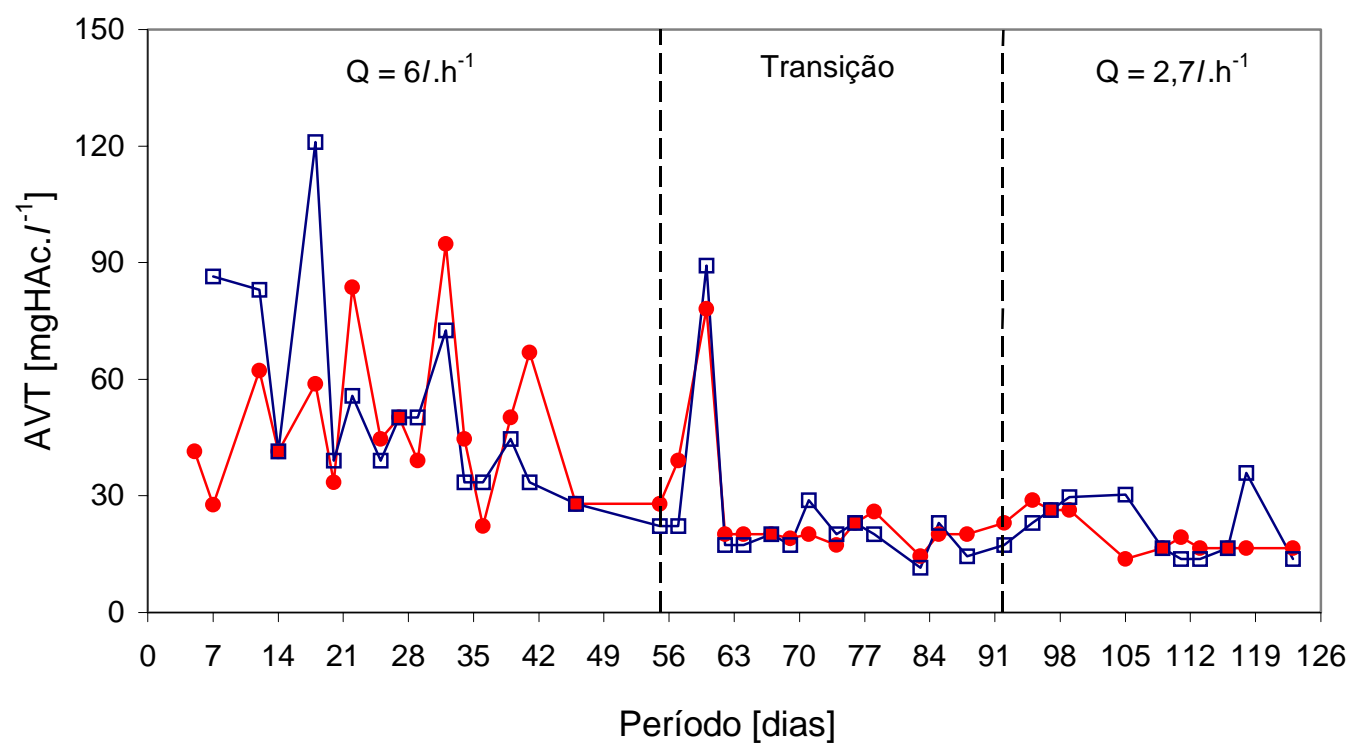

FIGURA 5.27 - Valores obtidos de AVT afluente $\bullet$ e efluente $\square$ do RAHLFa.

Os valores médios, afluente e efluente apresentaram-se muito próximos para a primeira condição sendo $49 \pm 20 \mathrm{mg} . I^{1}$ e $54 \pm 26 \mathrm{mg} \cdot I^{1}$, respectivamente.

Os valores de AVT apresentaram certa instabilidade até $060^{\circ}$ dia de operação devido à utilização de solução de hidróxido de sódio muito concentrada, como apresentado no item 5.2.1.

Os valores médios, afluente e efluente, para a segunda condição foram 20 $\pm 5 \mathrm{mg} . I^{1}$ e $22 \pm 8 \mathrm{mg} . I^{1}$, respectivamente.

Os valores obtidos pelas análises de SSV afluente e efluente do RAHLFa estão apresentados na Figura 5.28. 


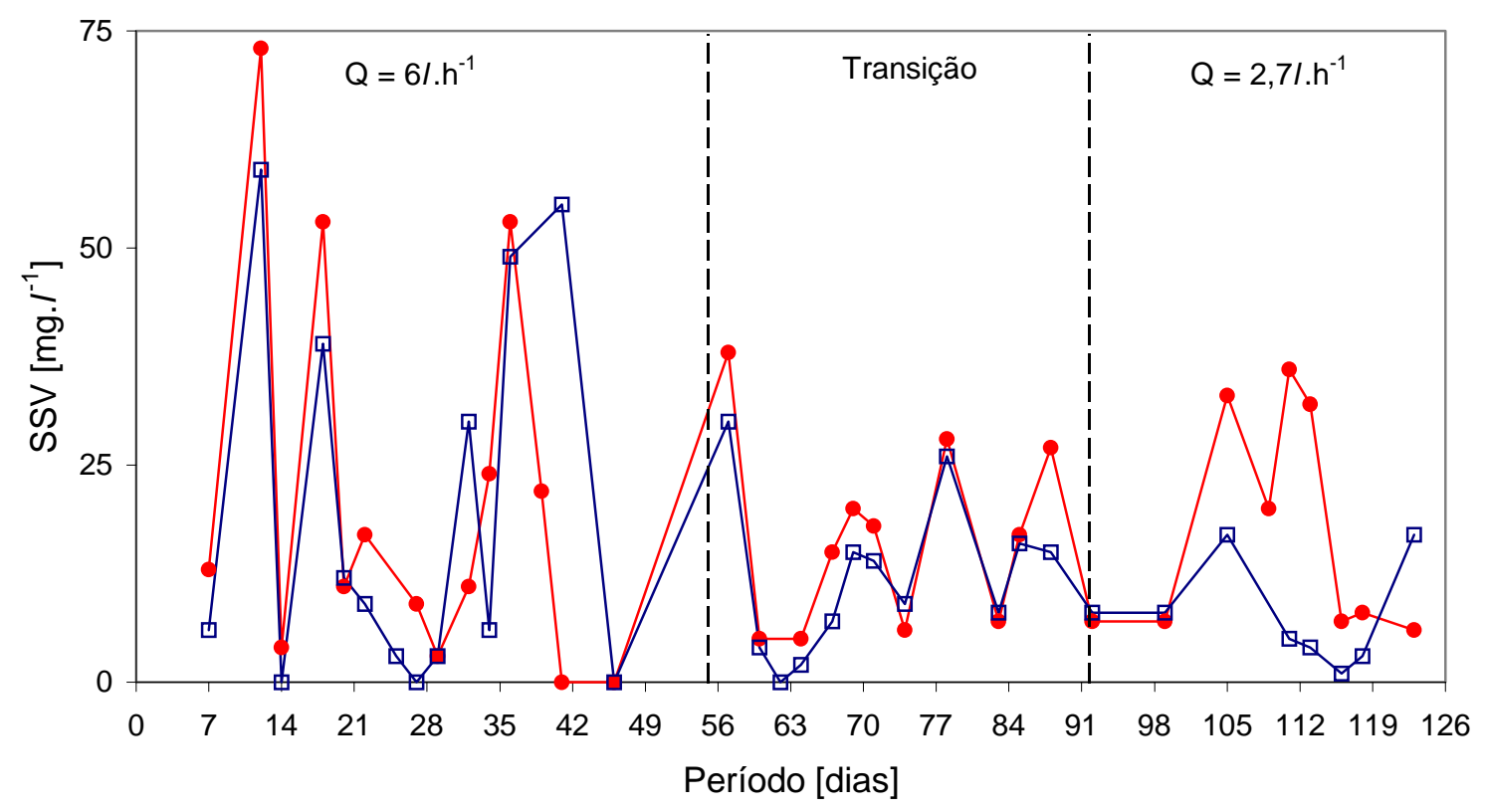

FIGURA 5.28 - Valores obtidos de SSV no afluente $\bullet$ e efluente $\square$ do RAHLFa.

A eficiência média de redução de SSV, para a primeira condição, foi de $62 \%$ e para a segunda de, apenas, 58\%. Essas eficiências de retenção de sólidos são aparentemente baixas. Entretanto, deve-se observar que, apesar da baixa eficiência aparente, os valores efluente obtidos de SSV, possibilitaram a obtenção de um efluente clarificado

As análises de SSV realizadas com amostras do afluente e do efluente do RAHLFa apresentaram, respectivamente, valores médios de $21 \pm 23 \mathrm{mg} . \mathrm{I}^{1}$ e $19 \pm$ $22 \mathrm{mg} \cdot \Gamma^{1}$, para a primeira condição. Para o afluente da segunda condição, o valor foi de $19 \pm 13 \mathrm{mg} \cdot I^{1}$ e o valor do efluente igual a $8 \pm 7 \mathrm{mg} \cdot I^{1}$. A maior instabilidade na primeira condição, comparada à segunda, foi devida, provavelmente, ao fato de a vazão utilizada na primeira ser, aproximadamente, o dobro da utilizada na segunda condição, o que provocou maior arraste de sólidos.

Nas análises de sólidos suspensos, observou-se que quase a totalidade de sólidos presentes, tanto no afluente como no efluente, eram compostos por SSV, sendo muito baixa ou não detectável a concentração de SSF (sólidos suspensos fixos).

A concentração de biomassa aderida ao suporte foi estimada em 2 mgSV.unid ${ }^{-1}$ suporte correspondente a 0,12 mgSV.mg-1 suporte. Estimando a quantidade de espumas utilizadas para preencher o reator em 45000 cubos de espuma de ploiuretano e o volume total do reator igual a 47 I, a concentração de 
biomassa por litro de reator foi estimada em 1,9 gSV. $I^{1}$. Comparando os resultados obtidos no RMRLF iguais a 5,1 gSV. $I^{1}$ e com os de VIEIRA (2000) que obteve concentração de aproximadamente $20 \mathrm{gSV} . I^{1}$ em reator similar, observa-se que a concentração de biomassa neste RAHLFa estava muito abaixo de sua capacidade de reter biomassa.

Como a nitrificação no RMRLF foi obtida somente após 55 dias de operação e esse processo foi considerado estável apenas após 93 dias, ocorreu um atraso na avaliação do RAHLFa como unidade de desnitrificação.

Durante a primeira condição, o RAHLFa foi alimentado somente com o efluente do RMRLF. Quando o processo de nitrificação foi iniciado no RMRLF, adicionalmente ao efluente do RMRLF foi fornecida solução de etanol, inicialmente, com relação $\mathrm{C} / \mathrm{N}$ igual a 1, conforme recomendado por HER \& HUANG (1995) e SANTOS et al. (2002), com objetivo de disponibilizar uma fonte de carbono à etapa de desnitrificação. Entretanto, não foi observada variação significativa da DQO efluente ao RAHLFa e não houve melhora na remoção de $\mathrm{N}^{-\mathrm{NO}_{3}}{ }^{-}$. Optou-se por aumentar gradativamente, em 2, 3 e 4 vezes, a concentração de etanol calculada

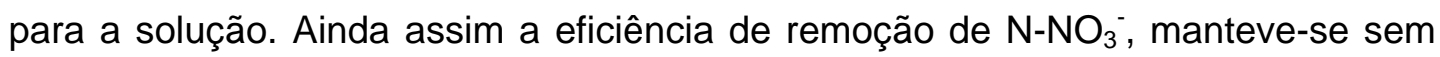
alteração significativa.

Nas Figuras 5.29 e 5.30 estão apresentados, respectivamente, os valores obtidos de N-NTK e de N-amon após o início da nitrificação no RMRLF.

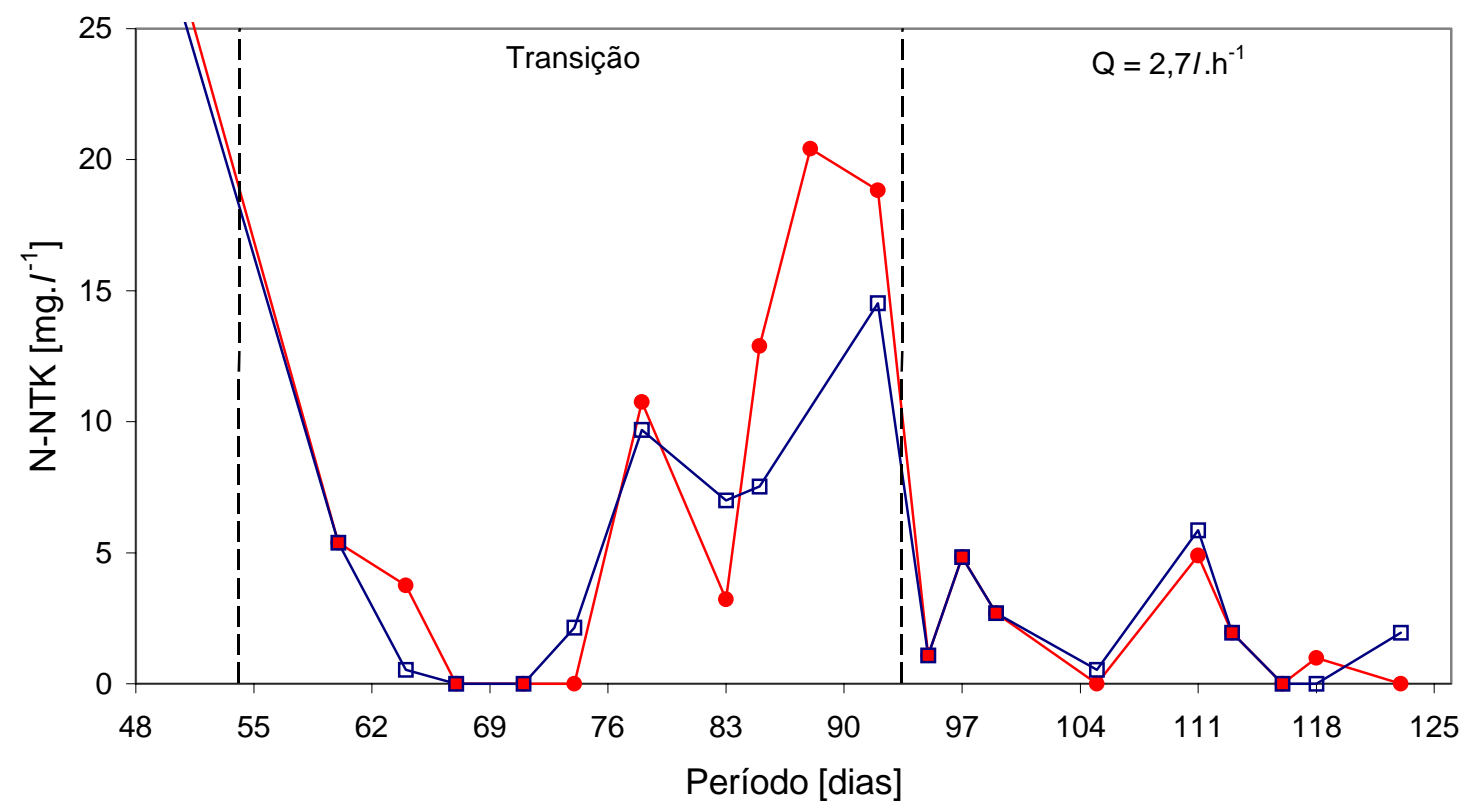

FIGURA 5.29 - Valores obtidos de N-NTK afluente $\bullet$ e efluente $\square$ do RAHLFa, a partir do início da nitrificação no RMRLF. 
As análises de N-NTK afluente e efluente apresentaram valores médios iguais a $2 \pm 2 \mathrm{mg} . I^{1}$ e $2 \pm 2 \mathrm{mg} . I^{1}$, respectivamente, estabelecido após o equilíbrio dinâmico da nitrificação.

De acordo com os resultados obtidos, não houve significativa alteração na concentração de N-NTK no reator.

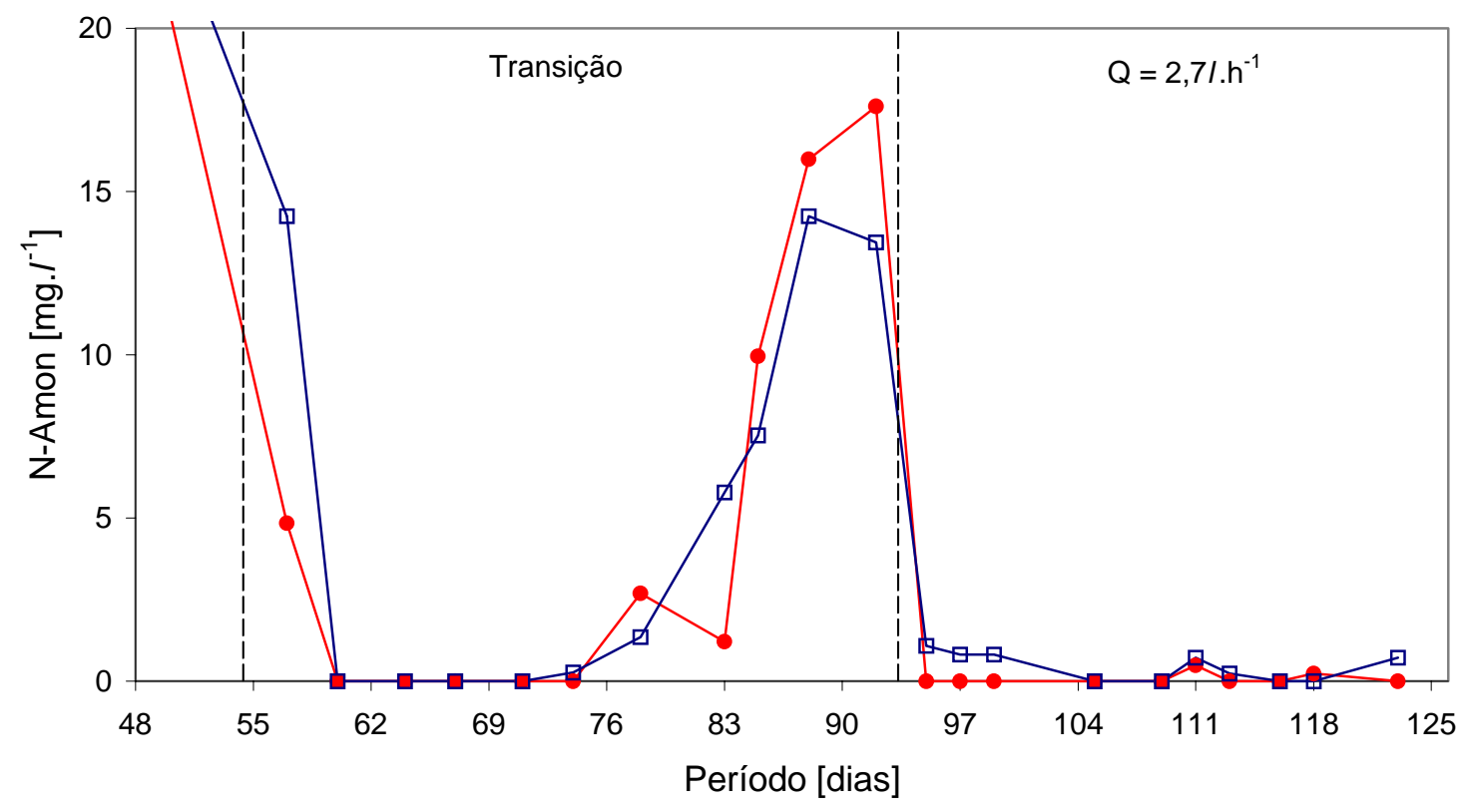

FIGURA 5.30 - Valores obtidos de N-Amon afluente $\bullet$ e efluente $\square$ do RAHLFa, a partir do início da nitrificação no RMRLF.

As concentrações de $\mathrm{N}$-amon no afluente e no efluente se mantiveram próximas a zero; o que indicou que o N-NTK afluente está na forma de N-org, e assim permaneceu ao longo do reator. Pôde-se concluir, também, que não houve formação de $\mathrm{N}$-amon pela rota metabólica de redução do $\mathrm{N}-\mathrm{NO}_{3}$.

Nas Figuras 5.31 e 5.32 podem ser observados, respectivamente, os resultados obtidos nas análises de $\mathrm{N}^{-\mathrm{NO}_{3}}{ }^{-}$e a eficiência do reator em relação à remoção de nitrato. 


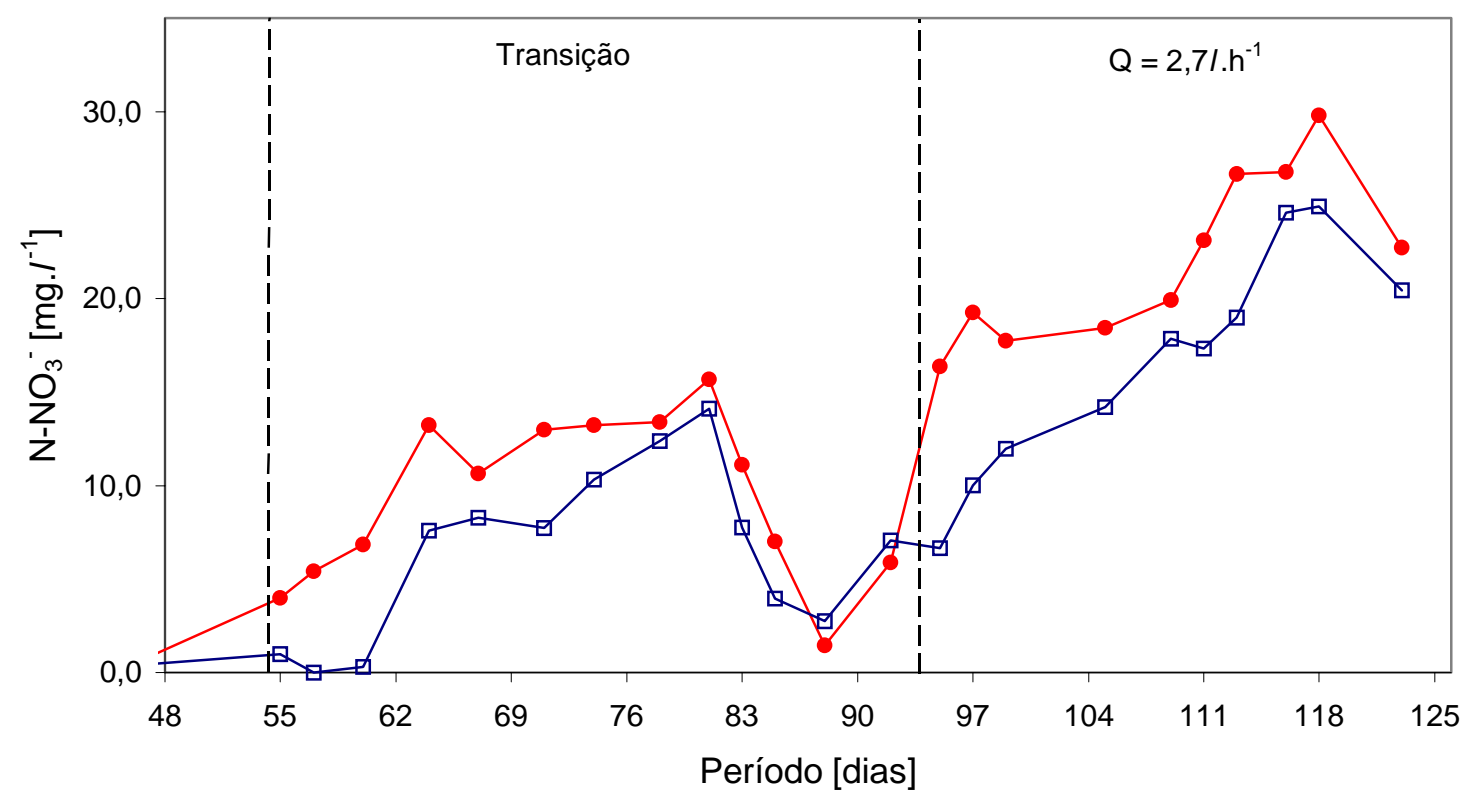

FIGURA 5.31 - Valores obtidos de $\mathrm{N}-\mathrm{NO}_{3}{ }^{-}$afluente $\bullet$ e efluente $\square$ do RAHLFa, a partir do início da nitrificação no RMRLF.

$\mathrm{O}$ valor médio de $\mathrm{N}^{-\mathrm{NO}_{3}}{ }^{-}$afluente, após atingido o equilíbrio dinâmico aparente da nitrificação foi de $22,1 \pm 4,5 \mathrm{mg} . I^{1}$ e o efluente obtido foi de $16,7 \pm 6,0$ mg. $I^{1}$. A eficiência média de remoção de nitrato foi de $24 \%$. O reator manteve a remoção de nitrato relativamente constante, como pode ser observado na Figura 5.32. Entretanto, não foi capaz de absorver o impacto do aumento dos valores de concentração de $\mathrm{N}-\mathrm{NO}_{3}{ }^{-}$afluente.

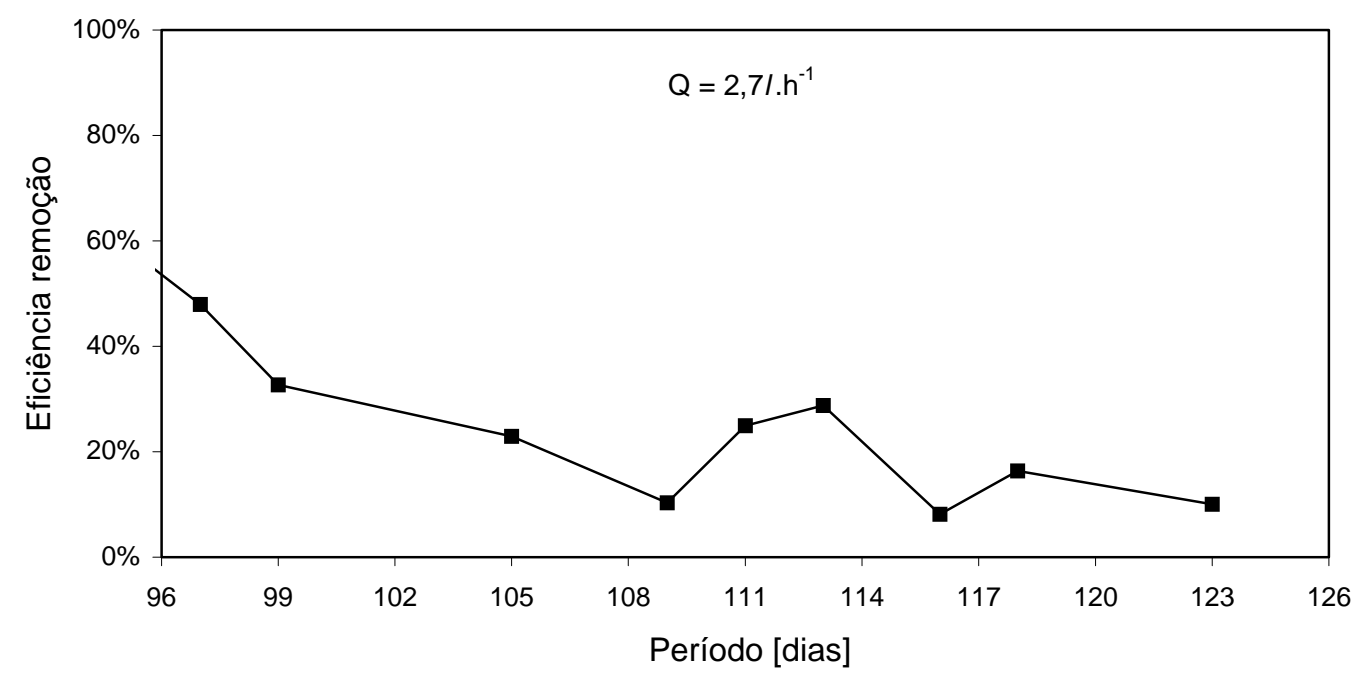

FIGURA 5.32 - Valores obtidos de eficiência de remoção $\mathrm{N}-\mathrm{NO}_{3}{ }^{-}$do RAHLFa. 
$\mathrm{Na}$ Figura 5.33 estão apresentados os valores obtidos com o monitoramento do parâmetro $\mathrm{N}^{-\mathrm{NO}_{2}}{ }_{2}$, afluente e efluente ao RAHLFa. O afluente apresentou valor médio de 0,3 $\pm 0,3 \mathrm{mg} \cdot \mathrm{I}^{1}$ e efluente de 0,3 $\pm 0,4 \mathrm{mg} \cdot \mathrm{I}^{1}$. Tais valores foram baixos e muito próximos, o que indicou haver provável equilíbrio no processo de desnitrificação, devido ao fato de não ter ocorrido acúmulo de $\mathrm{N}-\mathrm{NO}_{2}$.

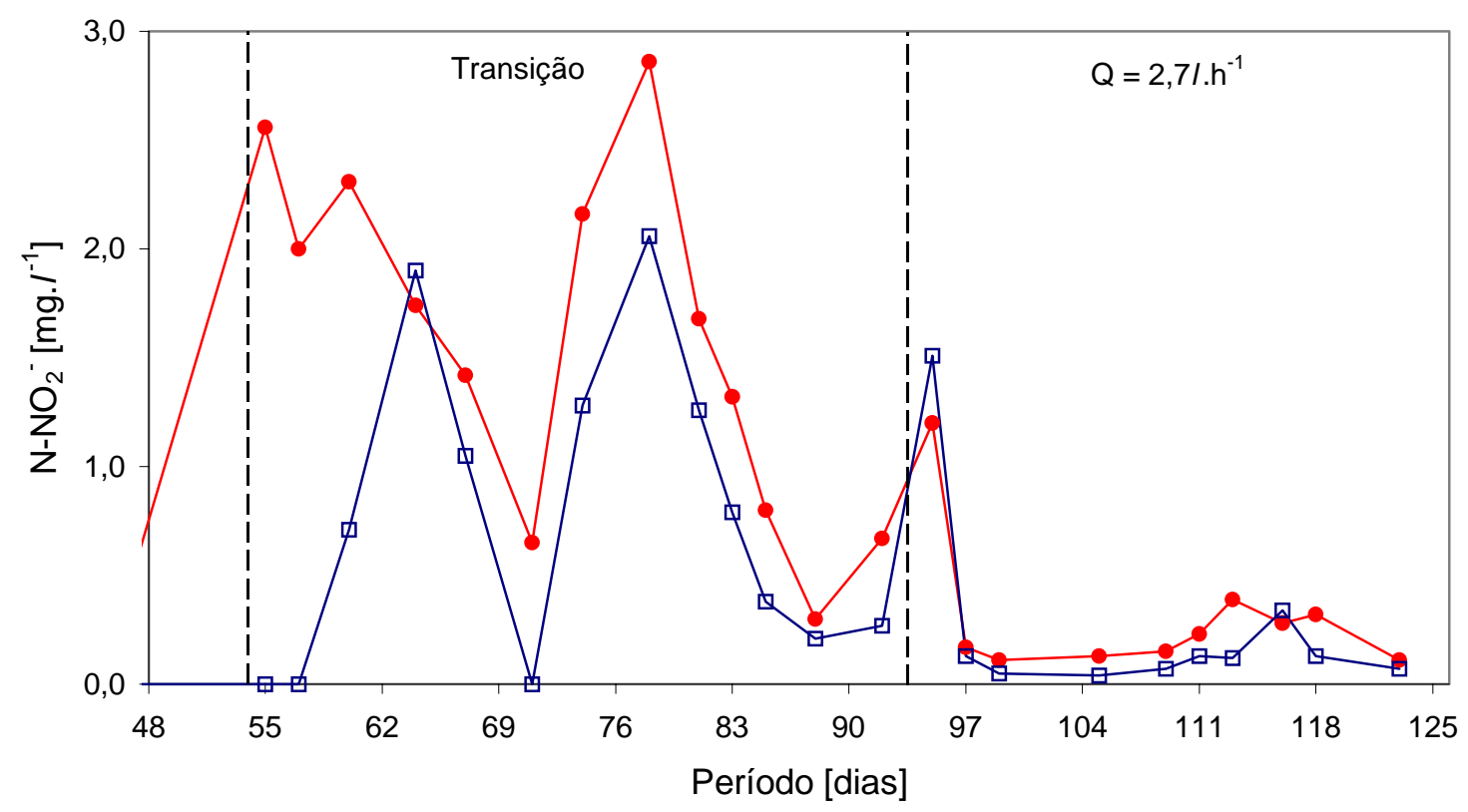

FIGURA 5.33 - Valores obtidos de $\mathrm{N}-\mathrm{NO}_{2}^{-}$afluente $\bullet$ e efluente $\square$ do RAHLFa, a partir do início da nitrificação no RMRLF.

O elevado valor do desvio padrão, na análise de nitrito efluente, é devido ao primeiro resultado obtido nas análises, após o equilíbrio dinâmico da nitrificação, ser relativamente alto em comparação aos demais resultados obtidos.

Durante a operação de reator similar para desnitrificação, VIEIRA (2000) obteve eficiência de remoção de $\mathrm{N}^{-\mathrm{NO}_{3}}{ }^{-}$de aproximadamente $97 \%$. A baixa eficiência apresentada pelo reator desnitrificante foi devida, provavelmente, a três motivos principais: a pouca biomassa presente no início da operação desta unidade de desnitrificação; a baixa concentração de uma fonte de carbono e a baixa velocidade de crescimento dos microrganismos deste reator.

Os valores obtidos nas análises de nitrogênio do $55^{\circ}$ ao $92^{\circ}$ dia de operação, período de transição - Figuras 5.29 até 5.32 - apresentaram grande oscilação. Essa oscilação é provavelmente devida à irregularidade da vazão 
afluente, a variação da concentração de N-NTK afluente do sistema, a qual variou durante a operação de 26 a $46 \mathrm{mg} . I^{1}$ e ao processo de nitrificação ser sensível a qualquer mudança nas condições de operação.

\subsection{Avaliação do sistema misto de leito fixo, em escala de bancada, para tratamento de esgoto sanitário}

A eficiência global do sistema em relação à remoção de DQO para a primeira condição, com vazão de $6 \mathrm{l} \cdot \mathrm{h}^{-1}$, foi de $81 \%$. Isso corresponde ao valor médio efluente de $86 \pm 22 \mathrm{mg} . I^{1}$ para DQO e $85 \%$ de eficiência, com valor médio final para DQOf de $68 \pm 9 \mathrm{mg} . I^{1}$. Para a segunda condição, com vazão efluente média de 2,7 I. $\mathrm{h}^{-1}$, foram obtidas eficiências de remoção de DQO e de DQOf de, respectivamente, $88 \%$ e $90 \%$, com valor médio efluente de $41 \pm 16 \mathrm{mg} . \mathrm{I}^{-1}$ e $36 \pm 15$ mg. $I^{1}$. Para o cálculo da carga orgânica foi utilizado o volume total do RMRLF sem a primeira câmara, o que corresponde a 53,1 / e o volume total do RAHLFa que corresponde a $47 \mathrm{I}$.

Nas Tabelas 5.4 e 5.5 estão resumidos os resultados obtidos nas análises para cada ponto de amostragem do sistema nas duas condições de operação.

TABELA 5.4 - Resumo dos resultados obtidos, na primeira condição, operando sistema misto anaeróbio/aeróbio/anóxico.

\begin{tabular}{cccccccc}
\hline Parâmetro & Unidade & $\begin{array}{c}\mathrm{n}^{\circ} \\
\mathrm{A}\end{array}$ & $\begin{array}{c}\text { Afluente } \\
\text { Sistema }\end{array}$ & Câmara 3 & $\begin{array}{c}\text { Efluente } \\
\text { RMRLF }\end{array}$ & $\begin{array}{c}\text { Efluente } \\
\text { RAHLFa }\end{array}$ & Eficiência \\
\hline Alcalinidade & $\mathrm{mgCaCO}_{3} I^{1}$ & 16 & $180 \pm 13$ & $187 \pm 11$ & $195 \pm 21$ & $199 \pm 11$ & - \\
$\mathrm{AVT}$ & $\mathrm{mgHAc} . I^{1}$ & 16 & $98 \pm 20$ & $46 \pm 14$ & $49 \pm 20$ & $54 \pm 26$ & - \\
$\mathrm{DQO}$ & $\mathrm{mg} \cdot I^{1}$ & 16 & $446 \pm 62$ & $613 \pm 598$ & $117 \pm 33$ & $86 \pm 22$ & $81 \%$ \\
$\mathrm{COV}$ & $\mathrm{KgDQO} / \mathrm{m}^{3} \cdot \mathrm{d}$ & 16 & 1,42 & 11,17 & 0,36 & - & - \\
DQOf & $\mathrm{mg} \cdot I^{1}$ & 15 & $316 \pm 32$ & $80 \pm 8$ & $80 \pm 8$ & $68 \pm 9$ & $85 \%$ \\
$\mathrm{pH}$ & --- & 16 & $7,3 \pm 0,3$ & $7,7 \pm 0,2$ & $7,7 \pm 0,2$ & $7,7 \pm 0,1$ & - \\
$\mathrm{ST}$ & $\mathrm{mg} \cdot I^{1}$ & 15 & $593 \pm 182$ & $681 \pm 160$ & $520 \pm 128$ & $519 \pm 123$ & - \\
$\mathrm{SST}$ & $\mathrm{mg} \cdot I^{1}$ & 15 & $59 \pm 19$ & $177 \pm 109$ & $25 \pm 21$ & $22 \pm 22$ & $62 \%$ \\
$\mathrm{SSV}$ & $\mathrm{mg} \cdot I^{1}$ & 15 & $51 \pm 22$ & $159 \pm 98$ & $21 \pm 23$ & $19 \pm 22$ & $62 \%$ \\
$\mathrm{SSF}$ & $\mathrm{mg} \cdot I^{1}$ & 15 & $7 \pm 7$ & $19 \pm 20$ & $4 \pm 5$ & $4 \pm 9$ & - \\
\hline
\end{tabular}


TABELA 5.5 - Resumo dos resultados obtidos, na segunda condição, operando sistema misto anaeróbio/aeróbio/anóxico.

\begin{tabular}{|c|c|c|c|c|c|c|c|}
\hline Parâmetro & Unidade & $\begin{array}{l}\mathrm{n}^{\circ} \\
\mathrm{A}\end{array}$ & $\begin{array}{l}\text { Afluente } \\
\text { Sistema }\end{array}$ & Câmara 3 & $\begin{array}{l}\text { Efluente } \\
\text { RMRLF }\end{array}$ & $\begin{array}{l}\text { Efluente } \\
\text { RAHLFa }\end{array}$ & Eficiência \\
\hline Alcalinidade & $\mathrm{mgCaCO}_{3} \cdot I^{1}$ & 10 & $208 \pm 15$ & $475 \pm 288$ & $449 \pm 287$ & $472 \pm 231$ & - \\
\hline AVT & $\mathrm{mgHAc} . I^{1}$ & 10 & $47 \pm 12$ & $22 \pm 7$ & $20 \pm 5$ & $22 \pm 8$ & - \\
\hline DQO & $\mathrm{mg} . I^{1}$ & 10 & $345 \pm 33$ & $78 \pm 30$ & $54 \pm 19$ & $41 \pm 16$ & $88 \%$ \\
\hline cov & $\mathrm{KgDQO} / \mathrm{m}^{3} \cdot \mathrm{d}$ & 10 & 0,37 & 0,17 & 0,07 & - & - \\
\hline DQOf & $\mathrm{mg} . I^{1}$ & 10 & $214 \pm 16$ & $31 \pm 8$ & $29 \pm 8$ & $36 \pm 15$ & $90 \%$ \\
\hline NTK & $\mathrm{mgNH}_{4} \cdot I^{1}$ & 9 & $41 \pm 4$ & $3 \pm 3$ & $2 \pm 2$ & $2 \pm 2$ & $95 \%$ \\
\hline $\mathrm{N}$-amon & $\mathrm{mgNH}_{4} \cdot \Gamma^{1}$ & 10 & $33 \pm 4$ & $\leq 1$ & $\leq 1$ & $\leq 1$ & $99 \%$ \\
\hline N-org & $\mathrm{mgNH}_{4} \cdot I^{1}$ & 9 & $7 \pm 3$ & $3 \pm 3$ & $2 \pm 2$ & $2 \pm 2$ & $78 \%$ \\
\hline Nitrito & $\mathrm{mgNO}_{2} \cdot I^{1}$ & 10 & $0,0 \pm 0,0$ & $0,6 \pm 0,4$ & $0,3 \pm 0,3$ & $0,3 \pm 0,4$ & - \\
\hline Nitrato & $\mathrm{mgNO}_{3} \cdot I^{1}$ & 9 & $0,0 \pm 0,0$ & $20,4 \pm 4,0$ & $22,1 \pm 4,5$ & $16,7 \pm 6,0$ & - \\
\hline $\mathrm{pH}$ & --- & 10 & $7,2 \pm 0,1$ & $8,3 \pm 0,2$ & $8,4 \pm 0,1$ & $8,1 \pm 0,2$ & - \\
\hline SST & $\mathrm{mg} \cdot I^{1}$ & 10 & $74 \pm 25$ & $32 \pm 19$ & $26 \pm 20$ & $17 \pm 8$ & $78 \%$ \\
\hline SSV & $\mathrm{mg} \cdot I^{1}$ & 10 & $58 \pm 28$ & $30 \pm 18$ & $19 \pm 13$ & $8 \pm 7$ & $86 \%$ \\
\hline SSF & $\mathrm{mg} . I^{1}$ & 10 & $16 \pm 14$ & $4 \pm 4$ & $9 \pm 12$ & $7 \pm 10$ & - \\
\hline
\end{tabular}

A redução de sólidos suspensos voláteis foi considerável nas duas condições de operação, obtendo, na primeira condição, a eficiência de $62 \%$, com o valor no efluente de $19 \pm 22 \mathrm{mg} \cdot I^{1}$. Na segunda condição, atingiu-se $86 \%$ de eficiência, resultando em concentração média efluente de $8 \pm 7 \mathrm{mg} \cdot I^{1}$. Devido à elevada eficiência de redução de SSV, não houve necessidade de utilizar decantador secundário para o polimento final do efluente, pois o mesmo apresentava-se clarificado.

Foram realizadas três análises de coliformes fecais do afluente e do efluente do RMRLF no final da operação do sistema. A concentração inicial foi de aproximadamente $2,1.10^{4} \mathrm{NMP} .100 \mathrm{~m} /^{1}$ e a remoção atingiu $95 \%$ de eficiência, o que não garante desinfecção do esgoto sanitário, cuja concentração final de coliformes fecais foi de, aproximadamente, $1000 \mathrm{NMP} .100 \mathrm{~m} /^{1}$. Contudo, o CONAMA $\mathrm{n}^{\circ} 20$ exige o valor máximo de $1000 \mathrm{NMP} .100 \mathrm{~m} /{ }^{1}$ para os rios de classe 2, 3 e 4. Portanto, esse efluente está em conformidade para ser lançado em rios com vazão igual ou superior a utilizada no sistema. 


\subsubsection{Avaliação e balanço de massa de nitrogênio no sistema}

Foi realizado balanço de massa para o nitrogênio presente no sistema, conforme apresentado na equação (5.1). Para que o nitrogênio presente no sistema esteja balanceado, a somatória de nitrogênio afluente deve ser igual à somatória do nitrogênio efluente nas diversas formas.

$$
\begin{aligned}
& \left(\mathrm{N} \text {-amon }+\mathrm{N} \text {-org }+\mathrm{N}-\mathrm{NO}_{2}^{-}+\mathrm{N}-\mathrm{NO}_{3}^{-}\right) \text {afluente }= \\
& =\left(\mathrm{N} \text {-amon }+\mathrm{N} \text {-org }+\mathrm{N}-\mathrm{NO}_{2}^{-}+\mathrm{N}-\mathrm{NO}_{3}^{-}+\mathrm{N}_{2}\right) \text { efluente }
\end{aligned}
$$

A produção de $\mathrm{N}_{2}$ não foi avaliada experimentalmente. No entanto, para efeito de balanceamento, foi considerado que o nitrogênio nas formas de nitrato e nitrito, eram desnitrificados, formando $\mathrm{N}_{2}$.

O processo de desnitrificação não ocorreu apenas no RAHLFa, mas, em grande parte, no RMRLF. É provável, inclusive, que tenha ocorrido a SND (nitrificação/desnitrificação simultânea) com origem física, que é explicada pela ocorrência de formação no reator de micro-sítios aeróbios, nos quais as bactérias nitrificantes estariam localizadas e outros micro-sítios anóxicos, regiões em que as bactérias desnitrificantes estariam localizadas.

Relações estequiométricas mostram que a relação entre produção de nitrogênio na forma molecular e consumo de nitrato é praticamente de $1 g N-N_{2} / g N-N O_{3}^{-}$, conforme item 2.2.2.

Para o balanceamento foram utilizados os valores médios obtidos na segunda condição de operação. A partir deles, foi estimada a quantidade de nitrogênio molecular efluente do sistema. A somatória da quantidade de nitrogênio, nas formas de nitrito e nitrato, reduzida no sistema foi, aproximadamente, $22 \mathrm{mg} . \digamma^{1}$. Esse valor foi considerado ser a concentração de $\mathrm{N}_{2}$ formada durante o processo de desnitrificação. Os cálculos realizados possibilitaram o desenvolvimento da Figura 5.34. 


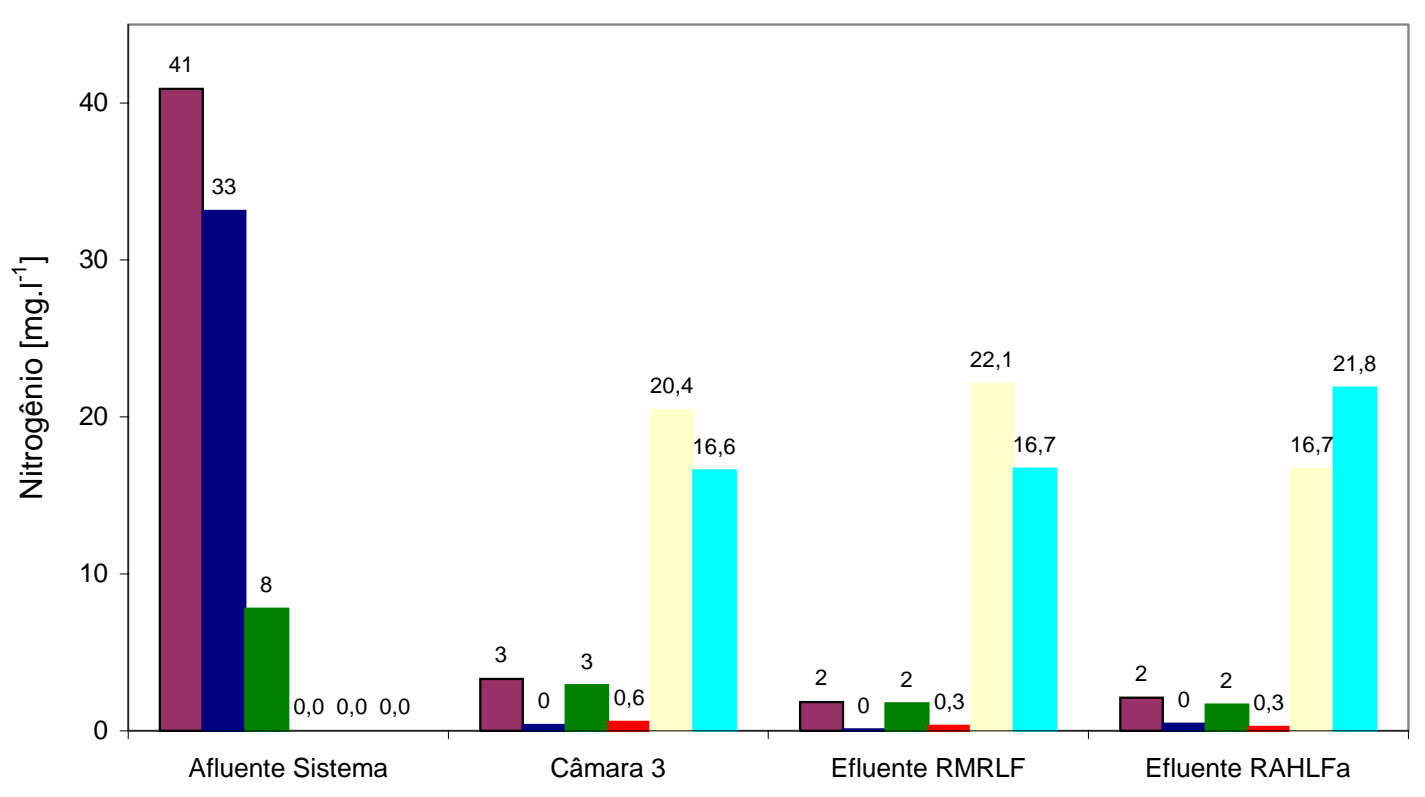

FIGURA 5.34 - Balanço de massa para o nitrogênio nos pontos de amostragem do sistema experimental com os valores de N-NTK $\square, \mathrm{N}$-amon $\square, \mathrm{N}$-org $\square, \mathrm{N}-\mathrm{NO}_{2}^{-} \square, \mathrm{N}^{-} \mathrm{NO}_{3}^{-} \quad$ e $\mathrm{N}_{2}$.

O sistema mostrou-se eficiente na remoção de $\mathrm{N}$-amon, obtendo eficiência de $99 \%$, com concentração no efluente final inferior a $1 \mathrm{mg} . I^{1}$. Esses valores de concentração de $\mathrm{N}$-amon estão dentro do valor máximo admissível, para o lançamento de efluentes de $5 \mathrm{mg} \cdot \mathrm{I}^{1}$, definido pela resolução CONAMA $\mathrm{n}^{\circ} 20$ (BRASIL, 1986).

A eficiência de remoção de nitrito foi satisfatória. Depois de atingido o equilíbrio dinâmico aparente no processo de nitrificação, a concentração de $\mathrm{N}-\mathrm{NO}_{2}{ }^{-}$ efluente apresentou valor médio igual a $0,3 \pm 0,4 \mathrm{mg} \cdot I^{1}$, o qual está abaixo do nível máximo de $1 \mathrm{mg} . I^{1}$ disposto no CONAMA $\mathrm{n}^{\circ} 20$ para as classes de rio de 1 a 3 (BRASIL, 1986).

O nitrato produzido durante 0 processo de nitrificação não foi satisfatoriamente removido do sistema, apresentando concentração média final de $16,7 \pm 6,0 \mathrm{mg} \cdot I^{1}$, a qual atenderá a legislação, que exige valor máximo de $\mathrm{N}-\mathrm{NO}_{3}{ }^{-}$ de $10 \mathrm{mg} . I^{1}$ nos corpos de água, somente se, a vazão efluente ao sistema for, no máximo, a metade da vazão média resultante do corpo receptor livre de nitrato (BRASIL, 1986). A pouca eficiência de remoção de $\mathrm{N}_{-} \mathrm{NO}_{3}^{-}$no RAHLFa foi, provavelmente, devido à baixa concentração de biomassa desenvolvida nesse reator, comprovada pela análise de sólidos voláteis apresentada no item 5.3.1. 
A baixa eficiência apresentada pelo reator desnitrificante deve-se, provavelmente, aos motivos citados anteriormente: pouca biomassa presente no início da operação da unidade de desnitrificação; baixa concentração de uma fonte de carbono e baixa taxa de crescimento dos microrganismos deste reator.

Duas hipóteses podem ser levantadas para justificar os baixos valores de $\mathrm{N}-\mathrm{NO}_{2}{ }^{-}$obtidos no efluente do RAHLFa: na primeira, a população consumidora de nitrito encontrava-se bem estabelecida no reator e, por isso, todo nitrito formado foi consumido; e na segunda, os microrganismos desnitrificantes que se desenvolveram no reator eram capazes de realizar toda a rota metabólica do processo de redução de $\mathrm{N}^{-\mathrm{NO}_{3}}{ }^{-}$à $\mathrm{N}_{2}$. A ocorrência de uma das duas hipóteses poderia ter sido investigada através da realização de perfil espacial de concentração de nitrato e nitrito, ao longo do reator. Caso a primeira hipótese seja considerada verdadeira, é possível supor que o período que os microrganismos redutores de nitrito, presentes no RAHLFa, passaram sem alimentação não prejudicou o desempenho dessa biomassa, pois as concentrações de nitrito mantidas no sistema foram muito baixas.

\subsection{Exame microscópico da biomassa imobilizada no sistema}

As morfologias registradas pela microscopia óptica de luz comum e de contraste de fase foram identificadas através de comparação com morfologias apresentadas por JENKINS et al. (1993) e VAZOLLER et al. (1992).

\subsubsection{Morfologias observadas no lodo de inóculo}

As morfologias observadas por microscopia óptica de luz comum e de contraste de fase, encontradas nas amostras maceradas do lodo utilizado como inóculo para a câmara 2 do RMRLF, estão apresentadas nas Figuras 5.35 e 5.36. 


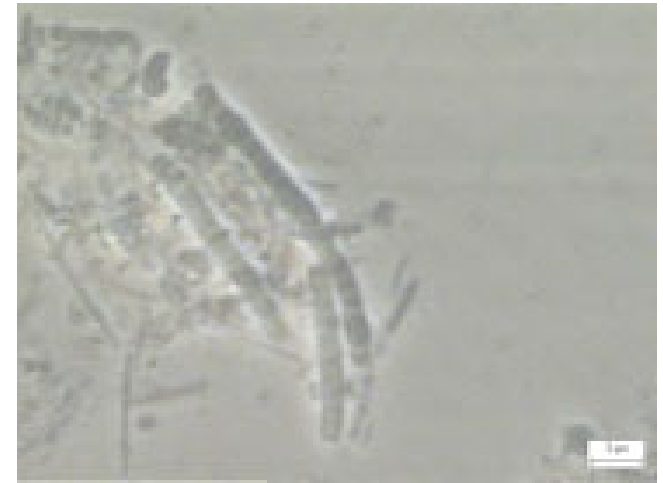

a)

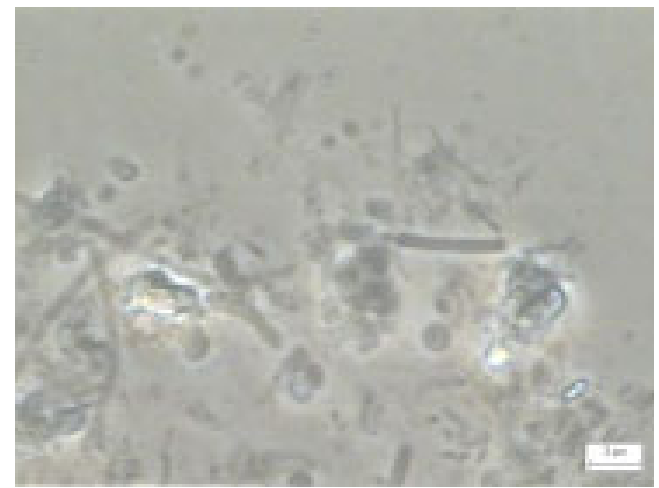

c)

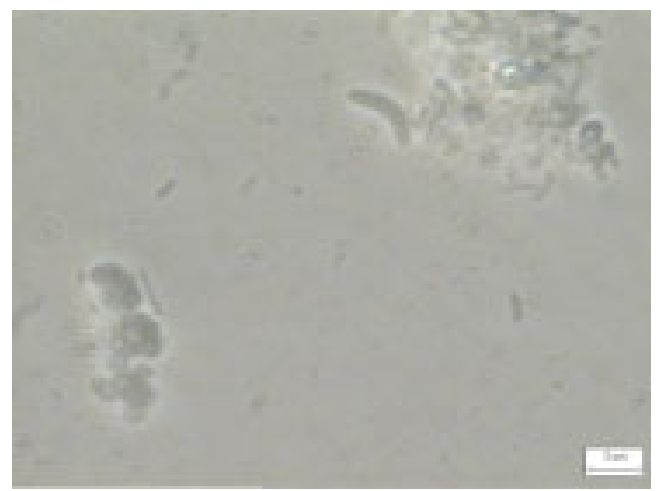

e)

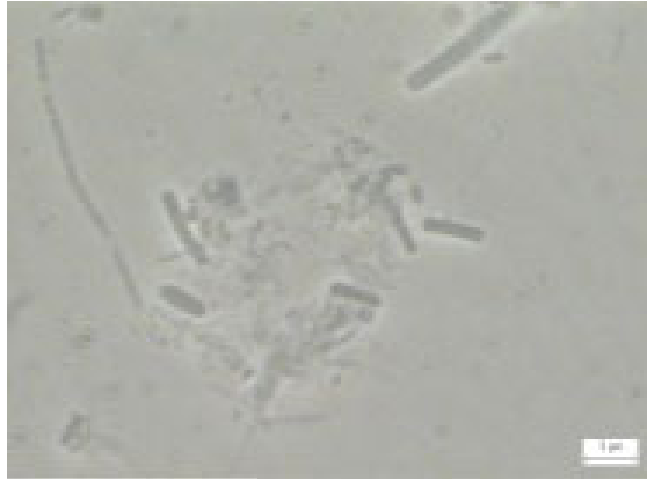

b)

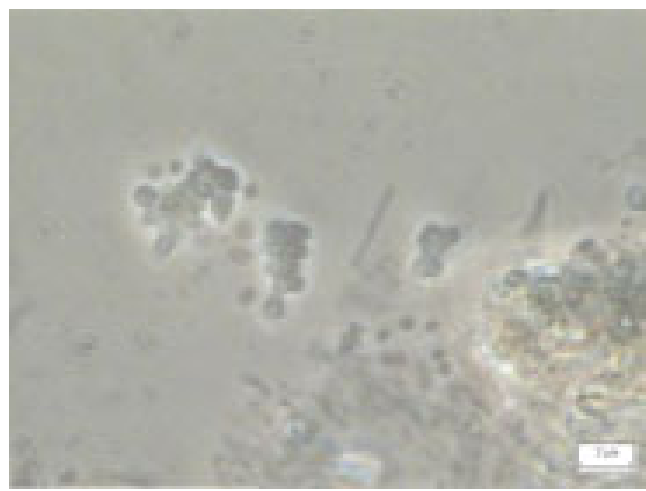

d)

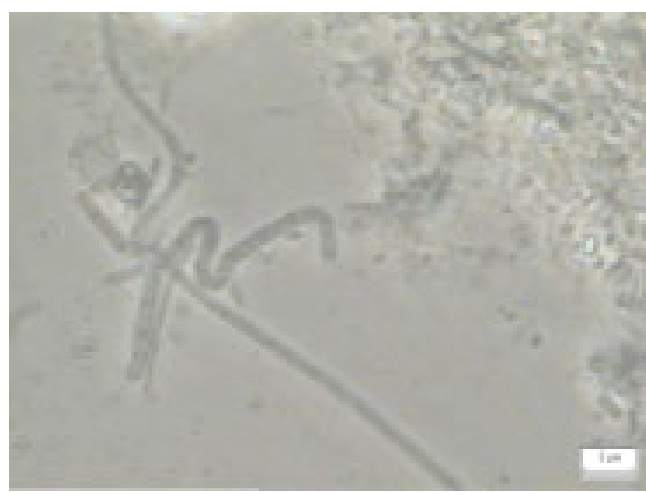

f)

FIGURA 5.35 - Morfologias observadas no lodo de inóculo, com aumento de 1600x e barras com $3 \mu \mathrm{m}$. Estruturas semelhantes a: a) filamentos septados; b) bacilos com extremidades arredondadas e filamentos; c) filamentos delgados semelhantes a Methanosaeta, bacilos com diversas dimensões e cocos isolados; d) bacilos e diplococos e arranjo de cocos; e) bacilos de diversos tamanhos, bacilo curvo semelhante a BRS e arranjo de cocos; f) filamentos semelhantes a Methanosaeta. 

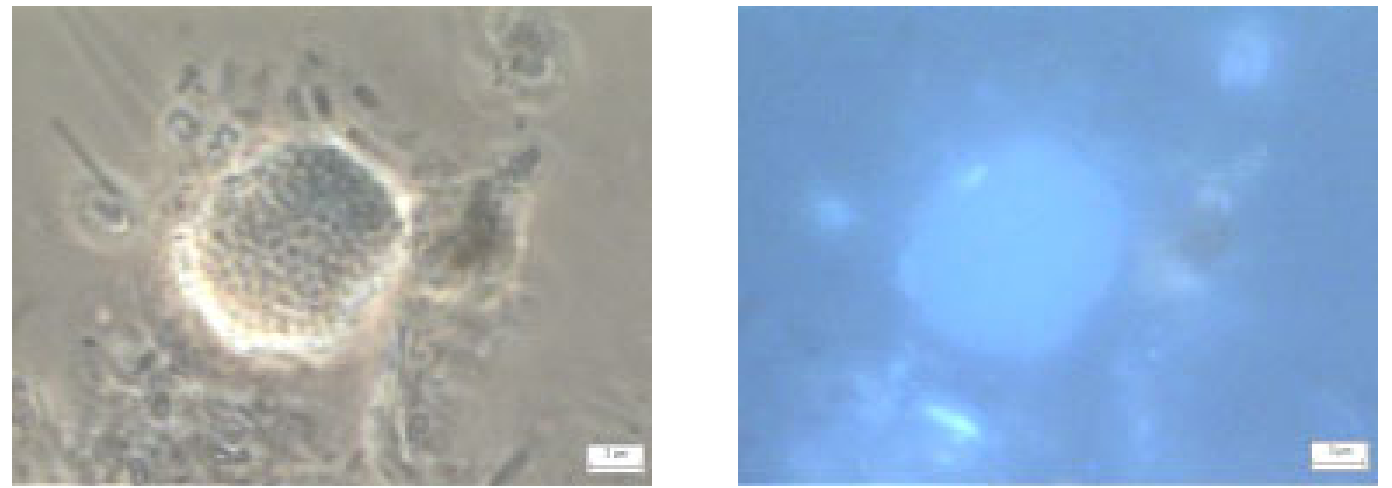

FIGURA 5.36 - Morfologia observada no lodo macerado de inóculo, com aumento de 1600x e barras com $3 \mu \mathrm{m}$. Estrutura semelhante a cisto de Methanosarcina.

O lodo de inóculo utilizado estava estocado em câmara fria. Após o lodo ser retirado da câmara fria e macerado, foi preparada lâmina para exame microscópico. No exame foi possível observar que esse lodo apresentava grande diversidade de morfologias de microrganismos anaeróbios. As morfologias mais encontradas foram de estruturas semelhantes a Methanosaeta, bacilos com diversas dimensões, bacilos curvos semelhante a BRS e arranjo de cocos.

\subsubsection{Morfologias observadas em amostras retiradas do RAHLFa antes do início de sua operação.}

As morfologias observadas por microscopia óptica comum e de contraste de fase foram provenientes de amostras de espuma de poliuretano retiradas do RAHLFa antes do início de sua operação. O objetivo foi confirmar a existência de microrganismos no meio suporte do reator. As imagens obtidas nesse exame microscópico estão apresentadas na Figura 5.37. 


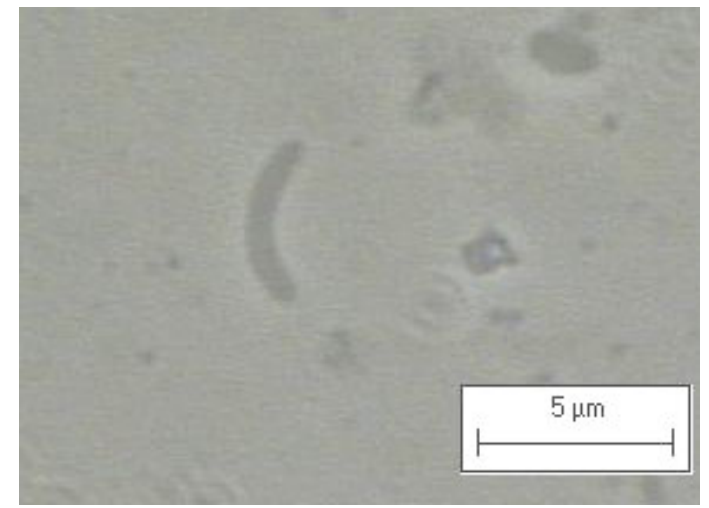

a)

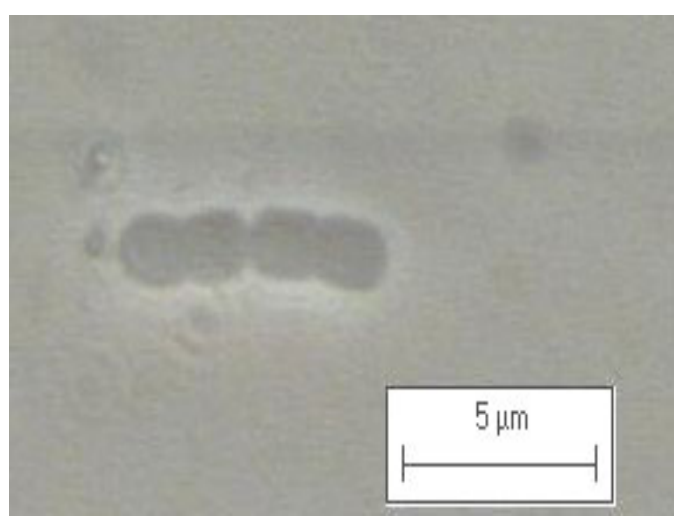

c)

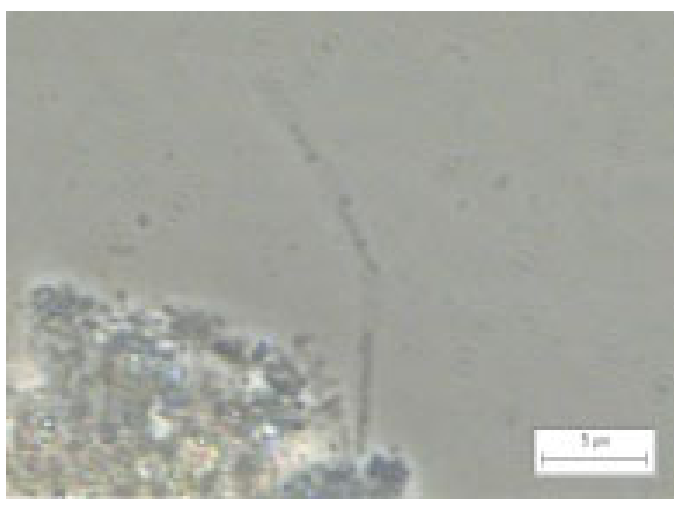

e)

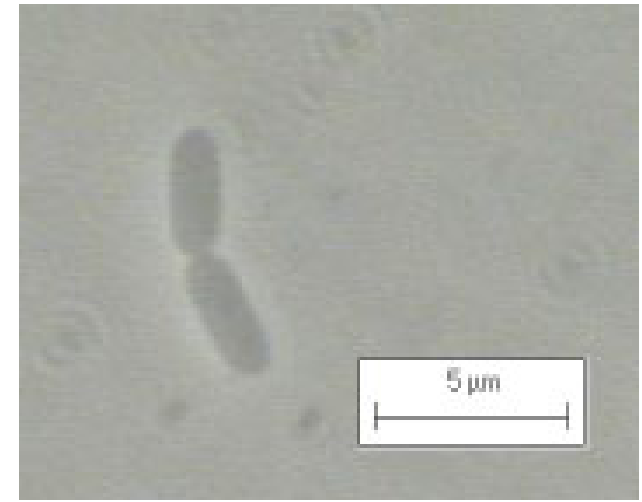

b)

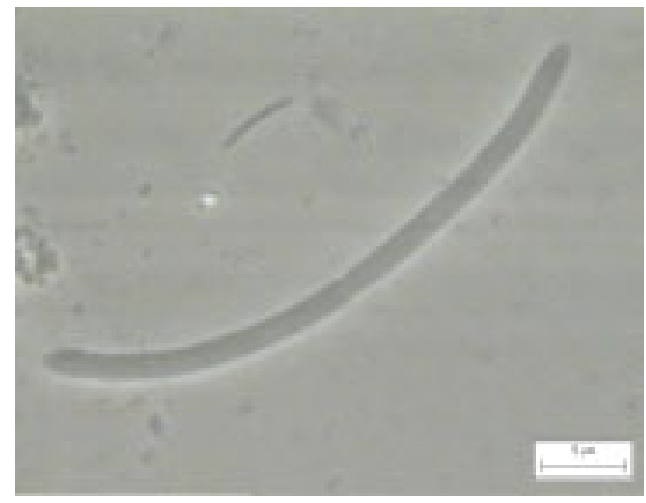

d)

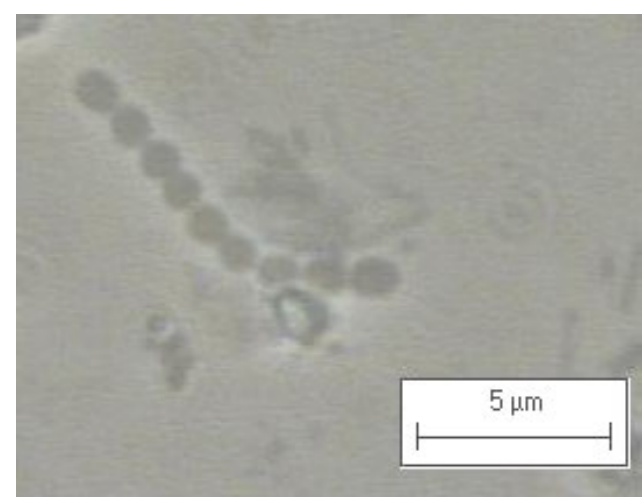

f)

FIGURA 5.37 - Morfologias observadas no meio suporte do RAHLFa, com aumento de $1600 x$ e barras com $5 \mu \mathrm{m}$. Estruturas semelhantes a: a) bacilo curvo semelhante a BRS; b) bacilos com extremidades arredondadas; c) cocobacilos; d) bacilo com extremidade arredondada e constrição central; e) filamento sem estrutura celular íntegra; f) estreptococos.

Através da microscopia realizada com amostras retiradas do RAHLFa, foi possível confirmar a existência de microrganismos imobilizados na espuma de 
poliuretano, com morfologias anaeróbias semelhantes a bacilos curvos, bacilos com extremidades arredondas e constrição central, cocos e filamentos. Entretanto, os microrganismos encontravam-se muito dispersos e a quantidade de células imobilizadas era aparentemente menor em relação à observação realizada na etapa anaeróbia do RMRLF, no início de sua operação.

Na Figura 5.37(e) pode ser observado microrganismo que não apresenta estrutura celular íntegra, o que indicou condição nutricional desfavorável.

Com a detecção de microrganismos imobilizados no meio suporte, optouse por operá-lo sem inoculação. Contudo, a biomassa desnitrificante não se desenvolveu suficientemente durante os 123 dias de operação a fim de proporcionar desnitrificação efetiva para o sistema.

\subsubsection{Morfologias observadas em amostras retiradas da câmara 3 do RMRLF, no período de grande desenvolvimento de filamentos}

As morfologias apresentadas neste item foram observadas através de microscopia óptica de luz comum e contraste de fase, a partir de amostras de filamentos retiradas da câmara 3, na qual ocorria a aeração do sistema. As imagens estão apresentadas nas Figuras 5.38 e 5.39.

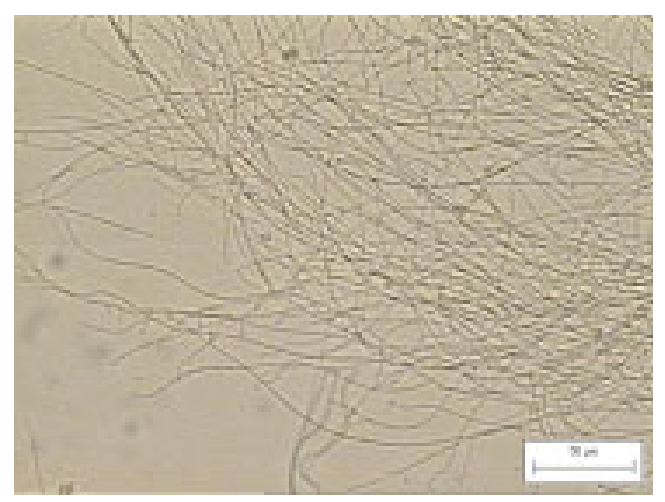

a)

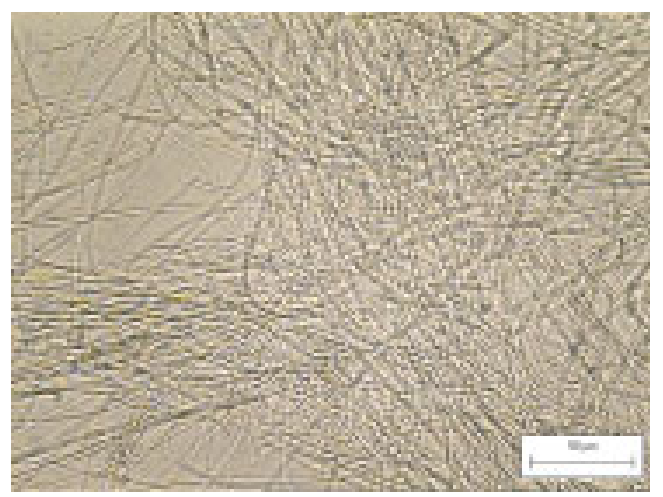

b) 


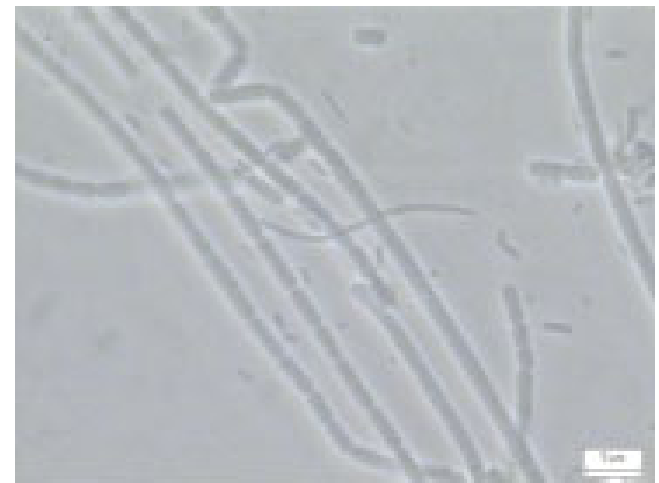

c)

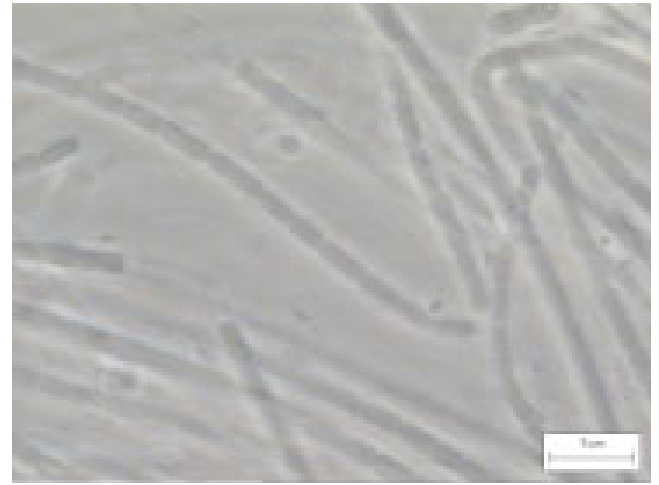

e)

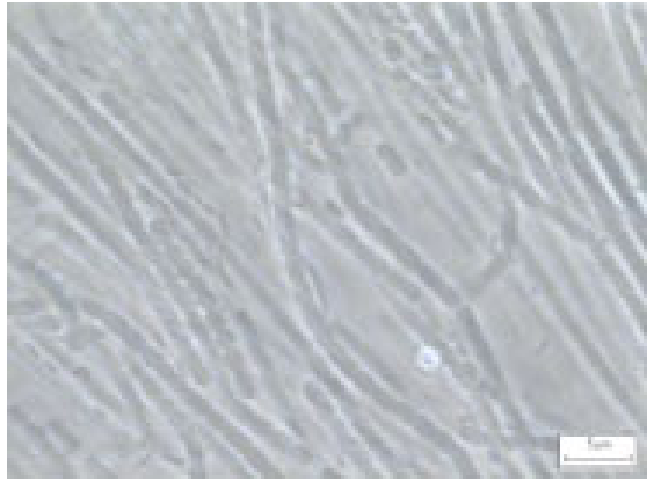

d)

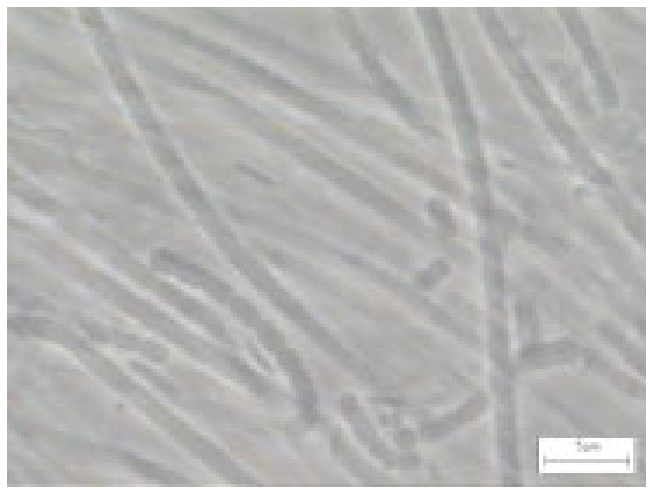

f)

FIGURA 5.38 - Morfologias observadas na câmara 3, com densa massa de filamentos. $O$ aumento foi de 100x para a) e b), com barras de 50 $\mu \mathrm{m}, 1000 x$ para c) e d), com barras de $5 \mu \mathrm{m}$ e de $1600 x$ para e) e f), com barras de $5 \mu \mathrm{m}$. Todas as estruturas aqui apresentadas são semelhantes à Sphaerotilus.

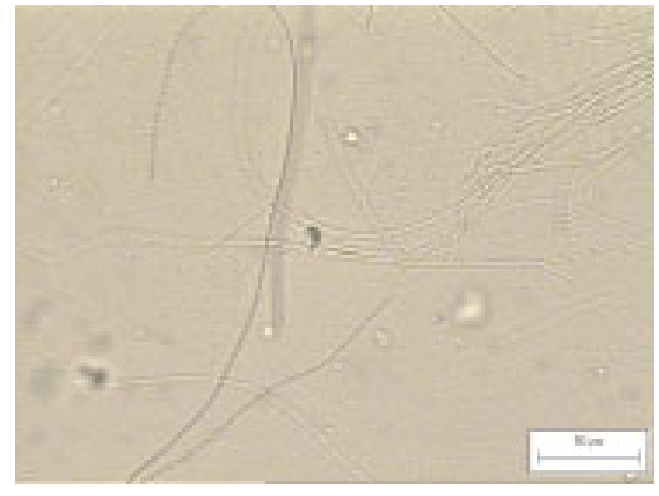

a)

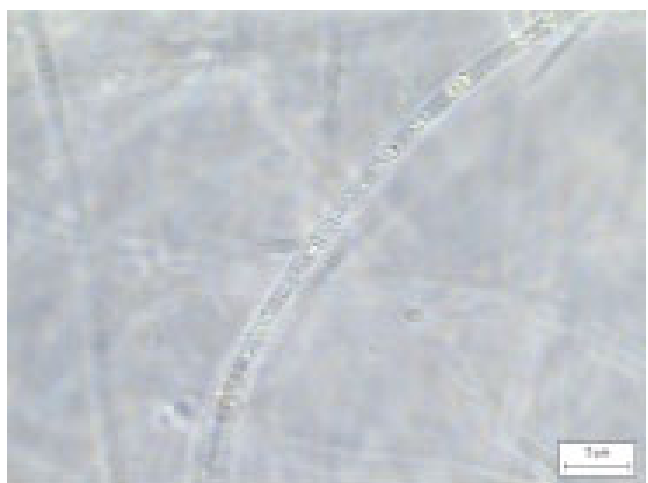

b) 


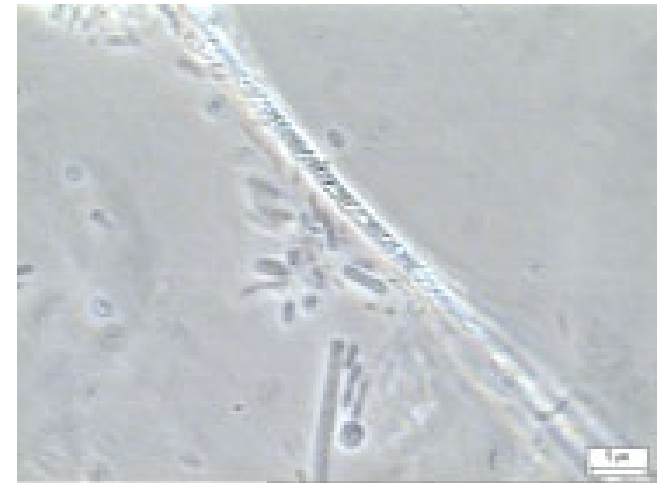

c)

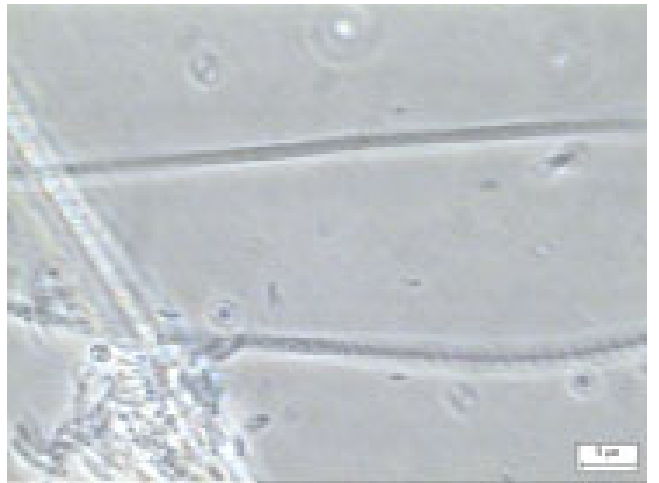

d)

FIGURA 5.39- Morfologias observadas na câmara 3 com densa massa de filamentos. $O$ aumento foi de 100x para a), com barra de 50 $\mu \mathrm{m}, 1000 \mathrm{x}$ para b), c) e d), com barras de $5 \mu \mathrm{m}$. As estruturas apresentadas são semelhantes a: a), b) e c) Beggiatoa e d) Thiothrix.

Durante a operação do sistema houve crescimento excessivo, na câmara 3, de microrganismos filamentosos característicos de ambientes com pouca oxigenação ou microaerófilos.

Foi possível detectar, em amostra de filamento retirado da câmara 3, predominância de morfologias semelhantes a Sphaerotilus e foram encontradas aparentemente em menor número morfologias semelhantes a Beggiatoa e Thiothrix.

Após o aparecimento dos filamentos na câmara 3 e a realização do exame microscópico, optou-se pelo aumento da vazão de ar na câmara 3. Inicialmente, o aumento na aeração do sistema, provocou agitação do fundo do leito do reator nessa câmara, o que provocou elevação dos valores de SSV e SSed. Após aproximadamente duas semanas, os SSed diminuíram até valores abaixo do limite de detecção do método, o que coincidiu com o desaparecimento dos filamentos da câmara 3. Da mesma forma, os SSV apresentaram redução do valor médio de 429 mg. $I^{1}$ para $16 \mathrm{mg} . I^{1}$. 


\subsubsection{Morfologias observadas em amostras retiradas do RMRLF na câmara 2 e próximo à câmara 3 , após 40 dias de operação}

As morfologias observadas por microscopia óptica de luz comum e de contraste de fase, encontradas nas amostras retiradas de cubos de espuma de poliuretano da câmara 2 do RMRLF, em posição na qual o valor médio do POR era próximo à -300 mV estão apresentadas nas Figuras 5.40 e 5.41.

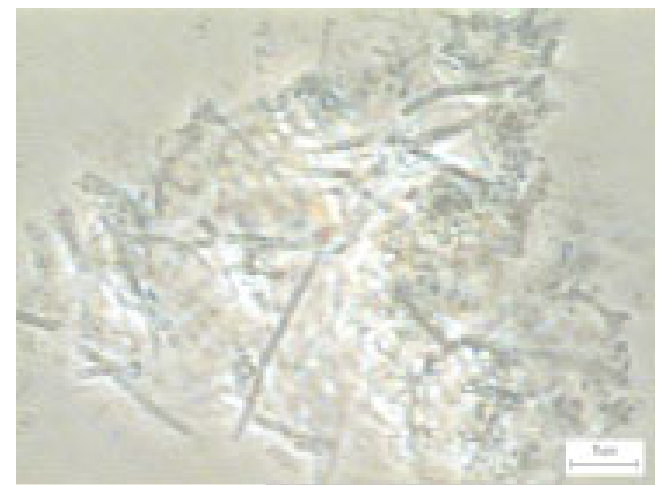

a)

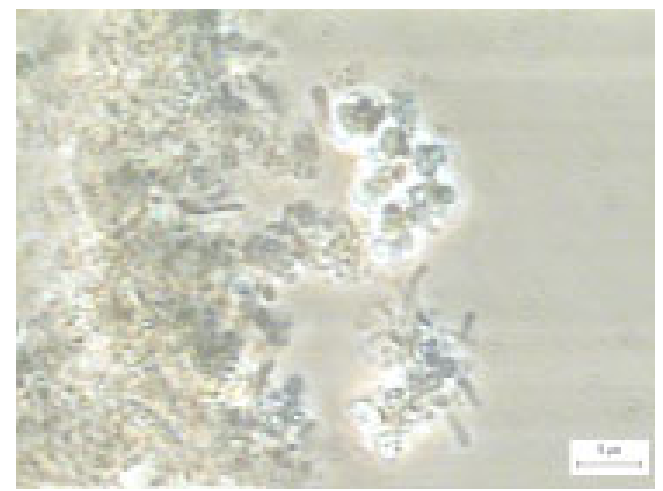

c)

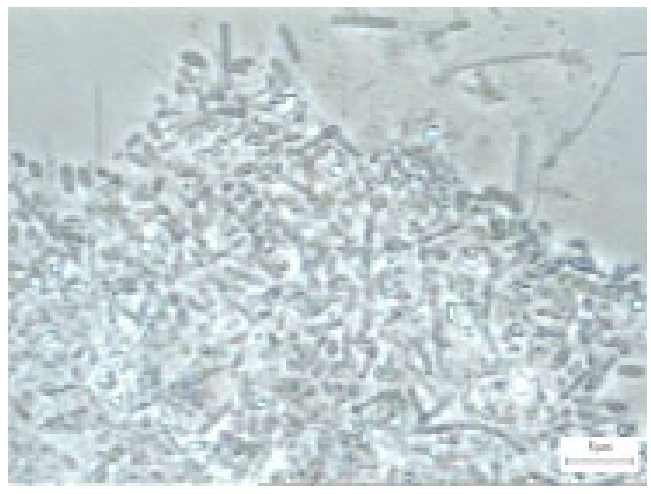

b)

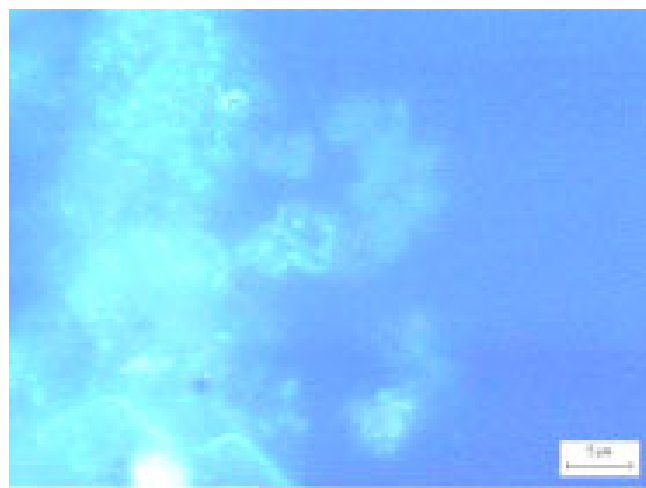

d)

FIGURA 5.40 - Morfologias observadas na câmara 2 com valor de POR próximo a $-300 \mathrm{mV}$, com aumento de $1250 \mathrm{x}$ e barras com $5 \mu \mathrm{m}$. As estruturas apresentadas são semelhantes a: a) filamentos; b)bacilos com extremidades arredondadas e não fluorescentes; c) e d) bacilos methanogênicos e Methanosarcina. 


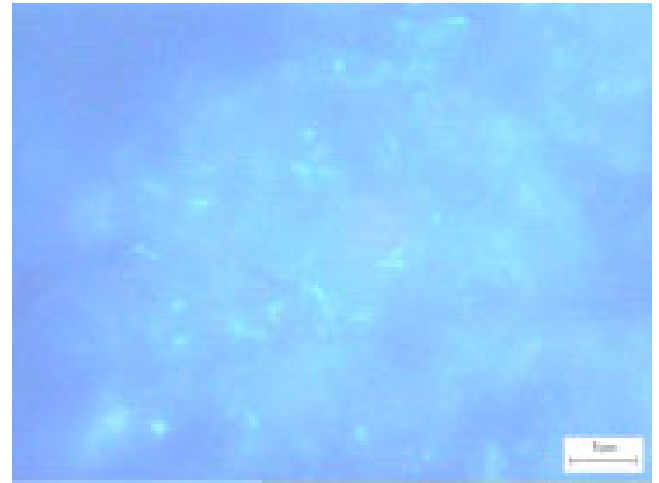

a)

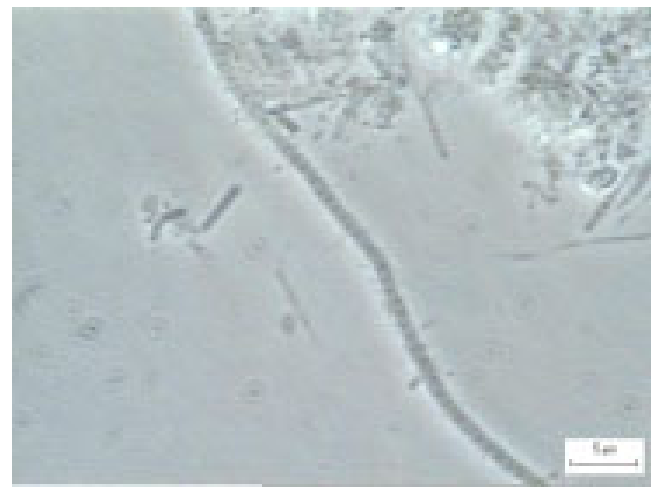

c)

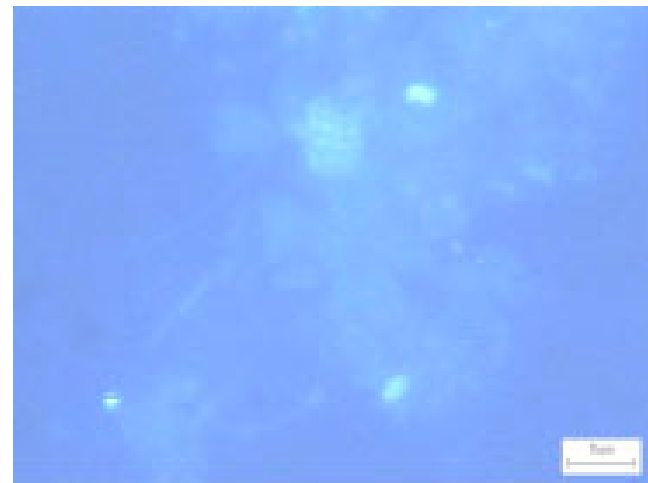

b)

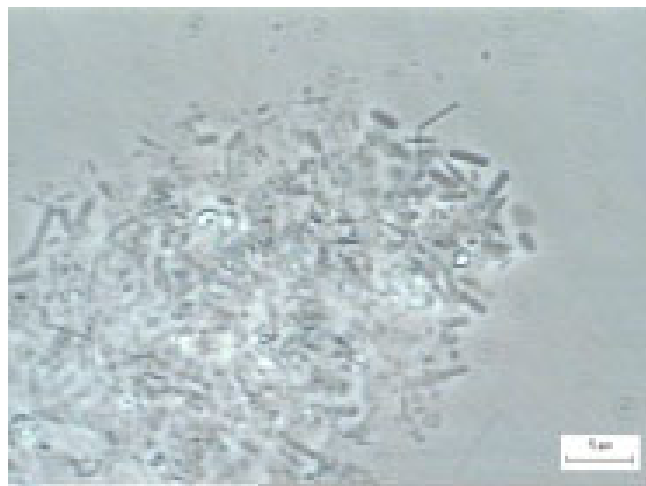

d)

FIGURA 5.41 - Morfologias observadas na câmara 2 com valor do POR próximo à $-300 \mathrm{mV}$, com aumento de $1250 \mathrm{x}$ e barras com $5 \mu \mathrm{m}$. As estruturas apresentadas são semelhantes a: a) bacilos fluorescentes; b) fluorescência de Methanosarcina; c) filamento septado, bacilos com diversas dimensões, filamentos delgados; d) bacilos de morfologias diversas.

A Figura 5.40 apresenta morfologias anaeróbias semelhantes a bacilos com extremidades arredondadas, não fluorescentes, bacilos methanogênicos e methanosarcinas.

$\mathrm{Na} 5.41(\mathrm{c})$ está apresentado filamento septado, possivelmente com metabolismo facultativo, pois morfologia semelhante foi identificada próxima a câmara 3.

As morfologias observadas por microscopia óptica de luz comum e de contraste de fase, encontradas nas amostras retiradas de cubos de espuma próximos à câmara 3 do RMRLF, em local no qual o POR apresentou valores próximos à $-170 \mathrm{mV}$ estão apresentadas nas Figuras 5.42, 5.43 e 5.44. 


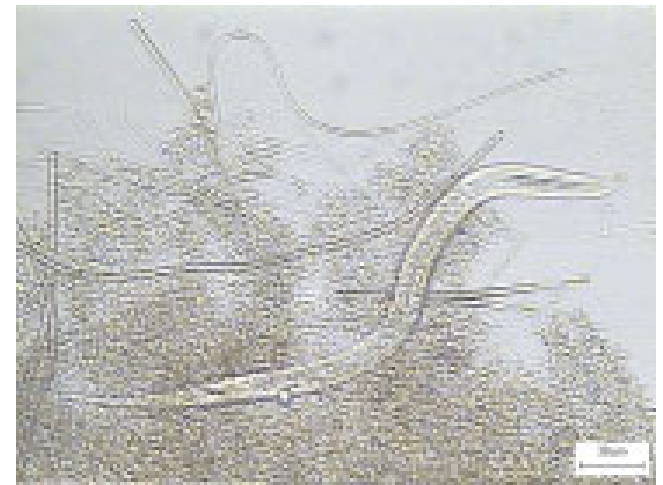

a)

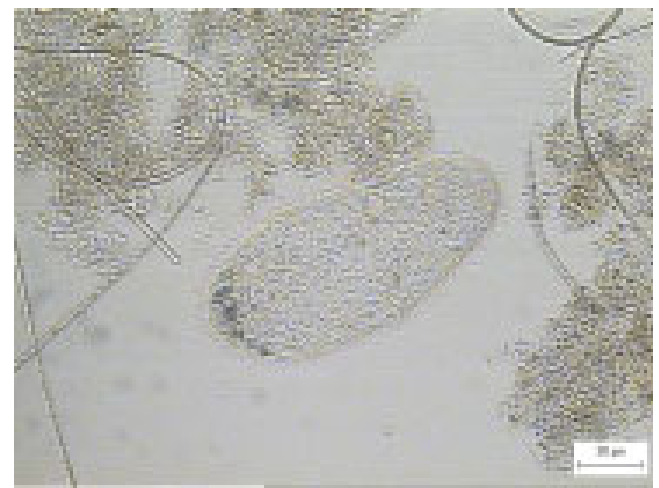

c)

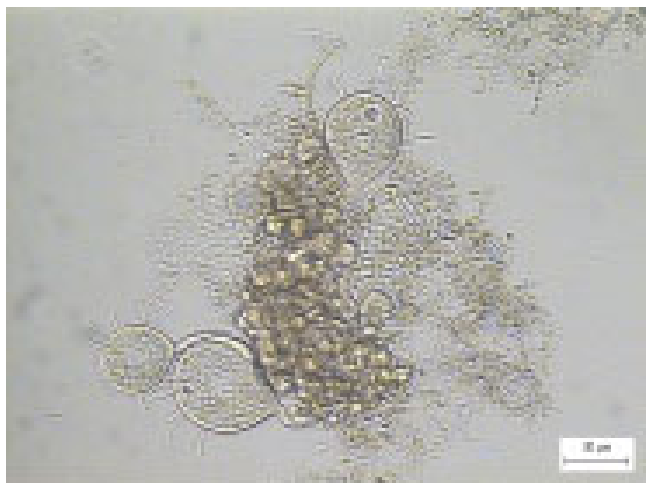

b)

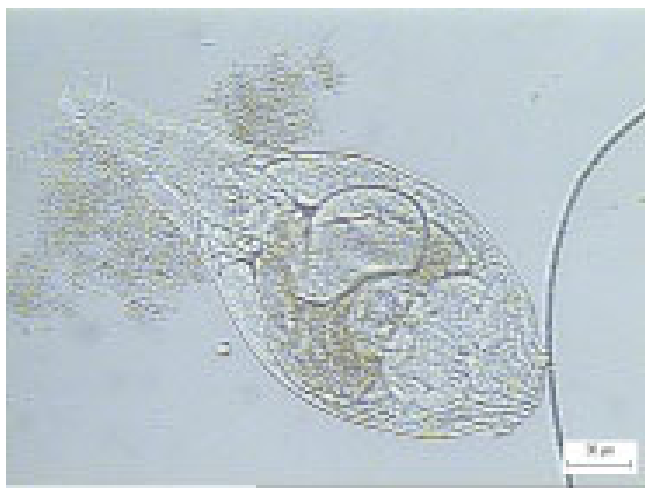

d)

FIGURA 5.42 - Morfologias observadas próximo a câmara 3, com aumento de 200x e barras com $30 \mu \mathrm{m}$. As estruturas apresentadas são semelhantes a: a) nematóide; b) protozoário suctória semelhante a Podophrya; c) Paramecium; d) rotífero semelhante a Epiphanes.

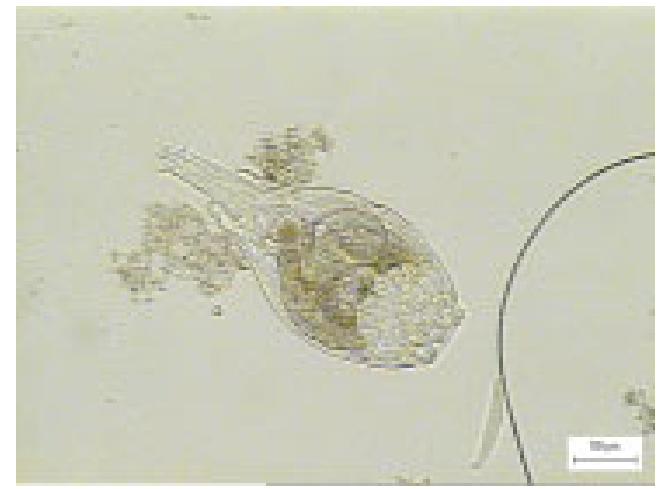

a)

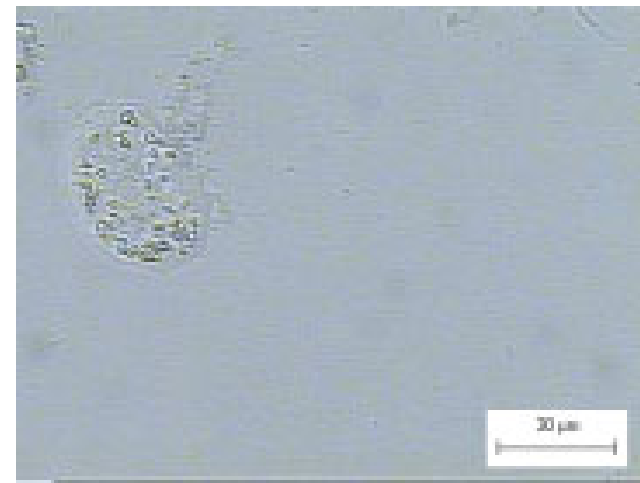

b) 


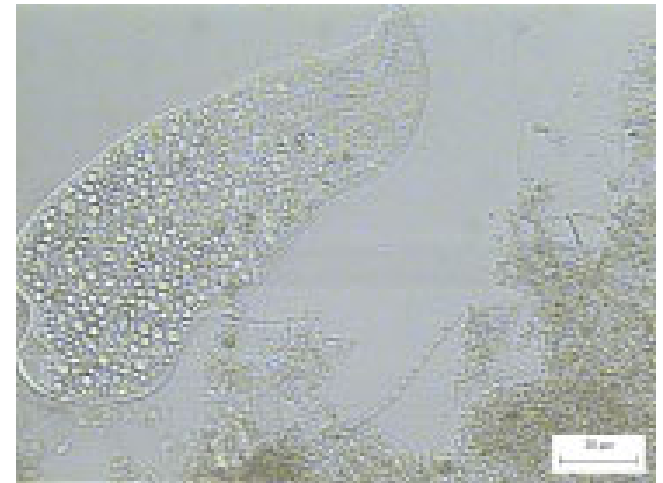

c)

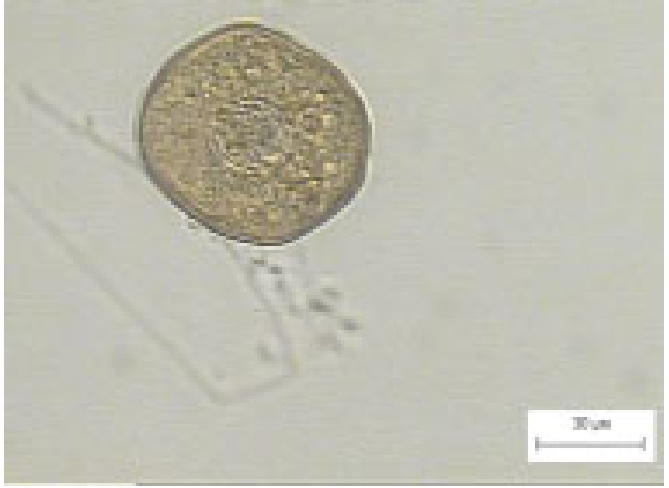

d)

FIGURA 5.43- Morfologias observadas próximo a câmara 3. As estruturas apresentadas são semelhantes a: a) com aumento de 125x e barra com $50 \mu \mathrm{m}$, rotífero semelhante a Epiphanes; com aumento de 250x e barra com $30 \mu \mathrm{m}$ b) protozoário rizópode semelhante a Amoeba; c) protozoário ciliado semelhante a Paramecium; d) rizópode semelhante a Arcella.

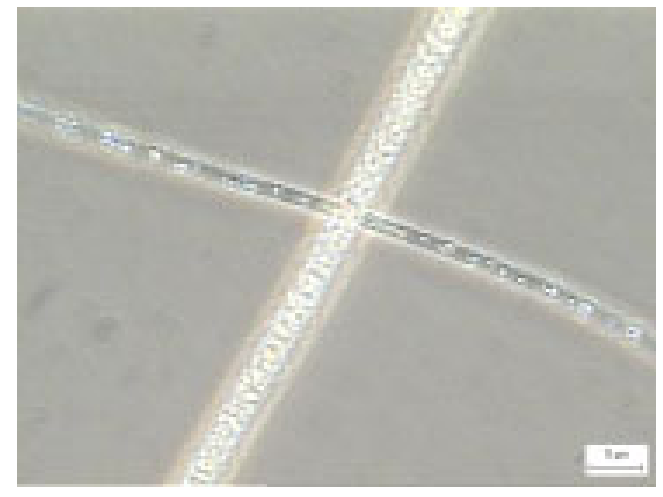

a)

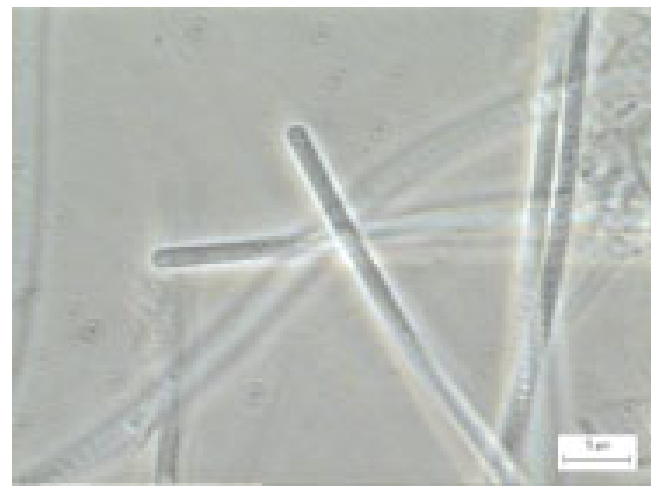

c)

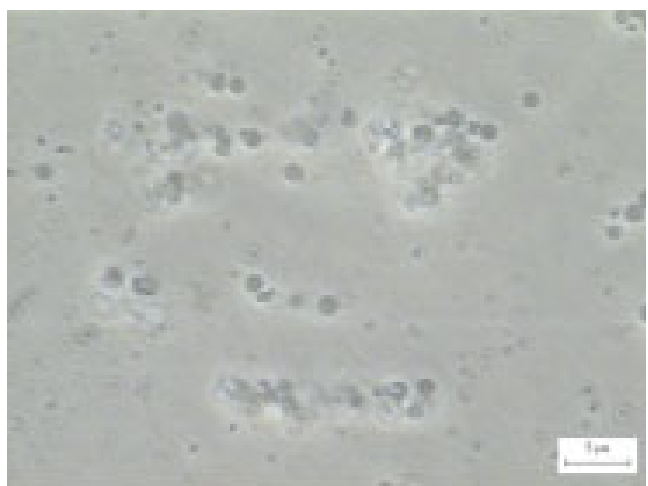

b)

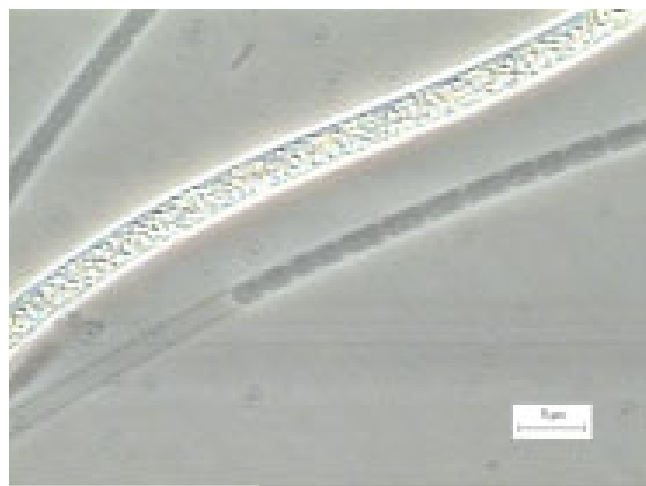

d) 


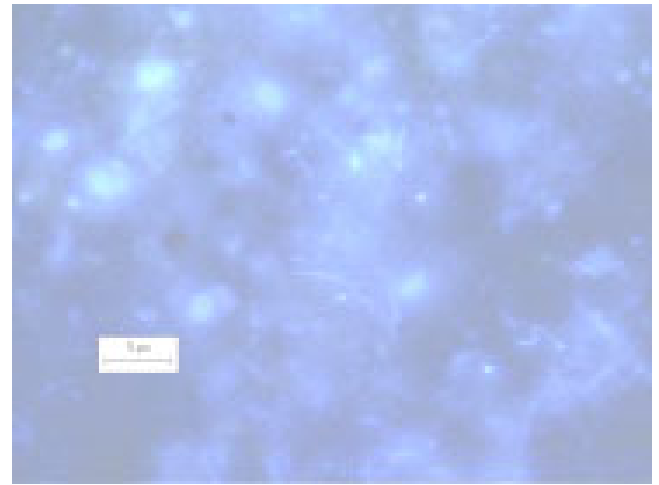

e)

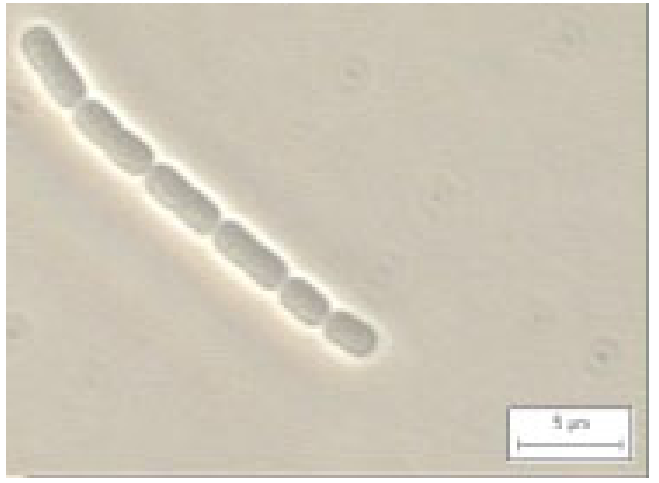

f)

FIGURA 5.44 - Morfologias observadas próximo a câmara 3. As estruturas apresentadas são semelhantes a: a) com aumento de 1000x e barra com $5 \mu \mathrm{m}$, Thiotrix e Beggiatoa; com aumento de 1250x e barra com $5 \mu \mathrm{m}$ b) cocos semelhantes a Nitrosococcus; c) Beggiatoa; d) Spherotilus com bainha e Beggiatoa; e) bacilos fluorescentes; f) Spherotilus.

Dentre as morfologias encontradas nessas amostras estão as seguintes classes: Nematoda (Figura 5.42a), como os nematóides; Ciliata (Figura 5.42b,c e Figura 5.43c) e Rotífera (Figura 5.42d e, Figura 5.43a), como os rotíferos.

Pertencente ao filo Protozoa, foram encontrados da classe Sarcodina, microrganismos como amebas (Figura 5.43b) e tecamebas (Figura 5.43d).

A ocorrência da nitrificação no local em que as espumas foram retiradas sugerem que as morfologias, apresentadas na Figura 5.44b sejam semelhantes às de bactérias nitrificantes.

A existência de sítios microaerófilos próximo a zona de aeração justifica a ocorrência das morfologias semelhantes a Spherotilus e Beggiatoa, apresentadas na Figura 5.44d. Da mesma forma, também foram observadas morfologias de bacilus fluorescentes (Figura 5.44e), o que indica a ocorrência de sítios anaeróbios próximo à câmara 3 do RMRLF. 


\section{Conclusões}

O trabalho realizado, utilizando sistema composto por reatores de leito fixo, reator radial misto seguido de reator anóxico horizontal para tratamento de esgoto sanitário, permite concluir que:

- O sistema apresentou bom desempenho na remoção de DQO e redução de SST. A eficiência na remoção de DQO, na primeira condição, com TDH de 6,3 e 3,2 h no RMRLF e RAHLFa, respectivamente, apresentou valor médio final de $81 \%$, com concentração efluente do sistema igual a $86 \pm 22$ mg. $I^{1}$. A eficiência média de redução de SSV no sistema foi de $62 \%$, apresentando valor médio de $19 \pm 22 \mathrm{mg} . I^{1}$ no efluente.

- Com a operação do sistema na segunda condição, com TDH de $18 \mathrm{~h}$ para o RMRLF e de $7 \mathrm{~h}$ para o RAHLFa, o sistema apresentou eficiência de remoção igual a $88 \%$ para DQO e redução de $86 \%$ para SSV, sendo os valores das frações no efluente iguais a $41 \pm 16 \mathrm{mg} \cdot /^{1}$ de $\mathrm{DQO}$ e de $8 \pm 7$ mg. $I^{1}$ de SSV. A DQO remanescente no efluente do sistema foi considerada como de difícil biodegradação. Os SSF no efluente do sistema apresentaram valores muito baixos, próximos ao limite inferior de detecção do método analítico utilizado.

- O RMRLF foi capaz de operar durante 123 dias sem apresentar sinais de produção de lodo em excesso ou de colmatação do seu leito.

- As espumas de poliuretano apresentaram-se como suporte adequado para imobilização da biomassa anaeróbia e aeróbia. A segunda câmara do RMRLF recebeu inóculo de UASB tratando efluente de abatedouro de 
aves e a quarta câmara não foi inoculada por ser predominantemente aeróbia. O RMRLF apresentou rápida partida, provavelmente devido às características do reator e do inóculo utilizado. O equilíbrio dinâmico na remoção de DQO foi obtido após 5 dias de operação, período este inferior ao de partida da maioria dos reatores anaeróbios ou mistos relatados na literatura.

- A baixa aeração da câmara 3 no início da operação permitiu o grande desenvolvimento de microrganismos microaerófilos, provocando um bulking de microrganismos filamentosos nesta câmara. A ocorrência deste fenômeno causou grande aumento nos valores de DQO, que atingiu aproximadamente $2200 \mathrm{mg} . I^{1}$ e aumento significativo no valor de sólidos sedimentáveis, chegando a $125 \mathrm{~m} / .^{1}$.

- A câmara 3, sem espuma de poliuretano e, conseqüentemente, com pouca biomassa, favoreceu a transferência de oxigênio no meio líquido, obtendo concentração média de OD igual a 5,4 mg. $I^{1}$.

- O RMRLF apresentou excelentes resultados na remoção de N-NTK e Namon. A eficiência de remoção do $\mathrm{N}$-amon foi de $99 \%$, obtendo-se valor efluente médio abaixo do detectável.

- Além da boa remoção de $\mathrm{N}$-amon, as condições operacionais favoreceram o processo de nitrificação/desnitrificação simultânea no RMRLF. Esse processo foi responsável pela desnitrificação parcial do $\mathrm{N}^{-\mathrm{NO}_{3}}{ }^{-}$, que atingiu remoção máxima de $70 \%$, aproximadamente. O principal motivo da remoção de nitrato não ter se mantido constante no RMRLF foi a flutuação nos valores de OD, que atingiu concentrações elevadas, inibidoras da desnitrificação.

- O RMRLF apresentou boa performance no tratamento e remoção de nitrogênio de esgoto sanitário. Entretanto, ficou claro que o fator limitante para redução do TDH foi a nitrificação, que permitiu a vazão máxima de $2,5 \mathrm{l} \cdot \mathrm{h}^{-1}$. 
- A solução alcalina fornecida ao reator prejudicou as análises de sólidos totais e dissolvidos. A perda de parte da massa devido à calcinação das amostras não foi devido à volatilização de matéria orgânica, como é pressuposto para as análises de SVT em condições normais, mas devido, provavelmente, à conversão do bicarbonato de sódio à $\mathrm{Na}_{2} \mathrm{O}$ em temperatura próxima a $500^{\circ} \mathrm{C}$.

- A baixa eficiência apresentada pelo reator desnitrificante deve-se, provavelmente, aos seguintes motivos: baixa concentração de biomassa presente no início da operação desta unidade; baixa concentração de uma fonte de carbono no início de sua operação e baixa taxa de crescimento dos microrganismos deste reator.

- O N-NTK afluente ao RAHLFa estava na forma de N-org e assim permaneceu ao longo da operação do reator. As condições ambientais e operacionais não permitiram a formação de $\mathrm{N}$-amon pela redução do $\mathrm{N}$ $\mathrm{NO}_{3}{ }^{-}$

- O sistema atingiu eficiência na remoção de coliformes fecais de 95\%. Esta eficiência não garante boa qualidade ao efluente, o qual apresentou concentração final de aproximadamente $1000 \mathrm{NMP} .100 \mathrm{~m} /{ }^{1}$ de coliformes fecais. Entretanto, o CONAMA $n^{\circ} 20$ exige valor máximo de 1000 NMP. $100 \mathrm{~m} /^{1}$ para os rios de classe 2, 3 e 4. Portanto, o efluente do reator pode ser lançado em corpos receptores, desde que a vazão média do rio seja igual ou superior à utilizada no sistema.

- O sistema é de fácil operação e controle simples, quando são utilizadas bombas de dimensões adequadas para as vazões pretendidas. 


\section{Sugestões}

De acordo com os resultados obtidos durante o desenvolvimento e operação do sistema RMRLF seguido de RAHLFa, são feitas as seguintes sugestões para pesquisas vindouras:

- Otimização do sistema RMRLF seguido de RAHLFa, enfocando as variáveis operacionais com objetivo de possbilitar menores TDH.

- Avaliação do processo de nitrificação/desnitrificação simultânea, para confirmar sua ocorrência no RMRLF e verificar se sua origem é física ou biológica.

- Avaliação do sistema misto de leito fixo na remoção biológica de fósforo.

- Desenvolver estudo hidrodinâmico no RMRLF.

- Modelagem matemática da cinética microbiana de degradação de matéria orgânica e conversão do nitrogênio no RMRLF.

- Validação do modelo, através da simulação com dados do grupo de trabalho do Laboratório de processos biológicos do Departamento de Hidráulica e Saneamento - EESC-USP.

- Operação do sistema por longo período de tempo para verificar os efeitos da acumulação de lodo no sistema. 


\section{Referências bibliográficas}

AISSE, M.M.; LOBATO, M.B.; BONA, A.; GARBOSSA, L.H.P.; SOBRINHO, P.A. (2000). Avaliação do sistema reator UASB e filtro biológico aerado submerso para o tratamento de esgoto sanitário. In: CONGRESSO INTERAMERICANO DE INGENIERIA SANITARIA Y AMBIENTAL, 27, Porto Alegre, 2000. Anais. Porto Alegre, AIDIS. CD-ROM.

BARNES, D.; BLISS, P. J. (1983). Biological control nitrogen in wastewater treatment. E. \& F. N. Spon, Cambridge, Great Britain.

BERNARDES, R. S.; KLAPWIJK, A. (1996). Biological nutrient removal in a sequencing batch reactor treating domestic wastewater. Water Science and Technology, v.33, n.3, p.29-38.

BISHOP, P.L.; YU, T. (1999). A microeletrode study of redox potential change in biofilms. Water Science and Technology, v.39, n.7, p.179-185.

BRASIL. Leis, etc. (1986). Resolução n. 20 de 18 de junho de 1986. Estabelecimento de classificação das águas doces, salobras e salinas do Território Nacional do Desenvolvimento Urbano e Meio ambiente. Conselho Nacional de Meio Ambiente. Diário Oficial da União, Brasília, DF, 30 julho. Seção I, p.11356-60.

CALLADO, N.H.; FORESTI, E. (2000). Tratamento de esgoto doméstico com remoção de nitrogênio e fósforo em reatores seqüenciais em batelada. In: CONGRESSO INTERAMERICANO DE INGENIERIA SANITARIA Y AMBIENTAL, 27, Porto Alegre, 2000. Anais. Porto Alegre, AIDIS. CD-ROM.

CALLADO, N.H. (2001). Reatores seqüenciais em batelada em sistema anaeróbio / aeróbio tratando esgoto sanitário sintético e com a remoção de nutrientes. 227p. Tese (Doutorado) - Escola de Engenharia de São Carlos, Universidade de São Paulo. 
CASTILLO, A.; CECCHF, F.; ALVAREZ, J.M. (1997). A combined anaerobic aerobic system to treat domestic sewage in coastal areas. Water Research, v.31, n.12, p.3057-63.

DILALLO, R.; ALBERTON, O. E. (1961). Volatile Acids by Direct Tritation. Journal Water Pollution Control Federation, v.33, p.356-65.

DINÇER, A.R.; KARGI, F. (2000). Cinética dos processos sequenciais de nitrificação e desnitrificação. Enzyme and Microbial Technology, v.27, p.37-42.

FAZOLO, A.; FORESTI, E.; ZAIAT, M. (2002). Estimativa dos parâmetros cinéticos e de transferência de massa em um reator aeróbio de leito fixo utilizado no póstratamento de efluente anaeróbio. In: SEMINÁRIO DO PROJETO TEMÁTICO, 1, São Carlos, 2002. Anais. São Paulo, EESC-USP. p.232-41.

FORD, D. L.; CHURCHWELL, R. L.; KACHTICK, J. W. (1980). Comprehensive analysis of nitrification of chemical processing wastewaters. Journal Water Pollution Control Federation, v.52, n.11, p.2726-46.

GÓRSKA, J.S.; CICHON, A.; MIKSCH, K. (1997). Nitrogen removal from wastewater with high ammonia nitrogen concentration via shorter nitrification and denitrification. Water Science and Technology, v.36, n.10, p.73-8.

HARPER, S.R.; POHLAND, F.G. (1986). Recent developments in hydrogen management during anaerobic biological wastewater treatment. Biotechnology and Bioengineering, v.28, p.585-602.

HELMER, C.; KUNST, S. (1998). Simultaneous nitrification/denitrification in aerobic biofilm system. Water Science and Technology, v.37, n.4-5, p.183-7.

HENZE, M.; HARREMOËS, P.; JANSEN, J.L.C.; ARVIN, E. (1997). Wastewater treatment, 2.ed. Germany, Springer.

HER, J.; HUANG, J. (1995). Influences of carbon source and $\mathrm{C} / \mathrm{N}$ ratio on nitrate/nitrite denitrification and carbon breakthrough. Bioresource Technology, v.54, p.45-51.

HOSAKA, Y.; MINAMI, T.; NASUNO, S. (1991). Fluidized-bed biological nitrogen removal. Water Environment \& Technology, p.48-51.

ISAACS, S.H.; HENZE, M. (1995). Controlled carbon source addition to an alternating nitrification-denitrification wastewater treatment process including biological P removal. Water Research, v.29, n.1, p.77-89.

JETTEN, M.S.M.; STROUS, M.; VAN DE PAS-SCHOONEN, K.T.; SCHALK, J.; VAN DONGEN, G.J.M.; VAN DE GRAAF, A.A.; LOGEMANN, S.; MUYZER, G.; 
VAN LOOSDRECHT, M.C.M.; KUENEN, J.G. (1999). The anaerobic oxidation of ammonium. FEMS Microbiology, v.22, p.421-37.

JENKINS, D; RICHARD, M.G.; DAIGGER, G.T. (1993). Manual on the causes and control of activated sludge bulking and foaming. 2.ed. Michigan, Lewis Publishers.

KUBA, T.; VAN LOOSDRECHT, M.C.M.; HEIJNEN, J.J. (1996). Phosphorus and nitrogen removal with minimal COD requirement by integration of denitrifying dephosphatation and nitrification in a two - sludge system. Water Research.

LEMMER, H.; ZAGLAUER, A.; METZNER, G. (1997). Denitrification in a methanolfed fixed-bed reactor. Part 1: Physico-chemical and biological characterization. Water Research, v.31, n.8, p.1897-902.

LIE, E.; WELANDER, T. (1994). Influence of dissolved oxygen and oxidationreduction potential on the denitrification rate of activated sludge. Water Science and Technology, v.30, n.6, p.91-100.

LOPES, D.D.; CAMPOS, J.R. (2000). Tratamento de esgoto sanitário em reatores compartimentados anaeróbio/aeróbio em série. In: OFICINA E SEMINÁRIO LATINO-AMERICANO DE DIGESTÃo ANAERÓBIA, 4, Recife, 2000. Anais. Pernambuco, v.2, p.203-6.

MACKERTH, F.J.H.; HERONS, J. \& TALLING, J.F. (1978). Water Analysis: Some Revised Methods for Limnologists. Freshwater Biological Association, n.36.

METCALF \& EDDY. INC. (1991). Wastewater Engineering - treatment disposal reuse. 3ed. New York, McGraw-Hill Book.

MÜNCH, E.V.; LANT, P.; KELLER, J. (1996). Simultaneous nitrification and denitrification in bench-scale sequencing batch reactors. Water Research, v.30, n.2, p.277-84.

ORGANIZAÇÃO MUNDIAL DA SAÚDE. (2002). Relatório anual da Organização Mundial da Saúde. http://www.who.int/en/ (2002).

POCHANA, K.; KELLER, J. (1999). Study of factors afecting simultaneous nitrification and denitrification (SND). Water Science and Technology, v.39, n.6, p.61-68.

RIPLEY, L.E.; BOYLE, W. C.; CONVERSE, J. C. (1986) Improved alkalimetric monitoring for anaerobic digestion of high-strength wastes. Journal Water Pollution Control Federation, v.58, n.5, p.406-11. 
RITTMANN, B.E.; REGAN, J.M.; STAHL, D.A. (1994). Nitrification as a source of soluble organic substrate in biological treatment. Water Science and Technology, v.30, n.6, p.1-8.

ROS, M. (1995). Denitrification kinetics in an activated sludge system. Water Science and Technology, v.32, n.9, p.323-330.

ROS, M.; VRTOVSEK, J. (1998). Wastewater treatment and nutrient removal in the combined reactor. Water Science and Technology, v.38, n.1, p.87-95.

SANTOS, S.G.; ONO, A.F.; FORESTI, E. (2002). Estudo comparativo entre três doadores de elétrons (metanol, etanol e metano) no processo de desnitrificação. In: : SEMINÁRIO DO PROJETO TEMÁTICO, 1, São Carlos, 2002. Anais. São Paulo, EESC-USP. p.245-54.

SASAKI, K.; YAMAMOTO, Y.; TSUMURA, K.; OUCHI, S.; MORI, Y. (1996). Development of 2-reactor intermittent-aeration activated sludge process for simultaneous removal of nitrogen and phosphorus. Water Science and Technology, v.34, n.1-2, p.111-8.

SEDLAK, R. I. (1991). Phosphorus and nitrogen removal from municipal wastewate: principles and practice. 2.ed. The soap and detergent association.

SOUSA, J.T.de. (1996). Pós-tratamento de efluente de reator anaeróbio de fluxo ascendente em reator aeróbio seqüencial em batelada de coluna de lodo anaeróbio para desnitrificação. 258p. Tese (Doutorado) - Escola de Engenharia de São Carlos, Universidade de São Paulo.

SPECTOR, M. (1998). Cocurrent biological nitrification and denitrification in wastewater treatment. Water Environment Research, v.70, n.7, p.1242-7.

SPEECE, R. E. (1996). Anaerobic biotechnology for industrial wastewaters. Tennessee, Archae Press.

STANDARD METHODS FOR THE EXAMINATION OF WATER AND WASTEWATER (1998). $19^{\text {th }}$ ed. American Public Health Association, American Water Works Association, Water Pollution Control Federation. Washington, D.C., USA.

STROUS, M.; VAN GERVEN, E.; ZHENG, P.; KUENEN, J.G.; JETTEN, M.S.M. (1997). Ammonium removal from concentrated waste streams with the anaerobic ammonium oxidation (ANAMMOX) process in different reactor configurations. Water Research, v.31, n.8, p.1955-62. 
SURAMPALLI, R. Y.;TYAGI, R. D.; SCHEIBLE, O. K.; HEIDMAN, J. A. (1997). Nitrification, denitrification and phosphorus removal in sequential batch reactors. Bioresource Technology, v.61, p.151-7.

TIEDJE, J.M. (1998). Ecology of denitrification and dissimilatory nitrate reduction to ammonium. In: ZEHINDER BIOLOGY OF ANAEROBIC MICROORGANISMS. John Willey \& Sons, 1998. Anais. New York, p.179-243.

TORRES, P; FORESTI, E. (2000). Domestic sewage treatment in a pilot system composed of UASB and SBR reactors. In: OFICINA E SEMINÁRIO LATINOAMERICANO DE DIGESTÃO ANAERÓBIA, 4, Recife, 2000. Anais. Pernambuco, v.l, p.368-75.

VAN HAANDEL, A.; MARAIS, G. (1999). O comportamento do sistema de lodo ativado. Campina Grande.

VAZOLLER, R.F.; GARCIA, M.A.R.; GARCIA JR, A.D.; CONCEIÇÃO NETO, J. (1992). Microbiologia de lodos ativados. São Paulo, CETESB.

VERSTRAETE, W.; PHILIPS, S. (1998). Nitrification-denitrification processes and technologies in new contexts. Environmental Pollution, v.102, p.717-26.

VIEIRA, L.G.T. (2000). Desenvolvimento de sistema misto (aeróbio/anaeróbio) de leito fixo para remoção de nitrogênio de esgoto sanitário pré-tratado em reator anaeróbio. 144p. Tese (Doutorado) - Escola de Engenharia de São Carlos, Universidade de São Paulo.

VIEIRA, L.G.T.; FAZOLO, A.; ZAIAT, M.; FORESTI, E. (2000). Desenvolvimento de reator aeróbio radial de leito fixo para remoção de nitrogênio de esgoto sanitário pré-tratado em reator anaeróbio. In.CHERNICHARO, C.A.L. (coordenador). Pós-tratamento de efluentes de reatores anaeróbios: coletânea de trabalhos técnicos. Belo Horizonte. P.135-42.

ZAIAT, M.; CABRAL, A. K. A.; FORESTI, E. (1994). Reator anaeróbio horizontal de leito fixo para tratamento de águas residuárias: concepção e avaliação preliminar de desempenho. Revista Brasileira de Engenharia - Caderno de Engenharia Química, v.11, n.2, p.33-42. 


\section{Apêndice I}

Tabelas com os resultados das análises obtidos durante a operação do sistema. 
TABELA I - Valores médios obtidos de vazão e temperatura do sistema

\begin{tabular}{|c|c|c|c|c|c|c|c|c|c|c|c|c|c|}
\hline \multirow[b]{2}{*}{ Data } & \multirow[b]{2}{*}{$\begin{array}{l}\text { Dias de } \\
\text { operação }\end{array}$} & \multirow[b]{2}{*}{$\begin{array}{c}\text { Hora da } \\
\text { coleta }\end{array}$} & \multirow{2}{*}{$\begin{array}{c}\text { Vazão } \\
\text { afluente } \\
L / h\end{array}$} & \multirow{2}{*}{$\begin{array}{c}\text { Vazão } \\
\text { Alcalin. } \\
\text { L/h }\end{array}$} & \multirow{2}{*}{$\begin{array}{c}\text { Vazão } \\
\text { Carbon. } \\
\text { L/h }\end{array}$} & \multicolumn{3}{|c|}{ Temperatura ambiente ${ }^{\circ} \mathrm{C}$} & \multirow[b]{2}{*}{$\begin{array}{l}\text { Situação } \\
\text { últ. 12h }\end{array}$} & \multicolumn{4}{|c|}{ Temperatura sistema ${ }^{\circ} \mathrm{C}$} \\
\hline & & & & & & Atual & Máxima & Mínima & & $\begin{array}{c}\text { Afluente } \\
\text { Bruto }\end{array}$ & Câmara 3 & $\begin{array}{l}\text { Efluente } \\
\text { RMRLF }\end{array}$ & $\begin{array}{l}\text { Efluente } \\
\text { RAHLFa }\end{array}$ \\
\hline \begin{tabular}{|l|}
$23-a b r-02$ \\
\end{tabular} & 5 & $14: 00$ & 5,1 & & & 29,0 & 30,0 & 22,0 & Sol & 28,0 & 25,0 & 25,0 & 26,5 \\
\hline 25-abr-02 & 7 & $7: 00$ & 5,8 & & & 20,0 & 30,0 & 20,0 & Sol & 22,0 & 24,0 & 24,0 & 22,0 \\
\hline 30 -abr-02 & 12 & 7:00 & 6,9 & & & 22,0 & 29,0 & 22,0 & Sol & 23,5 & 24,5 & 25,0 & 23,5 \\
\hline 2-mai-02 & 14 & 7:00 & 5,5 & & & 21,0 & 29,0 & 29,0 & Sol & 22,0 & 24,0 & 24,0 & 22,0 \\
\hline 6-mai-02 & 18 & 7:00 & 6,6 & & & 21,0 & 27,0 & 19,0 & Sol & 22,0 & 23,5 & 23,5 & 22,0 \\
\hline 8-mai-02 & 20 & 7:00 & 5,8 & & & 20,0 & 26,0 & 20,0 & Sol & 21,5 & 23,5 & 23,5 & 22,0 \\
\hline 10-mai-02 & 22 & 7:00 & 6,3 & & & 19,0 & 27,0 & 19,0 & Sol & 20,0 & 22,0 & 22,0 & 20,0 \\
\hline 13-mai-02 & 25 & 7:00 & 6,3 & & & 20,0 & 28,0 & 19,0 & Sol & 21,5 & 23,0 & 23,0 & 21,0 \\
\hline 15-mai-02 & 27 & 7:00 & 5,8 & & & 19,0 & 27,0 & 19,0 & Sol & 21,5 & 23,0 & 22,5 & 21,0 \\
\hline 17-mai-02 & 29 & 7:00 & 6,6 & & & 19,0 & 27,0 & 18,0 & Nublado & 21,0 & 21,5 & 21,5 & 20,0 \\
\hline 20-mai-02 & 32 & 7:00 & 4,8 & & & 18,0 & 28,0 & 18,0 & Nublado & 19,5 & 19,5 & 19,5 & 19,0 \\
\hline 22-mai-02 & 34 & 7:00 & 6,3 & & & 18,0 & 23,0 & 17,0 & Nublado & 19,0 & 19,5 & 19,5 & 19,0 \\
\hline 24-mai-02 & 36 & 7:00 & 6,9 & & & 15,0 & 22,0 & 15,0 & Sol & 17,0 & 18,0 & 18,0 & 16,5 \\
\hline 27-mai-02 & 39 & 7:00 & 6,9 & & & 14,0 & 22,0 & 14,0 & Sol & 17,5 & 17,0 & 17,0 & 16,0 \\
\hline 29-mai-02 & 41 & 7:00 & 5,4 & & & 15,5 & 22,0 & 15,5 & Sol & 17,0 & 17,0 & 17,5 & 16,0 \\
\hline 3-jun-02 & 46 & 7:00 & 4,5 & & & 17,0 & 26,0 & 16,0 & Sol & 19,5 & 20,0 & 19,5 & 19,0 \\
\hline 12-jun-02 & 55 & 8:00 & 0,5 & & & 20,0 & 26,0 & 19,0 & Sol & 22,0 & 21,0 & 21,0 & 20,0 \\
\hline 14-jun-02 & 57 & 7:30 & 3,0 & 0,7 & & 18,0 & 27,0 & 17,0 & Sol & 19,0 & 20,5 & 19,5 & 19,5 \\
\hline 17-jun-02 & 60 & 7:00 & 4,1 & 0,7 & & 17,0 & 26,0 & 17,0 & Sol & 19,0 & 20,0 & 19,0 & 19,0 \\
\hline 19-jun-02 & 62 & $7: 00$ & 2,3 & 0,7 & & 16,0 & 25,0 & 16,0 & Sol & 19,0 & 19,5 & 19,0 & 19,0 \\
\hline 21-jun-02 & 64 & 7:00 & 2,3 & 0,8 & & 15,0 & 23,0 & 15,0 & Sol & 17,5 & 18,5 & 18,0 & 17,5 \\
\hline 24-jun-02 & 67 & 7:00 & 2,8 & 0,8 & & 16,5 & 22,0 & 16,5 & Sol & 19,0 & 19,0 & 19,0 & 18,5 \\
\hline 26-jun-02 & 69 & 7:00 & 2,2 & 0,8 & & 18,0 & 24,0 & 16,0 & Sol & 20,0 & 19,0 & 19,0 & 18,0 \\
\hline 28-jun-02 & 71 & 7:00 & 1,5 & 0,8 & & 18,0 & 20,0 & 16,0 & Sol & 20,0 & 20,5 & 20,0 & 20,5 \\
\hline 1-jul-02 & 74 & 7:00 & 3,7 & 0,6 & & 17,0 & 26,0 & 15,0 & Sol & 17,5 & 20,0 & 20,0 & 17,0 \\
\hline 3-jul-02 & 76 & $8: 00$ & 2,0 & 0,7 & & 18,0 & 26,0 & 16,0 & Sol & 20,0 & 20,5 & 20,0 & 19,5 \\
\hline 5-jul-02 & 78 & $7: 00$ & 3,8 & 0,7 & & 17,0 & 25,0 & 17,0 & Sol & 18,0 & 20,5 & 20,0 & 18,5 \\
\hline 10-jul-02 & 83 & 7:00 & 3,6 & 0,7 & 0,8 & 11,0 & 18,0 & 9,0 & Sol & 12,5 & 14,5 & 14,0 & 12,5 \\
\hline 12-jul-02 & 85 & $6: 30$ & 3,8 & 0,6 & 0,7 & 16,0 & 21,0 & 11,0 & Sol & 16,7 & 17,0 & 16,9 & 17,0 \\
\hline 15-jul-02 & 88 & $7: 00$ & 6,0 & 0,6 & 0,7 & 12,0 & 21,0 & 12,0 & Sol & 15,0 & 16,6 & 15,6 & 14,0 \\
\hline 19-jul-02 & 92 & $7: 00$ & 2,9 & 0,7 & 0,0 & 15,0 & 22,0 & 12,0 & Sol & 16,3 & 17,3 & 17,3 & 16,3 \\
\hline 22-jul-02 & 95 & $7: 00$ & 1,7 & 0,7 & 0,3 & 17,0 & 23,0 & 16,0 & Nublado & 17,9 & 18,4 & 18,3 & 17,3 \\
\hline 24-jul-02 & 97 & $8: 00$ & 1,8 & 0,8 & 0,3 & 15,0 & 22,0 & 15,0 & Sol & 16,3 & 17,7 & 17,6 & 16,3 \\
\hline 26-jul-02 & 99 & $7: 00$ & 1,6 & 0,5 & 0,2 & 15,0 & 25,0 & 14,0 & Sol & 18,0 & 19,2 & 19,1 & 17,0 \\
\hline 1-ago-02 & 105 & $7: 00$ & 1,6 & 0,5 & 0,2 & 19,0 & 27,0 & 15,0 & Chuva & 19,0 & 20,5 & 20,5 & 19,5 \\
\hline 5-ago-02 & 109 & 7:00 & 2,0 & 0,5 & 0,2 & 17,0 & 24,0 & 15,0 & Chuva & 19,4 & 19,7 & 19,5 & 18,3 \\
\hline 7-ago-02 & 111 & $8: 00$ & 2,2 & 0,5 & 0,2 & 18,0 & 26,0 & 17,0 & Sol & 19,0 & 20,0 & 20,0 & 19,0 \\
\hline 9-ago-02 & 113 & $7: 30$ & 2,2 & 0,5 & 0,2 & 21,0 & 28,0 & 18,0 & Sol & 22,0 & 23,1 & 23,0 & 22,0 \\
\hline 12-ago-02 & 116 & 7:00 & 2,1 & 0,5 & 0,2 & 17,0 & 27,0 & 16,0 & Sol & 18,5 & 21,2 & 21,0 & 18,3 \\
\hline 14-ago-02 & 118 & 7:30 & 2,2 & 0,5 & 0,2 & 19,0 & 26,0 & 19,0 & Sol & 20,0 & 21,5 & 21,7 & 20,0 \\
\hline 19-ago-02 & 123 & $7: 30$ & 2,2 & 0,5 & 0,2 & 19,0 & 27,0 & 18,0 & Sol & 22,0 & 21,4 & 21,4 & 20,0 \\
\hline
\end{tabular}


TABELA II - Valores médios obtidos nas análises de DQO e DQOf do sistema e da solução alcalina

\begin{tabular}{|c|c|c|c|c|c|c|c|c|c|c|c|c|}
\hline \multirow[b]{2}{*}{ Data } & \multirow{2}{*}{$\begin{array}{l}\text { Dias de } \\
\text { operação }\end{array}$} & \multirow[t]{2}{*}{ Hora } & \multicolumn{2}{|c|}{$\begin{array}{l}\text { Afluente } \\
\text { Bruto }\end{array}$} & \multicolumn{2}{|c|}{ Câmara 3} & \multicolumn{2}{|c|}{$\begin{array}{l}\text { Efluente } \\
\text { RMRLF }\end{array}$} & \multicolumn{2}{|c|}{$\begin{array}{l}\text { Efluente } \\
\text { RAHLFa }\end{array}$} & \multicolumn{2}{|c|}{ Alcalinização } \\
\hline & & & DQO & $\mathrm{DQO}_{\mathrm{f}(1,2 \mu \mathrm{m})}$ & DQO & $\mathrm{DQO}_{\mathrm{f}(1,2 \mu \mathrm{m})}$ & $\mathrm{DQO}$ & $\mathrm{DQO}_{\mathrm{f}(1,2 \mathrm{~m})}$ & DQO & $\mathrm{DQO}_{\mathrm{f}(1,2 \mu \mathrm{m})}$ & $\mathrm{DQO}$ & $\mathrm{DQO}_{\mathrm{f}(1,2 \mu \mathrm{m})}$ \\
\hline 23-abr-02 & 5 & $14: 00$ & 483,0 & & 182,0 & & 127,0 & & 80,5 & & & \\
\hline 25-abr-02 & 7 & $7: 00$ & 542,5 & 355,0 & 398,0 & 92,5 & 126,9 & 96,4 & 87,2 & 76,6 & & \\
\hline 30-abr-02 & 12 & $7: 00$ & 402,5 & 299,5 & 376,5 & 80,5 & 229,9 & 77,9 & 89,8 & 73,9 & & \\
\hline 2-mai-02 & 14 & $7: 00$ & 342,0 & 250,5 & 194,5 & 71,3 & 83,2 & 76,6 & 64,7 & 59,4 & & \\
\hline 6-mai-02 & 18 & $7: 00$ & 410,0 & 299,0 & 217,0 & 88,5 & 121,6 & 93,8 & 93,8 & 85,8 & & \\
\hline 8-mai-02 & 20 & $7: 00$ & 376,0 & 281,0 & 284,5 & 80,5 & 87,2 & 75,2 & 79,2 & 72,6 & & \\
\hline 10-mai-02 & 22 & $7: 00$ & 468,0 & 326,0 & 256,0 & 83,2 & 101,7 & 77,9 & 83,2 & 71,3 & & \\
\hline 13-mai-02 & 25 & $7: 00$ & 419,0 & 327,5 & 282,5 & 83,2 & 107,0 & 91,1 & 79,2 & 73,9 & & \\
\hline 15-mai-02 & 27 & $7: 00$ & 416,0 & 329,0 & 421,0 & 89,8 & 112,3 & 88,5 & 88,5 & 70,0 & & \\
\hline 17-mai-02 & 29 & $7: 00$ & 392,0 & 292,5 & 426,0 & 77,9 & 97,8 & 72,6 & 77,9 & 59,4 & & \\
\hline 20-mai-02 & 32 & $7: 00$ & 395,0 & 294,0 & 828,0 & 75,6 & 118,9 & 76,6 & 81,9 & 68,6 & & \\
\hline 22-mai-02 & 34 & $7: 00$ & 428,5 & 344,0 & 988,0 & 84,5 & 129,5 & 79,2 & 83,2 & 64,7 & & \\
\hline 24-mai-02 & 36 & $7: 00$ & 478,0 & 371,0 & 1855,0 & 68,6 & 108,4 & 71,3 & 87,3 & 62,0 & & \\
\hline 27-mai-02 & 39 & $7: 00$ & 529,5 & 297,5 & 2208,0 & 85,8 & 120,3 & 81,9 & 81,9 & 69,9 & & \\
\hline 29-mai-02 & 41 & $7: 00$ & 514,0 & 333,0 & 442,0 & 62,0 & 100,4 & 73,9 & 58,0 & 47,4 & & \\
\hline 3-jun-02 & 46 & $7: 00$ & 534,0 & 346,5 & 447,0 & 75,2 & 97,8 & 72,6 & 162,5 & 70,0 & & \\
\hline 12-jun-02 & 55 & $8: 00$ & 592,5 & 343,0 & 226,0 & 140,1 & & 145,4 & erro & 138,6 & & \\
\hline 14-jun-02 & 57 & $7: 30$ & 868,0 & 375,0 & 183,0 & 104,0 & 210,0 & 161,0 & 176,0 & 109,7 & & \\
\hline 17-jun-02 & 60 & $7: 00$ & 330,0 & 239,0 & 78,0 & 74,0 & 73,5 & 68,5 & 73,0 & 62,0 & & \\
\hline 19-jun-02 & 62 & $7: 00$ & 351,0 & 318,5 & 120,5 & 103,1 & 133,5 & 100,4 & 117,6 & 109,7 & 225,0 & 140,1 \\
\hline 21-jun-02 & 64 & $7: 00$ & 667,5 & 454,5 & 224,0 & 149,4 & 122,9 & 133,5 & 122,9 & 109,7 & 298,0 & 335,5 \\
\hline 24-jun-02 & 67 & $7: 00$ & 633,0 & 322,5 & 130,0 & 96,4 & 133,5 & 96,4 & 99,1 & 80,5 & 226,5 & 196,5 \\
\hline 26-jun-02 & 69 & $7: 00$ & 506,5 & 344,0 & 176,5 & 95,1 & 136,2 & 187,8 & 118,9 & 96,4 & 308,0 & 217,0 \\
\hline 28-jun-02 & 71 & $7: 00$ & 552,5 & 395,0 & 89,8 & 76,6 & 92,5 & 88,5 & 99,1 & 87,2 & 264,5 & 231,0 \\
\hline 1-jul-02 & 74 & $7: 00$ & 430,5 & 368,5 & 200,0 & 83,2 & 97,8 & 89,8 & 89,8 & 85,8 & 272,0 & 230,0 \\
\hline 3-jul-02 & 76 & $8: 00$ & 386,0 & 296,0 & 111,0 & 43,5 & 46,1 & 43,5 & 51,4 & 40,8 & 137,0 & 94,0 \\
\hline 5-jul-02 & 78 & $7: 00$ & 344,0 & 273,5 & 116,5 & 44,8 & 48,8 & 43,5 & 44,8 & 35,5 & 178,0 & 69,9 \\
\hline 10-jul-02 & 83 & $7: 00$ & 241,5 & 184,5 & 46,0 & 44,7 & 40,8 & 38,2 & 42,1 & 36,9 & 153,0 & 77,9 \\
\hline 12-jul-02 & 85 & $6: 30$ & 310,5 & 220,5 & 63,3 & 46,1 & 51,4 & 44,8 & 47,4 & 36,9 & 150,0 & 75,2 \\
\hline 15-jul-02 & 88 & $7: 00$ & 371,0 & 246,0 & 138,8 & 56,7 & 71,3 & 54,0 & 46,1 & 34,2 & 104,5 & 44,8 \\
\hline 19-jul-02 & 92 & $7: 00$ & 427,5 & 173,0 & 59,4 & 47,5 & 46,3 & 48,8 & 43,5 & 31,6 & 174,5 & 108,0 \\
\hline 22-jul-02 & 95 & $7: 00$ & 323,0 & 212,5 & 55,4 & 44,8 & 80,5 & 42,1 & 75,2 & 67,3 & 117,6 & 73,9 \\
\hline 24-jul-02 & 97 & 8:00 & 419,0 & 201,0 & 44,8 & 39,5 & 39,5 & 31,6 & 54,1 & 54,1 & 109,7 & 81,9 \\
\hline 26-jul-02 & 99 & $7: 00$ & 354,5 & 232,5 & 35,5 & 32,9 & 36,8 & 31,6 & 44,8 & 36,9 & 118,9 & 60,7 \\
\hline 1-ago-02 & 105 & $7: 00$ & 326,0 & 240,0 & 86,0 & 27,4 & 52,7 & 24,9 & 31,6 & 30,2 & 85,8 & 62,0 \\
\hline 5-ago-02 & 109 & $7: 00$ & 356,5 & 197,0 & 113,6 & 31,6 & 44,8 & 31,6 & 43,5 & 30,2 & 132,2 & 92,5 \\
\hline 7-ago-02 & 111 & $8: 00$ & 334,5 & 231,5 & 44,8 & 14,3 & 88,5 & 14,3 & 17,0 & 18,3 & 115,0 & 71,3 \\
\hline 9-ago-02 & 113 & $7: 30$ & 335,0 & 208,5 & 115,0 & 34,2 & 72,6 & 24,9 & 35,5 & 31,6 & 153,4 & 89,8 \\
\hline 12-ago-02 & 116 & $7: 00$ & 329,0 & 214,5 & 89,8 & 32,9 & 42,1 & 35,5 & 31,6 & 32,9 & 125,6 & 79,2 \\
\hline 14-ago-02 & 118 & $7: 30$ & 301,5 & 210,0 & 87,2 & 28,9 & 44,8 & 36,8 & 39,5 & 30,2 & 96,4 & 72,6 \\
\hline 19 -ago-02 & 123 & $7: 30$ & 375,5 & 191,5 & 105,7 & 27,6 & 35,5 & 19,6 & 35,5 & 23,6 & 104,4 & 69,9 \\
\hline
\end{tabular}


TABELA III - Valores médios obtidos nas análises de alcalinidade, AVT e pH para o sistema e solução alcalina

\begin{tabular}{|c|c|c|c|c|c|c|c|c|c|c|c|c|c|c|c|}
\hline \multirow[b]{2}{*}{ Data } & \multirow{2}{*}{$\begin{array}{c}\text { Dias de } \\
\text { operação }\end{array}$} & \multirow{2}{*}{ Hora } & \multicolumn{3}{|c|}{ Afluente Bruto } & \multicolumn{3}{|c|}{ Câmara 3} & \multicolumn{3}{|c|}{ Efluente RMRLF } & \multicolumn{3}{|c|}{ Efluente RAHLFa } & \multirow[t]{2}{*}{ Alcalinização } \\
\hline & & & $\mathrm{pH}$ & Alcalin. & AVT & $\mathrm{pH}$ & Alcalin. & AVT & $\mathrm{pH}$ & Alcalin. & AVT & $\mathrm{pH}$ & Alcalin. & AVT & \\
\hline $23-a b r-02$ & 5 & $14: 00$ & 6,8 & 182,3 & 118,7 & 7,4 & 196,0 & 62,2 & 7,4 & 196,0 & 41,5 & 7,9 & & & \\
\hline 25-abr-02 & 7 & $7: 00$ & 6,6 & 168,6 & 127,9 & 7,4 & 180,3 & 31,1 & 7,5 & 235,2 & 27,6 & 7,4 & 209,7 & 86,4 & \\
\hline 30-abr-02 & 12 & $7: 00$ & 7,4 & 174,4 & 124,4 & 7,6 & 184,2 & 44,9 & 7,8 & 182,3 & 62,2 & 7,7 & 190,1 & 82,9 & \\
\hline 2-mai-02 & 14 & $7: 00$ & 7,6 & 158,8 & 86,4 & 7,8 & 172,5 & 34,6 & 7,7 & 252,8 & 41,5 & 7,6 & 184,2 & 41,5 & \\
\hline 6-mai-02 & 18 & $7: 00$ & 7,2 & 156,8 & 100,2 & 7,6 & 166,6 & 34,6 & 7,6 & 172,5 & 58,8 & 7,6 & 180,3 & 121,0 & \\
\hline 8-mai-02 & 20 & $7: 00$ & 7,6 & 180,1 & 89,2 & 7,8 & 193,6 & 50,2 & 7,9 & 203,3 & 33,5 & 7,8 & 197,5 & 39,0 & \\
\hline 10-mai-02 & 22 & $7: 00$ & 7,6 & 193,6 & 111,5 & 7,9 & 193,6 & 66,9 & 7,9 & 193,6 & 83,7 & 7,9 & 207,2 & 55,8 & \\
\hline 13-mai-02 & 25 & $7: 00$ & 7,6 & 178,1 & 94,8 & 7,7 & 203,3 & 33,5 & 7,8 & 193,6 & 44,6 & 7,7 & 214,9 & 39,0 & \\
\hline 15-mai-02 & 27 & $7: 00$ & 7,2 & 187,8 & 100,4 & 7,7 & 193,6 & 61,3 & 7,7 & 193,6 & 50,2 & 7,5 & 201,3 & 50,2 & \\
\hline 17-mai-02 & 29 & $7: 00$ & 7,2 & 193,6 & 117,1 & 7,7 & 193,6 & 44,6 & 7,7 & 195,5 & 39,0 & 7,6 & 211,0 & 50,2 & \\
\hline 20-mai-02 & 32 & $7: 00$ & 7,3 & 176,2 & 89,2 & 7,7 & 180,1 & 61,3 & 7,7 & 180,1 & 94,8 & 7,7 & 207,2 & 72,5 & \\
\hline 22-mai-02 & 34 & $7: 00$ & 7,4 & 185,9 & 111,5 & 7,8 & 191,7 & 55,8 & 7,8 & 189,7 & 44,6 & 7,8 & 191,7 & 33,5 & \\
\hline 24-mai-02 & 36 & $7: 00$ & 7,2 & 193,6 & 89,2 & 7,7 & 195,5 & 50,2 & 7,7 & 197,5 & 22,3 & 7,7 & 205,2 & 33,5 & \\
\hline 27-mai-02 & 39 & $7: 00$ & 7,5 & 160,7 & 61,3 & 7,9 & 172,3 & 61,3 & 7,9 & 172,3 & 50,2 & 7,9 & 195,5 & 44,6 & \\
\hline 29-mai-02 & 41 & $7: 00$ & 7,2 & 189,7 & 83,7 & 7,9 & 176,2 & 44,6 & 7,9 & 185,9 & 66,9 & 7,8 & 183,9 & 33,5 & \\
\hline 3-jun-02 & 46 & $7: 00$ & 7,6 & 192,0 & 61,3 & 8,0 & 192,0 & 22,3 & 8,0 & 178,6 & 27,9 & 7,8 & 204,5 & 27,9 & \\
\hline 12-jun-02 & 55 & $8: 00$ & 7,4 & 199,4 & 89,2 & 7,5 & 50,3 & 24,5 & 7,4 & 38,7 & 27,9 & 7,5 & 143,3 & 22,3 & \\
\hline 14-jun-02 & 57 & $7: 30$ & 7,5 & 218,8 & 89,2 & 8,4 & 336,9 & 50,2 & 8,3 & 338,8 & 39,0 & 7,4 & 87,1 & 22,3 & \\
\hline 17-jun-02 & 60 & $7: 00$ & 7,5 & 240,0 & 94,8 & 8,3 & 580,8 & 61,3 & 8,4 & 542,1 & 78,1 & 8,1 & 600,2 & 89,2 & \\
\hline 19-jun-02 & 62 & $7: 00$ & 7,7 & 329,1 & 60,5 & 8,4 & 604,0 & 20,2 & 8,5 & 619,5 & 20,2 & 8,3 & 592,4 & 17,3 & 1939,9 \\
\hline 21-jun-02 & 64 & $7: 00$ & 7,7 & 286,5 & 74,9 & 8,3 & 422,1 & 17,3 & 8,3 & 416,2 & 20,2 & 8,4 & 522,7 & 17,3 & 1999,9 \\
\hline 24-jun-02 & 67 & $7: 00$ & 7,6 & 205,2 & 60,5 & 8,3 & 455,0 & 17,3 & 8,3 & 464,6 & 20,2 & 8,2 & 524,7 & 20,2 & \\
\hline 26-jun-02 & 69 & $7: 00$ & 7,5 & 213,0 & 63,4 & 8,3 & 499,5 & 17,3 & 8,3 & 489,8 & 19,0 & 8,0 & 522,7 & 17,3 & 1022,2 \\
\hline 28-jun-02 & 71 & $7: 00$ & 7,5 & 226,5 & 72,0 & 8,4 & 727,9 & 20,2 & 8,6 & 695,0 & 20,2 & 8,1 & 557,6 & 28,8 & 1854,7 \\
\hline 1-jul-02 & 74 & $7: 00$ & 7,4 & 218,8 & 60,5 & 8,1 & 453,0 & 17,3 & 8,1 & 453,0 & 17,3 & 8,2 & 542,1 & 20,2 & 2032,8 \\
\hline 3-jul-02 & 76 & $8: 00$ & 7,3 & 211,0 & 60,5 & 8,3 & 619,5 & 20,2 & 8,3 & 606,0 & 23,0 & 8,1 & 484,0 & 23,0 & 2317,4 \\
\hline 5-jul-02 & 78 & $7: 00$ & 7,5 & 213,0 & 54,7 & 8,3 & 416,2 & 17,3 & 8,3 & 422,1 & 25,9 & 8,2 & 429,8 & 20,2 & 1649,5 \\
\hline 10-jul-02 & 83 & $7: 00$ & 7,6 & 152,9 & 34,6 & 8,1 & 265,2 & 17,3 & 8,1 & 247,8 & 14,4 & 7,8 & 247,8 & 11,5 & 1519,8 \\
\hline 12-jul-02 & 85 & $6: 30$ & 7,5 & 174,2 & 54,7 & 8,2 & 425,9 & 28,8 & 8,2 & 445,3 & 20,2 & 8,0 & 358,2 & 23,0 & 2133,5 \\
\hline 15-jul-02 & 88 & $7: 00$ & 7,4 & 164,6 & 40,3 & 8,0 & 315,6 & 20,2 & 8,0 & 315,6 & 20,2 & 8,0 & 362,0 & 14,4 & 1215,8 \\
\hline 19-jul-02 & 92 & $7: 00$ & 7,5 & 203,3 & 54,7 & 8,4 & 598,2 & 25,9 & 8,3 & 586,6 & 23,0 & 8,1 & 536,3 & 17,3 & 1597,2 \\
\hline 22-jul-02 & 95 & $7: 00$ & 7,5 & 209,1 & 46,1 & 8,6 & 927,3 & 31,7 & 8,5 & 952,5 & 28,8 & 8,2 & 870,8 & 23,0 & 1260,3 \\
\hline 24-jul-02 & 97 & $8: 00$ & 7,2 & 200,7 & 56,1 & 8,5 & 665,1 & 29,7 & 8,4 & 677,7 & 26,4 & 8,2 & 774,0 & 26,4 & 1381,5 \\
\hline 26-jul-02 & 99 & $7: 00$ & 7,4 & 213,3 & 46,2 & 8,5 & 549,0 & 23,1 & 8,5 & 544,5 & 26,4 & 8,4 & 670,5 & 29,7 & 1507,5 \\
\hline 1-ago-02 & 105 & $7: 00$ & 7,2 & 215,1 & 74,5 & 8,5 & 367,2 & 33,1 & 8,5 & 233,1 & 13,8 & 8,2 & 441,0 & 30,4 & 724,5 \\
\hline 5-ago-02 & 109 & $7: 00$ & 7,1 & 183,6 & 46,9 & 8,2 & 331,2 & 16,6 & 8,3 & 342,0 & 16,6 & 8,3 & 536,4 & 16,6 & 1088,1 \\
\hline 7-ago-02 & 111 & $8: 00$ & 7,1 & 203,4 & 52,4 & 7,9 & 227,7 & 13,8 & 8,1 & 232,2 & 19,3 & 8,0 & 373,5 & 13,8 & 983,7 \\
\hline 9 -ago-02 & 113 & $7: 30$ & 7,1 & 218,7 & 44,2 & 8,4 & 964,8 & 22,1 & 8,5 & 850,5 & 16,6 & 7,9 & 268,2 & 13,8 & 1092,6 \\
\hline 12-ago-02 & 116 & $7: 00$ & 7,1 & 221,4 & 35,9 & 8,2 & 211,5 & 13,8 & 8,4 & 194,4 & 16,6 & 8,0 & 225,0 & 16,6 & 1128,6 \\
\hline 14-ago-02 & 118 & $7: 30$ & 7,3 & 232,2 & 33,1 & 8,0 & 275,4 & 22,1 & 8,2 & 252,0 & 16,6 & 7,7 & 285,3 & 35,9 & 1374,3 \\
\hline 19-ago-02 & 123 & $7: 30$ & 7,1 & 187,2 & 33,1 & 8,2 & 231,3 & 16,6 & 8,3 & 214,2 & 16,6 & 8,3 & 273,6 & 13,8 & 965,7 \\
\hline
\end{tabular}


TABELA IV - Valores médios obtidos nas análises de sólidos do afluente bruto do sistema

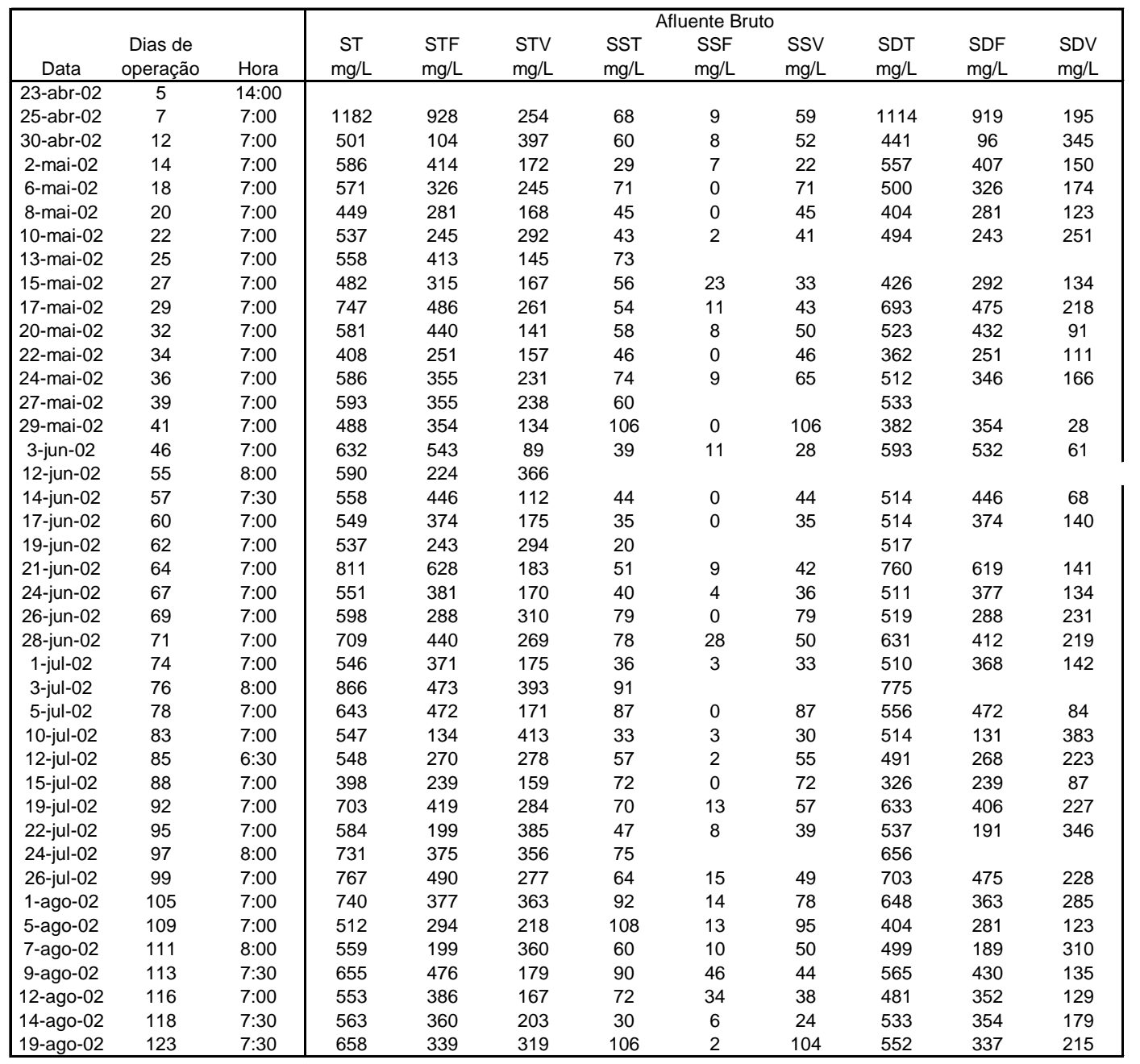


TABELA V - Valores médios obtidos nas análises de sólidos na câmara 3 do RMRLF

\begin{tabular}{|c|c|c|c|c|c|c|c|c|c|c|c|c|}
\hline \multirow[b]{2}{*}{ Data } & \multirow[b]{2}{*}{$\begin{array}{c}\text { Dias de } \\
\text { operação }\end{array}$} & \multirow[b]{2}{*}{ Hora } & \multicolumn{10}{|c|}{ Câmara 3} \\
\hline & & & $\begin{array}{c}\mathrm{ST} \\
\mathrm{mg} / \mathrm{L}\end{array}$ & $\begin{array}{l}\mathrm{STF} \\
\mathrm{mg} / \mathrm{L}\end{array}$ & $\begin{array}{l}\mathrm{STV} \\
\mathrm{mg} / \mathrm{L}\end{array}$ & $\begin{array}{l}\mathrm{SST} \\
\mathrm{mg} / \mathrm{L}\end{array}$ & $\begin{array}{l}\mathrm{SSF} \\
\mathrm{mg} / \mathrm{L}\end{array}$ & $\begin{array}{l}\mathrm{SSV} \\
\mathrm{mg} / \mathrm{L}\end{array}$ & $\begin{array}{l}\mathrm{SDT} \\
\mathrm{mg} / \mathrm{L}\end{array}$ & $\begin{array}{l}\mathrm{SDF} \\
\mathrm{mg} / \mathrm{L}\end{array}$ & $\begin{array}{l}\mathrm{SDV} \\
\mathrm{mg} / \mathrm{L}\end{array}$ & $\begin{array}{l}\text { Ssec } \\
\mathrm{mL} / \mathrm{L}\end{array}$ \\
\hline 23 -abr-02 & 5 & $14: 00$ & & & & & & & & & & \\
\hline 25-abr-02 & 7 & $7: 00$ & 1064 & 736 & 328 & 312 & 32 & 280 & 752 & 704 & 48 & \\
\hline 30 -abr-02 & 12 & 7:00 & 544 & 0 & 544 & 205 & 0 & 205 & 339 & 0 & 339 & \\
\hline 2-mai-02 & 14 & $7: 00$ & 507 & 445 & 62 & 37 & 8 & 29 & 470 & 437 & 33 & 12 \\
\hline 6-mai-02 & 18 & $7: 00$ & 569 & 269 & 300 & 71 & 4 & 67 & 498 & 265 & 233 & 22 \\
\hline 8-mai-02 & 20 & $7: 00$ & 519 & 317 & 202 & 69 & 0 & 69 & 450 & 317 & 133 & 19 \\
\hline 10-mai-02 & 22 & 7:00 & 520 & 267 & 253 & 47 & 0 & 47 & 473 & 267 & 206 & 14 \\
\hline 13-mai-02 & 25 & 7:00 & 608 & 405 & 203 & 78 & & & 530 & & & 11 \\
\hline 15-mai-02 & 27 & $7: 00$ & 586 & 361 & 225 & 230 & 47 & 183 & 356 & 314 & 42 & 44 \\
\hline 17-mai-02 & 29 & $7: 00$ & 751 & 462 & 289 & 149 & 23 & 126 & 602 & 439 & 163 & 90 \\
\hline 20-mai-02 & 32 & $7: 00$ & 802 & 510 & 292 & 310 & 53 & 257 & 492 & 457 & 35 & 40 \\
\hline 22-mai-02 & 34 & $7: 00$ & 646 & 376 & 270 & 186 & 10 & 176 & 460 & 366 & 94 & 66 \\
\hline 24-mai-02 & 36 & $7: 00$ & 803 & 369 & 434 & 383 & 50 & 333 & 420 & 319 & 101 & 100 \\
\hline 27-mai-02 & 39 & 7:00 & 789 & 441 & 348 & 262 & & & 527 & & & 125 \\
\hline 29-mai-02 & 41 & $7: 00$ & 640 & 354 & 286 & 222 & 0 & 222 & 418 & 354 & 64 & 65 \\
\hline 3-jun-02 & 46 & 7:00 & 871 & 632 & 239 & 96 & 18 & 78 & 775 & 614 & 161 & 9 \\
\hline 12-jun-02 & 55 & 8:00 & 695 & 413 & 282 & 26 & 8 & 18 & 669 & 405 & 264 & 0 \\
\hline 14-jun-02 & 57 & $7: 30$ & 851 & 739 & 112 & 40 & 0 & 40 & 811 & 739 & 72 & 0 \\
\hline 17-jun-02 & 60 & $7: 00$ & 1106 & 980 & 126 & 8 & 0 & 8 & 1098 & 980 & 118 & 0 \\
\hline 19-jun-02 & 62 & $7: 00$ & 1125 & 766 & 359 & 3 & & & 1122 & & & 0 \\
\hline 21-jun-02 & 64 & $7: 00$ & 1109 & 963 & 146 & 8 & 3 & 5 & 1101 & 960 & 141 & 0 \\
\hline 24-jun-02 & 67 & $7: 00$ & 1070 & 926 & 144 & 7 & 0 & 7 & 1063 & 926 & 137 & 0 \\
\hline 26-jun-02 & 69 & $7: 00$ & 1118 & 824 & 294 & 22 & 0 & 22 & 1096 & 824 & 272 & 0 \\
\hline 28-jun-02 & 71 & $7: 00$ & 1413 & 1199 & 214 & 34 & 14 & 20 & 1379 & 1185 & 194 & 0 \\
\hline 1-jul-02 & 74 & $7: 00$ & 979 & 801 & 178 & 8 & 1 & 7 & 971 & 800 & 171 & 0 \\
\hline 3-jul-02 & 76 & $8: 00$ & 1170 & 634 & 536 & 10 & 0 & 10 & 1160 & 634 & 526 & 0 \\
\hline 5-jul-02 & 78 & $7: 00$ & 1108 & 833 & 275 & 30 & 0 & 30 & 1078 & 833 & 245 & 0 \\
\hline 10-jul-02 & 83 & $7: 00$ & 647 & 419 & 228 & 11 & 2 & 9 & 636 & 417 & 219 & 0 \\
\hline 12-jul-02 & 85 & $6: 30$ & 721 & 587 & 134 & 6 & 1 & 5 & 715 & 586 & 129 & 0 \\
\hline 15-jul-02 & 88 & $7: 00$ & 671 & 463 & 208 & 34 & 0 & 34 & 637 & 463 & 174 & 20 \\
\hline 19-jul-02 & 92 & $7: 00$ & 1147 & 906 & 241 & 13 & 3 & 10 & 1134 & 903 & 231 & 0 \\
\hline 22-jul-02 & 95 & 7:00 & 1532 & 1241 & 291 & 25 & 0 & 25 & 1507 & 1241 & 266 & \\
\hline 24-jul-02 & 97 & $8: 00$ & 1253 & 1020 & 233 & 13 & & & 1240 & & & 0 \\
\hline 26-jul-02 & 99 & $7: 00$ & 1129 & 931 & 198 & 9 & 1 & 8 & 1120 & 930 & 190 & \\
\hline 1-ago-02 & 105 & 7:00 & 986 & 691 & 295 & 16 & 4 & 12 & 970 & 687 & 283 & \\
\hline 5-ago-02 & 109 & 7:00 & 1098 & 847 & 251 & 50 & 0 & 50 & 1048 & 847 & 201 & \\
\hline 7-ago-02 & 111 & $8: 00$ & 760 & 422 & 338 & 32 & 6 & 26 & 728 & 416 & 312 & \\
\hline 9-ago-02 & 113 & $7: 30$ & 1623 & 1389 & 234 & 42 & 10 & 32 & 1581 & 1379 & 202 & \\
\hline 12-ago-02 & 116 & $7: 00$ & 902 & 649 & 253 & 45 & 9 & 36 & 857 & 640 & 217 & \\
\hline 14-ago-02 & 118 & $7: 30$ & 842 & 695 & 147 & 22 & 5 & 17 & 820 & 690 & 130 & \\
\hline 19-ago-02 & 123 & $7: 30$ & 865 & 596 & 269 & 67 & 2 & 65 & 798 & 594 & 204 & \\
\hline
\end{tabular}


TABELA VI - Valores médios obtidos nas análises de sólidos no efluente do RMRLF

\begin{tabular}{|c|c|c|c|c|c|c|c|c|c|c|c|}
\hline \multirow[b]{2}{*}{ Data } & \multirow[b]{2}{*}{$\begin{array}{c}\text { Dias de } \\
\text { operação }\end{array}$} & \multirow[b]{2}{*}{ Hora } & \multicolumn{9}{|c|}{ Efluente RMRLF } \\
\hline & & & $\begin{array}{c}\mathrm{ST} \\
\mathrm{mg} / \mathrm{L}\end{array}$ & $\begin{array}{l}\mathrm{STF} \\
\mathrm{mg} / \mathrm{L}\end{array}$ & $\begin{array}{l}\mathrm{STV} \\
\mathrm{mg} / \mathrm{L}\end{array}$ & $\begin{array}{l}\mathrm{SST} \\
\mathrm{mg} / \mathrm{L}\end{array}$ & $\begin{array}{l}\mathrm{SSF} \\
\mathrm{mg} / \mathrm{L}\end{array}$ & $\begin{array}{l}\mathrm{SSV} \\
\mathrm{mg} / \mathrm{L}\end{array}$ & $\begin{array}{l}\mathrm{SDT} \\
\mathrm{mg} / \mathrm{L}\end{array}$ & $\begin{array}{l}\mathrm{SDF} \\
\mathrm{mg} / \mathrm{L}\end{array}$ & $\begin{array}{l}\mathrm{SDV} \\
\mathrm{mg} / \mathrm{L}\end{array}$ \\
\hline $23-a b r-02$ & 5 & $14: 00$ & & & & & & & & & \\
\hline 25-abr-02 & 7 & $7: 00$ & 823 & 702 & 121 & 14 & 1 & 13 & 809 & 701 & 108 \\
\hline 30-abr-02 & 12 & 7:00 & 517 & 347 & 170 & 73 & 0 & 73 & 444 & 347 & 97 \\
\hline 2-mai-02 & 14 & 7:00 & 543 & 456 & 87 & 8 & 4 & 4 & 535 & 452 & 83 \\
\hline 6-mai-02 & 18 & $7: 00$ & 451 & 355 & 96 & 53 & 0 & 53 & 398 & 355 & 43 \\
\hline 8-mai-02 & 20 & $7: 00$ & 388 & 313 & 75 & 11 & 0 & 11 & 377 & 313 & 64 \\
\hline 10-mai-02 & 22 & $7: 00$ & 362 & 281 & 81 & 22 & 5 & 17 & 340 & 276 & 64 \\
\hline 13-mai-02 & 25 & $7: 00$ & 617 & 379 & 238 & 34 & & & 583 & & \\
\hline 15-mai-02 & 27 & 7:00 & 459 & 324 & 135 & 26 & 17 & 9 & 433 & 307 & 126 \\
\hline 17-mai-02 & 29 & $7: 00$ & 539 & 447 & 92 & 14 & 11 & 3 & 525 & 436 & 89 \\
\hline 20-mai-02 & 32 & $7: 00$ & 632 & 522 & 110 & 13 & 2 & 11 & 619 & 520 & 99 \\
\hline 22-mai-02 & 34 & $7: 00$ & 375 & 282 & 93 & 24 & 0 & 24 & 351 & 282 & 69 \\
\hline 24-mai-02 & 36 & $7: 00$ & 409 & 334 & 75 & 56 & 3 & 53 & 353 & 331 & 22 \\
\hline 27-mai-02 & 39 & $7: 00$ & 585 & 505 & 80 & 26 & 4 & 22 & 559 & 501 & 58 \\
\hline 29-mai-02 & 41 & $7: 00$ & 445 & 370 & 75 & 0 & 0 & 0 & 445 & 370 & 75 \\
\hline 3-jun-02 & 46 & $7: 00$ & 660 & 620 & 40 & 6 & 6 & 0 & 654 & 614 & 40 \\
\hline 12-jun-02 & 55 & 8:00 & 643 & 551 & 92 & & & & & & \\
\hline 14-jun-02 & 57 & $7: 30$ & 931 & 740 & 191 & 38 & 0 & 38 & 893 & 740 & 153 \\
\hline 17-jun-02 & 60 & $7: 00$ & 1137 & 828 & 309 & 5 & 0 & 5 & 1132 & 828 & 304 \\
\hline 19-jun-02 & 62 & $7: 00$ & 1105 & 900 & 205 & 1 & & & 1104 & & \\
\hline 21-jun-02 & 64 & 7:00 & 1058 & 837 & 221 & 5 & 0 & 5 & 1053 & 837 & 216 \\
\hline 24-jun-02 & 67 & $7: 00$ & 1215 & 947 & 268 & 15 & 0 & 15 & 1200 & 947 & 253 \\
\hline 26-jun-02 & 69 & 7:00 & 1152 & 891 & 261 & 24 & 4 & 20 & 1128 & 887 & 241 \\
\hline 28-jun-02 & 71 & 7:00 & 1245 & 1087 & 158 & 36 & 18 & 18 & 1209 & 1069 & 140 \\
\hline 1-jul-02 & 74 & $7: 00$ & 932 & 699 & 233 & 6 & 0 & 6 & 926 & 699 & 227 \\
\hline 3-jul-02 & 76 & $8: 00$ & 1290 & 640 & 650 & 18 & & & 1272 & & \\
\hline 5-jul-02 & 78 & $7: 00$ & 977 & 769 & 208 & 28 & 0 & 28 & 949 & 769 & 180 \\
\hline 10-jul-02 & 83 & $7: 00$ & 738 & 400 & 338 & 7 & 0 & 7 & 731 & 400 & 331 \\
\hline 12-jul-02 & 85 & $6: 30$ & 878 & 592 & 286 & 17 & 0 & 17 & 861 & 592 & 269 \\
\hline 15-jul-02 & 88 & $7: 00$ & 552 & 444 & 108 & 27 & 0 & 27 & 525 & 444 & 81 \\
\hline 19-jul-02 & 92 & $7: 00$ & 1012 & 839 & 173 & 9 & 2 & 7 & 1003 & 837 & 166 \\
\hline 22-jul-02 & 95 & $7: 00$ & 1674 & 1193 & 481 & 27 & & & 1647 & & \\
\hline 24-jul-02 & 97 & $8: 00$ & 1169 & 1037 & 132 & 14 & & & 1155 & & \\
\hline 26-jul-02 & 99 & $7: 00$ & 1096 & 860 & 236 & 10 & 3 & 7 & 1086 & 857 & 229 \\
\hline 1 -ago-02 & 105 & $7: 00$ & 965 & 605 & 360 & 44 & 11 & 33 & 921 & 594 & 327 \\
\hline 5-ago-02 & 109 & $7: 00$ & 797 & 604 & 193 & 20 & 0 & 20 & 777 & 604 & 173 \\
\hline 7-ago-02 & 111 & $8: 00$ & 893 & 434 & 459 & 45 & 9 & 36 & 848 & 425 & 423 \\
\hline 9 -ago-02 & 113 & $7: 30$ & 1625 & 1334 & 291 & 67 & 35 & 32 & 1558 & 1299 & 259 \\
\hline 12-ago-02 & 116 & $7: 00$ & 859 & 639 & 220 & 21 & 14 & 7 & 838 & 625 & 213 \\
\hline 14-ago-02 & 118 & $7: 30$ & 958 & 704 & 254 & 8 & 0 & 8 & 950 & 704 & 246 \\
\hline -ago-02 & 123 & $7: 30$ & 954 & 541 & 413 & 6 & 0 & 6 & 948 & 541 & 407 \\
\hline
\end{tabular}


TABELA VII - Valores médios obtidos nas análises de sólidos no efluente do RAHLFa

\begin{tabular}{|c|c|c|c|c|c|c|c|c|c|c|c|}
\hline \multirow[b]{2}{*}{ Data } & \multirow[b]{2}{*}{$\begin{array}{c}\text { Dias de } \\
\text { operação }\end{array}$} & \multirow[b]{2}{*}{ Hora } & \multicolumn{9}{|c|}{ Efluente RAHLFa } \\
\hline & & & $\begin{array}{c}\mathrm{ST} \\
\mathrm{mg} / \mathrm{L}\end{array}$ & $\begin{array}{l}\mathrm{STF} \\
\mathrm{mg} / \mathrm{L}\end{array}$ & $\begin{array}{l}\mathrm{STV} \\
\mathrm{mg} / \mathrm{L}\end{array}$ & $\begin{array}{l}\mathrm{SST} \\
\mathrm{mg} / \mathrm{L}\end{array}$ & $\begin{array}{l}\mathrm{SSF} \\
\mathrm{mg} / \mathrm{L}\end{array}$ & $\begin{array}{l}\mathrm{SSV} \\
\mathrm{mg} / \mathrm{L}\end{array}$ & $\begin{array}{l}\mathrm{SDT} \\
\mathrm{mg} / \mathrm{L}\end{array}$ & $\begin{array}{l}\mathrm{SDF} \\
\mathrm{mg} / \mathrm{L}\end{array}$ & $\begin{array}{l}\mathrm{SDV} \\
\mathrm{mg} / \mathrm{L}\end{array}$ \\
\hline 23-abr-02 & 5 & 14:00 & & & & & & & & & \\
\hline 25-abr-02 & 7 & $7: 00$ & 725 & 599 & 126 & 7 & 1 & 6 & 718 & 598 & 120 \\
\hline 30-abr-02 & 12 & $7: 00$ & 444 & 328 & 116 & 59 & 0 & 59 & 385 & 328 & 57 \\
\hline 2-mai-02 & 14 & $7: 00$ & 582 & 476 & 106 & 0 & 0 & 0 & 582 & 476 & 106 \\
\hline 6-mai-02 & 18 & $7: 00$ & 506 & 287 & 219 & 39 & 0 & 39 & 467 & 287 & 180 \\
\hline 8-mai-02 & 20 & $7: 00$ & 405 & 176 & 229 & 12 & 0 & 12 & 393 & 176 & 217 \\
\hline 10-mai-02 & 22 & $7: 00$ & 397 & 296 & 101 & 9 & 0 & 9 & 388 & 296 & 92 \\
\hline 13-mai-02 & 25 & $7: 00$ & 549 & 474 & 75 & 7 & 4 & 3 & 542 & 470 & 72 \\
\hline 15-mai-02 & 27 & $7: 00$ & 399 & 336 & 63 & 32 & 32 & 0 & 367 & 304 & 63 \\
\hline 17-mai-02 & 29 & $7: 00$ & 452 & 395 & 57 & 5 & 2 & 3 & 447 & 393 & 54 \\
\hline 20-mai-02 & 32 & $7: 00$ & 712 & 551 & 161 & 39 & 9 & 30 & 673 & 542 & 131 \\
\hline 22-mai-02 & 34 & $7: 00$ & 359 & 301 & 58 & 6 & 0 & 6 & 353 & 301 & 52 \\
\hline 24-mai-02 & 36 & $7: 00$ & 429 & 320 & 109 & 58 & 9 & 49 & 371 & 311 & 60 \\
\hline 27-mai-02 & 39 & $7: 00$ & 643 & 389 & 254 & 8 & & & & & \\
\hline 29-mai-02 & 41 & $7: 00$ & 505 & 403 & 102 & 55 & 0 & 55 & 450 & 403 & 47 \\
\hline 3-jun-02 & 46 & $7: 00$ & 680 & 651 & 29 & 0 & 0 & 0 & 680 & 651 & 29 \\
\hline 12-jun-02 & 55 & $8: 00$ & 645 & 438 & 207 & & & & & & \\
\hline 14-jun-02 & 57 & $7: 30$ & 610 & 523 & 87 & 30 & 0 & 30 & 580 & 523 & 57 \\
\hline 17-jun-02 & 60 & $7: 00$ & 1149 & 1005 & 144 & 4 & 0 & 4 & 1145 & 1005 & 140 \\
\hline 19-jun-02 & 62 & $7: 00$ & 1039 & 765 & 274 & 0 & 0 & 0 & 1039 & 765 & 274 \\
\hline 21-jun-02 & 64 & $7: 00$ & 1171 & 975 & 196 & 4 & 2 & 2 & 1167 & 973 & 194 \\
\hline 24-jun-02 & 67 & $7: 00$ & 1128 & 979 & 149 & 7 & 0 & 7 & 1121 & 979 & 142 \\
\hline 26-jun-02 & 69 & $7: 00$ & 1172 & 824 & 348 & 15 & 0 & 15 & 1157 & 824 & 333 \\
\hline 28-jun-02 & 71 & $7: 00$ & 1122 & 937 & 185 & 32 & 18 & 14 & 1090 & 919 & 171 \\
\hline 1-jul-02 & 74 & 7:00 & 1194 & 894 & 300 & 9 & 0 & 9 & 1185 & 894 & 291 \\
\hline 3-jul-02 & 76 & $8: 00$ & 1088 & 563 & 525 & 20 & & & 1068 & & \\
\hline 5-jul-02 & 78 & $7: 00$ & 981 & 830 & 151 & 26 & 0 & 26 & 955 & 830 & 125 \\
\hline 10-jul-02 & 83 & $7: 00$ & 509 & 358 & 151 & 11 & 3 & 8 & 498 & 355 & 143 \\
\hline 12-jul-02 & 85 & $6: 30$ & 857 & 540 & 317 & 16 & 0 & 16 & 841 & 540 & 301 \\
\hline 15-jul-02 & 88 & 7:00 & 687 & 451 & 236 & 15 & 0 & 15 & 672 & 451 & 221 \\
\hline 19-jul-02 & 92 & 7:00 & 961 & 777 & 184 & 12 & 4 & 8 & 949 & 773 & 176 \\
\hline 22-jul-02 & 95 & 7:00 & 1145 & 785 & 360 & 22 & & & 1123 & & \\
\hline 24-jul-02 & 97 & $8: 00$ & 1221 & 1086 & 135 & 15 & & & 1206 & & \\
\hline 26-jul-02 & 99 & $7: 00$ & 1231 & 1027 & 204 & 12 & 4 & 8 & 1219 & 1023 & 196 \\
\hline 1-ago-02 & 105 & $7: 00$ & 1205 & 770 & 435 & 23 & 6 & 17 & 1182 & 764 & 418 \\
\hline 5-ago-02 & 109 & $7: 00$ & 1141 & 779 & 362 & 21 & & & 1120 & & \\
\hline 7-ago-02 & 111 & $8: 00$ & 749 & 534 & 215 & 6 & 1 & 5 & 743 & 533 & 210 \\
\hline 9-ago-02 & 113 & $7: 30$ & 917 & 644 & 273 & 31 & 27 & 4 & 886 & 617 & 269 \\
\hline 12-ago-02 & 116 & 7:00 & 1046 & 653 & 393 & 14 & 13 & 1 & 1032 & 640 & 392 \\
\hline 14-ago-02 & 118 & $7: 30$ & 990 & 686 & 304 & 4 & 1 & 3 & 986 & 685 & 301 \\
\hline 19-ago-02 & 123 & $7: 30$ & 835 & 590 & 245 & 17 & 0 & 17 & 818 & 590 & 228 \\
\hline
\end{tabular}


TABELA VIII - Valores médios obtidos nas análises de nitrogênio no afluente do sistema e a câmara 3 do RMRLF

\begin{tabular}{|c|c|c|c|c|c|c|c|c|c|c|c|c|}
\hline \multirow[t]{2}{*}{ Data } & \multirow{2}{*}{$\begin{array}{c}\text { Dias de } \\
\text { operação }\end{array}$} & \multirow[b]{2}{*}{ Hora } & \multicolumn{5}{|c|}{ Afluente Bruto } & \multicolumn{5}{|c|}{ Câmara 3} \\
\hline & & & $\mathrm{N}_{\text {total }}$ & $\mathrm{N}_{\text {amoniacal }}$ & $\mathrm{N}_{\text {org }}$ & Nitrito & Nitrato & $\mathrm{N}_{\text {total }}$ & $\mathrm{N}_{\text {amoniacal }}$ & $\mathrm{N}_{\text {org }}$ & Nitrito & Nitrato \\
\hline & & & $\mathrm{mgN} \mathrm{NH}_{4} / \mathrm{L}$ & $\mathrm{mgN}-\mathrm{NH}_{4} / \mathrm{L}$ & $\mathrm{gN}-\mathrm{NH}$ & $\mathrm{mgNO}_{2} /$ & $\mathrm{mgNO}_{2} / \mathrm{L}$ & $\mathrm{mgN}^{-\mathrm{NH}_{4} /}$ & $\mathrm{mgN}-\mathrm{NH}_{4} / \mathrm{L}$ & $\mathrm{N}-\mathrm{NH}_{4} /$ & $\mathrm{mgNO}_{2} / \mathrm{L}$ & $\mathrm{mgNO}_{2} / \mathrm{L}$ \\
\hline 12-jun-02 & 55 & $7: 00$ & & & & 0,00 & 0,00 & & & & 2,69 & 4,84 \\
\hline 14-jun-02 & 57 & $7: 30$ & & 37,4 & & 0,00 & 0,00 & & 2,6 & & 2,10 & 5,28 \\
\hline 17-jun-02 & 60 & $7: 00$ & 38,2 & 28,2 & 9,9 & 0,00 & 0,00 & 5,4 & 0,0 & 5,4 & 2,59 & 7,01 \\
\hline 21-jun-02 & 64 & $7: 00$ & 42,5 & 32,3 & 10,2 & 0,00 & 0,00 & 1,6 & 0,0 & 1,6 & 1,73 & 13,03 \\
\hline 24-jun-02 & 67 & $7: 00$ & 34,9 & 30,0 & 5,0 & 0,00 & 0,00 & 0,0 & 0,0 & 0,0 & 1,43 & 10,05 \\
\hline 28-jun-02 & 71 & $7: 00$ & 43,5 & 40,1 & 3,5 & 0,00 & 0,00 & 0,0 & 0,0 & 0,0 & 0,63 & 12,33 \\
\hline 1-jul-02 & 74 & $7: 00$ & 40,9 & 32,3 & 8,6 & 0,00 & 0,00 & 0,0 & 0,0 & 0,0 & 1,89 & 11,44 \\
\hline 5-jul-02 & 78 & $7: 00$ & 39,8 & 33,3 & 6,4 & 0,00 & 0,00 & 9,7 & 3,4 & 6,3 & 2,86 & 12,96 \\
\hline 8-jul-02 & 81 & 8:00 & & & & 0,00 & 0,00 & & & & 1,63 & 14,62 \\
\hline 10-jul-02 & 83 & $7: 00$ & 32,3 & 25,4 & 6,9 & 0,00 & 0,00 & 5,4 & 2,2 & 3,2 & 1,39 & 9,48 \\
\hline 12-jul-02 & 85 & $6: 30$ & 36,6 & 28,5 & 8,1 & 0,00 & 0,00 & 12,4 & 12,4 & 0,0 & 0,81 & 6,37 \\
\hline 15-jul-02 & 88 & $7: 00$ & 30,6 & 26,6 & 4,0 & 0,00 & 0,00 & 22,0 & 18,4 & 3,6 & 0,29 & 1,23 \\
\hline 19-jul-02 & 92 & $7: 00$ & 37,1 & 32,3 & 4,8 & 0,00 & 0,00 & 21,0 & 20,2 & 0,8 & 0,66 & 5,18 \\
\hline 22-jul-02 & 95 & $7: 00$ & 32,8 & 28,9 & 3,9 & 0,00 & & 3,2 & 2,8 & 0,4 & 1,50 & 16,38 \\
\hline 24-jul-02 & 97 & $8: 00$ & 43,6 & 32,4 & 11,2 & 0,00 & 0,00 & 2,2 & 0,0 & 2,2 & 0,39 & 16,93 \\
\hline 26-jul-02 & 99 & $7: 00$ & 43,6 & 33,7 & 9,8 & 0,00 & 0,00 & 7,5 & 0,0 & 7,5 & 0,32 & 17,68 \\
\hline 1-ago-02 & 105 & $7: 00$ & 43,0 & 36,8 & 6,2 & 0,00 & 0,00 & 0,0 & 0,0 & 0,0 & 0,30 & 15,57 \\
\hline 5-ago-02 & 109 & $7: 00$ & & 28,1 & & 0,00 & 0,00 & & 0,0 & & 0,35 & 18,73 \\
\hline 7-ago-02 & 111 & 8:00 & 44,0 & 35,7 & 8,3 & 0,00 & 0,00 & 6,8 & 0,5 & 6,4 & 0,47 & 21,34 \\
\hline 9-ago-02 & 113 & $7: 30$ & 42,0 & 34,9 & 7,1 & 0,00 & 0,00 & 3,9 & 0,0 & 3,9 & 0,71 & 23,55 \\
\hline 12-ago-02 & 116 & $7: 00$ & 38,1 & 35,9 & 2,2 & 0,00 & 0,00 & 3,9 & 0,0 & 3,9 & 0,62 & 23,88 \\
\hline 14-ago-02 & 118 & $7: 30$ & 45,9 & 37,4 & 8,6 & 0,00 & 0,00 & 1,0 & 0,2 & 0,7 & 0,65 & 27,40 \\
\hline 19-ago-02 & 123 & $7: 30$ & 35,2 & 27,4 & 7,8 & 0,00 & 0,00 & 1,0 & 0,2 & 0,7 & 0,46 & 23,02 \\
\hline
\end{tabular}


TABELA IX - Valores médios obtidos nas análises de nitrogênio no efluente do RMRLF, efluente do RAHLFa e na solução de alcalina.

\begin{tabular}{|c|c|c|c|c|c|c|c|c|c|c|c|c|c|c|c|}
\hline \multirow{2}{*}{ Data } & \multirow{2}{*}{$\begin{array}{c}\text { Dias de } \\
\text { operação }\end{array}$} & \multirow[b]{2}{*}{ Hora } & \multicolumn{5}{|c|}{ Efluente RMRLF } & \multicolumn{5}{|c|}{ Efluente RAHLFa } & \multicolumn{3}{|c|}{ Alcalinização } \\
\hline & & & $\mathrm{N}_{\text {total }}$ & $\mathrm{N}_{\text {amoniacal }}$ & $\mathrm{N}_{\text {org }}$ & Nitrito & Nitrato & $\mathrm{N}_{\text {total }}$ & $\mathrm{N}_{\text {amoniacal }}$ & $\mathrm{N}_{\text {org }}$ & Nitrito & Nitrato & $\mathrm{N}_{\text {total }}$ & $\mathrm{N}_{\text {amoniacal }}$ & $\mathrm{N}_{\text {org }}$ \\
\hline & & & $\mathrm{mgN}-\mathrm{NH}_{4} / \mathrm{L}$ & $\mathrm{mgN}-\mathrm{NH}_{4} / \mathrm{L}$ & $\mathrm{gN}-\mathrm{NH}_{2}$ & $\mathrm{mgNO}_{2} / \mathrm{t}$ & $\mathrm{mgNO}_{2} / \mathrm{L}$ & ${\mathrm{mgN}-\mathrm{NH}_{4} /}$ & $\mathrm{mgN}-\mathrm{NH}_{4} / \mathrm{L}$ & $\mathrm{gN}-\mathrm{NH}$ & $\mathrm{mgNO}_{2} / \mathrm{l}$ & $\mathrm{mgNO}_{2} / \mathrm{L}$ & $\mathrm{mgN}-\mathrm{NH}_{4} / \mathrm{L}$ & $\mathrm{mgN}-\mathrm{NH}_{4} / \mathrm{l}$ & $\mathrm{gNN}-\mathrm{NH}_{4} / \mathrm{L}$ \\
\hline 12-jun-02 & 55 & $7: 00$ & & & & 2,56 & 3,98 & & & & 0,00 & 0,99 & & & \\
\hline 14-jun-02 & 57 & $7: 30$ & & 4,8 & & 2,00 & 5,41 & & 14,3 & & 0,00 & 0,00 & & & \\
\hline 17-jun-02 & 60 & $7: 00$ & 5,4 & 0,0 & 5,4 & 2,31 & 6,85 & 5,4 & 0,0 & 5,4 & 0,71 & 0,30 & & & \\
\hline 21 -jun-02 & 64 & $7: 00$ & 3,8 & 0,0 & 3,8 & 1,74 & 13,23 & 0,5 & 0,0 & 0,5 & 1,90 & 7,60 & 40,3 & 30,9 & 9,4 \\
\hline 24-jun-02 & 67 & $7: 00$ & 0,0 & 0,0 & 0,0 & 1,42 & 10,64 & 0,0 & 0,0 & 0,0 & 1,05 & 8,29 & 34,9 & 30,8 & 4,2 \\
\hline 28-jun-02 & 71 & $7: 00$ & 0,0 & 0,0 & 0,0 & 0,65 & 13,00 & 0,0 & 0,0 & 0,0 & 0,00 & 7,73 & 39,8 & 36,4 & 3,4 \\
\hline 1-jul-02 & 74 & $7: 00$ & 0,0 & 0,0 & 0,0 & 2,16 & 13,23 & 2,2 & 0,3 & 1,9 & 1,28 & 10,31 & 40,3 & 38,3 & 2,0 \\
\hline 5-jul-02 & 78 & 7:00 & 10,8 & 2,7 & 8,1 & 2,86 & 13,40 & 9,7 & 1,4 & 8,3 & 2,06 & 12,37 & 40,3 & 33,6 & 6,7 \\
\hline 8-jul-02 & 81 & $8: 00$ & & & & 1,68 & 15,68 & & & 0,0 & 1,26 & 14,12 & & & 0,0 \\
\hline 10-jul-02 & 83 & $7: 00$ & 3,2 & 1,2 & 2,0 & 1,32 & 11,11 & 7,0 & 5,8 & 1,2 & 0,79 & 7,76 & 32,8 & 32,5 & 0,3 \\
\hline 12-jul-02 & 85 & $6: 30$ & 12,9 & 10,0 & 3,0 & 0,80 & 7,03 & 7,5 & 7,5 & 0,0 & 0,38 & 3,95 & 34,4 & 29,4 & 5,0 \\
\hline 15-jul-02 & 88 & $7: 00$ & 20,4 & 16,0 & 4,4 & 0,30 & 1,46 & & 14,3 & & 0,21 & 2,76 & 22,6 & & 22,6 \\
\hline 19-jul-02 & 92 & $7: 00$ & 18,8 & 17,6 & 1,2 & 0,67 & 5,90 & 14,5 & 13,4 & 1,1 & 0,27 & 7,06 & 37,1 & 26,9 & 10,2 \\
\hline 22-jul-02 & 95 & $7: 00$ & 1,1 & 0,0 & 1,1 & 1,20 & 16,38 & 1,1 & 1,1 & 0,0 & 1,51 & 6,67 & 32,8 & 30,2 & 2,6 \\
\hline 24-jul-02 & 97 & $8: 00$ & 4,8 & 0,0 & 4,8 & 0,17 & 19,25 & 4,8 & 0,8 & 4,0 & 0,13 & 10,02 & 35,5 & 29,8 & 5,6 \\
\hline 26-jul-02 & 99 & 7:00 & 2,7 & 0,0 & 2,7 & 0,11 & 17,76 & 2,7 & 0,8 & 1,9 & 0,05 & 11,96 & 43,0 & 34,4 & 8,6 \\
\hline 1-ago-02 & 105 & 7:00 & 0,0 & 0,0 & 0,0 & 0,13 & 18,43 & 0,5 & 0,0 & 0,5 & 0,04 & 14,20 & 42,5 & 26,9 & 15,6 \\
\hline 5-ago-02 & 109 & $7: 00$ & & 0,0 & & 0,15 & 19,92 & & 0,0 & & 0,07 & 17,87 & & 29,8 & \\
\hline 7-ago-02 & 111 & $8: 00$ & 4,9 & 0,5 & 4,4 & 0,23 & 23,10 & 5,9 & 0,7 & 5,1 & 0,13 & 17,34 & 44,0 & 34,9 & 9,0 \\
\hline 9-ago-02 & 113 & $7: 30$ & 2,0 & 0,0 & 2,0 & 0,39 & 26,65 & 2,0 & 0,2 & 1,7 & 0,12 & 18,99 & 39,1 & 35,2 & 3,9 \\
\hline 12-ago-02 & 116 & $7: 00$ & 0,0 & 0,0 & 0,0 & 0,28 & 26,76 & 0,0 & 0,0 & 0,0 & 0,34 & 24,59 & 34,0 & 34,0 & 0,0 \\
\hline 14-ago-02 & 118 & $7: 30$ & 1,0 & 0,2 & 0,7 & 0,32 & 29,79 & 0,0 & 0,0 & 0,0 & 0,13 & 24,93 & 36,2 & 35,4 & 0,7 \\
\hline 19-ago-02 & 123 & $7: 30$ & 0,0 & 0,0 & 0,0 & 0,11 & 22,73 & 2,0 & 0,7 & 1,2 & 0,07 & 20,45 & 34,2 & 31,0 & 3,2 \\
\hline
\end{tabular}


TABELA X - Valores médios obtidos nas análises de OD medido na câmara 3 e no efluente do RMRLF.

\begin{tabular}{|c|c|c|c|c|}
\hline Data & $\begin{array}{l}\text { Dias de } \\
\text { operação }\end{array}$ & Hora & $\begin{array}{c}\text { Câmara } 3 \\
\text { OD }\end{array}$ & $\begin{array}{c}\text { Efluente } \\
\text { RMRLF } \\
\text { OD }\end{array}$ \\
\hline 20-mai-02 & 32 & $7: 00$ & 2,3 & 0,0 \\
\hline 22-mai-02 & 34 & $7: 00$ & 4,5 & 0,0 \\
\hline 24-mai-02 & 36 & $7: 00$ & 5,2 & 0,0 \\
\hline 27-mai-02 & 39 & $7: 00$ & 5,8 & 0,0 \\
\hline 29-mai-02 & 41 & 7:00 & 5,8 & 0,1 \\
\hline 3-jun-02 & 46 & $7: 00$ & 5,3 & 1,7 \\
\hline $12-$ jun-02 & 55 & $8: 00$ & 5,0 & 3,5 \\
\hline 14-jun-02 & 57 & $7: 30$ & 6,0 & 5,0 \\
\hline 17-jun-02 & 60 & $7: 00$ & 6,7 & 2,5 \\
\hline 19-jun-02 & 62 & $7: 00$ & 6,9 & 2,4 \\
\hline 21-jun-02 & 64 & $7: 00$ & 6,1 & 3,8 \\
\hline 24-jun-02 & 67 & $7: 00$ & 4,9 & 3,6 \\
\hline 26-jun-02 & 69 & $7: 00$ & 5,2 & 3,5 \\
\hline 28-jun-02 & 71 & $7: 00$ & 5,3 & 3,1 \\
\hline 1-jul-02 & 74 & $7: 00$ & 4,6 & 3,1 \\
\hline 3-jul-02 & 76 & 8:00 & 4,9 & 3,0 \\
\hline 5-jul-02 & 78 & $7: 00$ & 4,2 & 2,6 \\
\hline 10-jul-02 & 83 & $7: 00$ & 6,7 & 3,8 \\
\hline 12-jul-02 & 85 & $6: 30$ & 6,5 & 3,4 \\
\hline 15-jul-02 & 88 & $7: 00$ & 5,2 & 1,9 \\
\hline 19-jul-02 & 92 & $7: 00$ & 5,2 & 2,1 \\
\hline 22-jul-02 & 95 & 7:00 & 5,3 & 1,5 \\
\hline 24-jul-02 & 97 & $8: 00$ & 5,2 & 2,0 \\
\hline 26-jul-02 & 99 & $7: 00$ & 5,2 & 2,2 \\
\hline 1-ago-02 & 105 & $7: 00$ & 5,5 & 5,2 \\
\hline 5-ago-02 & 109 & $7: 00$ & 5,9 & 5,8 \\
\hline 7-ago-02 & 111 & 8:00 & 5,2 & 5,2 \\
\hline 9-ago-02 & 113 & $7: 30$ & 4,7 & 5,0 \\
\hline 12-ago-02 & 116 & $7: 00$ & 4,5 & 4,8 \\
\hline 14-ago-02 & 118 & $7: 30$ & 5,0 & 5,0 \\
\hline 19-ago-02 & 123 & $7: 30$ & 5,3 & 0,7 \\
\hline
\end{tabular}

